Portland State University

PDXScholar

1993

\title{
Thermoregulation in Mice under the Influence of Ethanol
}

Candace Sharon O'Connor

Portland State University

Follow this and additional works at: https://pdxscholar.library.pdx.edu/open_access_etds Let us know how access to this document benefits you.

Recommended Citation

O'Connor, Candace Sharon, "Thermoregulation in Mice under the Influence of Ethanol" (1993). Dissertations and Theses. Paper 1181.

https://doi.org/10.15760/etd.1180

This Dissertation is brought to you for free and open access. It has been accepted for inclusion in Dissertations and Theses by an authorized administrator of PDXScholar. Please contact us if we can make this document more accessible: pdxscholar@pdx.edu. 
THERMOREGULATION IN MICE UNDER THE INFLUENCE OF ETHANOL

\author{
by \\ CANDACE SHARON O'CONNOR
}

A dissertation submitted in partial fulfillment of the requirements for the degree of

\author{
DOCTOR OF PHILOSOPHY \\ in \\ ENVIRONMENTAL SCIENCES AND RESOURCES: \\ BIOLOGY
}

Portland State University

1993 
TO THE OFFICE OF GRADUATE STUDIES:

The members of the Committee approve the dissertation of Candace Sharon O'Connor presented April 29, 1993.
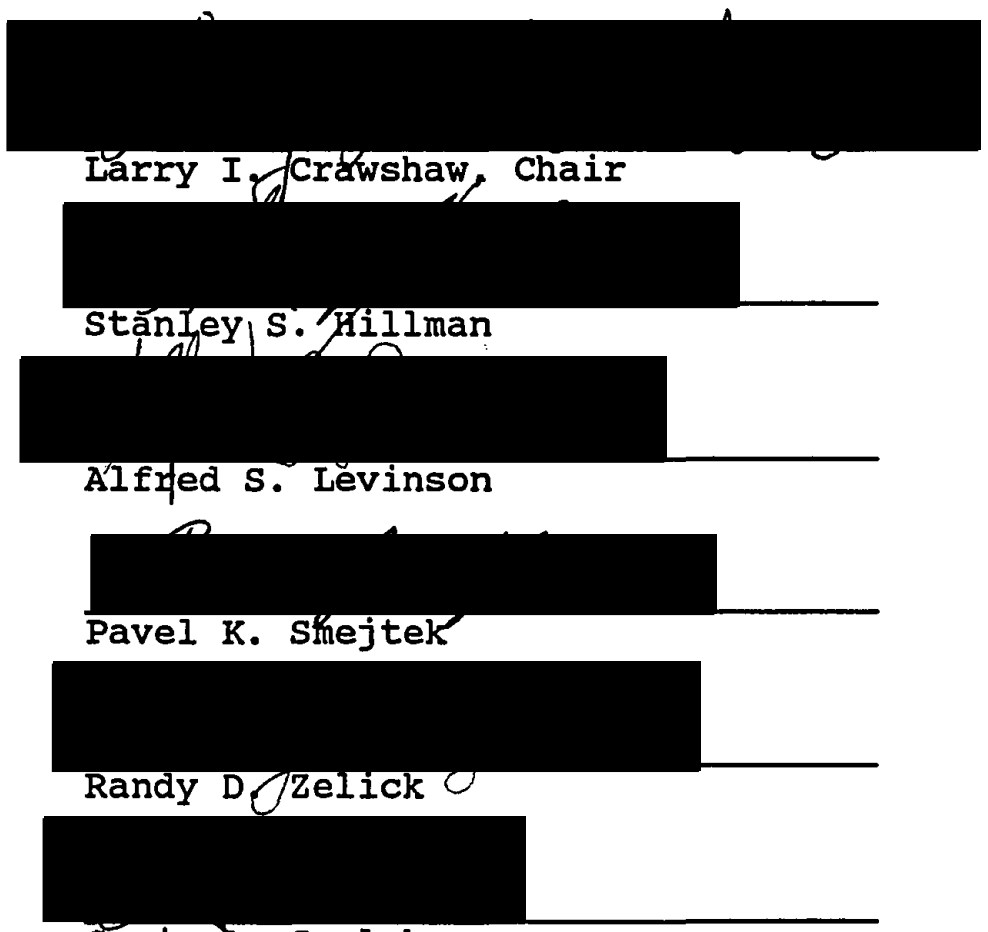

Graig A. Spolek

\section{APPROVED:}

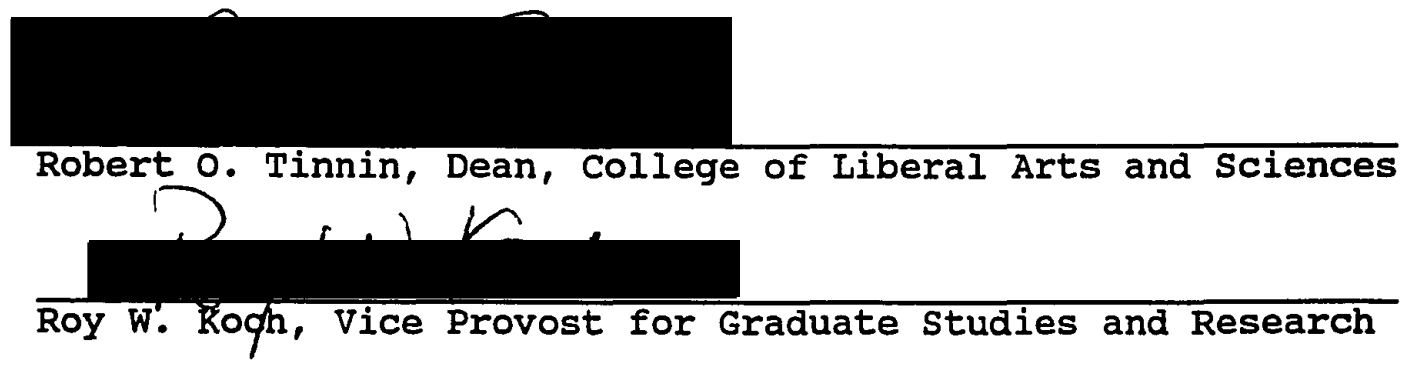


AN ABSTRACT OF THE DISSERTATION OF Candace Sharon O'Connor for the Doctor of Philosophy in Environmental sciences and Resources: Biology presented April 29, 1993.

Title: Thermoregulation in Mice Under the Influence of Ethanol.

APPROVED BY THE MEMBERS OF THE DISSERTATION COMMITTEE:

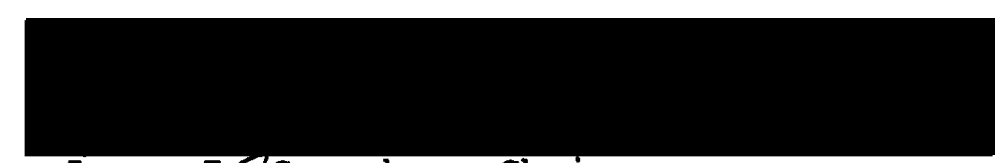

Larry IfJcrawshaw, chair

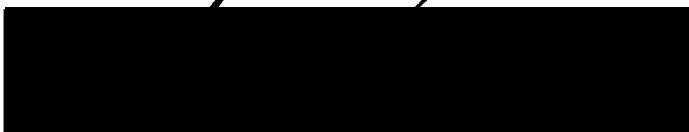

SEaniey S./Hillman

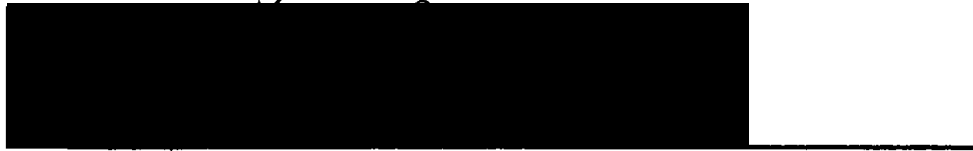

Alfréd S. Levinson

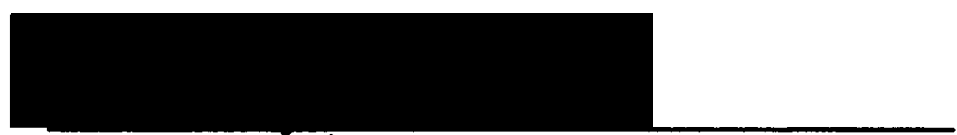

Pavel K. Smejtek

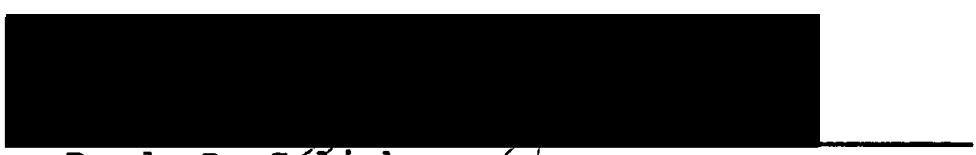

Randy D. Zólick

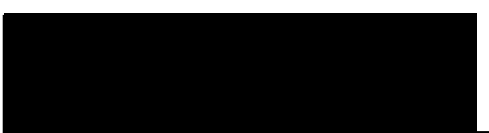

Graig A.'Spolek 
Thermoregulation after acute ethanol, during chronic exposure and during withdrawal from ethanol dependency was studied using genetically heterogeneous (HS) mice, and lines of mice selected in replicate for smaller (HOT1, HOT2) or greater (COLD1, COLD2) decline in rectal temperature $\left(T_{r e}\right)$ after intraperitoneal ethanol. First, HS mice were injected with $20 \%$ ethanol in $0.9 \% \mathrm{NaCl}$, or $\mathrm{NaCl}$ alone during sessions of behavioral thermoregulation in individual temperature gradients $\left(9-38^{\circ} \mathrm{C}\right)$. Internal temperature $\left(T_{i}\right)$ was monitored with implanted telemetry devices. An imaging system recorded selected temperature $\left(T_{\text {sel }}\right)$ within the gradient every $5 \mathrm{sec}$. Acute 2.25 and $2.60 \mathrm{~g}$ ethanol $/ \mathrm{kg}$ produced significantly lower $T_{i}$ than $\mathrm{NaCl} .2 .60 \mathrm{~g} / \mathrm{kg}$ also produced significantly lower $T_{\text {sel }}$ than $2.25 \mathrm{~g} / \mathrm{kg}$ or $\mathrm{NaCl}$. $2.75 \mathrm{~g} / \mathrm{kg}$ and above incapacitated mice. Comparison of responses using a thermoregulatory index indicated 2.25 or $2.60 \mathrm{~g} / \mathrm{kg}$ decreased the regulated temperature. Similar methodology was followed using the selected lines and $10 \%$ ethanol $(2.0,2.25,2.65 \mathrm{~g} / \mathrm{kg}$ to COLD mice; $2.65,2.85 \mathrm{~g} / \mathrm{kg}$ to HOT mice; $3.0 \mathrm{~g} / \mathrm{kg}$ to HOT2 mice) or $\mathrm{NaCl}$. All responded similarly to $\mathrm{NaCl}$, with transient rise in $T_{i}$. After an effective ethanol dose mice manifested a regulated decrease in $T_{i}$, by lowering $T_{\text {sel }}$ concomitant with falling $T_{i}$. In both replicate pairs cold mice were more sensitive than HOT, indicating that a true difference in the CNS regulator of body temperature was selected for in these animals. 
Photoperiod effect was characterized by quantifying thermoregulatory behavior of COLD2 mice after acute $2.60 \mathrm{~g}$ $7.5 \%$ ethanol $/ \mathrm{kg}$ or $\mathrm{NaCl}$, at $0400,0800,1200,1600,2000$ and 2400 hours, using above methodology. Baseline $T_{i}$ was significantly lower during hours of light, than during darkness. Photoperiod had little effect on thermoregulatory response to ethanol, possibly because of arousal associated with experiments.

Thermoregulatory tolerance to ethanol was investigated using HS mice implanted with telemetry devices and monitored in the gradient on days $1,2,4,7$ and 11 of 11 consecutive days of $10 \%$ ethanol $(2.75 \mathrm{~g} / \mathrm{kg})$ or $\mathrm{NaCl}$ injections. Dispositional, rapid and chronic tolerance developed, indicating that functional tolerance is a regulated phenomenon in mice. In a separate experiment HS mice were implanted with telemetry devices and injected with ethanol for 11 consecutive days at constant temperature; dispositional but not functional tolerance developed.

To characterize thermoregulation during withdrawal, HS mice were made dependent upon ethanol using a vapor chamber; $T_{i}, T_{\text {sel }}$ and activity were monitored in the gradient until 26 hours postwithdrawal. Withdrawing mice showed unaltered regulated temperature, but lower $T_{\text {sel }}$ than controls. This suggested increased metabolic heat production. Thermoregulation during withdrawal was similarly studied using the selected mouse lines. CoLD mice responded like Hs mice. 
Withdrawing HOTl mice were more active than controls; withdrawing HOT2 mice showed lowest $\mathrm{T}_{\text {sel }}$ of any genotype but maintained $T_{i}$ above controls. These results suggest a more severe withdrawal reaction in HOT, than in COLD mice.

To investigate a possible mechanism underlying ethanol hypothermia, responses of HOT and COLD mice to intracerebroventricular serotonin were characterized. Dosedependent decreases in $T_{r e}$ were measured in mice equipped with indwelling brain cannulae and held at constant temperature after injection of $0.3,0.8,2.0,5.0$ or $11.0 \mu \mathrm{g}$ serotonin into the lateral brain ventricle. CoLD mice were significantly more sensitive than HOT mice. Subsequently HOTI and COLDl mice were equipped with brain cannulae and implanted telemetry devices; thermoregulatory behavior after $11.0 \mu \mathrm{g}$ serotonin was monitored. Both genotypes lowered $T_{i}$ significantly more in the gradient than did similar mice at constant ambient temperature, indicating that decline in $T_{i}$ after serotonin was a regulated phenomenon. The serotonergic system was altered during selection for differential $T_{r e}$ response to ethanol, indicating a role for serotonin in mediating ethanol hypothermia. 


\section{ACKNOWLEDGEMENTS}

I wish to express my gratitude to the many people without whose help this work could not have been accomplished, including the technicians and students who helped with experiments and animal care, especially Ethan Bauer, Charles Culbertson, Jeff Duerr, Amy Eden, Parham Ghavami, Mimi Hoang, Steve Levenhagen, and Carlos Ramos at Portland state University, and Emmett Young, Eric Terdahl and Cathy Merrill at the Portland Veteran's Administration Research Center.

I am especially indebted to Ann Kosobud of the VA for instructing me in mouse handling and surgery, and to $\mathrm{Dr}$. John c. Crabbe for intellectual stimulation, patient tutoring in statistics, and a generous supply of mice. I am also particularly grateful to David Hayteas of Portland state University for his invaluable help with surgeries and data collection, and to my fellow graduate student Rick Rausch for emotional and intellectual support throughout this process.

Special and affectionate thanks go to the teachers who most influenced me to reach further than I thought I could; Bro. Brian Dybowski of the College of Santa Fe, Dr. Charles MaKinney, vintner extraordinaire, of the University of Texas Lands and Surface Leasing office, Dr. George o'Connor (no relation!) of New Mexico State University, and especially Dr. Larry Crawshaw, my advisor and friend, whose cheerful patience 
is extraordinary and whose material and intellectual support has been unfailing.

I particularly wish to thank two people. Robert c. Bedichek of the University of Washington created and continues to support the software utilized in these experiments, and has been not only an unfailing source of computer wisdom and advice, but also a stalwart and exceptional friend. My husband, Rudolf zupan, designed and built much of the apparatus utilized in this study, and has unselfishly supported me in my efforts. I owe him more than I can say. 
TABLE OF CONTENTS

PAGE

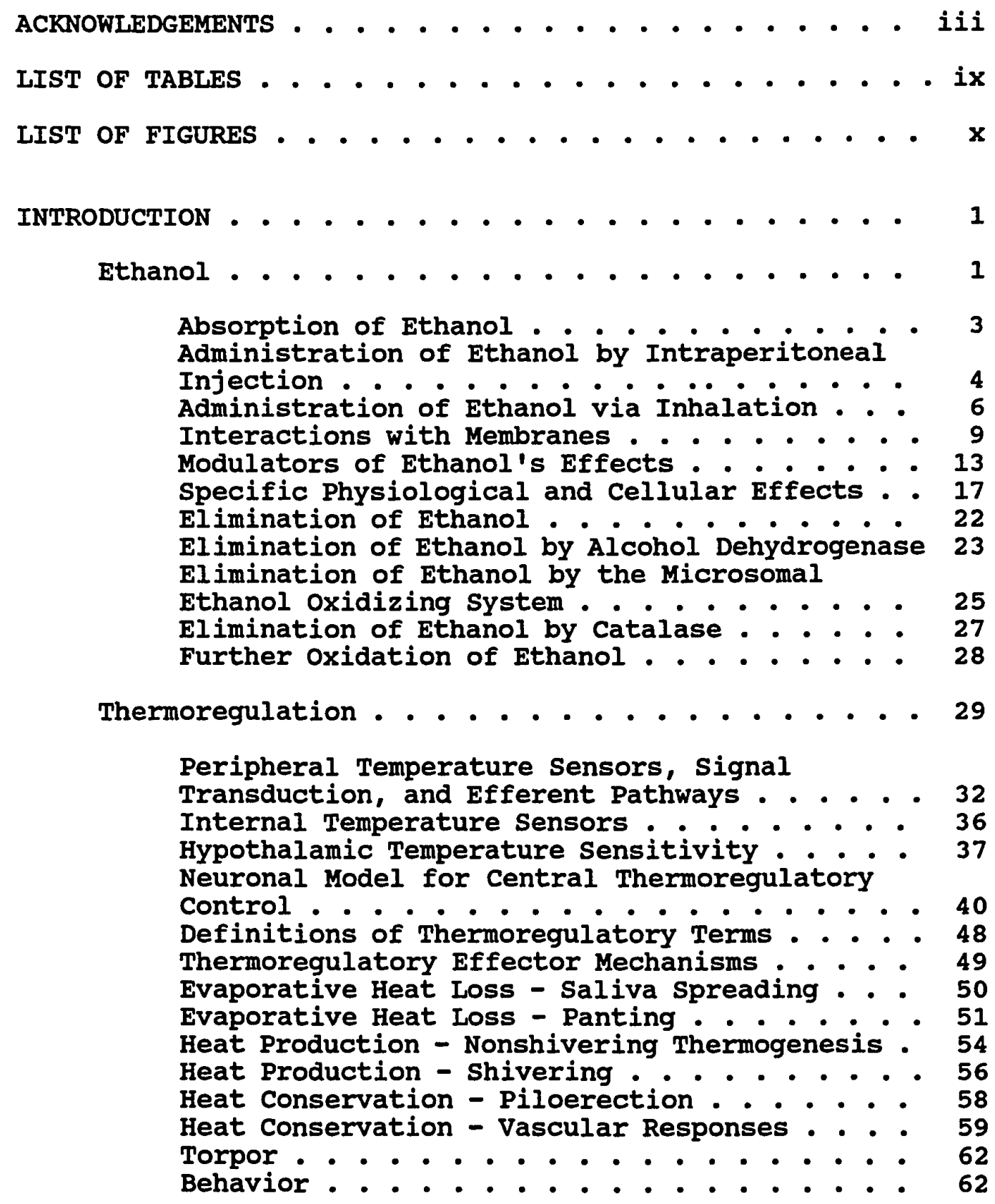


The Mouse . . . . . . . . . . . . . 67

History . . . . . . . . . . . . 68 Genetic Animal Models . . . . . . . . . 72 Methods of Selection ............ 75 Uses for Selected Lines of Mice . . . . . . 76 Using the Mouse to Study Responses to Ethanol • 79

Thermoregulation During Acute Exposure to Ethanol • 79

Development of Thermoregulatory Tolerance to Ethanol 86

Thermoregulation During withdrawal from Ethanol

Dependency . . . . . . . . . . . . 98

Serotonin and the Acute Thermoregulatory Response

to Ethanol . . . . . . . . . . . . . 103

MATERIALS AND METHODS . . . . . . . . . . . 106

Animals . . . . . . . . . . . . . 106

Housing . . . . . . . . . . . . . 108

Surgical, Medical and Injection Procedures . . . 109

Mini-Mitter Implantation . . . . . . . . 109

Implantation of Chronic Indwelling Brain

Cannulae . . . . . . . . . . . . . 110

Administration of Ethanol . . . . . . . . 113

Blood Ethanol Determination . . . . . . . . 114

Sacrifice and Histologies . . . . . . . . 115

Experimental Apparatus and Procedures . . . . . 116

Behavioral Temperature Selection Apparatus . . 116

Internal Temperature Measurements Using

Mini-Mitters . . . . . . . . . . . . . 118

General Procedure for Quantifying Internal

and Selected Temperature in the Temperature

Gradient . . . . . . . . . . . . . . 119

Validation of Behavioral Temperature

Selection Protocol . . . . . . . . . . 120

Activity Measurements during Behavioral

Experiments ............... . . 121

Specific Methodology for Each Study . . . . . . 121

Thermoregulatory Effect of Acute Ethanol

in Genetically Heterogeneous Mice . . . . . . . 121

Thermoregulatory Effect of Acute Ethanol

in Selected Lines of Mice . . . . . . . . 122 
Influence of Time of Day on Response to Acute Ethanol . . . . . . . . . . . . . . . . 124 Development of Tolerance to Ethanol

Hypothermia . . . . . . . . . . . . . 125 Thermoregulation During withdrawal from Ethanol Dependency in Genetically Heterogeneous Mice . 127 Thermoregulation During Withdrawal from Ethanol Dependency in Selected Lines of Mice . . . . . 132 Body Temperature Response to i.c.v. 5-HT in Selected Lines of Mice at Constant Ambient Temperature . . . . . . . . . . . . . 135 Thermoregulatory Response to i.c.v. 5-HT in Selected Lines of Mice in a Temperature Gradient ................ 138

Data Analysis . . . . . . . . . . . . 139

Thermoregulatory Effect of Acute Ethanol in Genetically Heterogeneous Mice . . . . . . . 141 Thermoregulatory Effect of Acute Ethanol in Selected Lines of Mice . . . . . . . . . . 141 Influence of Time of Day on Response to Acute Ethanol .................. 143 Development of Tolerance to Ethanol Hypothermia 144 Thermoregulation During Withdrawal from Ethanol Dependency in Genetically Heterogeneous Mice . 145 Thermoregulation During Withdrawal from Ethanol Dependency in Selected Iines of Mice . . . . . 146 Body Temperature Response to i.c.V. 5-HT in Selected Lines of Mice at Constant Ambient Temperature . . . . . . . . . . . . . 147 Thermoregulatory Response to i.c.v. 5-HT in Selected Lines of Mice in a Temperature Gradient . . . . . . . . . . . . . 148

RESULTS . . . . . . . . . . . . . . . . . 149

The Effects of Acute Ethanol on Thermoregulation in Genetically Heterogeneous Mice . . . . . . . 149

The Effects of Acute Ethanol on Thermoregulation in Selected Lines of Mice . . . . . . . . . . 154

Influence of Time of Day on Thermoregulatory Response to Ethanol . . . . . . . . . . . . 161

Development of Tolerance to Ethanol Hypothermia . . 166

Thermoregulation During Withdrawal from Ethanol Dependency in Genetically Heterogeneous Mice . . . 179 
viii

Thermoregulation During Withdrawal from Ethanol

Dependency in Selected Lines of Mice . . . . . . 187

Temperature Response to i.c.v. 5-HT in Selected

Iines of Mice . . . . . . . . . . . . 198

DISCUSSION . . . . . . . . . . . . . . . 208

Thermoregulatory Behavior During Acute Exposure

to Ethanol ... . . . . . . . . . . . 208

Influence of Time of Day on Thermoregulatory

Behavior After Acute Ethanol ......... . . 216

Development of Tolerance to Ethanol Hypothermia . . 218

Thermoregulatory Behavior During withdrawal from

Ethanol Dependency ................ 233

Temperature Response to Centrally Administered

Serotonin . . . . . . . . . . . . . . . 246

Conclusion . . . . . . . . . . . . . . 257

Future Directions ............. 261

REFERENCES . . . . . . . . . . . . . . . . 264 


\section{LIST OF TABLES}

TABLE

PAGE

I Injections Given to HOT and COLD Mice . . . 123

II Withdrawal in Selected Lines of Mice -

Timing of Critical Events . . . . . 134

III Blood Ethanol content . . . . . . . . 171

IV $T_{\mathbf{i}}, T_{\text {sel }}$ and Activity in withdrawing HS

Mice . . . . . . . . . . 181

$\mathrm{V}$ Body Temperatures During Induction of and

Withdrawal From Ethanol Dependency at

Constant Ambient Temperature . . . . . 184

VI Responses of Selected Lines, 4-10 Hrs

Postwithdrawal . . . . . . . 187

VII $T_{\text {re }}$ after creatinine sulfate Control solution

or Sham Injection. . . . . . . 200

VIII Activity After Control or 5-HT Injection . . 205 


\section{LIST OF FIGURES}

FIGURE

PAGE

1. Neuronal Model for Thermoregulation . . . 46

2. Mouse Head in Stereotaxic Surgery Unit . . 111

3. Dorsal view of an Adult Male Mouse skull • 112

4. Disassembled Brain Cannula . . . . . . 113

5. Top View of Aquatic Temperature Gradient . . 116

6. Schematic of Information Flow during

Behavioral Thermoregulation

Experiments . . . . . . . . . 117

7. Thermoregulatory Responses of Three

Individual HS Mice to Acute EtoH

or NaCl ........... . . 150

8. Responses of Three Individual Mice

Transformed to Thermoregulatory Index

Values ............ 151

9. Thermoregulatory Index for $60 \mathrm{Min}$ after

Injection of NaCl or Two Doses of EtOH 152

10. Thermoregulatory Responses of HOT and

COLD Mice to Acute EtOH . . . . . . 155

11. Responses of HOT and COLD Mice Transformed

to Thermoregulatory Index Values . . 157

12. Dose Response Curves for HOT and COLD Mice

After Acute EtOH . . . . . . . 159 
13. Activity Responses of HOT and COID Mice to Increasing Doses of EtoH . . . . 161

14. Baseline Internal Temperatures at Various Times of Day . . . . . . . . . 162

15. Thermoregulatory Responses of COLD2 Mice to EtoH, NaCl or No Drug at Various Times of Day . . . . . . . . . . 163

16. Responses of COID2 Mice at Various Times of Day Transformed to Thermoregulatory Index Values . . . . . . . . . 164

17. Difference Between Thermoregulatory Index After NaCl and EtOH at Various Times of Day . . . . . . . . . . . 166

18. Responses of HS Mice to Acute EtOH or $\mathrm{NaCl}$ on Day 1 of Mixed Protocol Tolerance Experiment . . . . . . . . . 167

19. Thermoregulatory Index of Response of HS Mice to NaCl or EtoH on Day 1, Day 4 and Day 11 of Mixed Protocol Tolerance Experiment . . . . . . 168

20. Difference Between Thermoregulatory Index after EtOH and $\mathrm{NaCl}$ on Gradient Days of Mixed Protocol Tolerance Experiment ............ 170 
21. Thermoregulatory Index of Response of HS

Mice to EtOH and NaCl on Gradient

Days of Mixed Protocol Tolerance

Experiment . . . . . . . . . 171

22. Temperature Responses of HS Mice to EtOH

or NaCl on First and Last Days of Box

Protocol Tolerance Experiment . . . . 173

23. Temperature Responses of HS Mice to EtOH or

NaCl on All Eleven Days of Box

Protocol Tolerance Experiment . . . 174

24. Change from Preinjection Temperature of HS

Mice after EtOH or NaCl on First and

Last Days of Box Protocol Tolerance

Experiment . . . . . . . . . 175

25. Change from Preinjection Temperature of HS

Mice after EtoH or NaCl on All Eleven

Days of Box Protocol Tolerance

Experiment . . . . . . . . . 176

26. Body Weight Changes of HS Mice in Tolerance

Experiments . . . . . . . . . 178

27. Thermoregulation and Activity of HS Mice

During Withdrawal from EtoH Dependency

in a Temperature Gradient . . . . . 180 
28. Thermoregulation and Activity of HS Mice

During Withdrawal from EtoH Dependency

Begun at $0300 \mathrm{Hr}$ in a Temperature

Gradient . . . . . . . . . . 183

29. Drive of HS Mice to Dissipate Heat During

Withdrawal from EtoH Dependency in a

Temperature Gradient . . . . . . 185

30. Difference Between Withdrawing and Control

HS Mice in Drive to Dissipate Heat

in a Temperature Gradient . . . . . 186

31. Thermoregulation and Activity of COLDl Mice

During Withdrawal from EtOH Dependency

in a Temperature Gradient . . . . . 192

32. Thermoregulation and Activity of COLD2 Mice

During Withdrawal from EtOH Dependency

in a Temperature Gradient . . . . . 193

33. Thermoregulation and Activity of HOTI Mice

During Withdrawal from EtoH Dependency

in a Temperature Gradient . . . . . . 194

34. Thermoregulation and Activity of HOT2 Mice

During Withdrawal from EtoH Dependency

in a Temperature Gradient . . . . . 195

35. Difference Between Withdrawing and Control

Selected Lines of Mice in Drive to

Dissipate Heat in a Temperature

Gradient ............ 197 
36. Temperature Responses of Individual Mice to i.c.v. 5-HT or creatinine . . . . 199

37. Response of an Individual Mouse to a single Dose of i.c.v. 5-HT . . . . . . . 200

38. Responses of Selected Lines of Mice to Four Doses of i.c.v. 5-HT ........ 201

39. Dose Response Curves for HOT and COLD Mice After All Doses of i.C.v. 5-HT . . . 203

40. Thermoregulatory Responses of 2 Individual Mice in a Temperature Gradient After i.c.v. 5-HT or Creatinine . . . . . 204

41. Comparison of Temperature Responses of Mice After i.c.v. 5-HT at Constant Ambient Temperature, or in a Temperature Gradient . . . . . . . . . 206

42. The Serotonergic Neuron . . . . . . . 251 


\section{INTRODUCTION}

The subject of this dissertation is the effect of ethanol on thermoregulation in the mouse. We will begin by considering ethanol in some detail, including administration, effects, and disposition of the drug within the body. Next the characteristics of the thermoregulatory system will be presented, emphasizing that which is of relevance to the mouse, followed by a discussion of the mouse itself, the creation of selected lines of mice in genetic selection experiments, and their usefulness as animal models. This Introduction will continue with a presentation of information available from the literature relevant to the specific experiments that will be discussed here. These include the effect of ethanol on thermoregulation in the mouse after acute exposure, during the development of tolerance to ethanol, and during withdrawal from ethanol dependency. The Introduction will conclude with evidence for participation of the neurotransmitter serotonin in the acute thermoregulatory effects of ethanol.

ETHANOL

Ethanol (alcohol, ethyl alcohol) is the oldest synthetic organic chemical (Morrison and Boyd, 1973, p.499); it is also one of the most important. For industrial purposes, ethanol 
is prepared both by cracking of petroleum to ethylene and subsequent hydration to ethyl alcohol, and by yeast fermentation of sugar from molasses, or starch from various grains; thus prepared, it is used as a solvent for lacquers, varnishes, perfumes and flavorings, as a medium for chemical reactions, and in recrystallizations (Morrison and Boyd, 1973, p.499)

Drinking alcohol is prepared by yeast fermentation of the sugars in a wide variety of vegetables, fruits and grains. Fermented juices, grain, and honey (mead) were produced as long ago as the Paleolithic (Devor and cloninger, 1989). Evidently problems of alcohol abuse are also ancient, since the first known temperance tract was produced by the ancient Egyptians (Devor and cloninger, 1989). Yeasts die at an ethanol concentration of around twelve percent, so an ethanol solution must be distilled to produce alcoholic beverages of a higher concentration. The Arabs discovered distillation, and our word "alcohol" comes from the Arabic word meaning "finely divided spirits". The Arabs introduced the technique of distillation into Europe in the Middle Ages. European alchemists believed that ethanol was the long-sought elixir of life, and a remnant of this old belief lives on in the word "whiskey", which comes from the Gaelic "usquebaugh" meaning "water of life" (Rall 1990). 
Absorption of Ethanol

Ethanol has legitimate uses in modern medical practice (from Rall, 1990). Ethanol is an excellent solvent, and is frequently used as vehicle for medicinal mixtures. Ethanol is a solvent for the chemical (toxicodendrol) in poison ivy that causes skin reaction and itching in susceptible individuals; prompt and thorough washing with ethanol after exposure to poison ivy will lessen or eliminate the unpleasant reaction. Ethanol cools the skin as it evaporates, and is used in rubs to lessen fevers. Ethanol is the most commonly used skin disinfectant. Ethanol may be injected to destroy nerves causing severe pain, as occurs in inoperable cancer. Ethanol is also used as a specific remedy in cases of methanol and ethylene glycol poisoning (Goldstein, 1983, p.13; Klaassen, 1990). Methanol, itself less toxic than ethanol, is oxidized to formaldehyde. The presence in the retina of the enzyme alcohol dehydrogenase, which mediates this reaction, accounts for the retinal toxicity of methamol. oxalic acid, the oxidation product of ethylene glycol, is similarly toxic to the kidney. Metabolism of these substances by alcohol dehydrogenase can be greatly slowed by administering the competitive substrate ethanol, affording time for hemodialysis and other supportive therapies.

Human beings may ingest ethanol for recreational purposes. Laboratory rodents may also be persuaded to drink ethanol, if they are offered a "mixed drink" of ethanol and 
something tasty, like chocolate Carnation slender. A dilute ethanol solution can be provided as sole source of fluid for drinking; C.P. Richter showed as long ago as the $1920^{\prime}$ s that rats could thrive with ten percent ethanol solution as their only fluid, and they can survive on concentrations as high as twenty-five percent, for at least seven months (Pohorecky and Brick, 1988). Another commonly used method of administering ethanol to rodents is via gavage. Ethanol moves out of the stomach into the intestine fairly quickly, but the rate is variable and depends upon the ethanol concentration, and particularly upon the amount of food in the stomach (Goldstein, 1983, p.3). Intraperitoneal injection is probably the most common method for administering ethanol to experimental animals. Injection affords the advantages of rapid absorption and predictable time course of effect. When dependency upon ethanol must be induced, inhalation is the means of administration offering the most advantages. These latter two methods will be discussed in more decail below.

\section{Administration of Ethanol by Intraperitoneal Injection}

The peritoneal cavity is lined with epithelial membrane which does not offer significant resistance to the passage of fluid; in addition, lymphatic drainage of the peritoneal cavity ensures that excess fluid within the cavity (such as that present after an intraperitoneal injection) will be transported to the lymph system, and back into the blood stream (Guyton, 1981, p. 390). Ethanol is infinitely soluble 
in water, and goes wherever water goes in the body. After injection, ethanol is found in tissues in a concentration that depends upon the water content of the tissue (Goldstein, 1983, p.6); because the brain is highly vascularized, brain ethanol levels peak rapidly after drug administration. There is evidence that plasma blood levels of ethanol are higher, and drug effects greater after same-dose injections using increasingly concentrated ethanol solutions (between eight and thirty-two percent) (Linakis and Cunningham, 1979). However, although peak plasma ethanol levels are higher with higher concentration, the time to reach peak plasma levels does not seem to vary with the concentrations normally utilized for injections given to rats. The time course to peak blood level averages about ten minutes (Linakis and Cunningham, 1979) for moderate doses; one study (Platanow et al, 1963) found the peritoneal cavity nearly free of ethanol fifteen minutes after injection.

A problem of the concentration of injected ethanol which has been little addressed in the literature, but which should be of concern to behavioral researchers, is the problem of pain. Appropriate volumes of injected vehicle (usually saline) can control for the effects of injection-associated handling and volume loading. But if an injected ethanol solution causes pain and injected vehicle does not, a significant aspect of the experimental procedure is not shared by control animals. Observation of mice during saline or 
ethanol injection reveals a marked difference in behavior. The great majority of restrained mice do not move, squeak, struggle, or try to kick the needle during saline injection; they tend to remain passive and quiet. However during ethanol injection, after ethanol solution has begun to flow into the peritoneal cavity (about one second after beginning to depress the syringe plunger), most mice begin determined struggling, often accompanied by squeaks and attempts to bite; a few mice learn to kick the needle, and will do so with surprising force during ethanol injection (personal observations). One group of researchers inferred that injections of high ethanol concentration were painful to their rats, because rats receiving thirty percent ethanol solution manifested a significant though transient hyperthermia after intraperitoneal injection, which was attributed to pain stress. Rats injected with twenty percent ethanol showed a smaller, non significant transient hyperthermia. In subsequent experiments fifteen percent ethanol solution was used, and the hyperthermia was not observed (Spiers et al, 1984).

\section{Administration of Ethanol via Inhalation}

Mice metabolize and eliminate ethanol rapidly, so it is difficult to maintain high levels of ethanol in the mouse using intraperitoneal injections. However, since ethanol is a volatile substance, it can also be inhaled. Ethanol readily moves from the lungs into the circulatory system; it has been 
known for more than one hundred years that ethanol can enter the body via this route (Pohorecky and Brick, 1988). Ethanol is very soluble in blood, with a blood solubility to air solubility ratio of about 2100 to 1 (Goldstein, 1972). Especially for studies of physical dependence, when maintaining constant systemic levels of the drug is desirable, inhalation is a superior method of administration. During inhalation the exposure to drug is more nearly constant, and the fright and pain associated with frequent ethanol injections are eliminated.

During induction of dependency, if drug levels within the body were allowed to fluctuate, intermittent partial recovery might occur in physiological systems that respond quickly to changing ethanol levels (Goldstein, 1972). Theoretically, stable blood ethanol levels could be maintained during inhalation by calculating the rate of ethanol metabolism and balancing this rate with pulmonary intake by varying the ambient ethanol vapor concentration, but clearly this would be difficult to achieve in practice; changes in rate of drug metabolism would rapidly throw the system out of balance (Goldstein and Pal, 1971). In practice, a "priming" dose of ethanol is given at the beginning of inhalation exposure, to quickly establish the approximate blood ethanol level that is to be maintained via inhalation. This avoids the lag in attaining stable blood ethanol levels that would otherwise occur (Goldstein, 1972). Blood ethanol levels 
during inhalation vary with, and can be roughly estimated from ethanol vapor concentrations (Goldstein, 1972), although assays of actual blood ethanol content are required to determine precise blood levels. At blood ethanol concentrations of about $1.5 \mathrm{mg} / \mathrm{ml}$ and above, mice exhibit ataxia, tremors, and abnormal sleeping posture (on their backs, for example) during inhalation exposure (Goldstein, 1972). This blood ethanol level results when mice are kept in an inhalation chamber with an ambient ethanol concentration of approximately $10 \mathrm{mg} / 1$ (Goldstein, 1972). In addition, weight loss during ethanol vapor exposure, like blood ethanol concentration, is proportional to ethanol vapor concentration (Goldstein, 1972). Therefore to maximize mouse survival and subsequent viability for experiments, it is safest to maintain air ethanol concentrations below $10 \mathrm{mg} / \mathrm{l}$.

If mice are exposed only to ethanol during inhalation experiments, in practice many die; blood levels vary widely in different mice, or in the same individual at different times, so that some mice reach lethal levels in an experiment where the mean blood concentration remains moderate (Goldstein, 1972). To maintain stable blood ethanol levels, the major liver isozyme of liver alcohol dehydrogenase (ADH) in mice, $A D H-A_{2}$ (Rout, 1992), is inhibited using pyrazole, which acts as a competitive inhibitor of the enzyme in vivo, leading to a greatly slowed rate of disappearance of ethanol from the blood in a dose-dependent fashion (Goldberg and Rydberg, 
1969). Pyrazole acts by combining at the active site of the enzyme after $\mathrm{ADH}$ has combined with its coenzyme nicotinamide adenine dinucleotide (NAD), to create an inactive complex (Goldstein 1983, p.8). Complete inhibition of the enzyme would require a dose of pyrazole that is toxic to mice; a compromise dose of $1 \mathrm{mmole} / \mathrm{kg}(68 \mathrm{mg} / \mathrm{kg})$ inhibits ethanol elimination by about seventy percent (Goldstein and Pal, 1971) and is about one-eighth the $\mathrm{LD}_{50}$ for mice (Goldstein, 1972). Pyrazole has a half-life of about ten hours in mice (Goldstein, 1974), and pyrazole injections are given daily during production of physical dependence on ethanol by inhalation. After each pyrazole injection, blood ethanol rises. However when pyrazole levels start to fall, rising ethanol concentration in the system begins to overcome the inhibition of the enzyme by pyrazole, and blood ethanol levels begin to decline. The daily variation in blood ethanol is approximately in the range of $0.5 \mathrm{mg} / \mathrm{ml}$ at this dose of pyrazole (Goldstein, 1972). Physical dependence (measured by manifestation of withdrawal syndrome upon cessation of ethanol exposure) develops in mice within about three days when the inhalation protocol is used (Goldstein, 1974; Pohorecky and Brick, 1988).

\section{Interactions with Membranes}

Once ethanol enters the circulation, it is distributed throughout the water compartments of the body, arriving first at tissues with the greatest blood supply (i.e. brain, lung, 
kidney and liver) and last at the least vascular tissues (i.e. bone) (Pohorecky and Brick, 1988). When ethanol in the blood reaches a cell, it interacts with the cellular membrane. Lipid solubility and membrane perturbation effects of alcohols vary directly with chain length (Feller and Crabbe, 1991), and at least for alcohols of up to six carbons in length, the solubility and disordering effects correlate well with effects in living mice; both the hypnotic dose (Goldstein, 1984) and the dose required to elicit a given decrease in rectal temperature (Feller and Crabbe, 1991) decrease with increasing chain length. Alcohols of seven to ten carbons in length are less potent in mice, possibly because they are too waterinsoluble to be delivered to the cell in sufficient concentrations in the blood (Goldstein, 1984). Ethanol itself is generally accepted to be about ten times more soluble in water than in membrane lipid (Goldstein, 1983, p.6).

The effects produced in a membrane by the incorporation of a substance can be measured by a variety of methods. These include nuclear magnetic resonance, calorimetric measures of changes in solid-to-liquid transition temperatures, and measurements of the mobility of labels incorporated into the membrane. Electron paramagnetic resonance (EPR, also called electron spin resonance) techniques depend upon absorption of energy by a spin label probe (an unpaired electron) in a magnetic field (Goldstein, 1983, p.54). The spin label is attached to a compound which can be taken up into the 
membrane, and in the region in which it is located (which may not represent the membrane as a whole), reports its own motion (Goldstein, 1983, p.54). Many methods and many investigators agree on the basic observation that anesthetic drugs, including ethanol, disrupt the structure of membranes; both membrane "order", as determined by measuring the movement of spin labels, and transition temperatures decrease in liposomes made solely of phospholipids, in erythrocyte membranes, in plasma membranes of neurons and liver cells, and in intracellular membranes such as those of microsomes and mitochondria (Goldstein, 1989).

This disruptive effect is not uniform throughout the lipid bilayer, but rather differentially affects regions or domains within the membrane, reflecting the nonuniform distribution of phospholipids and cholesterol in the membrane (Rall, 1990). Increasing concentrations of ethanol, like increasing temperature, disorder the more fluid regions of the membrane core to a greater extent than the stiffer membrane surface regions (Chin and Goldstein, 1981). Cholesterol blocks the disordering effect of ethanol in lecithin bilayers (Chin and Goldstein, 1977), cholesterol-enriched plasma membranes, and erythrocytes of animals fed cholesterolenriched diets (Chin and Goldstein, 1981). This evidence suggests that the lipid composition of local membrane regions may determine their vulnerability to ethanol (Goldstein, 1984). There may also be a second partitioning between the 
lipid membrane and hydrophobic amino acid residues on the surfaces of folded membrane proteins residing within the membrane, producing probable effects on protein function (Goldstein, 1989). In such a way, the relatively nonspecific membrane disordering actions of ethanol could result in some quite specific effects on membrane function, including the function of membrane receptors.

Genetic evidence collected from strains of mice differentially sensitive to the acute effects of ethanol supports the idea of a correlation between the amount of membrane disorder, and the effect of the drug in the living animal. In a population of genetically heterogeneous mice, in vitro tests showed that the membranes from individuals most sensitive to ethanol ataxia were disordered to a greater extent by ethanol than were the membranes of ethanol-resistant individuals (Goldstein et al, 1982). Similarly, mice bred for resistance to the hypnotic effects of ethanol had plasma membranes that were less disordered by ethanol, in vitro, than were membranes from mice of a sensitive line (Goldstein et al, 1982) .

If disordering of membranes by ethanol were the cause of its effects, then ethanol ought to be more potent in a warm, than in a cold environment. This postulate is supported by a wealth of evidence (Dinh and Gailis, 1979; Malcolm and Alkana, 1981; Pohorecky and Rizek, 1981; Malcolm and Alkana, 1983; Wenger and Alkana, 1984; Finn et al, 1990). Likewise, one 
might suspect that high pressure, which counteracts the fluidization of the membrane caused by ethanol, might mitigate or prevent the effects of the drug. Again, this appears to be true (Malcolm and Alkana, 1982; Alkana et al, 1991; Berge and Garcia-Cabrera, 1991).

The amount of membrane disordering caused by ethanol has been compared to that caused by temperature using the methods discussed above. The amount of disorder caused by anesthetic concentrations of ethanol can be mimicked by a rise in temperature of only about half a degree (Goldstein, 1989). In addition, sensitivity to hypnotic doses of ethanol appears to decline with increasing temperature in $129 / \mathrm{J}$ inbred mice and the IS selected line of mice (Finn et al, 1990). It seems therefore that the explanation for ethanol's effects cannot be a simple statement that it disorders and fluidizes membranes.

\section{Modulators of Ethanol's Effects}

Factors besides temperature and pressure can modulate the effects of ethanol. One such factor is age. Aging animals become more sensitive to the intoxicating effects of ethanol, although their aging membranes become less vulnerable to disordering (Goldstein, 1989). This, of course, argues against a mechanism of membrane disordering to explain ethanol intoxication. However, a decrease in blood flow through the liver or other decrease in liver function, or a change in body composition with age (such as a shift in mass from muscle to fat, decreasing the total water compartment of the body and 
decreasing the dilution of ethanol), might explain the agerelated shift in sensitivity (Pohorecky and Brick, 1988).

Acute stress can alter response to ethanol. Peris and Cunningham (1986) found that handling stress, which significantly elevates heart rate in the rat, seemed to accentuate body temperature response to both drug and control injections. The elevation in body temperature normally seen after a saline injection was greater when temperature was measured repeatedly with a rectal probe, than when temperature was measured with an implanted telemetry device; the decline in body temperature normally seen after ethanol injection was likewise greater when ethanol injection was paired with additional handling. In a followup study, it was found that a bright, flashing light produced effects just like those of handling on body temperature response to either saline or ethanol (Cunningham and Bischof, 1987).

Chronic stress can alter ethanol metabolism. After two weeks of immobilization stress (two and a half hours per day) in rats, significant increases in liver $\mathrm{ADH}$ and rate of ethanol metabolism were found, although there was no effect on the activity of other ethanol-metabolizing enzyme systems (Mezey et al, 1979). Stress alone can significantly increase plasma levels of corticosterone, norepinephrine and epinephrine (Livezey et al, 1985). Administration of corticoids did not alter liver $\mathrm{ADH}$ activity in rats or mice, but adrenalectomy prevented chronic ethanol-induced elevation 
in liver $\mathrm{ADH}$, suggesting that the adrenal catecholamines may be important mediators of this change in ethanol metabolism (Pohorecky and Brick, 1988).

circadian variations exist in the absorption, distribution, metabolism and excretion of many drugs (LeBrecque and Bélanger, 1991). Time of day is an important factor influencing biological response to, and disposition of ethanol in the body, and circadian effects have been documented in a wide variety of studies. However, results do not always agree. Mice were most susceptible to the toxic effect of a large dose of ethanol when it was injected in the lights-out period, a time which coincides with their normal peak of body temperature and activity (Haus and Halberg, 1959; Deimling and Schnell, 1980). Ethanol levels in blood, brain and liver of rats measured one hour after ethanol injection at various times of day showed higher levels during the dark phase, when rats (like mice) are normally most active and their body temperature is normally highest (Soliman and Walker, 1979). Similar results have been obtained using the mouse: (Walker et al, 1982). However others have found either that ethanol was metabolized much more quickly by rats during the dark phase (sturtevant and Garber, 1980), or that there was no difference in the rate of ethanol metabolism at different times throughout the day-night cycle in rats (Brick et al, 1984) or in mice (Deimling and Schnell, 1980; Gilliam and collins, 1983), or in the activity of ADH in vitro 
(Deimling and Schnell, 1980). There appears to be more agreement as to the effect of time-of-day on body temperature response to ethanol; generally there has been a greater decrease in temperature measured after ethanol injections during the light, than during the dark phase in rats (Sturtevant and Garber, 1980) and mice (Haus and Halberg, 1959 ; Deimling and Schnell, 1980; Walker et al, 1982). Normal rats respond to a saline injection with a rise in circulating levels of corticosterone. The elevation of corticosterone was significantly greater after ethanol injection, than after saline injection at all times of day except in the middle of the lights-on period (Brick et al, 1984).

One interesting study (Sturtevant and Garber, 1980) was performed to investigate time-of-day effects on ethanol response by using rats on shifted photoperiods. Six groups of rats were all kept on the typical photoperiod of twelve hours of light and twelve hours of darkness, but lights-on was staggered by four hour intervals for the groups (the lights came on for group 1 at 0100, for group 2 at 0500, etc). Some groups of shifted-photoperiod animals had food always available to them throughout the day. Other groups were offered food for only four hours at the same clock time, which occurred at a different point in their photoperiod cycle for each of the six groups. The animals restricted to four hours per day access to food (which gained weight at a rate similar to that of freely feeding animals) showed a rate of ethanol 
clearance from the blood significantly less if they had been without food for sixteen or more hours before injection, than if they had eaten twelve hours or less before injection. This finding has obvious implications for all the results discussed above. To further complicate the picture, the familiar circadian rhythm of body temperature in the normal rat can be essentially abolished by stress over which the animal has no control (Kant et al, 1991). Since experimental regimens commonly are fraught with stresses over which the experimental animal has no control whatsoever, it becomes very difficult to construct a coherent picture of the true effect of time-of-day on temperature response to ethanol.

\section{Specific Physiological and Cellular Effects}

As alluded to above, the process of ethanol's entry into cell membranes, which might seem at first glance to be a generalized process that would be expected to produce generalized effects stemming from bulk disordering of membranes, can have quite specific consequences for particular physiological systems, and membrane and cellular components and processes. One such specific effect of ethanol is its well-known ability to activate the hypothalamic-pituitaryadrenal (HPA) system. In rodents, the hypothalamus responds to acute ethanol by releasing corticotropin releasing hormone, which stimulates cells in the pituitary to liberate adrenal corticotropic hormone into the bloodstream, leading to secretion of glucocorticoids by the adrenal cortex (Waltman 
and Wand, 1992). In this way, ethanol acts like other stressors do, causing release of glucocorticoids which subsequently act first to break down stored fats, then proteins, and to stimulate glucose-6-phosphatase activity, resulting in release of significant amounts of glucose into the bloodstream (Gorbman et al, 1983, p.447). There appears to be cross-tolerance in this system to the effects of ethanol and stress. Exposure to stress blunts subsequent response to ethanol, and vice versa; this apparent cross-tolerance does not result from altered corticosterone metabolism, altered adrenal responsiveness to adrenocortcotropic hormone, variance in ethanol blood levels or change in rate of ethanol metabolism (Waltman and Wand, 1992). The mechanism by which ethanol stimulates hypothalamic release of corticotropin releasing hormone is not known (Waltman and Wand, 1992). Ethanol also affects release of $\beta$-endorphin from the hypothalamus. This effect is dose dependent. Low concentrations of ethanol stimulate release of $\beta$-endorphin, perhaps mediating the mild euphoria associated with ethanol ingestion. However endorphin release becomes progressively smaller as the concentration of ethanol increases, perhaps contributing to the depression and anxiety that may be experienced following excessive ethanol consumption (Gianoulakis, 1990).

A primary effect of ethanol intoxication is deterioration of cerebellar function, manifested by a loss of physical 
coordination. Within the cerebellum, the most abundant cells are the granule cells, which initiate information processing by neurons in the cerebellum (Huang and Huang, 1992). Ethanol specifically and selectively affects synaptic transmission in a subpopulation of ethanol-sensitive granule cells (Huang and Huang, 1992). The hippocampus is important in attention and responding and memory, and is implicated in the mediation of epileptic seizures. Ethanol reduces the release of acetylcholine from neurons within the hippocampus by a specific effect on cholinergic neurons, rather than through a general reduction of all neuronal activity (Gonzalez and Sun, 1992).

Much interest has been focused on the specific effect of ethanol on neurotransmitter receptors which act as ligandgated ion channels. The sedating and anticonvulsant actions of ethanol are believed to be mediated via the inhibitory neurotransmitter gamma-aminobutyric acid (GABA) (Ticku and Kulkarni, 1988). This receptor, called the GABAbenzodiazepine receptor ionophore complex, is believed to consist of four subunits, with binding sites for GABA, benzodiazepine, picrotoxin and barbiturates, associated with a chloride channel (Ticku and Kulkarni, 1988). In addition there may be multiple steroid regulatory sites associated with the complex (Melchior and Ritzmann, 1992). Ethanol, in concentrations present during acute intoxication, potentiates GABA receptor-mediated chloride transport. This potentiation 
is believed to be a specific effect on chloride flux. It is specifically antagonized in membrane vesicles prepared from brain cells and in cultured spinal cord cells by GABA receptor antagonists, by the chloride channel blocker picrotoxin, and by the benzodiazepine receptor inverse agonists R015-4513 and FG-7142 which bind to the benzodiazepine receptor to produce effects opposite to those produced by the natural ligand (Mehta and Ticku, 1988; Leidenheimer and Harris, 1992). The stimulation by ethanol of GABA-mediated chloride flux may be region-specific in the brain. Membrane vesicles prepared from cerebellum or cortex, but not from hippocampus display this sensitivity (Leidenheimer and Harris, 1992). In whole animals, bicuculline, a GABA receptor antagonist, diminishes ethanol-induced impairment of performance on a tilting plane task in rats (Ticku and Kulkarni, 1988). Animals are protected by R015-4513 against intoxication and mortality from very large doses of ethanol, although blood ethanol concentration is not affected (Ticku and Kulkarni, 1988).

Ethanol also appears to interact with the glutaminergic system in a specific manner. Glutamate, a major excitatory neurotransmitter in the central nervous system, acts through at least three receptor subtypes; one of these, the N-methylD-aspartate (NMDA) receptor, is thought to be particularly involved in cognitive function and certain forms of behavior (Lovinger et al, 1989), including short-term memory in the hippocampus. In a concentration range corresponding to the 
range in which intoxication occurs in humans, ethanol specifically inhibits NMDA-activated ion (calcium, sodium and potassium) flux in a dose-dependent manner (Lovinger et al, 1989).

Ethanol has effects on important cell membrane enzyme systems. One such is the sodium- and potassium-activated adenosine triphosphatase ( $\mathrm{Na}^{+} / \mathrm{K}^{+}$ATPase) ion pump, found in membranes throughout the body. This pump prevents dissipation of the ionic gradient across a membrane by actively transporting $\mathrm{K}^{+}$into the cell and $\mathrm{Na}^{+}$out, against their electrochemical gradients, using energy from the hydrolysis of ATP to ADP. Ethanol is well known to inhibit the activity of this membrane transporter (Pohorecky and Brick, 1988). Evidently ethanol interacts with relatively superficial sites in the cell membrane, disturbing (fluidizing) the normal lipid environment of the protein, and interfering with the function of the externally oriented $K^{+}$site of the ATPase (Kalant et al, 1978).

An important cell regulatory system is that of cyclic adenosine $3^{\prime}, 5^{\prime}$-monophosphate (CAMP) and cyclic guanosine $3^{\prime}, 5^{\prime}$-monophosphate (CGMP). This system is coupled to a receptor and consists of three parts; the receptor, a regulatory protein (G protein) and a catalytic unit. When a neurotransmitter binds to its receptor in such systems, the complex associates with a form of the G protein which is bound to GDP (hence its name). The receptor-G protein interaction 
causes release of GDP and binding of GTP; this event lowers the affinity of the receptor for the neurotransmitter, and the $G$ protein dissociates into its component subunits, one of which (still bound to GTP) activates adenylate cyclase to form CAMP (Hoffman and Tabakoff, 1990). Cyclic AMP in turn activates specific protein kinases which promote protein phosphorylation or phosphorylation of histones, causing changes in DNA/RNA transcription (Pohorecky and Brick, 1988). Low concentrations of ethanol selectively promote the activation of one member of the $G$ protein family $\left(G_{s}\right)$, but have no effect on the function of other identified $G$ proteins (Hoffman and Tabakoff, 1990). Chronic ethanol exposure results in a decrease in the effect of neurotransmitters that act via $G_{s}$; reduced basal and receptor-stimulated CAMP levels have been demonstrated in the lymphocytes of alcoholics, and reduced adenylate cyclase activity in response to stimulation in their platelets (Hoffman and Tabakoff, 1990).

\section{Elimination of Ethanol}

Ethanol is eventually eliminated from living animals. This elimination is accomplished by a variety of mechanisms. Some ethanol (perhaps two to ten percent) (Goldstein, 1983, p.6; Rall, 1990) is excreted unchanged from the lungs, in the sweat, and in the urine. Excreted ethanol may have forensic importance to human beings, for instance in determining whether an erratic driver is drunk; ethanol concentration measured in breath is multiplied by the factor 2100 to convert 
to arterial blood concentration (Goldstein, 1983, p.7). Urine gives a much less precise estimate of systemic ethanol, since the contents of the bladder represent an integration over time of the ethanol concentrations that have reached it since the bladder was last emptied (Goldstein, 1983, p.7). The lion's share of ethanol introduced into the body is completely oxidized, first to acetaldehyde, then to water and carbon dioxide. There are three different systems by which the metabolism of ethanol is primarily accomplished; alcohol dehydrogenase, the microsomal ethanol oxidizing system, and the enzyme catalase.

\section{Elimination of Ethanol by Alcohol Dehydrogenase}

The first step in the metabolism of ethanol is its oxidation to acetaldehyde. This is accomplished mainly in the liver, by liver $A D H$. The major mouse liver enzyme $A D H-A_{2}$ is one of three different isozymic forms of $A D H$ which have been characterized in the mouse. It has a very high affinity for ethanol and is sensitive to pyrazole inhibition (Rout, 1992). $A$ second isozyme, $A D H-B_{2}$, is widely distributed in mouse tissues, oxidizes ethanol only at high concentrations, and is insensitive to pyrazole inhibition (Rout, 1992). The primary ethanol-oxidizing enzyme found in the stomach and eye of the mouse is the third isozyme, $A D H-C_{2}$. It accepts a broad range of alcohols as substrates, and is situated between the other two isozymes both in its affinity for ethanol, and its sensitivity to pyrazole inhibition (Rout 1992). Henceforth, 
the generic term "ADH" used in this Introduction will refer to the major mouse liver isozyme $A D H-A_{2}$.

The oxidation of ethanol is begun according to the following reaction;

$$
\mathrm{CH}_{3} \mathrm{CH}_{2} \mathrm{OH}+\mathrm{NAD}^{+}{ }_{\mathrm{NOH}} \rightarrow \mathrm{CH}_{3} \mathrm{CHO}+\mathrm{NADH}+\mathrm{H}^{+}
$$

In this reaction, first the hydrogen acceptor $\mathrm{NAD}^{+}$combines with the enzyme ADH; ethanol subsequently combines with this enzyme-coenzyme complex (Goldstein, 1983, p.8). The affinity of ethanol for $A D H$ is very high, so that the enzyme is saturated even at low levels of ethanol (Pohorecky and Brick, 1988); in consequence, the rate of disappearance of ethanol from the blood is nearly linear, independent of the ethanol concentration. After the oxidation of ethanol to acetaldehyde has taken place, the acetaldehyde dissociates from the enzyme. The last step, dissociation of NADH from the enzyme, is slow because the affinity of NADH for the enzyme active site is very high (Goldstein, 1983, p.8).

In vivo, the regeneration of $\mathrm{NAD}^{+}$limits the rate of ethanol metabolism. The stoichiometry of the above reaction requires a mole of $\mathrm{NAD}^{+}$for every mole of ethanol oxidized. A heavy evening of drinking (about six strong drinks) might amount to one hundred grams, or just over two moles of ethanol, requiring two moles, or a kilogram and a half of NAD to oxidize it via this pathway (Goldstein, 1983, p.9)! The liver must regenerate its store of $\mathrm{NAD}^{+}$from the NADH which remains at the end of the reaction. NADH does not cross the 
mitochondrial membrane, so $\mathrm{NADH}$ in the cytosol reduces a substrate (such as oxaloacetate to malate) which can cross the mitochondrial membrane, become oxidized by the respiratory chain, and emerge to be reduced again, in the process oxidizing another NADH to $\mathrm{NAD}^{+}$. This process slows, or possibly stops the Krebs cycle, and metabolism of other compounds, such as fatty acids, is severely disrupted (Goldstein 1983, p.10). Efforts to find a sober-up magic bullet have centered around substrates that can be reduced by NADH; pyruvate, fructose, and other NADH oxidizing compounds have been shown to increase the rate of ethanol metabolism and decrease acute ethanol intoxication (Goldstein, 1983, p.10; Pohorecky and Brick, 1988). However, because of the stoichiometry of the reaction, the dose of magic bullet must be of about the same magnitude as the dose of ethanol to have a significant effect.

Elimination of Ethanol by the Microsomal Ethanol Oxidizing System

Microsomal fractions of liver tissue can oxidize ethanol in the presence of molecular oxygen and the reduced form of nicotinamide adenine dinucleotide phosphate (NADPH) (Goldstein, 1983, p.14). This phenomenon is due to a second ethanol-oxidizing mechanism, the microsomal ethanol oxidizing system (MEOS), which requires oxygen and NADPH in the following reaction (Pohorecky and Brick, 1988);

$$
\mathrm{CH}_{3} \mathrm{CH}_{2} \mathrm{OH}+\mathrm{NADPH}+\mathrm{H}^{+}+\mathrm{O}_{2} \rightarrow \mathrm{CH}_{3} \mathrm{CHO}+\mathrm{NADP}^{+}+2 \mathrm{H}_{2} \mathrm{O}
$$


This system is situated on the membrane of the smooth endoplasmic reticulum (Lehninger, 1975, p.502) and is responsible for oxidation of a number of drugs besides ethanol (Petersen and Atkinson, 1980). In this reaction the $\mathrm{Fe}^{3+}$ form of microsomal cytochrome P-450 combines with ethanol, and is reduced by one electron from NADPH to the $\mathrm{Fe}^{2+}$ form; the ethanol-P-450 complex is oxygenated, the second electron from NADPH converts the bound oxygen to the $\mathrm{O}_{2}^{-}$radical, and an oxidation-reduction reaction produces acetaldehyde and free water (which contains the oxygen originally introduced as $\mathrm{O}_{2}$ ) (Lehninger, 1975, p.503). Although MEOS probably contributes little to the oxidation of occasional acute ethanol, it is believed that this system is responsible for much of the increased rate of ethanol elimination observed after chronic administration (Lehninger, 1975, p.502; Petersen and Atkinson, 1980; Goldstein, 1983, p.15; Pohorecky and Brick, 1988; Rall, 1990). In rats, chronic ethanol increases MEOS activity, hepatic microsomal protein, smooth endoplasmic reticulum, and cytochrome P-450 (Goldstein, 1983, p.15). In a study of the development of metabolic tolerance in mice (Petersen and Atkinson, 1980), cytochrome P-450 content and MEOs activity increased in parallel to ethanol consumption during chronic ethanol administration. The existence of this system may explain inhibition by ethanol of the metabolism of a number of other drugs, as well as metabolic cross-tolerance with some of these drugs (Goldstein, 1983, p.15). 
Elimination of Ethanol by Catalase

During electron transport, as well as in hydroxylation and oxygenation reactions, toxic partial reduction products of oxygen may be formed (Lehninger, 1975, p.503). Hydrogen peroxide and the superoxide anion, $\mathrm{O}_{2}^{-}$, are extremely reactive and capable of damaging biological molecules. The enzyme superoxide dismutase converts superoxide into hydrogen peroxide and molecular oxygen. In microbodies (peroxisomes) of liver cells the enzyme catalase mediates the reaction

$$
\mathrm{H}_{2} \mathrm{O}_{2} \underset{\text { CAT }}{\rightarrow} \mathrm{H}_{2} \mathrm{O}+\frac{2}{2} \mathrm{O}_{2}
$$

to decompose the hydrogen peroxide formed by superoxide dismutase (Lehninger, 1975, p. 504). Interestingly, catalase also serves as the third system participating in ethanol metabolism when it mediates the following reaction (Pohorecky and Brick, 1988);

$$
\mathrm{H}_{2} \mathrm{O}_{2}+\mathrm{CH}_{3} \mathrm{CH}_{2} \mathrm{OH} \rightarrow 2 \mathrm{H}_{2} \mathrm{O}+\mathrm{CH}_{3} \mathrm{CHO}
$$

Ethanol is a good substrate for the reaction in vitro (Goldstein, 1983, p.13). The reaction seems to contribute little to ethanol metabolism in living livers, however, possibly because hydrogen peroxide is not formed in sufficient quantities to account for the oxidation of large amounts of ethanol (Goldstein, 1983, p.13; Pohorecky and Brick, 1988). In humans, at least, methanol is apparently oxidized by catalase, as well as by $\mathrm{ADH}$; ethanol competes with methanol for the active site on both enzymes (Goldstein, 1983, p.13). 
Further oxidation of Ethanol

All the above reactions have succeeded only in producing acetaldehyde from ethanol. The oxidation of acetaldehyde to acetic acid in the liver and elsewhere is mediated mainly by NAD-linked nonspecific aldehyde dehydrogenase (ALDH) as follows (Goedde and Agarwal, 1989);

$$
\mathrm{CH}_{3} \mathrm{CHO}+\mathrm{NAD}^{+}+\underset{\mathrm{ALDH}}{\mathrm{H}_{2} \mathrm{O}} \rightarrow \mathrm{CH}_{3} \mathrm{COOH}+\mathrm{NADH}+\mathrm{H}^{+}
$$

A wide range of straight and branched chain, aliphatic and aromatic aldehydes may serve as substrates in this irreversible reaction, producing the corresponding acids (Goedde and Agarwal, 1989). Usually some acetate is released into the blood, where it is converted to carbon dioxide in other tissues, particularly in the skeletal muscle (Goldstein, 1983, p.18). Multiple isozymic forms of ALDH exist, located in a variety of tissues besides liver, including stomach, hair root follicles, brain, erythrocytes, and the placenta in pregnant mammals (Goedde and Agarwal, 1989).

Normally the ALDH in liver does not quite keep up with the production of acetaldehyde, and small amounts escape to circulate in the blood during the oxidation of ethanol (Goldstein, 1983, p.19). In the case of organisms with ALDH deficiency, larger amounts of acetaldehyde may be present in the body, resulting in symptoms such as hypotension, peripheral vasodilation, and irregular heartbeat (Goedde and Agarwal, 1989). In experiments using dogs, the effects of infused acetaldehyde were blocked by propanolol, indicating 
that they are mediated by norepinephrine release at $\beta$ adrenergic receptor sites (Goldstein, 1983, p.22).

\section{THERMOREGULATION}

It is presumably true that, for any living organism, there is a temperature, or temperature zone, which is optimal for function; likewise there are lower and upper temperature bounds which may not be exceeded by the living organism. The actual temperatures which define the zone of optimal function, and the upper and lower limits compatible with life, vary enormously among different groups of living things, and also for an individual organism under varying circumstances. If we consider only the mammals, we find normal core temperatures from about $30^{\circ} \mathrm{C}$ in the echidna, to $38^{\circ} \mathrm{C}$ or more in many animals (Schmidt-Nielsen, 1990, p.244). Curiously, it seems widely true for endothermic animals that the upper body temperature compatible with continuing life (upper lethal temperature) is about $6^{\circ} \mathrm{C}$ above the normal core temperature (Schmidt-Nielsen, 1990, p.244).

Endotherms (from the Greek endon, "within" [Satinoff and Hendersen, 1977]), such as birds and mammals, can aid their high body temperature maintenance by means of internal heat production; ectotherms (from the Greek ektos, "outside" [Satinoff and Hendersen, 1977]), such as most fishes, amphibians, reptiles and insects, rely solely on external sources of heat, primarily supplied (directly or indirectly) 
by the sun (Schmidt-Nielsen, 1990, p.218). Mammals continuously produce heat from metabolism and muscle activity, and lose heat to (or gain heat from) the environment via radiation, evaporation, convection and conduction. Although environmental conditions change, mammals maintain body temperature within narrow limits by means of the thermoregulatory system. Sensors monitor skin and deep body temperature; a variety of responses can be marshalled to defend the regulated body temperature against perturbation. Mammals have three general ways to deal with a thermal stress (from Crawshaw, 1980). Temperature acclimation, which occurs over hours or days, is a long-term adjustment which will not concern us here. Behavioral responses and physiological adjustments, which may be activated almost immediately in response to thermal stress (or even in anticipation of thermal stress), will be further considered within this section, with emphasis upon the mouse.

The range of normal mouse body temperature is generally accepted to be about $36.5^{\circ} \mathrm{C}$ to $38.0^{\circ} \mathrm{C}$ (Harkness and Wagner, 1989, p.41), and a temperature range as wide as $34^{\circ} \mathrm{C}$ to $40^{\circ} \mathrm{C}$ is seen at extremes of environmental temperature (Jakobson, 1981). The upper lethal internal temperature is about $44^{\circ} \mathrm{C}$ (Jakobson, 1981), and mice can spontaneously recover normal body temperature after a lowering of core temperature to at least $26^{\circ} \mathrm{C}$ (personal observation). For the tiny mouse, maintenance of a constant body temperature is a major 
challenge; this is true primarily because of the large surface-to-volume ratio characteristic of the animal. In the cold, this large relative surface area means large heat losses through radiation, conduction and convection. The fur of the mouse, like the fur of most very small mammals, is thin and light, and does not thicken appreciably in cold conditions (Schmidt-Nielsen, 1990, p.257). The mouse has several weapons with which to defend body temperature in the cold. One is a high metabolic rate. As the ambient temperature declines from $30^{\circ} \mathrm{C}$ to $15^{\circ} \mathrm{C}$, the heat production of a mouse may double, rising from 880 kilocalories to 1740 kilocalories per square meter of surface area per day (Bernstein, 1966). Heat conservation also depends upon fur, and circulatory adjustments, and behavior. A cold mouse can huddle next to conspecifics, or curl up into a ball, tucking nearly naked ears, feet and tail beneath the furry body: a mouse may also simply choose a warmer environment, if a range of temperatures is available. In a hot environment, as long as ambient temperature does not exceed body temperature, skin surfaces which must be protected in the cold become radiators for losing heat which is picked up by the circulatory system and carried from the body core to the skin. Behavior is of major importance to the overly warm mouse. The animal can spread saliva over its thinly furred abdomen to encourage evaporative heat loss, adopt a sprawled position, or simply retreat to an underground burrow to wait for cooler times. 
Peripheral Temperature Sensors, Signal Transduction, and Efferent Pathways

The first requirement for successfully coping with a thermal stress, is detecting that a temperature change has occurred. For this purpose, mammals are richly supplied with temperature detectors - warm receptors and cold receptors. Basically, two criteria have been used to assign a thermosensory function to a neuron. First, its static firing rate is dependent upon its own temperature; second, its anatomical site coincides with an area known to evoke thermoregulatory responses to local warming or cooling (Jessen, 1990) - Peripheral thermodetectors exhibit a low, steady, temperature-dependent discharge rate ( $<15$ impulses per second) (Hensel, 1973a). Both cold and warm receptors increase their frequency of discharge as temperature is changed in the appropriate direction (cooling stimulates cold receptors, warming stimulates warm receptors), with the frequency of discharge proportional to the rate of change (Hensel, 1973a). Both types of receptors are transiently inhibited by a sudden change in the opposite direction.

Cutaneous cold receptors may be either myelinated fibers (higher conduction velocity, more common in smooth skin or facial skin) or non-myelinated fibers (low conduction velocity, more common in hairy skin and peripheral areas) (Hensel, 1973a; Iggo and Young, 1975). They are located less than two hundred micrometers deep in the skin, in the epidermis (Hensel, 1973a). As a population they display a 
relationship of static discharge to constant temperature that graphs as a bell-shaped curve with a maximum between $25^{\circ} \mathrm{C}$ and $30^{\circ} \mathrm{C}$, but individual fibers differ and may respond with static discharge between $-5^{\circ} \mathrm{C}$ and $+43^{\circ} \mathrm{C}$, with individual maximum responsiveness as low as $+10^{\circ} \mathrm{C}$ (Jessen, 1990). Cutaneous warm receptors display static discharges at temperatures above $30^{\circ} \mathrm{C}$, attain maximum static frequency between $40^{\circ} \mathrm{C}$ and $47^{\circ} \mathrm{C}$, and decrease at higher levels (Jessen, 1990). Their endings are located slightly deeper in the skin than are those of the cold receptors, at a depth of three hundred to six hundred micrometers (Hensel, 1973a).

By what sort of mechanism may a temperature change be transformed into a nerve impulse? The mechanism is not yet precisely understood, but plausible mechanisms have been postulated based upon the existence of temperature-dependent ionic transport processes within the cell membrane. A nerve signal begins with a change in membrane ion conductance. One hypothesis suggests a differential effect of temperature upon at least two ionic transport processes which exert opposite effects on membrane potential (simon et al, 1986). Because it is technically difficult to directly analyze the minute thermoreceptor free nerve endings with intracellular microelectrodes, studies have been done using other excitable structures as models for temperature transducers (simon et al, 1986). Mollusc neurons have primarily been used; most increase their discharge rates upon warming (behave like a 
warm receptor) (Simon et al, 1986). Studies on invertebrate neurons suggest that warm sensory signal transduction is mediated by a differential effect of temperature on membrane permeability to sodium and potassium ions. At higher temperatures, there is relatively more depolarizing sodium current than hyperpolarizing potassium current, resulting in depolarization and increased firing rates with warming (simon et al, 1986; Boulant et al, 1989; Kiyohara et al, 1989; Nakashima et al, 1989).

In Aplysia cold-sensitive neurons, the temperature dependent electrogenic pump $\mathrm{Na}^{+} / \mathrm{K}^{+}$-ATPase, which normally transports three sodiums out of the cell for two potassiums transported into the cell to help maintain the resting membrane potential, is inhibited by cooling; this results in depolarization of the cell (simon et al, 1986; prosser and Heath, 1991), whose membrane is quite permeable to sodium. Warming results in a hyperpolarization of the cold receptor membrane (and consequent failure to generate an action potential) at high temperatures (Nakashima et al, 1989). This hyperpolarization can be reversed by ouabain, which blocks the action of the pump and leads to depolarization (Boulant et al, 1989). Application of ouabain to frog or rat skin cold receptors blocks or reduces cold sensitivity (Boulant et al, 1989) .

Temperature signals from the body and legs, like all sensory inputs, travel from the periphery via the dorsal root 
ganglion and the dorsal horn neurons of the spinal cord (Brück and Hinckel, 1990; Jessen, 1990). Afferents from the facial area travel via the trigeminal ganglion to the lower brain stem (Brück and Hinckel, 1990). Some ascending fibers connect to the thalamus (Brück and Hinckel, 1990) and thence to the sensory cortex (Crawshaw et al, 1990), while others travel to the hypothalamus via the reticular and raphe areas (Crawshaw et al, 1990). Impulses travel in pathways from the hypothalamus to the thalamus via the mammillothalamic tract and the dorsal longitudinal fasciculus; activity of thalamic neurons which respond to skin warming or cooling is affected by changes in hypothalamic temperature (Sakata et al, 1989). In sum, it is postulated (from Brück and Hinckel, 1990) that the adrenergic subcoeruleus cell groups, located in the brainstem, are innervated (via the dorsal horn of the spinal cord) by skin cold receptors, and project to integrative networks in the posterior hypothalamus determining thresholds of heat production effector networks. Warm receptors, also arriving via the dorsal horn, project to the serotonergic nucleus raphé magnus in the brainstem, from which projections ascend to the integrative hypothalamic networks controlling heat dissipation effector networks. Parallel projections from the cold receptors ascend via the spinal route to the nucleus reticularis gigantocellularis, the nucleus raphe dorsalis (both in the brain stem), and on to the thalamus and the 
sensory cortex. Mutual inhibitory paths connect the nucleus raphe magnus and the subcoeruleus region.

\section{Internal Temperature Sensors}

Deep core thermoreceptors exist within the body, outside the central nervous system. In the rabbit, thermoreceptors have been found in tissue around the kidney and near major blood vessels supplying the intestine; thermal stimulation of these fibers can evoke panting and cutaneous vasodilation (Jessen, 1990). In the cat, cold-sensitive fibers have been located in nerves arising from the lower esophagus and stomach (Jessen, 1990); in the ewe, panting and shivering can be evoked by intra-abdominal heating and cooling (Hales, 1974). The spinal cord itself is thermosensitive, and has thermoregulatory capabilities. Cold-sensitive neurons in the spine of the cat exhibit depolarization due to a decrease in potassium permeability relative to sodium permeability; this suggests that in some cold-sensitive neurons potassium permeability is more temperature sensitive than is sodium permeability, and the decrease in potassium permeability upon cooling results in depolarization and an increase in firing rate in these neurons (Boulant et al, 1989).

The spinal cord is especially important for shivering. In the cooled guinea pig, heat generated in brown fat via nonshivering thermogenesis keeps the spinal cord warm and suppresses shivering, though nonshivering thermogenesis can be suppressed by local warming of the preoptic area; in the rat 
nonshivering thermogenesis can also be suppressed by high spinal cord temperatures, but shivering is inhibited at a lower temperature than nonshivering thermogenesis (Brück and Hinckel, 1990). In the goat, spinal cord heating evokes panting and inhibits shivering (Brück and Hinckel, 1990). Nonshivering thermogenesis is a more economical warming mechanism than is shivering, and this control through spinal heat receptors helps body temperature to be maintained by the most economical means (Brück and Hinckel, 1990).

Hypothalamic Temperature Sensitivity

It has long been known that the hypothalamus is of primary importance in the control of thermoregulation (Magoun et al, 1938). Thermal stimulation experiments in the goat and guinea pig indicate that hypothalamic thermosensitivity is mainly confined to the preoptic nucleus and the anterior hypothalamic area (Brück and Hinckel, 1990). Together these loci are termed the $\mathrm{PO} / \mathrm{AH}$. Neurons in the $\mathrm{PO} / \mathrm{AH}$ receive input from peripheral and internal thermoreceptors, and thermal stimulation of this area can evoke thermoregulatory responses. There are likely also interactions between the temperature information arriving at the hypothalamus, the thermoregulatory control network, and the pleasure-pain system in the brainstem (Crawshaw et al, 1990); for example, in human subjects, internal body temperature determines whether an external temperature stimulus is perceived as comfortable or uncomfortable (Cabanac, 1971). The hypothalamus, however, 
serves functions besides temperature regulation, including regulation of osmotic balance, food intake, and reproductive functioning. Many individual hypothalamic neurons are sensitive both to temperature and to other stimuli, such as osmotic pressure, sex steroids, and glucose (Boulant and Silva, 1988). The specificity of function found in peripheral thermoreceptors does not apply to these central neurons, many of which appear to be multimodal, providing for interactions between various physiological control mechanisms; this makes analysis of the function of an individual unit very difficult (Jessen, 1990). In addition, because hypothalamic thermosensitive neurons tend to have small cell bodies, direct electrophysiological recording from them is technically challenging (Boulant et al, 1989).

There appears to be a preponderance of warm-sensitive units in the PO/AH (Brück and Hinckel, 1990; Jessen, 1990). This warm sensitivity is maintained even when synaptic transmission is blocked, which indicates that the neurons are themselves thermosensitive (possess primary thermosensitivity) (Jessen, 1990). In tissue slice preparations, warm-sensitive $\mathrm{PO} / \mathrm{AH}$ neurons which are highly sensitive to temperature changes between $35^{\circ} \mathrm{C}$ and $40^{\circ} \mathrm{C}$ lose their warm sensitivity when tetrodotoxin (which blocks voltage-gated sodium channels) is added to the perfusing medium (Kiyohara et al, 1989). Recordings made in slice preparations from septal neurons with primary warm sensitivity likewise indicate that the 
depolarization caused by increasing temperature is due to sodium channels with high sensitivity to temperature (Nakashima et al, 1989). This suggests a mechanism for signal transduction in PO/AH neurons like the mechanism already discussed for peripheral warm thermosensors.

Cold-sensitive PO/AH neurons, however, appear to behave differently from cold-sensitive peripheral thermosensors. Ouabain does not block the cold sensitivity of cold-sensitive neurons in perfused PO/AH tissue slices (Curras et al, 1986), but many or most cold-sensitive neurons in the $\mathrm{PO} / \mathrm{AH}$ lose thermosensitivity when synaptic transmission is blocked (Jessen, 1990). Unlike the peripheral cold-sensitive neurons discussed above, these central "cold-sensitive" neurons may in fact lack inherent temperature sensitivity, rather being primarily synaptically driven (Boulant et al, 1989).

The preoptic and anterior hypothalamic areas that make up the $\mathrm{PO} / \mathrm{AH}$ appear somewhat dissimilar in function. Injections of norepinephrine into the anterior hypothalamus causes increased body temperature in guinea pigs, while similar injections into the preoptic have no effect; on the other hand, heating the preoptic area suppresses nonshivering thermogenesis, but heating the anterior hypothalamus has no effect (Crawshaw et al, 1990). This evidence indicates that the anterior hypothalamus is more important in heat conservation responses (response to cold), while the preoptic 
is more important in heat dissipation responses (response to heat) in the guinea pig.

Neuronal Model for Central Thermoregulatory Control

Given this complex vista of inputs and interconnections, how might a controller of body temperature within the $\mathrm{PO} / \mathrm{AH}$ function? Conceptually, the existence of thermoregulation implies that

... internal temperature is compared in some way with a reference, and when a difference occurs an appropriate response is made tending to reduce that difference... it is the sign and magnitude of the difference between (body) temperature and some 'virtual set' or 'reference' temperature that determines both the type and the magnitude of response. The response must always be appropriate to reduce the magnitude of the difference (Hammel, 1970).

In the language of control systems theory, the thermoregulatory system could be described as a negative feedback control system, consisting of

... a controlled system, the body, which may be subjected to a disturbance, environmental heat or cold or metabolic heat. This disturbance causes a change in the controlled variable, some body temperature. The value of the controlled variable is detected by a sensor, and a corresponding feedback signal is generated. Any deviation of the controlled variable from the reference value constitutes a load error which activates a controller. The controller institutes a control action in such a way as to counteract the deviation of the controlled variable. This model includes a reference in the form of a signal, generated physiologically, against which the feedback signal is compared. The value of this reference signal is then the set-point for the system (Hensel et al, 1973). 
Is this the way that temperature regulation works? Without question, disturbances of the thermal status of the body occur; the disturbances are sensed, as discussed above; the organism responds to preserve or restore body temperature, in ways discussed below. But first we must consider what constitutes the "set-point" for body temperature. Is it Hammel's "'virtual set' or 'reference' temperature"? The engineer's "physiologically generated reference signal"? Postulating such a master reference temperature somewhere within the brain may be a useful working idea, but on closer examination the idea prompts more questions. How would such a thermostat be set? How would this signal reference be changed to a different level (as it can be, discussed below), then restored to its former setting? In fact we can propose a functional thermostat using neurons in the brain that respond with increasing activity to rises in the controlled variable (body temperature) and neurons that respond with increasing activity to declines in the controlled variable, without resorting to a single "... reference point in the sense of a reference signal generated by a definable neural structure" (Hensel et al, 1973).

Hammel (1965) proposed a model to explain central control of thermoregulation in light of the results of studies done on thermoregulatory responses of dogs after hypothalamic heating. This model

...has had a major impact on the field of thermoregulation for over a decade...it (formed) 
the basis of nearly all subsequent neuronal models (and) offered a very good explanation of the proportional changes in thermoregulatory responses and the apparent shifts in set-point temperature regulation during fever, exercise, and changes in peripheral temperature. The importance of this model should not be underestimated (Boulant, 1980).

Hammel's model basically proposed two groups of thermoregulatory control neurons in the PO/AH. One heat loss control group with a high $\ell_{10}$ (neurons with firing rates very sensitive to hypothalamic temperature change) would stimulate heat loss mechanisms (i.e. panting) and inhibit heat conservation or production mechanisms (i.e. vasoconstriction and shivering). A second heat conservation control group with a low $Q_{10}$ (little change in firing rates with change in hypothalamic temperature) would do the reverse: stimulate heat conservation/production responses, and inhibit heat loss mechanisms. Hammel envisioned a competition between the heat conservation and heat dissipation control groups of hypothalamic neurons in effector activation. The shivering effectors, for example, would receive stimulatory input from the heat conservation/production control group and inhibitory input from the heat dissipation control group, and the relative balance between those inputs would determine whether shivering would occur, or be suppressed. In this model, the different $Q_{10}$ characteristics of these two control groups determined whether heat loss or heat conservation effectors would be stimulated. At high temperature, the high $Q_{10}$ neurons would be much more active than the inhibitory low $\boldsymbol{Q}_{10}$ neurons, 
stimulating heat loss responses. At low temperature, the sensitive high $\ell_{10}$ neurons would decrease their firing rates much more than the relatively insensitive low $Q_{10}$ neurons, and heat conservation and production effectors would receive greater stimulation. The "set-point" would naturally occur at the point of intersection, where firing rates of the high $Q_{10}$ and low $Q_{10}$ neurons were the same.

It had been observed in experiments that skin temperature affected the hypothalamic threshold temperature required to elicit thermoregulatory responses. For instance, if an animal's skin was warm it would begin panting at a lower hypothalamic temperature than if its skin were cold, as if the threshold for eliciting this response had been altered by skin temperature. Hammel's model also explained these shifts in set point temperature, by including inputs from cutaneous warm and cold receptors. Input to the high $Q_{10} \mathrm{PO} / \mathrm{AH}$ neurons controlling heat loss responses would come from warm receptors; input to the low $Q_{10} \mathrm{PO} / \mathrm{AH}$ neurons controlling heat conservation responses would come from cold receptors. During skin warming, for example, before the temperature of the $\mathrm{PO} / \mathrm{AH}$ itself changed, the high $Q_{10}$ neurons would receive excitatory input from cutaneous warm receptors, increasing the firing rates of the high $Q_{10} \mathrm{PO} / \mathrm{AH}$ neurons. At the same time the input to low $Q_{10}$ neurons from cutaneous cold receptors would be decreased, decreasing the firing rates of the low $Q_{10}$ neurons. The net result of displacing the firing curves of 
the two groups of $\mathrm{PO} / \mathrm{AH}$ control neurons, would be to move the temperature at which their firing rates intersect (the setpoint) to the left, or to a lower hypothalamic temperature; in other words, when the skin is warm, heat loss effectors would be activated at a lower hypothalamic temperature than they would be if the skin were cold, and vice versa.

Hammel's fundamental insights - that competitive neuronal inputs to pools of $\mathrm{PO} / \mathrm{AH}$ neurons with different $\mathbf{Q}_{10}$ characteristics could explain activation of thermoregulatory effectors, existence of a set point for body temperature, and changes in that set point - built a foundation for subsequent thinking about, and modelling of the controller of body temperature. Like all good models it stimulated experimental efforts to better understand the system, and the original model has required elaboration and expansion as more information was collected.

Much more is known about the temperature response characteristics of both warm-sensitive and cold-sensitive PO/AH neurons than was known when Hammel constructed his model. As already briefly discussed above, cold-sensitive neurons per se may not exist in the PO/AH. studies of such neurons in fish (Nelson and Prosser, 1981) and rats (Perlmutter and Boulant, 1983) suggest that so-called coldsensitive neurons may lack primary temperature sensitivity; their output may be dependent upon stimulation from cutaneous cold receptors and inhibition from warm-sensitive neurons. If 
this is true, warming the PO/AH would increase synaptic inhibition, and the "cold-sensitive" neuron would decrease its firing rate; $\mathrm{PO} / \mathrm{AH}$ cooling would reduce inhibition, and the "cold-sensitive" neuron would increase its firing rate (Boulant et al, 1989).

Warm-sensitive $\mathrm{PO} / \mathrm{AH}$ neurons appear to exist in at least three different pools, with different types of rate sensitivities to temperature change (from Boulant et al, 1989). One group exhibits a very low spontaneous firing rate, and extreme sensitivity to $\mathrm{PO} / \mathrm{AH}$ temperatures above $40^{\circ} \mathrm{C}$. $\mathrm{A}$ second group of medium-firing-rate warm-sensitive neurons exhibits a linear curve of rate response to temperature. A third group, the high-firing-rate warm-sensitive neurons, seems insensitive to temperature increases above about $39^{\circ} \mathrm{C}$, but very sensitive to decreases in temperature below that level.

The observed characteristics of PO/AH neurons are incorporated into a conceptual whole in the model presented in Figure 1 (Boulant et al, 1989). As indicated in Figure 1a, the low-firing-rate warm-sensitive neurons may be important in the activation of heat-loss responses such as panting, sweating, and saliva spreading. Their low firing rates may be accounted for by relatively less excitatory input, or perhaps by a relatively greater amount of inhibitory input than is received by other pools of warm-sensitive neurons. 


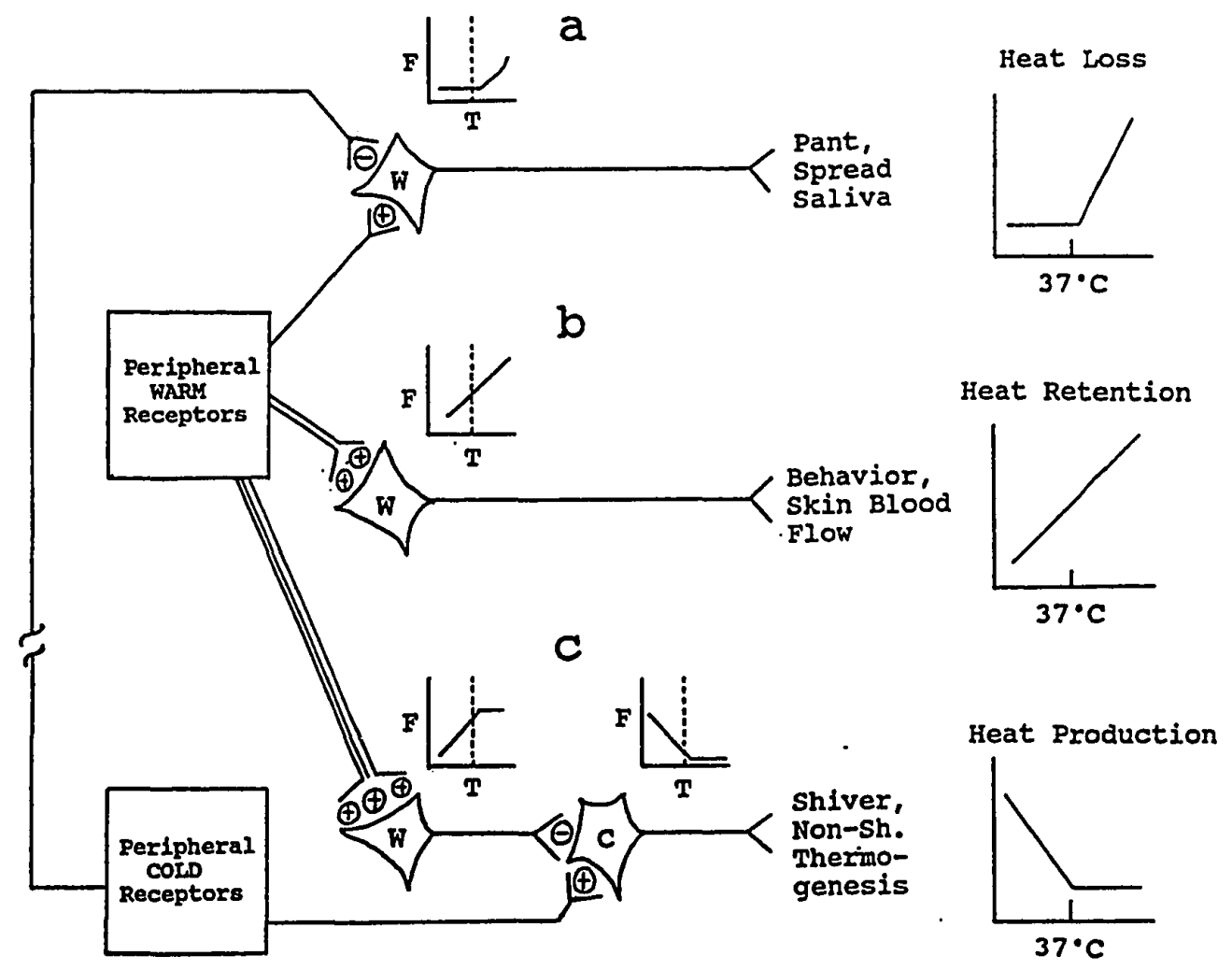

Figure 1. Neuronal model for thermoregulation. W indicates a warm-sensitive neuron; $c$, a coldsensitive neuron; $(+)$, excitatory input; $(-)$, inhibitory input. The hypothalamic thermoresponses of the various neuronal types are shown next to those neurons. $F$ refers to firing rate; $T$, preoptic temperature; dashed line, thermoneutral preoptic temperature (redrawn from Boulant et al, 1989).

Medium-firing-rate warm-sensitive neurons are represented by Figure 1b. These neurons may receive relatively more excitatory input than the neurons shown in Figure 1a. Because these neurons are thermosensitive across all ranges of $\mathrm{PO} / \mathrm{AH}$ temperature, they may be important in controlling effector responses such as skin blood flow and behavior that are 
important above and below thermoneutrality, and are responsive to slight increases and decreases in central temperature.

The high-firing-rate warm-sensitive $\mathrm{PO} / \mathrm{AH}$ neurons are shown in Figure 1c. These neurons receive the most excitatory input, and their spontaneous activity may be near their maximum firing rate, so that $\mathrm{PO} / \mathrm{AH}$ warming cannot cause further increases in firing rate. Decreases in excitatory input would account for their sensitivity to lower PO/AH temperatures. These neurons may function, as indicated, to control heat-production effectors such as shivering and nonshivering thermogenesis. As Figure 1c also indicates, these high-firing-rate neurons may inhibit activity in synaptically driven cold-sensitive neurons when $\mathrm{PO} / \mathrm{AH}$ temperature is high; reduced activity in the high-firing-rate neurons would reduce inhibition on the "cold-sensitive" neurons, which would proportionally increase their activity. As indicated in the model (Figure 1c), "cold-sensitive" neurons also receive direct afferent input. In one study, seventy-three percent of cold-sensitive neurons were affected by skin or spinal temperature, and sixty-four percent by stimulation of various brain sites, including the midbrain reticular formation (Boulant et al, 1989).

This model predicts that peripheral temperature should have its greatest effect on high-firing-rate warm-sensitive neurons, cold-sensitive neurons, and heat production responses (Figure 1c), and peripheral temperature should have its 
smallest effect on low-firing-rate warm-sensitive neurons and heat loss responses (Figure 1a), because the low-firing-rate warm-sensitive neurons receive less synaptic input from the periphery (are less sensitive to changes in peripheral temperature) than the high-firing-rate warm-sensitive neurons (Boulant et al, 1989). These predictions are supported by experimental evidence that decreasing skin temperature has a much greater effect on increasing heat production, than increasing skin temperature has on stimulation of evaporative heat loss (Hellstrom and Hammel, 1967; Boulant, 1980). In one study (Boulant and Hardy, 1974), in response to changes in skin or spinal cord temperature, only seventeen percent of the low-firing-rate warm-sensitive PO/AH neurons changed their firing rates; this increased to sixty-seven percent of the medium-firing-rate, and eighty percent of the high-firing-rate warm-sensitive neurons after the same peripheral stimulation. The predictions of the model presented in Figure 1 are in agreement with much experimental evidence; the model is a helpful way to conceptualize thermoregulation and the activation of thermoregulatory responses.

\section{Definitions of Thermoregulatory Terms}

Thus, there is a temperature at which the body is regulated. In an individual animal at different times this regulated temperature, or set point, may be adjusted upwards or downwards. In addition, in situations of increased heat load the body temperature may exceed the regulated 
temperature; or, if heat loss exceeds heat production and conservation measures, body temperature may fall below the regulated level. There are specific terms used to describe these relationships between actual body temperature and set point temperature. In the case of increased temperature, "hyperthermia" is used to describe a body temperature that has risen above the regulated level (as a result, for example, of exercise), while "fever" describes an increase in the regulated body temperature itself (Kluger, 1991). In the case of decreased temperature, unfortunately, two such precise terms do not exist, although the two comparable situations arise. When body temperature is colder than normal, whether this is due to an inadvertent loss of body heat or due to a downward adjustment in the level of the regulated temperature, "hypothermia" is the only term available. This imprecision creates a problem for thermoregulatory physiologists who ask the question, Is an observed decrease in body temperature a regulated or an unregulated change? Generally one is left with the unsatisfactory solution of calling the former "regulated hypothermia" or "a downward adjustment in the regulated temperature", and reserving the simple term "hypothermia" for the latter case.

\section{Thermoregulatory Effector Mechanisms}

It is a relatively straightforward matter to distinguish between unregulated and regulated changes in body temperature. Mammals are equipped with a versatile toolbox of 
thermoregulatory effectors with which to accomplish rapid body temperature adjustments. These effectors may include panting, sweating, vasodilation and behavior for dissipating heat, and shivering, nonshivering thermogenesis, piloerection, vasoconstriction and behavior for conserving heat, although not all mammals possess all these effector mechanisms. If a measured change in internal temperature is a regulated change, thermoregulatory effector mechanisms will be marshalled to assist that change; if a change in internal temperature is not regulated, thermoregulatory effector mechanisms will be activated to oppose the change in temperature and effect a return to the regulated level. We will briefly examine the thermoregulatory effector mechanisms that are most important to the mouse in the following section.

\section{Evaporative Heat Loss - Saliva Spreading}

To evaporate one kilogram of water, 580 kilocalories of heat are required (Schmidt-Nielsen, 1990, p.273). Many animals take advantage of this fact by evaporating water from body surfaces to lose excess heat, using three strategies; panting, sweating, and saliva spreading. Sweating is of no importance to the mouse, since the animal lacks sweat glands (Prosser and Brown, 1961, p. 268), and will not be discussed further. Saliva spreading is utilized by a limited set of animals, including Australian marsupials, rats (SchmidtNielsen, 1990, p.273), mice (Hainsworth and stricker, 1970; personal observation) and even by turtles (Prosser and Heath, 
1991), but it has not been well studied in mice (Jakobson, 1981). In rats, saliva spreading appears to be controlled by the hypothalamus (Hainsworth and stricker, 1970). Rats show increased salivation and saliva spreading at a body temperature of $38.5^{\circ} \mathrm{C}$ to $40^{\circ} \mathrm{C}$. The ability to utilize this thermoregulatory effector is compromised in rats when normal nerve pathways between the $\mathrm{PO} / \mathrm{AH}$ and the midbrain are interrupted by lesions (Hainsworth and Stricker, 1970).

Evaporative Heat Loss - Panting

Panting is a widespread method of losing heat through evaporating water, used by most nonprimate mammals of less than one hundred kilograms in weight (Jessen, 1990), as well as by reptiles and birds. Panting has two major advantages over sweating; air flow over the evaporative surface is automatically provided, and panting animals do not lose electrolytes as sweating animals do (Schmidt-Nielsen, 1990, p.274). Panting also carries two disadvantages. The first is that increased ventilation may cause an excess loss of carbon dioxide, and result in alkalosis. In so-called first phase panting (Jessen, 1990) this problem is avoided by utilizing shallow respiration at a high frequency, so that increased ventilation takes place in the dead spaces of the upper respiratory tract (Schmidt-Nielsen, 1990, p.274). However if heat stress continues, the respiration changes to second phase panting, which is characterized by a decrease in rate and an increase in tidal volume from first phase panting, and is 
associated with severe respiratory alkalosis (Jessen, 1990). Apparently normal respiratory sensitivity to the level of carbon dioxide is blunted in this situation; anesthetized dogs continue second phase panting when body temperature exceeds $40^{\circ} \mathrm{C}$, even when arterial partial pressure of carbon dioxide falls as low as $5 \mathrm{~mm} \mathrm{Hg}$ (Hales, 1974). The second potential disadvantage to panting is extra heat generated by the muscular work required. This heat production is greatly reduced because the respiratory system is elastic, and has a natural frequency of oscillation; animals take advantage of this fact and pant at a resonant elastic frequency, which requires only a small muscular effort (Schmidt-Nielsen, 1990, p.274).

Respiration is regulated from a widely dispersed group of neurons in the medulla and pons, located in three major areas; a dorsal medullary group of neurons (mainly an inspiratory area), a ventral respiratory group (mainly expiratory), and an area in the pons that helps to control respiratory rate, called the pneumotaxic center (Guyton, 1981, p.516). Respiration is controlled in a variety of ways. The chemosensitive area, which is stimulated directly by hydrogen ions (indirectly by carbon dioxide, which forms dissociable carbonic acid), stimulates the nearby inspiratory area (Guyton, 1981, p.518). Low oxygen, or increased carbon dioxide or hydrogen ions in the blood, stimulate chemoreceptors (carotid and aortic bodies) which have nerve 
connections to the respiratory center (Guyton, 1981, p.520). The cerebral cortex anticipates increased respiratory requirements during exercise by stimulating respiration before a buildup in carbon dioxide occurs (Guyton, 1981, p.524). Thermoregulatory panting can apparently be stimulated in two ways. In calves and sheep, external heat stress too mild to cause an elevation in core temperature causes first phase panting, and this may be due entirely to an effect on cutaneous thermoreceptors (Jessen, 1990). However a high correlation has been found between panting and increased core temperature (in dogs and rabbits) or mean body temperature (in sheep), and in dogs and goats second phase panting can be elicited by heating the hypothalamus and spinal cord (Jessen, 1990). The midbrain area responsible for controlling respiration receives direct projections from the hypothalamus (Crawshaw et al, 1990). In turn, the respiratory center governs activity of the phrenic motoneurons; devreased phrenic nerve activity is paralleled by the decreased tidal volume observed in panting respiration (Pleschka and Wang, 1975). For panting, as for most or all thermoregulatory effector mechanisms, the $\mathrm{PO} / \mathrm{AH}$ receives the most widespread information from the interior and surface of the body, and can exercise coordinated control of thermoregulatory adjustments; but auxiliary, lower-level controls also exist which receive their own, more limited input, and which may function independently 
of the $\mathrm{PO} / \mathrm{AH}$ to elicit thermoregulatory responses (Blatteis, 1980).

Heat Production - Nonshivering Thermogenesis

In a variety of mammals, heat can be produced in the brown adipose tissue (BAT). BAT clearly plays a role in longterm cold acclimation, but evidence indicates that BAT may also be important in acute response to cold; elevation in metabolism may occur as quickly as one minute after BAT is stimulated (Cossins and Bowler, 1987, p.109; Himms-Hagen, 1990). Heat production by BAT is important to mice at temperatures below thermoneutral; indeed, the primary effect of noradrenaline in mice is to stimulate nonshivering thermogenesis in BAT, which may provide forty percent to seventy percent of cold-induced heat production (Jakobson, 1981). BAT is distributed in discrete locations throughout the body. In mice acclimated to $30^{\circ} \mathrm{C}$ (thermoneutral), about fifty percent of brown fat is found in the interscapular region, about thirty percent in the subscapular and suprasternal regions, about twenty percent in the dorsal cervical areas, and a small amount as subvertebral deposits; the total is about one percent of body weight, although exposure to cold can greatly increase brown fat deposits (Jakobson, 1981).

Brown fat cells differ from white fat cells in a variety of ways. The two types of cells differ in appearance; brown fat cells contain numerous large mitochondria, and contain 
many fat deposit droplets. Brown fat cells are stimulated, not by circulating insulin and adrenaline, but by noradrenaline; BAT receives direct sympathetic innervation from an ample supply of sympathetic nerve endings (siemen and Weber, 1989; Himms-Hagen, 1990). BAT also possesses an extensive capillary network. But the most important difference between the two types of fat cells is the existence of an uncoupling protein (UCP) in BAT mitochondria (HimmsHagen, 1990).

Normal oxidation of fuel produces carbon dioxide, water, ATP and heat (from Himms-Hagen, 1990). The rate of heat production depends only on the overall rate of oxidation; the rate of oxidation is principally controlled by the rate at which ATP is utilized, providing ADP. ATP synthase, driven by the proton gradient generated by the electron transport system, resynthesizes ATP and concomitantly reduces the proton gradient. Electron transport restores the gradient, regenerating $\mathrm{NAD}^{+}$and $\mathrm{FAD}^{+}$for the tricarboxylic acid cycle and fatty acid oxidation. In skeletal muscle, for example, mitochondria have a large capacity for electron transport and oxidative phosphorylation, and large amounts of heat are generated during exercise or during shivering. But in BAT, mitochondria have an alternate way to dissipate the proton gradient generated by electron transport - a special proton conductance pathway, mediated by the UCP, which speeds up electron transport and substrate oxidation without involving 
ATP synthetase. Noradrenaline from sympathetic nerves innervating BAT, via adenylate cyclase and CAMP, stimulates a protein kinase to phosphorylate triacylglycerol lipase to its active form, increasing lipolysis and the fatty acid level within the cell. Fatty acids both stimulate the UCP, and provide fuel for increased levels of oxidation. Increased thermogenesis persists until the stimulus, noradrenaline, is removed (nervous system input subsides).

An additional portion of BAT thermogenesis is due to a so-called "non-selective channel" which allows sodium to enter the brown fat cell; the cell counteracts this influx with sodium-potassium-ATPase activity, which increases heat production (Siemen and Weber, 1989). This mechanism has not been entirely worked out, but it is estimated that five to fifteen percent of BAT heat production may be generated in this way (Siemen and Weber, 1989). The control mechanism for the increased blood flow measured in BAT during thermogenesis is also not understood, but may involve adenosine; BAT cells do liberate adenosine, which can act as a vasodilator (HimmsHagen, 1990).

Heat Production - Shivering

Shivering may be defined as "an increase in reflex, nonlocomotor muscular tone attributable to exposure to cold, with and without visible tremor" (Kleinebeckel and Klussmann, 1990). Non-shivering thermogenesis is initiated first in the mouse; shivering only begins when non-shivering thermogenesis 
proves inadequate, and body temperature drops $2^{\circ} \mathrm{C}$ or more (Jakobson, 1981). In warm-acclimated mice acutely exposed to cold, skeletal muscle accounts for about thirty percent of heat production; this decreases to ten percent or less in the cold-acclimated animal (where BAT greatly increases its contribution) (Jakobson, 1981). The primary motor center for shivering, in the dorsomedial portion of the posterior hypothalamus, is normally inhibited by heat signals from the preoptic, but is stimulated by signals from peripheral and spinal cold receptors; when stimulated, this center transmits nonrhythmic impulses down the brain stem and through the spinal cord (Werner, 1990). The path from the PO/AH travels through the midbrain reticular formation and the pontine and medullary rubrospinal tract; neurons in these areas respond to local temperature as well as to $\mathrm{PO} / \mathrm{AH}$ and skin temperature, and stimulation or inhibition can release or inhibit shivering, suggesting that descending thermal signals from the PO/AH may control shivering through their actions on coldsensitive reticular formation neurons (Hori et al, 1989).

Although the descending impulses are not rhythmic, the visible movements of shivering certainly are. Rhythmic shivering can be induced in both intact dogs and chronically spinalized dogs and rabbits by cooling the spinal cord; severing the ascending thermoregulatory pathways does not affect shivering heat production in rabbits (Kleinebeckel and Klussmann, 1990). To produce shivering, motoneurons are 
activated in sequence. During the first phase of cold stimulation (either from cold receptors in skin, or from direct spinal cooling), activity of the tonic alpha motoneurons increases, causing generalized increased muscle tone; continued cooling results in recruitment of larger phasic motoneurons, and familiar shivering tremors become visible (Kleinebeckel and Klussmann, 1990). The frequency of shivering is related to body size. The grouped discharges (rhythmical synchronization of muscle action potentials producing shivering tremor) in mouse muscle have been measured at about $35 \mathrm{~Hz}$, as compared with about $30 \mathrm{~Hz}$ in the rat and 18 $\mathrm{Hz}$ in the rabbit (Kleinebeckel and Klussmann, 1990).

\section{Heat Conservation - Piloerection}

Although mouse fur is relatively thin and light, fur contributes about thirty to forty percent of total insulation (Jakobson, 1981), and mice respond to a decrease in body temperature by erecting their fur to trap a layer of insulator air next to the skin, decreasing heat transfer from mouse to environment. The piloerector muscles contract and raise the hairs when stimulated by the sympathetic nervous system (Guyton, 1981, p.715). This response is part of a unified response to cold. Piloerection is complementary to, and occurs along with vascular contraction which also results from sympathetic stimulation. 
Heat Conservation - Vascular Responses

Changes in vascular state are certainly important to the mouse as it responds to both heat and cold. Blood vessels are involved in the maintenance of a stable body temperature in two ways. They take up metabolically generated heat from internal organs, and in the skin they lose heat to the environment by direct conduction or radiation (Grayson, 1990). To think of blood vessels as "vasodilated" in the heat and "vasoconstricted" in the cold, however, is a gross oversimplification of a complicated and flexible system. Vascular tone is not static. In a state of "vasoconstriction" (from Grayson, 1990), few of the arterioles in a vascular bed are open at any one time; those that are open to blood flow are fully open, while a greater number are completely closed. Each vascular unit actively opens and closes, and although the number of arterioles open in a tissue may remain constant over a period of time, it is different individual arterioles that are open at different times. In "vasodilation" many arterioles are open, and few are closed at a given time. The determining factor is the rate of vasomotion (movement between open and closed state); the period of vasomotion is slow in the state corresponding to vasodilation, and more rapid in the state corresponding to vasoconstriction.

The opening and closing of vessels (vasomotion) in the microcirculation is due to thick, muscular, elastic arteriole walls. Arterioles as small as $20 \mu$ are supplied with alpha 
receptors and can constrict in response to norepinephrine or sympathetic stimulation (Grayson, 1990). It was once thought that precapillary sphincters regulated flow through the smallest vessels, but now it is believed that such sphincters do not exist, and vessels smaller than $20 \mu$ do not respond to nerve action (Grayson, 1990).

The vasomotor center in the brainstem sends sympathetic nerve fibers through the spinal cord to the sympathetic ganglia, and out to blood vessels throughout the body (Guyton, 1981, p.238). The vasomotor center consists of two parts. The upper and lateral portions are tonically active, to maintain a partial state of contraction in the blood vessels; if the brain stem is severed above the vasomotor center, it will continue to maintain approximately normal vascular tone through tonic sympathetic activity (Guyton, 1981, p.240), since blood vessels in the skin respond to sympathetic stimulation by contracting (Guyton, 1981, p.715). The medial and lower portions of the vasomotor center, when stimulated, inhibit the excitatory centers and allow dilation of blood vessels (Guyton, 1981, p.240). However, this is not the result of a fixed autonomic reaction. There is instead a differentiation of regional sympathetic output; for instance, heating (of skin, hypothalamus or spinal cord) evoked decreased activity in a branch of the sympathetic nervous system supplying the ear (resulting in vasodilation), but increased activity in the splanchnic nerve and a branch of the 
cardiac sympathetic nerve (increased vascular tone) (Iriki and Simon, 1973). The same thermal stimuli applied separately to skin, hypothalamus or spine evoked identical patterns of response, which tends to support the idea that the pattern is produced as a thermoregulatory response by the central nervous controller (the hypothalamus), in areas of the skin where central control of the circulation is important (Iriki and Simon, 1973). Heat is also itself a vasodilator; local heat, applied anywhere on the body, produces local vasodilation (Grayson, 1990). Local cold likewise produces local vasoconstriction; in human beings, only in distal extremities, lips and ears is there neurological control over the microcirculation (Grayson, 1990). Within the microcirculation of the sheep, the effect of local temperature is of more importance in regulation of capillary flow, while the nervous system regulates flow in the arteriovenous anastomoses (Hales et al, 1978). It does not appear that blood flow through the arteriovenous anastomoses increases at the expense of capillary flow; that is, at least in the sheep, capillary flow does not decline as flow in arteriovenous anastomoses increases (Hales et al, 1978).

Mice have naked or nearly naked skin surfaces on ears and tail, and for the mouse, the tail is the most important skin area for heat loss; tail amputation reduces the ability of the mouse to thermoregulate in a hot environment (Jakobson, 1981). In the pig, spinal, hypothalamic, or skin heating or cooling 
results in increased or decreased tail skin blood flow (Ingram and Legge, 1971). In the mouse, central administration of the neurotransmitter serotonin, which appears to cause a regulated decline in body temperature, also stimulates increased tail blood flow (personal observation).

\section{Torpor}

When allowed free access to food and water, mice can maintain normal body temperature throughout a range of environmental temperature from $2.5^{\circ} \mathrm{C}$ to $38^{\circ} \mathrm{C}$; but removal of food or severe food or water restriction will cause mice to enter torpor (Jakobson, 1981). Torpid mice maintain body temperature at $16^{\circ} \mathrm{C}$ to $19^{\circ} \mathrm{C}$, even if environmental temperature drops below this level.

\section{Behavior}

The first defense of an organism against cooling or warming is behavioral (Prosser and Heath, 1991). This is true even of bacteria (Maeda et al, 1976) and protozoa (Prosser and Heath, 1991). For ectothermic animals, behavior is essentially the only short-term thermoregulatory effector available (Crawshaw et al, 1990). Endothermic animals possess more options, in the form of both autonomic and behavioral thermoregulatory effectors. The two means of thermoregulation are interchangeable (within limits), so the relative contribution of behavioral thermoregulation depends both upon the efficiency of the behavioral response, and upon the 
capacity for physiological thermoregulation (Corbit, 1970). Rats with control of physiological effectors impaired by brain lesions or other treatments maintain approximately normal body temperature at room temperatures far from thermoneutral by bar pressing for heat or cold (Satinoff and Hendersen, 1977). In a study of the effects of cold rearing $\left(5^{\circ} \mathrm{C}\right)$ or warm rearing $\left(25^{\circ} \mathrm{C}\right)$ from birth to age twenty-five days on the behavior of mice subsequently housed at $5^{\circ} \mathrm{C}$, it was found that cold-reared animals had higher brown fat weights, but built smaller nests than warm-reared animals which responded to the cold by building large nests (Jakobson, 1981).

Huddling together to conserve warmth is a common behavior used by mice for energy conservation; huddles of five mice reduced food consumption over thirty percent in the cold, and metabolism of weanling mice decreased up to fifty percent in huddles of seven mice at $25^{\circ} \mathrm{C}$ (Jakobson, 1981). In a $24^{\circ} \mathrm{C}$ room, groups of four and five adult male mice sleeping together generated a local ambient temperature of $30^{\circ} \mathrm{C}$ to $32^{\circ} \mathrm{C}$ (personal observation), which is thermoneutral for the mouse. Adjustment of body position is another important behavioral effector for the mouse. Mice that are too warm sprawl and raise their tails; mice that are cold curl up into a ball, tucking head and feet beneath the body (personal observations).

Beyond simple observation of naturally occurring behaviors, behavioral thermoregulation can also be studied and 
deliberately manipulated in the laboratory. The thermoregulatory behaviors of representatives of every vertebrate class have been examined, as well as the behavior of many invertebrates and some microorganisms. Thermoregulatory behaviors studied in the laboratory may be so similar to natural behaviors that little training is required, and extremely simple animals can easily perform such tasks, which include moving into and out of the heat field of a warming lamp, and choosing a preferred ambient temperature in a temperature gradient. Many animals can also be trained to perform more complicated tasks to control temperature. Such tasks include pressing a lever or button to receive cool or warm air, or to directly cool or warm the brain via implanted thermodes. No matter the specific thermoregulatory task chosen, the success of any behavioral thermoregulatory experiment is directly related to efficiency (Corbit, 1970); that is, the animal ought to receive a rewarding temperature stimulus for a relatively small amount of work. The idea that animals balance the cost and benefit of behavioral thermoregulation is supported by field studies of lizards (Huey and Slatkin, 1976) and laboratory studies using monkeys (Adair and Wright, 1976). In both cases, as the cost (effort) of behavioral thermoregulation became higher, the animals tolerated lower and more variable body temperatures; the monkeys eventually gave up and resorted to shivering. In addition, the animal should have complete control over the 
duration of temperature reinforcement (Corbit, 1970). Both these requirements are particularly well met by temperature gradient devices, in which normal locomotory movements bring the animal into its zone of preferred temperature, where it can remain for as long as it wishes. An important condition for such experiments is that the range of ambient temperature extends into both hot and cold aversive temperature values, so that the expression of thermal preference is not limited. Given an appropriate range of temperatures from which to choose, a freely moving animal will prefer a distinct temperature or temperature zone characteristic of others of its species with the same temperature history (adaptation). This temperature is called the preferred temperature, the temperature preferendum, or the temperature optimum (Laudien, 1973). If a sufficiently broad range of ambient temperatures is available to an animal, measurement of preferred environmental temperature (when considered along with changes in internal temperature) provides a sensitive means with which to assess alterations in the regulated temperature (Hammel, 1968; Satinoff, 1979).

The rat is richly represented in the behavioral thermoregulatory literature; indeed, the first laboratory demonstration that animals could control their body temperature by behavioral means came in 1957, using rats and heat lamps (Satinoff and Hendersen, 1977). Rats have operated heating and cooling devices to keep hypothalamic temperature 
constant, or in response to changes in brain or skin temperature (Corbit, 1969; Murgatroyd and Hardy, 1970; Corbit, 1973; Hensel, 1973b). Rats can make behavioral thermoregulatory decisions to apply a temperature correction to a local source of internal temperature error; rats provided with the means to separately control both hypothalamic and skin temperature specifically chose brain cooling when the brain was warmed, and skin cooling when the periphery was warmed (Corbit and Ernits, 1974; Dib and Cabanac, 1984). Rats can behaviorally thermoregulate by spending varying amounts of time under an infrared heat lamp ( Cox et al, 1975; Lomax et al, 1980), working to maintain a comfortable ambient temperature (Carlisle, 1968), or detecting and occupying a preferred temperature in a temperature gradient (Yehuda and Wurtman, 1974; Gordon et al, 1988a; Owen et al, 1991).

The behavioral thermoregulatory responses of mice have been much less utilized in experiments than have the responses of rats. Because mice are very small, building appropriately sized heating and cooling devices and implanting them in the mouse brain is more difficult than installing such implants in the much larger rat brain. But mice quickly learn to choose a preferred temperature in a temperature gradient, and this behavior has been investigated to find out more about the mouse itself (Ogilvie and Stinson, 1966), or following drug or toxin administration (Gordon and Stead, 1986; Gordon et al, 1988b), or after neurotransmitter system manipulation 
(Goodrich et al, 1989). Regrettably, reports in the literature of "thermoregulatory" responses of mice following some manipulation often consist merely of rectal temperature measurements of mice held at ambient laboratory temperature, which in most laboratories is considerably below thermoneutral for the mouse. Such measurements yield little or no information about the effect of a manipulation on the regulated temperature of the mouse, although claims may be made to the contrary by experimenters who choose to employ such methods. Given a chance, the mouse can behaviorally thermoregulate with precision and reproducibility; much can be learned about thermoregulation by asking questions of the mouse, when it is provided with the means to fully respond.

\section{THE MOUSE}

The consequences of the use (and misuse) of ethanol by human beings provides the impetus for research into the effects of ethanol, thermoregulatory and otherwise. However it was neither ethically nor practically possible to conduct this series of experiments using human subjects; human beings cost too much to keep, breed slowly, and would possibly object to indefinite confinement in a controlled laboratory environment. Our fellow mammal the mouse, in contrast, is small, inexpensive to house and feed, requires little space, and breeds quickly; no difficult ethical choices need be made before deciding to select for specified characteristics in a 
mouse population, or to breed close mouse relatives together. It is commonly accepted that individual human beings differ in response to ethanol, and that this variability is due to both genetic and environmental factors; genetic selection experiments using mice can help to separate genetic and environmental influences (Harris and Allan, 1989). Therefore although problems of ethanol abuse within the mouse population do not exist (or, if they exist, do not concern researchers), the animal of choice for this series of experiments was the mouse.

\section{History}

The association of mice with human beings is an ancient one. Skeletal remains ascribed to Mus musculus are found associated with Middle Pleistocene hominid sites (about one million years ago) in China, western Asia, central Europe and Greece; in Twelfth Dynasty (about 1700 B.C.) ruins in Egypt, there is abundant evidence of mouse tunneling in human habitations (Brothwell, 1981). Deification of the cat in Egypt, which occurred about 2800 B.C., may have been a response to the severity of the mouse infestation at that time (Lauber, 1971, p.23; Festing and Lovell, 1981). In what is now northeastern Iran, archaeologists have discovered the remains of mousetraps made by people who lived around 2500 B.C. (Lauber, 1971, p.21). Oux word "mouse", like the German word "maus", comes from the sanskrit; in that language, the house mouse was "musha", which means "thief" (Lauber, 1971, p.36). 
In some ancient cultures, mice were held in high esteem. Apollo Smintheus (God of Mice) was mentioned in Homeric legends about 1200 B.C. (Festing and Lovell, 1981). In 400 B.C. Cretan invaders who worshipped Apollo smintheus were able to conquer the people of Asia Minor because, according to legend, mice gnawed the leather straps from the shields of the defenders, rendering them useless; in gratitude, the cretans built a temple to Apollo Smintheus on the nearby island of Tenedos, where mice were worshipped (Lauber, 1971, p.23). Mouse worship spread through many parts of the ancient world, and continued in some places until the 1400's (Lauber, 1971, p.24). Aristotle refers to the white mice of Pontis, and the oldest Chinese dictionary (about 1100 B.c.) contains a word for "spotted mouse" (Festing and Lovell, 1981). The Chinese word for "white mouse" is yet more ancient, with no record of when it first appeared in the language (Lauber, 1971, p.29). Waltzing mice have been known in China, where they may have originated, since at least 80 B.C. (Festing and Lovell, 1981). Waltzer mice are afflicted with various abnormalities of the inner ear; they are deaf, and exhibit circling and headtossing behavior (Green, 1966b). A writer of the Han dynasty recorded that

... in the ninth moon, a yellow mouse was found
dancing with its tail in its mouth in the gateway
of the palace of the Kingdom of Yen. The animal
danced incessantly. The king asked the queen to
feed it with wine and meat, but this did not
interfere with the performance. The mouse died
during the night (Lauber, 1971, p.30).


The mouse was not looked upon with such kindness in Christian Europe, where it was associated with witches and sorcerers; considered "voluptuous and libidinous", mice were often raised by curious churchmen to observe their "wicked and lustful actions" (Festing and Lovell, 1981). Although no written record chronicled the event, it was probably as a stowaway on European vessels of exploration and trade that Mus musculus reached the New World.

Pliny (born 23 A.D.) gave Mus musculus its species name, which means "little mouse" (Lauber, 1971, p.36), and he may have recorded the earliest role for the mouse in science when he mentioned the use of white mice for auguries, noting "...how the lobes and filaments of their livers and bowels do increase or decrease in number according to the days of the Moon's age..." (Festing and Lovell, 1981). Such use of mice in auguries was an ancient practice indeed; white mice were collected by the chinese for this purpose at least three thousand years ago (Lauber, 1971, p.29). In Europe, mice were used in scientific experiments at least as early as 1664, when Robert Hooke used a mouse to study the properties of air (Festing and Lovell, 1981).

In one sense, an interest in mouse genetics dates back at least to the 1600 's, when Japanese collectors sought out unusual or attractive mutant, or "fancy" mice in Japan and also in China and other foreign countries; by the late 1700's Japanese collectors had found and documented white mice, 
yellow mice, chocolate-brown mice, spotted mice, waltzing mice, and others (Lauber, 1971, pp.52-54). Breeding Methods of Striking Mice was published in Japan in 1787 (Festing and Lovell, 1981). About thirty years before the publication of Gregor Mendel's work on patterns of inheritance in peas, a pharmacist from Geneva (M. Caladon) systematically bred together mice with different coat colors, and obtained results which would be in excellent agreement with Mendelian predictions (Searle, 1981).

In 1900 Hugo de Vries, a Dutch botanist who studied patterns of inheritance in a colony of wild American evening primroses, rediscovered (as did carl correns in Germany and Erik von Tschermak-Seysenegg in Austria, at the same time and independently) the neglected work of Gregor Mendel, which had been published thirty-four years earlier (Gardner, 1975, p.3). It was not initially known whether Mendel's laws of inheritance, the fruit of experiments using plants, would have general applicability to other kinds of organisms. The variety of mice available, and the experience of mouse fanciers with breeding them, facilitated early confirmation that Gregor Mendel's laws of inheritance held true for animals as well as for plants (Searle, 1981). In the early 1900's, Iucien Cuenot showed that genes controlled coat color in the mouse (Gardner, 1975, p.3). The first inbred strain of mice, DBA, was developed by C.C. Little in 1909; Little also founded The Jackson Laboratory in 1929 (Festing and Lovell, 1981). 
Little was interested in cancer research, and he believed that eliminating the great genetic diversity found in unrelated animals would facilitate the study of this disease which is subject to so much environmental influence (staats, 1966). The majority of the older inbred strains of mice, including the familiar $B A L B / C, C 57 B L, C 57 B R, S W R$ and $A K R$ mice, were developed for use in cancer research, to prove or disprove the existence of genetic factors influencing the development of cancer (Staats, 1966). By 1942, I.C. Strong suggested that "...within the near future all research on mice should be carried out on inbred animals or on hybrid mice of known (genetically controlled) origin, where the degree of biological variability has been carefully controlled" (Festing and Iovell, 1981). Subsequent events confirmed his prescience.

\section{Genetic Animal Models}

In general, it can be said that the purpose of any breeding system "...is to preserve or control the genetic causes of variability in traits of interest"; random mating in the absence of selection will preserve genetic variability, whereas inbreeding will reduce it (Green, 1966a). A strain of mice is defined as "inbred" when there have been twenty or more consecutive generations of brother-sister matings, or twenty or more consecutive generations of parent-offspring matings, provided the offspring was mated to the younger parent (Roderick and Schlager, 1966; Staats, 1966). Although 
inbreeding in itself does not change the proportion of alleles in a population, continued mating among close relatives tends to eliminate heterozygotes and to produce homozygotes; completely "pure" lines, in which all allelic pairs are homozygous, would represent the ultimate result of inbreeding (Gardner, 1975, p.465; Harris and Allan, 1989). Although this theoretical limit may never actually be reached, inbreeding results in animals that are almost identical genetically, so that behavioral differences between inbred strains maintained under identical environmental conditions can be ascribed to genetic influences (Roderick and Schlager, 1966; Harris and Allan, 1989; Plomin, 1990). Indeed, according to theory, animals bred brother-to-sister for at least twenty generations should be homozygous at more than ninety-nine percent of their loci; the animals should theoretically be all genetically uniform (as alike as identical twins, except for sex differences) (Roderick and Schlager, 1966). This supposition is supported by evidence, for instance, that mice from a single inbred strain were as alike as identical twins at the histocompatibility loci (genes that determine susceptibility and resistance to tissue transplants) (Snell and stimpfling, 1966). In one study, no evidence for genetic variation was detected in a study of skeletal variability in inbred strains of mice (Roderick and Schlager, 1966). However, the fixation of alleles that is the result of inbreeding is random (nondirectional) (Harris and Allan, 1989). 
Inbred mice are often utilized as the foundation of a genetic selection experiment. Although the inbred lines themselves possess essentially no genetic diversity upon which selection could be based, by crossing inbred strains, offspring with a high degree of genetic diversity are produced, to serve as a starting point for selection (Green, 1966a). This method of synthesizing foundation populations of mice, referred to as "genetically heterogeneous" mice, is accomplished by crossing two, three, four or more inbred strains of genetically different origins (Roderick and Schlager, 1966). This method has the advantage of permitting the possibility of replication of the selection experiment by replicating the foundation stock of genetically heterogeneous animals at a future point in time.

Selection has been defined as "the nonrandom differential reproduction of genotypes" (Lerner, 1954, p.134). Artificial selection in mice occurs through conscious human effort to bring about this differential reproduction of genotypes, and has historically been used principally for two reasons; to explore the genetic theory of selection, and to produce a large divergence in a particular trait in order to study the physiological genetics of the trait (Roderick and Schlager, 1966). It is the latter use of artificial selection that will concern us here. 
Methods of Selection

Modern selection experiments using mice generally have two goals; to develop oppositely-selected lines of animals that differ markedly in the phenotypic characteristic under selection, and to discover the presence of correlated responses to selection. The essential process of bidirectional selection consists of testing animals to measure the phenotype of interest upon which selection is to be based, and allowing the genotype of animals that exhibit the greatest and least responses to the test procedure to be carried forward into the next generation. Within this general procedure, there are three specific methods of selection which are most often utilized (from Crabbe et al, 1990b). "Family selection" chooses breeding animals on the basis of the deviation of the family (not individual) mean from the population mean. This method of selection is utilized when the characteristic of interest exhibits low heritability. The second, and most intuitively obvious method of selection is termed "mass selection". Following this method, breeders are chosen simply on the basis of their deviation from the population mean; the animals (both male and female) exhibiting the largest deviations in both directions are mated to produce the next generation. This method is the simplest, and may produce a quick response to selection, but exacts the penalty of reducing the genetic variability that is the basis for continuing response to selection; inbreeding hazard is 
present. The third method, called "within-family selection", selects breeding animals on the basis of their individual deviation from family (not population) mean. All families contribute to the next generation, so although response to selection may not proceed as quickly as it can under the mass selection protocol, rare genetic combinations and sources of future variability are preserved. The within-family method of selection produced the HOT and COLD lines of mice (Crabbe et al, 1987) which were utilized to collect much of the data presented in this dissertation.

\section{Uses for Selected Lines of Mice}

Genetic analysis of behavior is difficult. Most behaviors do not exhibit a convenient bimodal segregation, like Gregor Mendel's smooth or wrinkled peas. Instead, most behaviors appear to be influenced by many genes, each exerting a small effect (Broadhurst and Jinks, 1963; Roderick and Schlager, 1966; Plomin, 1990). Of course, behavior is usually heavily influenced by nongenetic (environmental) factors (Plomin, 1990). Mice selected for sensitivity (COLD mice) and resistance (HOT mice) to the decreased rectal temperature caused by ethanol injection, for example, continue to show an increasing divergence in response after more than twenty generations of selection. If one or a few major genes were responsible for this (or any other) behavioral trait, they would sort into high and low lines in but a few generations (Plomin, 1990). The continued divergence of behaviorally 
selected lines over many generations is excellent evidence that many genes affect behavior (Plomin, 1990).

A major use of selected lines of mice is to detect correlated responses to selection. Successful selection implies a change in gene frequencies as its underlying cause (Crabbe et al, 1990b). As selection for a particular phenotype proceeds, often the changes that result in the characteristic of interest will be accompanied by alterations in other, nonselected characteristics. These associated responses may or may not be genetically or causally linked to the response under selection (Harris and Allan, 1989). Nonselected altered responses are termed "correlated responses" if they have changed because they are genetically associated with the trait under selection, and not because of chance. The two traits (the trait under selection, and the correlated response) may be genetically linked. Genetic linkage is a term describing the tendency of genes residing close together on the same chromosome to remain together during meiosis, and to enter the same gamete (Gardner, 1975, p.143). More commonly, however, traits change together because they are under a common genetic influence (pleiotropy) (Roderick and Schlager, 1966; Crabbe et al, 1990b).

The ability to detect correlated responses is greatly improved by replication of a selection experiment. Replication is accomplished by maintaining two genetically independent lines of mice, derived by the same process of 
selection from the same foundation stock. Within each line, mice are selected for increased and decreased responsiveness to the selection test. This has been done with the HOT and COLD lines of mice, to create HOT1-COLD1 and HOT2-COLD2 replicate pairs. If selection is successful, as it has been with the HOT and COLD mice, the replicate lines will both show divergence in the character of interest. If these genetically independent replicate lines both also show divergence in some nonselected character, the putative correlated response, it is much more likely that there is a true genetic correlation between the two responses than if divergence in a nonselected character is observed in one replicate only. If the suspected correlated response varies gradually with successive generations as the phenotype under selection gradually responds to selection pressure, there is a high probability that it is a true correlated response (Roderick and Schlager, 1966). It is improbable that the same selection-irrelevant trait would be fixed in replicated sensitive and resistant lines by chance (Crabbe et al, 1990b).

In addition to replication of the selection experiment in genetically independent lines, most modern selection experiments include a non-selected control line to serve as a reference point for the selected lines (Crabbe et al, 1990b). Control mice, whose progenitors came from the same genetically heterogeneous stock as did the progenitors of the selected lines of mice, are randomly bred. They serve to identify 
changes over time due to genetic drift, or random changes in gene frequencies for reasons not related to deliberate selection pressure.

Using the Mouse to Study Responses to Ethanol

Alcoholism is a complex disorder of human beings. No animal model of alcoholism exists (although perhaps some of the ethanol-preferring strains of rats come close). But animal models are nevertheless useful in ethanol research, because they enable us to ask specific questions that cannot easily be answered using human subjects. Does ethanol affect the regulated body temperature? If so, how? Does the effect of ethanol remain the same, from the first acute drug exposure through development of tolerance over many days of administration? Does a thermoregulatory effect of ethanol, if present initially, stay the same, reverse itself, or disappear entirely during withdrawal from ethanol dependency? If ethanol affects the regulated temperature, by what mechanism might it exert its influence? These are questions that can be asked of the mouse, and answered particularly well by mice selected especially for their differential temperature response to ethanol - the HOT and COLD selected lines of mice.

THERMOREGULATION DURING ACUTE EXPOSURE TO ETHANOL

It has been known for more than one hundred years that ethanol affects body temperature. In 1865, A. Walther reported that a rabbit given thirty-five milliliters of brandy 
by gavage died after its body temperature had declined from $38.8^{\circ} \mathrm{C}$ to $20^{\circ} \mathrm{C}$ in a cold $\left(12.5^{\circ} \mathrm{C}\right)$ room; the body temperature of a control rabbit kept under the same conditions varied by only $2^{\circ} \mathrm{C}$ (Freund, 1979). Much more is known today about both the actions of ethanol in the body and the thermoregulatory system than was understood in 1865. Ethanol can produce a broad range of physiological effects, including changes in vascular state (Rall, 1990), a range of primary and secondary alterations in nervous system function (Eckhart et al, 1981), and modification of cell membrane properties (Chin and Goldstein, 1981; Rottenberg et al, 1981; Goldstein, 1989). Such effects might impinge at various points upon the sensing, integrating, and response components of the thermoregulatory network. Indeed, ethanol has been reported to decrease panting, shivering, and $\mathrm{PO} / \mathrm{AH}$ neuronal firing rates, and to alter respiratory depth and frequency, sweat secretion, and behavior (Kalant and Le, 1984; Pohorecky and Brick, 1988). At the systems level, ethanol could affect the central nervous thermoregulatory mechanism. The set point of the regulated body temperature could be adjusted upwards or downwards, or abolished completely; or the range within which body temperature is regulated could be broadened. Despite all the knowledge accumulated about ethanol since 1865, the specific thermoregulatory sequelae of ethanol administration remain poorly elucidated. However we possess much better tools than 
did Walther, in the form of much more information, with which to understand these effects.

If ethanol acted to lower the set point, a mouse would activate behavioral and physiological responses to lower its body temperature. Such an animal would seek out cooler environmental temperatures, while peripheral vasodilation augmented the effect of the behavioral response. If ethanol acted to raise the set point, opposite behavioral and vascular changes would occur as the animal sought to raise its body temperature.

If ethanol were mainly disruptive, low doses would be expected to broaden the set point, and an animal might allow its body temperature to rise or fall several degrees before acting to oppose the change. Such a disruption could be detected, not only by measuring an increased variation in internal temperature, but also by observing a decreased precision of thermoregulatory behavior. Higher doses of ethanol would be expected to abolish the set point, and the animal's body temperature would vary with ambient temperature. Indeed, there is evidence from mice (Freund, 1973) and rats (Myers, 1981) that high doses of ethanol entirely disrupt thermoregulation, producing animals whose body temperature drifts unopposed with changing environmental temperature.

If ethanol left the set point unaltered, but acted only on peripheral effector mechanisms, an animal could utilize remaining, uncompromised systems to oppose induced thermal 
loads. If, for instance, ethanol caused peripheral vasodilation, an animal in an environment below thermoneutral would be subjected to excessive heat loss. Such an animal could defend its (unchanged) regulated temperature by shivering, piloerecting, and approaching heat sources.

Experiments designed to evaluate how ethanol affects body temperature have produced divergent results. Intragastric gavage with high doses of ethanol $(2.0$ or $4.0 \mathrm{~g} / \mathrm{kg})$ disrupts thermoregulatory mechanisms in rats (Myers, 1981). However in another experiment, rats injected intraperitoneally with ethanol $(1.5 \mathrm{~g} / \mathrm{kg})$ at a thermoneutral temperature for rats $\left(26^{\circ} \mathrm{C}\right)$ exhibited a small but statistically significant fall in body temperature (Lomax et al, 1981). The decline occurred without observed alterations in either metabolic rate or tail blood flow; tail blood flow was high both before, and for thirty minutes after injection. However a sudden decrease in tail blood flow occurred in concert with a rise in core temperature beginning thirty minutes after injection. The authors concluded that the fall in core temperature was caused by a decrease in the thermoregulatory set point. They speculated that the bare skin of the feet may have provided sufficient additional heat exchange surface to facilitate the modest (about $0.7^{\circ} \mathrm{C}$ ) decline in core temperature, and that the decrease in tail blood flow at the point of lowest body temperature indicated activation of heat conservation mechanisms as the set point returned to normal. In another 
laboratory, rats injected with $2.0 \mathrm{~g} / \mathrm{kg}$ and maintained at about the same temperature $\left(25^{\circ} \mathrm{C}\right)$ also showed no difference from controls in tail blood flow, but exhibited a reduction in metabolic rate accompanying a decline in internal temperature (Fregly and Spiers, 1984; Spiers et al, 1984).

Investigations of the effect of ethanol on behavioral thermoregulatory responses in ectotherms have indicated an effect on the set point. Goldfish swimming in an ethanol solution chose significantly cooler temperatures in a temperature gradient than did similar control fish in water (O'Connor et al, 1988). Since goldfish lack effectors other than behavior, they are especially useful in the study of thermoregulatory mechanisms. The body temperature of a small fish is always essentially at ambient water temperature; behavioral changes produced by a change in the central nervous system regulator of body temperature result in body temperature adjustments via selection of an appropriate ambient temperature, if that is possible.

Results from behavioral studies of endotherms have not proved so straightforward to interpret. In one study, rats escaped from a heat source at the same time that their internal temperature was falling after a dose of ethanol (Lomax et al, 1980), indicating a decline of the regulated temperature. In another study, mice selected cooler ambient temperatures in a temperature gradient after intraperitoneal injections of ethanol, but no internal temperature 
measurements of the animals in the gradient were made (Gordon and Stead, 1986). A similar rat study continuously monitored selected temperature after ethanol and recorded a decrease in preferred temperature, but internal temperature was measured only once, at two hours after ethanol gavage (Gordon et al, 1988a). While suggestive, such studies do not allow a clear conclusion to be drawn about the effects of ethanol on thermoregulatory mechanisms, since core and ambient temperatures were not continuously and simultaneously monitored. To clarify the picture of the effect of ethanol on body temperature, therefore, thermoregulatory behavior was the effector chosen for monitoring, along with internal body temperature, in most of the experiments presented in this dissertation.

Much of the individual variability in sensitivity to the effect of ethanol on body temperature reflects genetic differences (Crabbe et al, 1982a). Bidirectional genetic selection, performed in replicate, for a lesser or greater decrease in internal temperature after intraperitoneally injected ethanol has produced lines of mice that differ substantially and reliably in this characteristic (Crabbe et al, 1987). For a given dose of ethanol, insensitive HоT1 and HOT2 mice experience a much smaller decline in rectal temperature than do sensitive COLD1 and COLD2 mice.

Although the magnitude of the differences between HOT and COLD mice has been clearly established (Crabbe et al, 1987; 
Crabbe et al, 1989), the mechanisms underlying the genetic difference have not been elucidated. At least for the first three hours postinjection, their rates of ethanol metabolism do not differ (Crabbe et al, 1989). During genetic selection, the mice are characterized at $24^{\circ} \mathrm{C}$, an ambient temperature well below thermoneutrality for the mouse (Prosser and Brown, 1961, p.266). Since rectal temperature is the only response to ethanol assessed during selection, it is not possible to determine whether the decrease in rectal temperature is due to a regulated decline in body temperature, or to a fall in internal temperature due to the direct activation of heat loss effectors. To understand how selective breeding is altering body temperature responses in these lines of mice, it is essential to know the extent to which the observed divergence in rectal temperature after ethanol is due to a direct effect on the central nervous system regulator. A selection-induced difference in the regulated responses of HOT and COLD mice would open up the exciting possibility of using these selected lines to elucidate the specific mechanisms by which ethanol affects central nervous system control of body temperature. Therefore, to determine whether a regulatory difference has been selected for between the lines, thermoregulatory behavior after ethanol was quantified in the HOT and COLD mice. 
DEVELOPMENT OF THERMOREGULATORY TOLERANCE TO ETHANOL

Drug tolerance is defined as "... a diminution of a drug effect after a period of administration of that drug" (Goldstein, 1983, p.83). Various types of tolerance exist. Neither the mechanisms mediating each type, nor the relationships between the categories of tolerance are well understood (Pohorecky and Brick, 1988).

There are two main categories of ethanol tolerance. The first, called dispositional tolerance, is the lessening of drug effect over time because there is less of it at its site of action (Goldstein, 1983, p.83). Dispositional tolerance could conceivably develop as a result of changes in drug absorption or distribution, but significant changes in these processes have not been demonstrated (Goldstein, 1983, p.83; Pohorecky and Brick, 1988). Dispositional tolerance appears to reflect increased metabolism of the drug that develops after chronic administration. This increase in metabolism, when it occurs, may be easily demonstrated. Blood, or brain, or breath ethanol levels are lower in the same animal at the same time after the same dose of ethanol, on successive days of ethanol administration. The increased metabolism could involve any of the ethanol-metabolizing enzyme systems already considered - ADH, MEOS, or catalase. As previously discussed, it is believed that MEOS is responsible for much of the increased rate of ethanol elimination observed after chronic administration (Lehninger, 1975, p.502; Petersen and Atkinson, 
1980; Goldstein, 1983, p.15; Pohorecky and Brick, 1988; Rall, 1990).

An increase in the rate of ethanol metabolism following chronic exposure has been demonstrated in both rodents and human beings (Yuki and Thurman, 1980). The degree to which metabolism may be increased in human alcoholics is not known; in animals, liver metabolism of ethanol may increase by thirty to fifty percent after chronic exposure (Pohorecky and Brick, 1988). The ability to develop dispositional tolerance may be genetically mediated, and furthermore may be unrelated to the ability to develop other types of tolerance. The contribution (if any) of dispositional tolerance to the expression of other forms of tolerance is unknown (Pohorecky and Roberts, 1992). Apparently, all mice do not develop dispositional tolerance. In a study using two groups of Swiss mice (Rigter et al, 1980), animals which had received ethanol the day before did not metabolize ethanol at a rate different from animals which had received saline the day before. In another study of mice selectively bred for differences in response to hypnotic doses of ethanol (Tabakoff et al, 1980), five days of ethanol treatment produced no significant difference in the rate of ethanol metabolism by either selected line, although they differed significantly in the ability to acquire chronic tolerance. In both cases, of course, perhaps a longer period of ethanol exposure might have resulted in the expression of dispositional tolerance. 
The second category of ethanol tolerance is functional tolerance. Functional tolerance

...denotes an actual change in the sensitivity of the brain to a given concentration of the drug. Included in this definition are some types of behaviorally augmented or conditioned tolerance. The various forms of tolerance have different mechanisms and presumably different sites, time courses, and dose relations, even though all have the same ultimate effect in that the subject appears less intoxicated after chronic ethanol administration (Goldstein, 1983, p.84).

Functional tolerance manifests itself over three time courses. Acute tolerance develops over a matter of minutes or hours. An animal is more functionally impaired (however impairment is measured) at a given blood or brain or breath ethanol concentration when concentration is rising (soon after administration of the drug), than at the same ethanol concentration when concentration is falling. Rapid tolerance is manifested over the course of one day. After one exposure to ethanol, the animal's response to ethanol twenty-four hours later is diminished (Rigter et al, 1980). Chronic tolerance develops over a matter of days or weeks. An animal gradually becomes progressively less impaired at the same systemic ethanol concentration as it is exposed repeatedly to ethanol. The complexity of the phenomenon becomes particularly evident as we consider functional tolerance.

Acute tolerance is defined as "...a change in the sensitivity of the (central nervous system) to ethanol occurring during the time that a single dose of ethanol is present in the system" (Tabakoff et al, 1980). The concept 
was first proposed by Mellanby in 1919, after he observed that dogs exhibited greater functional impairment at the same blood level while ethanol levels were rising, compared to when they were falling; acute tolerance is still referred to as the Mellanby effect (Pohorecky and Brick, 1988). Acute tolerance is measured in a variety of ways. One method is to measure blood ethanol concentration at the time that some behavioral function (such as mouse righting reflex) is lost, then to measure blood ethanol again when the function returns (when the mouse can again right itself). One problem with this method is that ethanol concentrations in blood and brain do not reach equilibrium for fifteen to thirty minutes after an intraperitoneal injection of ethanol (Smolen and smolen, 1989). Another difficulty is that blood ethanol levels rise very rapidly after injection, so it is difficult to obtain reproducible results. A better method is to measure brain ethanol concentration when the ability to perform the function of interest is lost, and measure again when function returns. obviously, since an animal can contribute its brain only once, individual development of acute tolerance cannot be measured by this method. Another procedure that has been suggested (Keir and Deitrich, 1990) is to give animals a range of ethanol doses, and measure blood ethanol concentration upon regain of function, such as awakening from ethanol hypnosis. The hypothesis behind this method is that if there is no development of acute tolerance, the blood ethanol 
concentration should be the same in all animals when they wake up, no matter what the original dose was; only sleep times should differ. If the blood ethanol content at wakeup is a function of the original dose, and not a constant value, one may infer that acute tolerance has occurred. Breath samples can also be analyzed for a noninvasive measure of ethanol content.

In humans, acute tolerance develops to a greater degree to the impairment of cognitive, than of motor tasks (Pohorecky and Brick, 1988). In animals, motor skills are more often measured. Acute tolerance, measured as ability to balance on a rotating dowel, has been documented in rats (Pohorecky and Roberts, 1992). Interestingly, acute tolerance may appear and disappear. In another rat study (Abu-Murad and Thurman, 1980), ethanol was administered for various time periods via inhalation; rats were removed from the inhalation chamber, injected with ethanol, and blood ethanol at loss of righting reflex was estimated by measuring breath ethanol content. Acute tolerance developed after two or four hours of inhalation, but disappeared at subsequent measuring times (six, eight, ten and twelve hours of inhalation).

Some, but not all mice develop acute tolerance. In a study of mice selectively bred for differences in length of sleep time after hypnotic doses of ethanol (long-sleep and short-sleep mice), no evidence for development of acute tolerance was found; brain ethanol levels at the time of loss 
and regain of righting reflex were not different within strains (Tabakoff et al, 1980). This result has been both confirmed (Smolen and Smolen, 1987) and contradicted (Keir and Deitrich, 1990) by a pair of studies which measured blood ethanol content at regain of righting reflex as a function of differing doses. A genetic component to the ability to develop acute tolerance seems likely. Comparison of the C57, C3H and DBA inbred strains showed that although they lose the righting reflex at similar brain ethanol levels, C3H and C57 mice develop acute tolerance (regain righting reflex at a higher brain ethanol level than the level at which it is lost) while DBA mice do not develop acute tolerance (Ritzmann and Tabakoff, 1980).

So-called "rapid" tolerance to the effect of ethanol on rectal temperature has been demonstrated in Swiss mice (Crabbe et al, 1979; Rigter et al, 1980) and in rats (Khanna et al, 1992; Pohorecky and Roberts, 1992; Stewart et al, 1992). Rapid tolerance may be manifested in the absence of dispositional tolerance (Crabbe et al, 1979; Rigter et al, 1980; Khanna et al, 1992; stewart et al, 1992) and is believed to be primarily functional in nature (Khanna et al, 1991). It has been suggested that rapid tolerance may be a predictor for chronic tolerance (Khanna et al, 1992). However it is not known whether the two forms of tolerance rest upon the same mechanisms; validation of the predictive value of rapid tolerance for chronic tolerance must wait for more extensive 
experimental comparisons with a variety of models (Khanna et al, 1992).

Chronic tolerance is commonly defined as having "...a gradual onset and rate of development (reaching) maximum levels generally between 14-21 days" (Pohorecky and Roberts, 1992). Chronic tolerance to ethanol has been demonstrated using many different measures, including hypothermia, incoordination, ataxia, startle response, heart rate, memory, and locomotor activity (Pohorecky and Brick, 1988). Like acute tolerance, the ability to develop chronic tolerance may be genetically mediated, but it appears to be unrelated to the ability to develop acute tolerance. A study of twenty inbred strains of mice found a significant correlation between initial rectal temperature decline after ethanol, and development of tolerance to this effect over eight days of exposure (Crabbe et al, 1982a). In agreement with this study, it was found that COLD mice develop tolerance to ethanol's effect on body temperature, but HOT mice do not (Crabbe et al, 1989). Similarly, sensitive long-sleep mice develop chronic tolerance rapidly, but the resistant short-sleep line becomes tolerant very slowly (Tabakoff et al, 1980) or not at all (Erwin et al, 1992). However, as mentioned above, no evidence of acute tolerance was detected in either long-sleep or shortsleep mice (Tabakoff et al, 1980). Manifestation of acute tolerance may disappear with longer treatment duration (as chronic tolerance develops) (Grieve and Littleton, 1979; 
Pohorecky and Roberts, 1992) further suggesting that different mechanisms are responsible for the two forms of tolerance.

It has been suggested that tolerance develops, not to the ethanol itself, but to the degree of functional disturbance caused by the drug (Kalant and Lê, 1984). Correlations between initial sensitivity and ability to develop tolerance discussed in the preceding paragraph support this hypothesis (Tabakoff et al, 1980; Crabbe et al, 1982a; Crabbe et al, 1989). Peris and Cunningham (1986) have demonstrated that stress increases body temperature decline after ethanol in rats, and Mansfield and Cunningham (1980) suggest that stress accelerates the development of tolerance to ethanol hypothermia. Perhaps this acceleration is the result of an increased functional disturbance when stress and ethanol are paired. There also appears to be an additional innate capacity to develop tolerance that exists independent of cues, learning or degree of behavioral disturbance. It has been demonstrated (Lê et al, 1986) that although the degree of hypothermia following drug exposure affects the rate of tolerance development, even rats receiving ethanol at an ambient temperature of $36.5^{\circ} \mathrm{C}$ (a temperature which prevents hypothermia) can develop tolerance to the hypothermic effects of ethanol, albeit more slowly than animals that experience lower body temperatures.

It is clear that environmental components contribute to the development of tolerance. Tolerance is more readily 
acquired when ethanol is administered in the presence rather than the absence of external cues (Lê et al, 1987), and is generally maintained for much longer when a learned, rather than an unlearned response is used to measure tolerance (Holloway and King, 1989; stewart et al, 1992). This suggests that there are both cellular and learning components involved in the development of tolerance to the behavioral effects of ethanol. This idea is supported by an experiment discussed above, in which rats prevented from experiencing a decline in body temperature after ethanol nevertheless developed tolerance to ethanol hypothermia (Lê et al, 1986). Cellular and learned components may be more or less important depending upon the response in question, and may be separable if the correct experiments are designed (Mackenzie-Taylor and Rech, 1991).

It has been suggested that tolerance is a manifestation of a classically conditioned compensatory response opposite in direction to the unconditioned response. The hypothesis of drug-opposite compensatory behavior underlying tolerance development was first elucidated by $S$. Siegel (1975) after work with morphine tolerance acquisition by rats. Holloway and King (1989) studied food-deprived rats which received nourishment only as a reward for lever pressing. Ethanol initially caused a reduction in the rate of lever pressing; with intoxicated practice, the rate was restored. If intoxication causes a reduction in rate of reinforcement (such 
as reduced food acquisition resulting from an impairment in the ability to press a lever), a coping or compensatory mechanism might come into play to counteract the disruption and restore the reinforcement rate during intoxicated responding (Holloway and King, 1989).

Although certain responses to ethanol (such as the lethal effects of large doses, or a decline in body temperature) are not themselves learned responses, they might be subject to classical conditioning if drug administration is paired with predictable environmental cues (Lê et al, 1987). In a study of the effect of conditioning on ethanol lethality (Melchior, 1990), it was found that mice are significantly more sensitive to the lethal effect of ethanol in a novel environment, than in an environment previously associated with ethanol injection. similarly, although the unconditioned response to ethanol is a decline in body temperature, repeated drug exposure in the same environment might result in the emergence of a conditioned compensatory response of increased body temperature; the sum of unconditioned and conditioned responses may be a reduced hypothermic response (Stewart et al, 1992), which is how we define thermoregulatory tolerance.

The original concept of functional tolerance to drug effects was based upon an idea of biochemical and physiological adaptation to drug perturbation (MackenzieTaylor and Rech, 1991) which would allow an animal to function fairly normally in the presence of the drug after repeated 
exposure. As discussed above, learned components are clearly present; but there is more to tolerance than learning. The similarity between ethanol and temperature effects on cell membranes has already been discussed. Both microorganisms and ectothermic vertebrates compensate for long-term changes in ambient temperature by alterations in membrane lipid composition. Sinensky (1974) has termed this process homeoviscous adaptation. Studies using cultured goldfish cells indicate that this process is at least partially a "direct adaptation" mediated at the cellular level, and not totally dependent upon higher level nervous or hormonal regulatory systems of the animal (Tsugawa and Lagerspetz, 1990). The process, or at least the end result of membrane adaptation to ethanol appears similar to temperature adaptation - similar enough that mammalian cells in tissue culture develop cross-tolerance to ethanol and to high temperature (Grieve and Littleton, 1979). Membranes from both liver and brain cells of ethanol-fed rats show increased rigidity, and decreased partitioning of ethanol into the cell membrane (Rottenberg et al, 1981). In the presence of moderate concentrations of ethanol, membranes from ethanol-fed animals are as fluid as membranes from control animals, which presumably exist in a state optimal for membrane function (Rottenberg et al, 1981). The increase in membrane order (decrease in fluidity) that occurs after chronic exposure to ethanol in vivo may result in part from partial 
interdigitation of the bilayer hydrocarbon chains, at least in liver plasma membranes (Lewis et al, 1989). After chronic ethanol the degree of saturation in fatty acids of mouse brain phospholipids is also increased; chronic administration of ethanol may therefore alter membranes both chemically and physically (Goldstein, 1984; Pohorecky and Brick, 1988).

The ability to increase originally decremented functionality as drug exposure continues has clear benefits for an organism. To give an admittedly artificial example, if a rat must lever press to obtain all of its food, and if acute ethanol exposure decreases the rate of responding, underfeeding will result. Tolerance development will allow the rat to press faster when under the influence of ethanol (Holloway and King, 1989) enabling it to restore normal food procurement. Acquisition of tolerance may also protect against the lethal effects of a high dose of the drug (Melchior, 1990). If conditioned tolerance is blocked by administration of the drug in the absence of cues previously associated with its administration, however (Melchior, 1990), tolerance may in practice be of less value to the organism. In the experiments herein which focus upon the development of tolerance to the thermoregulatory effects of ethanol, an attempt was made to separate the characteristics of tolerance development in mice with the ability to easily alter originally decremented function after ethanol, from tolerance 
development in mice possessing a much more limited set of options.

THERMOREGULATION DURING WITHDRAWAL FROM ETHANOL DEPENDENCY

The withdrawal reaction, which occurs after ethanol intake by dependent animals is halted, is characterized by a number of physiological disturbances collectively referred to as the alcohol withdrawal syndrome. This syndrome has been recognized at least since the time of Hippocrates, who wrote, "If the patient be in the prime of life and from drinking he has trembling hands, it may be well to announce beforehand either delirium or convulsion" (Pohorecky and Brick, 1988). The altered function seen in the muscular, autonomic, gastrointestinal, thermoregulatory, orienting, arousal and other systems is largely based on a severe autonomic hyperactivity (Goldstein, 1983, p.101; Pohorecky and Brick, 1988; Glue and Nutt, 1990). The increased sympathetic activity is a symptom of disturbances in norepinephrine, corticotropin-releasing factor, GABA, and NMDA receptormediated glutamate neurotransmitter systems (Glue and Nutt, 1990). In humans, increases in body temperature are commonly observed in clinical settings during withdrawal, and patients exhibiting a body temperature of over $40^{\circ} \mathrm{C}$ frequently fail to survive (Tavel et al, 1961). Although the increase in body temperature is often described as a fever, this designation is probably inaccurate. Withdrawing patients with high body 
temperatures exhibit apparent activation of heat loss mechanisms, evidenced by peripheral vasodilation and profuse sweating (Kalant and Lê, 1984). Fever, by definition, involves an increase in the regulated temperature (Kluger, 1991); activation of mechanisms to dissipate heat would not accompany such an increase. The responses observed in withdrawing patients appear to indicate an increase in heat production, but not necessarily a change in the regulated temperature (Freund, 1979). This condition is properly described as hyperthermia (Stitt, 1979).

Many studies have utilized animal models in an attempt to understand the changes in the thermoregulatory system that occur during withdrawal. Dietary intake, intubation, and inhalation have been used to produce ethanol dependence; subsequent measurements of changes in body temperature during withdrawal have yielded a confusing assortment of results (Friedman, 1980; Kalant and Lê, 1984). During withdrawal, body temperature has been seen to increase (Pieper, 1972; Kakihana and Moore, 1977), decrease (Ritzmann and Tabakoff, 1976), and remain the same (Brick and Pohorecky, 1977; Ferko and Bobyock, 1978) during the period when other withdrawal symptoms are maximal. Since few investigators have monitored thermoregulatory effector mechanisms such as vasculature status, shivering, or temperature selection, it is not possible to draw conclusions about withdrawal effects (if any) on the regulated temperature from the preceding studies. In 
one case behavior was monitored, but the results are difficult to interpret. Brick and Pohorecky (1977) gave rats undergoing withdrawal a choice of three ambient temperatures $\left(2^{\circ} \mathrm{C}, 19^{\circ} \mathrm{C}\right.$ and $30^{\circ} \mathrm{C}$ ). Rectal temperatures of withdrawing and control animals did not differ before withdrawal began, or for fourteen days following cessation of ethanol exposure, but the withdrawing animals preferred the warmest location for about five days after withdrawal began. However, temperature preference was measured for only four minutes at a time, two four-minute periods on the first day of withdrawal and one per day on subsequent days.

of particular interest, in light of this general overwhelming lack of understanding concerning thermoregulatory status during withdrawal, is an assertion in Pohorecky and Brick's generally excellent review (1988), "(the) simplest and most widely used procedures (for quantifying the withdrawal reaction) in mice are the convulsions elicited by handling....and the hypothermia that develops during withdrawal". Clearly there is a pressing need to improve our understanding of this aspect of the withdrawal reaction.

Kalant and Lê (1984) note that observations of increased body temperature, or preference for a warmer environment during withdrawal could indicate a rebound effect; that is, if acute ethanol lowers the set point, physiological mechanisms which adjusted to constant ethanol during the acquisition of tolerance might overcompensate and be manifested as an 
increase in the thermoregulatory set-point during withdrawal. A similar general hypothesis proposed to account for physiological perturbations during withdrawal suggests that if the continuous presence of a drug that mimics the effect of warming on the cell membrane results in adaptation of membrane lipids, as discussed previously, increased membrane rigidity might mediate the hyperexcitability of withdrawal, since it is opposite to the primary sedative effect of the drug which accompanies the disordering of acute exposure (Goldstein, 1984).

The creation of selected lines of mice that differ in the severity of handling-induced convulsions during withdrawal from ethanol (withdrawal-seizure-sensitive and-resistant mice) (Crabbe et al, 1985) demonstrates that at least this facet of withdrawal is under genetic control. In fact, there is substantial evidence for a genetic component to all responses to ethanol (Belknap, 1980). A major goal of ethanol research is to identify some "marker" that could predict the chance of an individual to develop ethanol-related problems; that is, some easily measured response to ethanol might be used to predict the susceptibility of a given individual to severe ethanol withdrawal seizures (Crabbe et al, 1983b). The withdrawal-seizure-sensitive or -resistant mice differ neither in initial sensitivity to the hypnotic effects of ethanol, nor in tolerance development (Crabbe and Kosobud, 1986); similarly, mice selected for a difference in 
sensitivity to acute hypnotic effects of ethanol show no difference in withdrawal reactions (Goldstein and Kakihana, 1975). However, an analysis of the responses of a panel of inbred strains of mice indicated a seeming relationship between body temperature response to ethanol, and degree of withdrawal severity (Crabbe et al, 1983b). There appears to be a significant positive correlation between initial hypothermic sensitivity and subsequent development of tolerance to ethanol's effect on body temperature (Crabbe et al, 1982a), and a significant negative correlation between withdrawal severity and ability to acquire tolerance (Crabbe et $a 1,1983 \mathrm{~b})$. These results suggest the possibility of a genetic correlation between withdrawal severity and some aspect of ethanol's effect on the thermoregulatory system. To clarify the effect of withdrawal from ethanol dependency on the thermoregulatory system, behavioral thermoregulatory studies were first undertaken using genetically heterogeneous mice. Both internal and selected temperatures were continuously monitored in these animals during withdrawal from inhalation-induced physical dependence on ethanol. Subsequently, to assist in the elucidation of the genetic correlation (if any) between withdrawal seizure severity and thermoregulatory response to ethanol, thermoregulatory behavior during withdrawal was also studied using the HOT and COLD selected lines of mice. 
SEROTONIN AND THE ACUTE THERMOREGULATORY RESPONSE TO ETHANOL

There is clear evidence for the participation of serotonin in central thermoregulatory events, although the precise thermoregulatory role of this neurotransmitter has not been entirely defined (Brück and Hinckel, 1990). Serotonergic cell bodies are found in the midline areas of the brainstem in close association with the raphe nuclei; ascending serotonergic fibers to the hypothalamus originate mainly in raphé nuclei (Van de Kar, 1991). It is true that in raphé nuclei, which are considered a multiple transmitter complex, at least ten cell types using different neurotransmitters have been described (Brück and Zeisberger, 1990). However the nucleus raphé magnus contains a high percentage of warm- and cold-sensitive serotonergic neurons, with a preponderance of the former (Brück and Hinckel, 1990). The nucleus raphé magnus appears to be a relay station linking afferent pathways from scrotum, trunk and legs to the thalamus and the hypothalamus (Jessen, 1990).

Microiontophoretic application of serotonin to $\mathrm{PO} / \mathrm{AH}$ neurons excites warm-sensitive, and inhibits cold-sensitive units (Murakami, 1973). Injections of serotonin into the ventricles of the brain causes a fall in body temperature in both restrained (Feldberg and Lotti, 1967) and partially restrained (Crawshaw, 1972) rats, and in restrained mice as well (Brittain and Handley, 1967). Electrical stimulation of the raphé nuclei (Lin et al, 1983) or injection of serotonin 
into the dorsal raphé (Hillegaart, 1991) or PO/AH (Lin et al, 1983) causes hypothermia in rats. In sheep, either high temperature or intracerebroventricular serotonin causes an increase in respiratory rate which can be prevented by infusion of a serotonin receptor blocker (Brück and Hinckel, 1990)

Intracerebroventricular serotonin has been shown to increase the body temperature decline after ethanol in mice (Ritzmann and Tabakoff, 1976), and acute injection of ethanol (4 $\mathrm{g} / \mathrm{kg})$ causes both a fall in body temperature of rats, and an accompanying significant (ten to fifteen percent) elevation in endogenous levels of serotonin in the hypothalamus, telencephalon, midbrain and brainstem (Pohorecky et al, 1974). This evidence suggests a possible role for serotonin in the mediation of ethanol hypothermia. However, if animals are monitored at ambient temperatures below thermoneutrality (as normal laboratory temperature is, for mice), a decline in body temperature following administration of serotonin might be due to an effect on the regulator of body temperature, or to derangement of regulation, or to a direct influence on the effector mechanisms. In contrast, in a temperature gradient, if serotonin causes a regulated decline in body temperature, mice can occupy cool positions and maximize heat loss, perhaps achieving body temperatures lower than those of similar animals held at laboratory temperature. But if the fall in body temperature is due to a direct influence on effectors, 
mice in a temperature gradient can easily utilize their behavioral option to counteract the increased conductance and prevent inadvertent heat loss, perhaps maintaining internal temperature above temperatures recorded from similar animals held at laboratory temperatures.

The experimental protocol used to establish the HOT and COLD mice exerts selection pressure on one characteristic only - rectal temperature response to acute ethanol. This observable, measurable phenotypic characteristic, which serves as the basis for discrimination between individuals during selection, is a product of underlying physiological and biochemical processes which are controlled by genes. The process of successfully selecting for a phenotypic difference between HOT and COLD mice must also produce changes between the lines in the mechanisms which generate this response. Because of the evidence suggesting a possible role for serotonin in the mediation of ethanol hypothermia, the body temperature responses of HOT and COLD mice to intracerebroventricular serotonin were characterized, using both mice held at constant ambient temperature, and mice free to exercise thermoregulatory choice in a temperature gradient. 
MATERIALS AND METHODS

All experiments done as part of this project shared a basic goal of improving our understanding of the thermoregulatory effects of ethanol (EtOH). Within those broad parameters, however, the specifics of experimental animals, surgical procedures, testing protocol (both behavioral and non-behavioral) and statistical treatment of data varied among the diverse experiments. Separate portions of the project focused upon the acute effects of EtoH, the development of tolerance to EtOH, behavior during withdrawal from EtOH dependency, and the effect of a centrally administered neurotransmitter. The materials and methods section will therefore adhere to a format of an initial general discussion of each method or approach, followed where necessary by a separate discussion of variations on the general methodology utilized for each experiment.

\section{ANIMALS}

Only adult male mice were utilized in this series of experiments. All mice were generously supplied from the breeding colony of Dr. John C. Crabbe at the Veteran's Administration Research Center in Portland, oregon. In all cases, the mice utilized in these studies were experimentally naive, and ranged from 8 to 20 weeks of age. 
In experiments investigating acute EtOH, the effect of time of day on response to EtoH, withdrawal from EtoH dependency, and the effect of 5-HT on thermoregulation, mice of four selected lines were utilized. To establish these lines of mice, an initial population of 20 genetically heterogeneous breeding pairs of HS/Ibg mice were utilized (Crabbe et al, 1990a). This parent stock was derived from crossing eight inbred strains. Lines of mice with an augmented (COLD mice) or attenuated (HOT mice) decline in rectal temperature $\left(T_{\text {re }}\right)$ after $\mathrm{EtOH}$ have been selected for, in replicate, resulting in COLD1 - HOT1 and COLD2 - HOT2 replicate pairs. In addition, a randomly selected genetically heterogeneous control line (CON) was maintained. The withinfamily selection protocol involves an intraperitoneal (i.p.) injection of $3 \mathrm{~g} \mathrm{EtOH} / \mathrm{kg}$ administered to a naive mouse held at laboratory temperature $\left(24^{\circ} \mathrm{C}\right)$. The change from preinjection body temperature is measured for each mouse with a rectal probe at 30 and 60 min postinjection (Crabbe et al, 1987). By the 18th selected generation, average changes from baseline during selection testing were: HоT1 $=-2.0^{\circ} \mathrm{C}$; нот2 $=-1.0^{\circ} \mathrm{C}$; COLD1 $=-5.3^{\circ} \mathrm{C} ;$ COLD2 $=-5.5^{\circ} \mathrm{C}$ (Phillips and Crabbe, 1991). Mice used in these studies were from the 14 th to 20 th generations of selection.

Investigations of the development of thermoregulatory tolerance to EtOH, as well as initial studies on both the acute effects of EtOH on thermoregulation, and the 
thermoregulatory behavior of mice undergoing withdrawal from EtoH dependency, were performed using the genetically heterogeneous coN mice maintained as genetic controls, as described above.

\section{HOUSING}

Mice were housed singly, or in groups of two to five animals on hardwood shavings in standard mouse cages. Bedding material was changed twice weekly, except for singly housed animals, whose bedding was, changed once per week. The animal room was normally maintained at $24 \pm 2^{\circ} \mathrm{C}$ on a $12: 12$ L:D photoperiod, with lights on at 06:30. Food (Purina Rodent Laboratory (how) and water were available ad libitum; fresh water was provided three times per week.

Mice participating in the 5-HT study were equipped with permanent indwelling brain cannulae (see below) which necessitated a variation on housing arrangements. After surgery, these mice were housed individually to prevent chewing damage to implants and scalp wounds. Cage tops in standard configuration provided insufficient head space, so each cage top was turned upside down and secured in place with two open-ended Hoffman clamps. Since the cage top food hopper was useless in this configuration, a few pellets of mouse chow were given to each mouse twice a day. Water bottles were wedged in place through the wires. An important advantage of this method was that each mouse could be supplied with a much 
deeper bed of shavings $(8 \mathrm{~cm})$ than is possible in a normally arranged mouse cage. These mice were also supplied with torn pieces of toweling for nest material. Individually housed mice nested deep in their shavings, presumably to facilitate maintenance of a normal body temperature in the absence of cage mates. In addition, during the period of this series of experiments the animal room temperature was maintained at a higher temperature $\left(28 \pm 2^{\circ} \mathrm{C}\right)$ with a supplemental heater.

\section{SURGICAL, MEDICAL AND INJECTION PROCEDURES}

\section{Mini-Mitter Implantation}

In rodents, stress produced by procedures such as restraining the animal (Nagasaka et al, 1979) and measuring body temperature with rectal probes (Poole and Stephenson, 1977; Gallaher and Egner, 1987) causes a rise in internal temperature $\left(T_{i}\right)$. To avoid perturbing one of the measured parameters, mice utilized in most of these studies were implanted with Model $\mathrm{x}$ (for initial study of acute effect of EtoH using genetically heterogeneous mice, and studies of effect of time of day on response to EtOH) or Model XM-FH (all other studies) battery-powered mini-mitter radio transmitters (Mini-Mitter Co. Inc., sunriver, OR). The mini-mitters broadcast a radio carrier signal (500-1600 $\mathrm{kHz})$ with pulse rate $(300-600 \mathrm{~Hz})$ inversely proportional to temperature. Mice were anesthetized with a cocktail of ketamine hydrochloride (Ketaset, Bristol-Meyers Co.) and xylazine hydrochloride 
(Rompun, Haver-Lockhart Co.) $(400 \mu l 50 \mathrm{mg} / \mathrm{ml}$ Ketaset: $200 \mu \mathrm{l} 20$ $\mathrm{mg} / \mathrm{ml}$ Rompun: $400 \mu \mathrm{l} 0.98 \mathrm{NaCl}, 2.9-3.3 \mu \mathrm{l} / \mathrm{g}$ mouse wt). The abdomen of an anesthetized mouse was shaved, and a left parasagittal incision approximately $1.2 \mathrm{~cm}$ long was made in the hypogastric region. A previously calibrated mini-mitter, coated with paraffin, was then inserted into the peritoneal cavity, and secured with nonabsorbable suture to the abdominal wall. The muscle incision was closed with suture, and the skin incision with $7.5 \mathrm{~mm}$ wound clips. During surgery and until wakeup, corneal surfaces were coated with ophthalmic ointment. In earlier surgeries (initial experiments with genetically heterogenous mice, and time-of-day experiments) each animal received $0.5 \mathrm{ml}$ gentamycin antibiotic solution in the peritoneal cavity before closure. In later surgeries, mice received a postsurgical intramuscular injection of $3 \mathrm{mg}$ chloramphenicol. Body temperature was kept at $37^{\circ} \mathrm{C}$ until wakeup; initially this was accomplished by placing mice in a small plastic chamber heated with a light bulb, and later by using Deltaphase Isothermal Pads (Braintree Scientific, Inc.). Mice were allowed a minimum of 4 days of rest postsurgery before being utilized in any procedure.

\section{Implantation of Chronic Indwelling Brain Cannulae}

Forty-two HOT and COLD mice were implanted with chronic indwelling brain cannulae for the study investigating the effect of intracerebroventricular (i.c.v.) 5-HT on body temperature. The animals were anesthetized as described 
above, the scalp was shaved, and the mouse was placed in a Kopf Instruments stereotaxic device which had been extensively modified for mice (Figure 2).

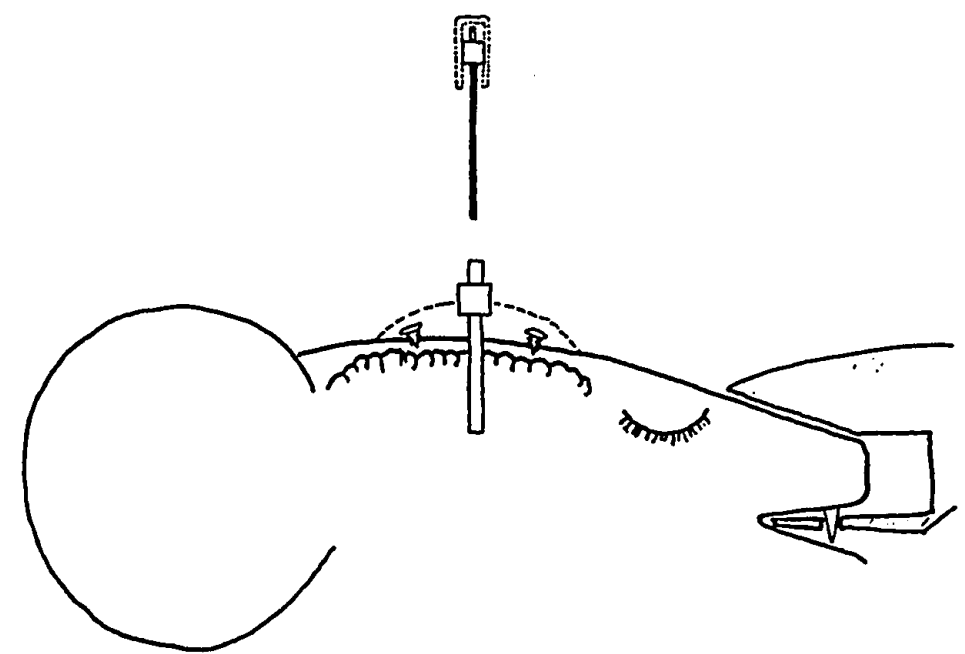

Figure 2. Mouse head in stereotaxic surgery unit. Brain cannula implant drawn approximately to scale.

Corneal surfaces were protected both from drying and from the bright light utilized for this procedure with gauze pads coated with ophthalmic ointment. The skull was levelled, and a stereotaxic atlas (Slotnick and Leonard, 1975) was used as a guide to cannula placement, with coordinates posterior 0.1 $\mathrm{mm}$, lateral $1.0 \mathrm{~mm}$ and vertical $-1.7 \mathrm{~mm}$ (zero reference at Bregma) (Figure 3).

A $7 \mathrm{~mm}$ long 26-ga guide cannula was installed in the forebrain and secured in place with a dental acrylic bridge to two stainless steel self-tapping screws (\#000 X 3/32") installed in the diagonally opposed frontal and parietal 
bones. An indwelling stylet of .008" tungsten wire (Figure 4), $0.1 \mathrm{~mm}$ longer than the guide cannula, was inserted into the guide cannula to keep the open end free of obstruction.

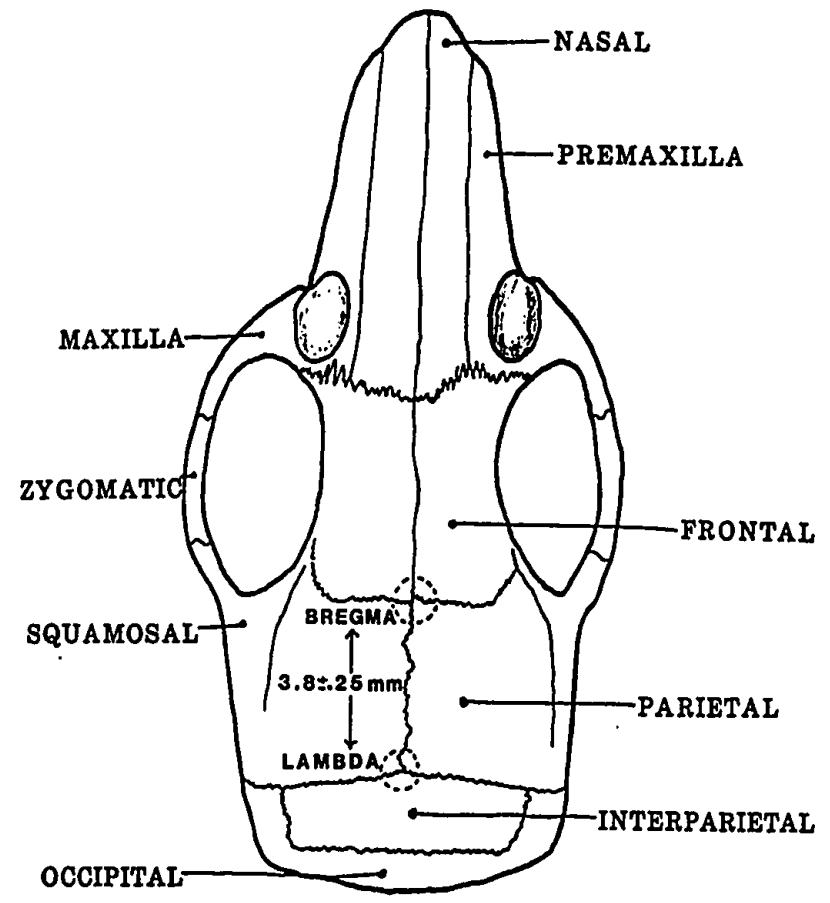

Figure 3. Dorsal view of an adult male mouse skull. The bregma and lambda skull reference points are indicated. Redrawn from Slotnick and Leonard (1975).

A cap of PE-20 tubing, sealed shut at the top, fit tightly over a 26-ga collar on the wire stylet and kept the stylet securely attached to the cannula. The collar insured that the stylet protruded $0.1 \mathrm{~mm}$ below the cannula. The surgical procedure took about $20 \mathrm{~min}$. The scalp incision was closed with two or three $7.5 \mathrm{~mm}$ wound clips. Mice were allowed to recuperate for at least 14 days before participating in experiments. 

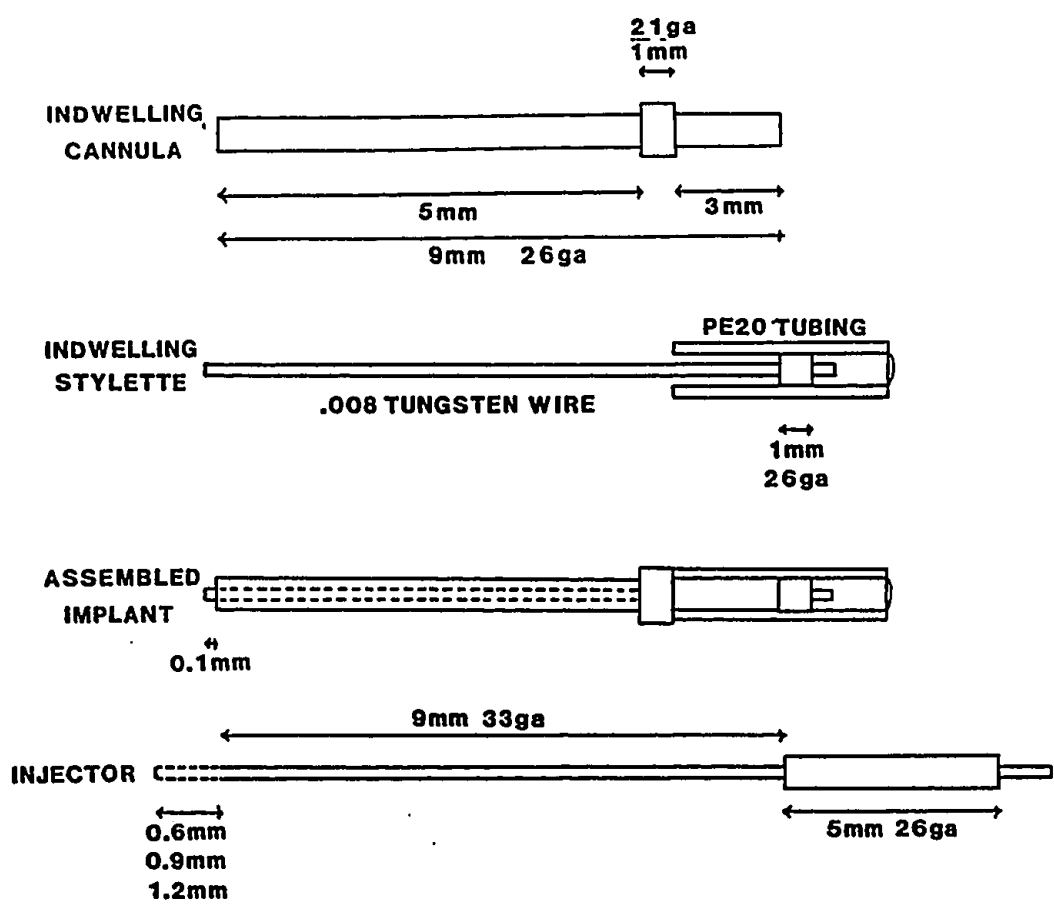

Figure 4. Disassembled brain cannula. Illustrated are indwelling cannula, indwelling stylette, complete assembled implant ready for implantation in mouse brain, and injector to replace removable indwelling stylette for injection.

A subset of 8 mice intended for behavioral experiments in the temperature gradient were implanted with both indwelling brain cannulae and mini-mitters, as described above. These mice were first equipped with brain cannulae, and 10 days later were implanted with calibrated mini-mitters. Mice were allowed to recuperate for 4 additional days before experimentation was begun.

Administration of Ethanol

To achieve uniformity in the time course of effect, and also for simplicity of administration, in the series of 
experiments presently under discussion EtOH was administered to mice via intraperitoneal injection, except for withdrawal studies, where mice were exposed to three days of an EtoH vapor atmosphere to produce physical dependency on EtOH. The characteristics of these two routes of EtOH administration have already been discussed.

\section{Blood Ethanol Determination}

As indicated below where appropriate, for some of these studies, blood EtOH content (BEC) was determined. Blood samples were obtained by snipping the tail tip of a restrained mouse, and filling a heparinized $20 \mu l$ calibrated micropipette. Samples from control animals were discarded. Tail tips were dipped in melted paraffin to stop bleeding. BEC was determined according to the method of Crabbe et al (1989). Briefly, each $20 \mu l$ blood sample was added to $50 \mu l$ of chilled $5 \% \mathrm{ZnSO}_{4}$ and stored on ice until all samples were obtained. Fifty $\mu \mathrm{I}$ of $0.3 \mathrm{~N} \mathrm{Ba(OH})_{2}$ and $300 \mu l$ distilled water were added to each sample. The samples collected at the VA Research Center (all withdrawal experiments) were mechanically shaken for 5 sec (Scientific Products Vortex-Genie Mixer, Model $\mathrm{K}-550-\mathrm{G})$ and centrifuged for $5 \mathrm{~min}$ at $12,000 \mathrm{rpm}$ (Beckman microfuge 12). The supernatant was transferred to crimp-top glass vials and analyzed for EtoH concentration by gas chromatography using an autosampler (Hewlett-Packard Model 7673A) injecting $2 \mu \mathrm{l}$ per sample. Eight external standards of known EtOH concentration $(0.5$ to $4.0 \mathrm{mg} / \mathrm{ml})$ were run together 
with the samples. Other samples were collected at Portland State University as described above, mechanically agitated (Super-Mixer vortexer, Lab-Line Instruments) and centrifuged for $5 \mathrm{~min}$ at $1,000 \mathrm{X} G$ (Adams Sero-Fuge, Clay Adams Co.). Supernatant was decanted into a snap tube, and both samples and standards $(0.2$ to $7.9 \mathrm{mg} \mathrm{EtOH} / \mathrm{ml}$, prepared at the same time) were flash frozen with dry ice and kept frozen at $-70^{\circ} \mathrm{C}$ until assay by gas chromatography as described above.

\section{Sacrifice and Histologies}

Mice implanted with mini-mitters were sacrificed by cervical dislocation, except for a subset of mice implanted with both indwelling brain cannulae and mini-mitters, sacrificed as detailed below.

To confirm cannula placement in mice bearing indwelling brain cannulae, animals were injected with $0.1 \mathrm{ml}$ heparin (heparin sodium, 1,000 USP units/ml, LyphoMed Inc.) and about $10 \mathrm{~min}$ later were anesthetized as previously described. Dye (0.1 $\mu 1$ cresyl violet) was injected into the brain using the same length injection stylet which had previously been utilized to elicit a response to 5-HT in that animal. The mice were sacrificed by cardiac perfusion, and the brain dissected out and placed in $2.5 \%$ glutaraldehyde for a minimum of $24 \mathrm{hr}$. The brain was sectioned in iced buffer on a Iancer Vibratome series 1000. Forty $\mu \mathrm{m}$ thick sections were cut through the implant and injection area, mounted on slides, and utilized to verify cannula placement in the lateral ventricle. 
EXPERIMENTAL APPARATUS AND PROCEDURES

\section{Behavioral Temperature Selection Apparatus}

Temperature selection $\left(\mathrm{T}_{\text {sel }}\right)$ of as many as 9 mice could be simultaneously quantified in Plexiglas tubes about $2.2 \mathrm{~m}$ long and $4.5 \mathrm{~cm}$ in diameter. The tubes were weighted with iron rods and submerged, one to a lane, in the lanes of an aquatic temperature gradient which has been previously described (Figure 5) (O'Connor et al, 1988).

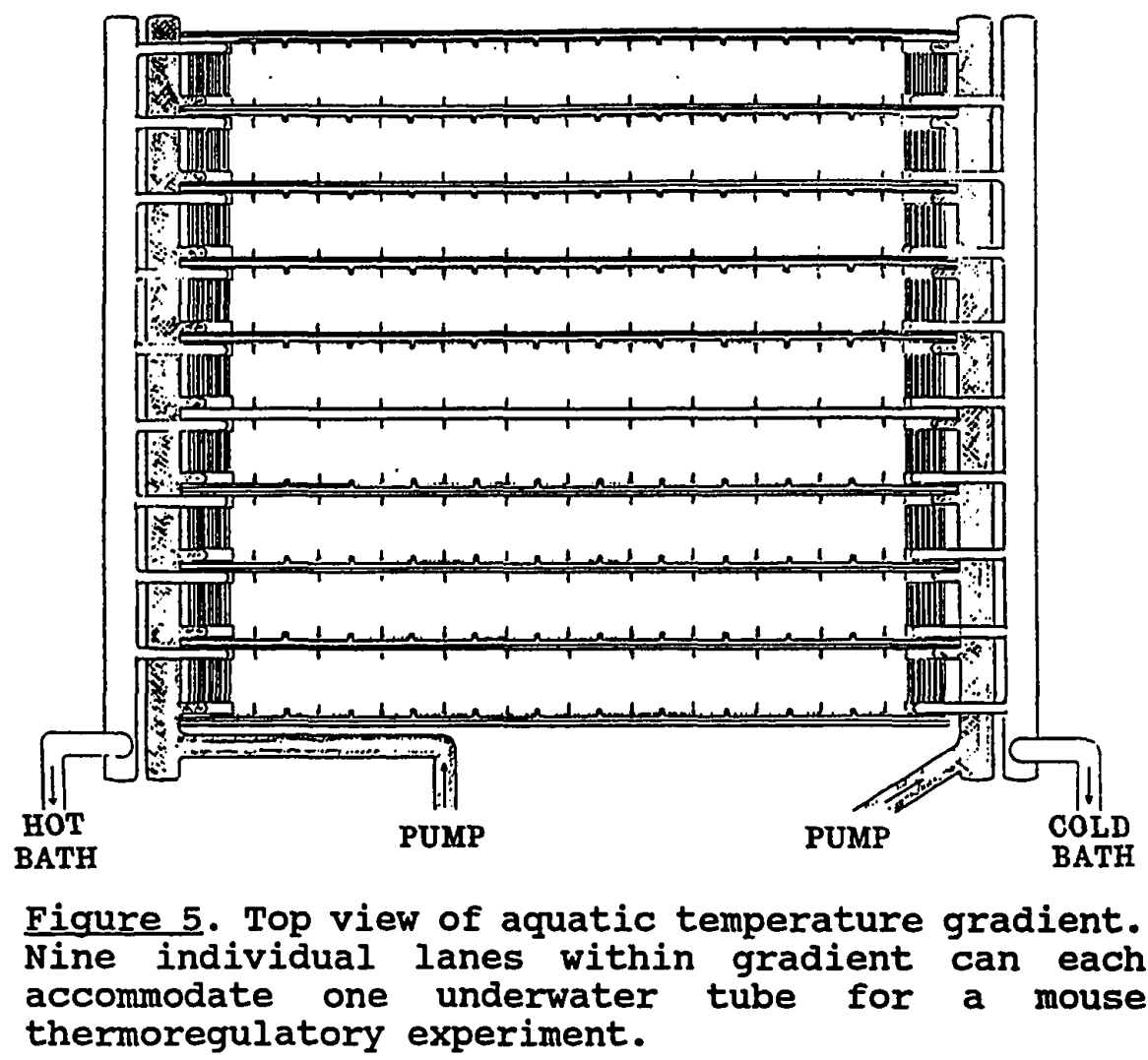

The ends of each tube made a $90^{\circ}$ bend upwards out of the water to allow insertion and removal of the mice. Removable barriers at each end prevented escape but fit loosely enough 
to allow air circulation through the tubes. One end of each lane of the gradient was equipped with a heat exchanger coupled to a heat source, the other end similarly equipped and coupled to a cold source, yielding a water temperature range of about $8-40^{\circ} \mathrm{C}$. Measurements revealed a small, regular difference between the air temperature inside the tubes and the water temperature outside the tubes (tube temperature less than water temperature), except for the cold end of the tubes, where air and water temperatures were about equal. Data were corrected for these systematic discrepancies as appropriate. During experiments, the light level was kept dim. A low light video camera mounted above the gradient (Figure 6) wasconnected to an Oculus frame grabber (Coreco Co., Quebec, Canada) installed in a computer.

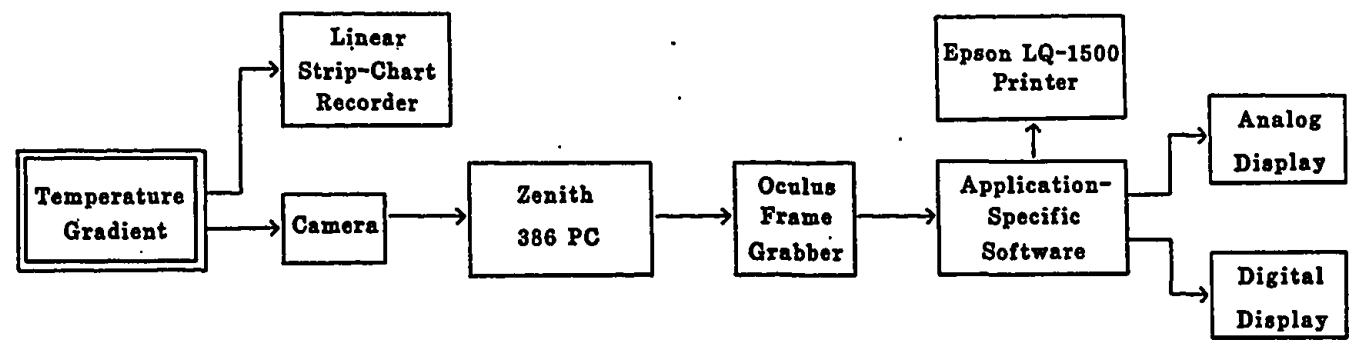

Figure 6. Schematic of information flow during behavioral thermoregulation experiments.

In the earliest experiments (initial experiments investigating the effect of acute EtoH in genetically heterogeneous mice) this computer was an IBM PC XT. A Zenith 386 computer was utilized for the remainder of the behavioral experiments. Each animal's position within its tube was 
recorded at 5 or $6 \mathrm{sec}$ intervals, except for the withdrawal experiments, which utilized a 10 sec recording interval. output from the image analyzer to 2 video monitors permitted observation of the animals' behavior. After each experiment, the apparatus was calibrated by measuring the water temperature at 10 locations in each lane. The temperature information obtained during calibration was used to translate animal position into selected temperature for data analysis.

\section{Internal Temperature Measurements Using Mini-Mitters}

To pick up the radio emissions of the mini-mitters in the temperature gradient, each submersible tube was wound with wire which acted as an antenna to carry the signal of each mini-mitter out of the gradient. In the earliest experiments in this series, a portable hand held receiver (home-made) was utilized to read the emissions of each mini-mitter in turn by sequentially connecting the receiver to each pair of antenna wires. In those experiments, the signal was read and recorded at 5 min intervals preinjection, and 2 min intervals postinjection. In later experiments, the antenna wires from each tube were connected to an individual receiver (model RA1000-TH, Mini-mitter Co., Sunriver, OR), which automatically relayed the signal to the computer for display and recording.

A non-behavioral subset of the tolerance experiments involved injecting mini-mitter-implanted mice with EtoH or $\mathrm{NaCl}$ and monitoring change in $\mathrm{T}_{\mathrm{i}}$ while animals were held at 
room temperature. For those experiments, pre- and postinjection $T_{i}$ data were collected from mice held in individual plastic containers, without bedding. Each container was placed atop a mini-mitter receiver, and the radio signals were collected by the receivers and relayed to the computer as described.

General Procedure for Quantifying Internal and Selected Temperature in the Temperature Gradient

Two days before mice were implanted with mini-mitters, they were trained in gradient tubes until they entered the tubes promptly and exited willingly. Training consisted of an initial bout in the gradient lasting about $1.5 \mathrm{hrs}$, a rest period of about 2 hrs, and a second bout in the gradient of 45-60 min. After recovery from mini-mitter implantation surgery, mice were given an additional training refresher day, following the procedure just described. All mice received the same amount of training time. Beginning with the first training run and continuing through all experimental runs, insertion and removal of the mice was randomized between the hot and cold ends of the tubes. In addition, no mouse was run in the same lane on more than one day. All training and testing occurred between 1000 and $1400 \mathrm{hr}$ with the exception of withdrawal experiments, where mice remained in the tubes for many hours, and experiments designed to examine the effect of time of day on response to EtoH, where mice were tested at various times throughout the day and night (see later for 
specifics of these experiments). After experiments tubes were very thoroughly washed, and dried between days of use.

On the day of a behavioral experiment (except for the time-of-day and withdrawal studies), each mouse was weighed and released into one of the gradient tubes. Both $\mathbf{T}_{\text {sel }}$ and $\mathbf{T}_{\mathbf{i}}$ were monitored for $1 \mathrm{hr}$, then mice were removed and returned to their home cages to rest for about an hour. Next, mice were injected i.p. with the appropriate dose of $20 \%, 10 \%$, or $7.5 \%$ EtOH $(w / v)$ in $0.98 \mathrm{NaCl}$, or with a volume of $0.98 \mathrm{NaCl}$ usually equivalent to the volume of the largest dose of EtoH utilized in that particular study. Although EtOH concentration varied among experiments (detailed below where appropriate), concentration was always calculated as $\mathrm{w} / \mathrm{v}$. After injection, each mouse was immediately returned to the same tube occupied before injection, and $\mathbf{T}_{\mathbf{i}}$ and $\mathbf{T}_{\text {sel }}$ were monitored for $1 \mathrm{hr}$ (except in the time-of-day and withdrawal experiments, as detailed below). Although mice develop shortterm tolerance to the hypothermic effect of injected EtoH, tolerance disappears by $48 \mathrm{hr}$ after the last EtOH injection (Crabbe et al, 1979). Excluding exceptions itemized below, EtoH injections were given at least 4 days apart.

\section{Validation of Behavioral Temperature Selection Protocol}

To ascertain whether cues other than ambient temperature could be causing the behavior observed in the gradient tubes, an experiment was performed in the absence of a thermal gradient. Six male coN mice were trained in the gradient 
tubes. On the day of this experiment, the gradient heater was used to raise the temperature of the warm end of the gradient to about $32^{\circ} \mathrm{C}$. The heater was turned off, and submersible pumps were used to circulate the water in each lane until measurements showed the temperature throughout the lanes had stabilized at about $29^{\circ} \mathrm{C}$. The tubes were placed in the gradient and allowed $45 \mathrm{~min}$ to come into equilibrium with the water temperature. Water temperature was measured at 27 locations throughout the gradient to verify that thermal equilibrium had been achieved; temperature was $27 \pm 1^{\circ} \mathrm{C}$ at all locations. Six mice were injected with $2.6 \mathrm{~g} 20 \% \mathrm{EtOH} / \mathrm{kg}$ and placed individually in gradient tubes, and activity and preferred location were monitored for $60 \mathrm{~min}$.

Activity Measurements During Behavioral Experiments

Activity was quantified as the distance in $\mathrm{cm}$ moved in the gradient tube per sample interval $(5,6$ or $10 \mathrm{sec})$.

\section{SPECIFIC METHODOLOGY FOR EACH STUDY}

Thermoregulatory Effect of Acute Ethanol in

Genetically Heterogeneous Mice

Eight male coN mice were utilized in this, the first study performed to characterize the effect of acute EtoH on behavioral thermoregulation. In preliminary experiments, groups of 2 or 3 mice were administered $20 \%$ EtOH at doses of $1.5,2.25,2.60,2.75,2.90$ and $3.10 \mathrm{~g}$ EtoH/kg body wt. Following EtoH administration, mice were placed in the 
temperature gradient tubes. Internal temperature and $\mathbf{T}_{\text {sel }}$ were measured, and the behavior of the mice was carefully observed. Doses of $1.50,2.25$, and $2.60 \mathrm{~g}$ EtOH/kg did not produce observable decrements in locomotor behavior; $1.50 \mathrm{~g} \mathrm{EtOH} / \mathrm{kg}$ produced little or no change in $T_{i}$. Doses of $2.75 \mathrm{~g} \mathrm{EtOH} / \mathrm{kg}$ and higher produced increasing behavioral derangement, and the mice would often become insensible in thermally untenable locations. The doses chosen for further analysis were 2.25 and $2.60 \mathrm{~g} \mathrm{EtOH} / \mathrm{kg}$. On a given day, 4 mice were injected with EtoH and 4 with $\mathrm{NaCl}$. During the next run, the mice who had received EtOH were given $\mathrm{NaCl}$, and vice versa. Testing protocol was as described above, with injections given at least 4 days apart.

In a separate experiment to determine the effect of low ambient temperature on $T_{i}, 4$ implanted mice were placed in plastic containers with thermal characteristics similar to the Plexiglas gradient tubes and held at $26 \pm 0.3^{\circ} \mathrm{C}$. After a $40 \mathrm{~min}$ baseline period, mice were injected with $0.98 \mathrm{NaCl}$ (volume equivalent to that of a dose of $2.60 \mathrm{~g} \mathrm{EtOH} / \mathrm{kg}$ ) and immediately returned to the plastic containers. Ambient temperature and $T_{i}$ were monitored for $45 \mathrm{~min}$ after injection.

Thermoregulatory Effect of Acute Ethanol in Selected Lines of Mice

Thermoregulatory differences in response to acute EtOH were characterized in the HOT and COLD mice which had been selected for a differential $T_{r e}$ response to acute EtOH. 
Thirty-six mice 8 to 10 weeks old were used in this study, and housed, trained, and implanted with mini-mitters as described above, except that this group of animals was allowed 6 days of recuperation before experimentation began. Since only 9 mice could be tested per day, these animals were divided into 4 groups of 9 mice each. Each group consisted of a mixture of HОT1, НОT2, COLD1 and COLD2 mice (i.e., group 1 contained 3 HOT1, 2 HOT2, 2 COLD1 and 2 COLD2 animals, group 2 contained 2 HOT1, 3 HОT2, 2 COLD1 and 2 COLD2 animals, etc) so that each genotype of mouse was represented on each day of testing. A few mice died over the course of these experiments, so results from 9 animals of each genotype were not obtained. Mice in this study were injected i.p. with $10 \%$ EtOH in doses of 2.0 , $2.25,2.65,2.85$ or $3.0 \mathrm{~g} \mathrm{EtOH} / \mathrm{kg}$, or with $0.9 \% \mathrm{NaCl}$. Because the HOT and COLD animals differed substantially in their sensitivity to EtOH, it was not appropriate to test all mice at all doses. However, each animal was tested at multiple doses; the specific doses and order of administration are given in Table $I$.

TABLE I

INJECTIONS GIVEN TO HOT AND COLD MICE

Genotype Injection order

1st 2nd 3rd 4th

\begin{tabular}{lllll}
\hline HOT1 & $2.65 \mathrm{~g} / \mathrm{kg}$ & $\mathrm{NaCl}$ & $2.85 \mathrm{~g} / \mathrm{kg}$ & ---- \\
HOT2 & $2.65 \mathrm{~g} / \mathrm{kg}$ & $\mathrm{NaCl}$ & $2.85 \mathrm{~g} / \mathrm{kg}$ & $3.0 \mathrm{~g} / \mathrm{kg}$ \\
COID1 & $2.65 \mathrm{~g} / \mathrm{kg}$ & $\mathrm{NaCl}$ & $2.25 \mathrm{~g} / \mathrm{kg}$ & $2.0 \mathrm{~g} / \mathrm{kg}$ \\
COLD2 & $2.65 \mathrm{~g} / \mathrm{kg}$ & $\mathrm{NaCl}$ & $2.25 \mathrm{~g} / \mathrm{kg}$ & $2.0 \mathrm{~g} / \mathrm{kg}$
\end{tabular}


Influence of Time of Day on Response to Acute Ethanol

For this study, 9 COLD2 mice were trained in the gradient tubes and implanted with mini-mitters as described. For this study only, $7.5 \%$ EtoH was utilized, with a dose of $2.60 \mathrm{~g}$ EtoH/kg, or an equivalent volume of $0.9 \% \mathrm{NaCl}$. For this experiment, mini-mitter signals were read with the hand held receiver at $2 \mathrm{~min}$ postinjection intervals. No preinjection data were collected, because arousal due to the long delay between bringing the mice into the laboratory and injecting them with EtoH, if preinjection data had also been recorded, would likely have obscured any effect of time of day. Generally, about 30 min elapsed between the time the mice were collected in the animal room, and the time the last mouse was injected and released into his tube. Animals were run at $0400,0800,1200,1600,2000$, and $2400 \mathrm{hr}$ according to the following schedule.

First, in lieu of preinjection data, baseline data were collected by initial runs without injection, on the following timetable. Day 1: postsurgery retraining run. Day 2: 1200 and $2400 \mathrm{hr}$. Day 3: 0800 and 2000 hr. Day 4: 0400 and 1600 hr. Days 5 and 6: rest days. During the subsequent experimental runs, each individual mouse received EtoH for one run, and NaCl for the next. The set of experimental runs was therefore performed twice, to yield EtoH and control data for each mouse, according to the following timetables. Day 7: 1200 and $2400 \mathrm{hr}$. Days 8 and 9: rest days. Day 10: 0800 and 
2000 hrs. Days 11 and 12: rest days. Day 13: 0400 and 1600 hrs. Days 14 and 15: rest days. At this point, for the second rotation through the sequence, time pairs were reversed, according to the following timetable. Day 16: 2400 hr. Day 17: $1200 \mathrm{hr}$. Day 18: rest day. Day 19: $2000 \mathrm{hr}$. Day 20: $0800 \mathrm{hr}$. Day 21: rest day. Day 22: $1600 \mathrm{hr}$. Day 23: 0400 hr.

\section{Development of Tolerance to Ethanol Hypothermia}

Thirty-six male coN mice, 12 to 14 wks old, were used in this study. Three animals died during experiments, and data collected from them were omitted from analysis.

These experiments consisted of 3 separate protocols. The first procedure ("Mixed Protocol") involved quantifying the effect of 11 days of exposure to EtOH $(2.75 \mathrm{~g} / \mathrm{kg} 10 \%$ EtOH i.p.) or $\mathrm{NaCl}$ on the regulated temperature. Because the tolerance experiments involved repeated days of i.p. injection, care was taken to alternate injection sites between the left and right sides of the abdomen. To monitor changes in the regulated temperature, both $\mathrm{T}_{\mathbf{i}}$ and $\mathrm{T}_{\text {sel }}$ were measured as already described. Because reasonably calm animals are essential for effective use of the behavioral paradigm, it seemed inadvisable to run mice every day for 11 days in the gradient. Therefore these mice were monitored in the gradient on days $1,2,4,7$ and 11 of the 11 days of EtoH or Nacl exposure. On each gradient day, tail blood samples were taken from all mice at times $60 \mathrm{~min}, 120 \mathrm{~min}$ and $180 \mathrm{~min}$ 
postinjection, and were analyzed for BEC, according to the procedure previously described. On the remaining days $(3,5$, $6,8,9$ and 10), the animals were injected with EtOH or $\mathrm{NaCl}$ and $\mathrm{T}_{\mathbf{i}}$ only was monitored at laboratory ambient temperature, following a procedure described below. Control animals received daily injections of $0.9 \% \mathrm{NaCl}$, volume equivalent to that of an EtoH injection; tail blood samples were collected from control mice and discarded. Eighteen mice (2 groups of 9 animals each) were implanted with mini-mitters for this portion of the study. One control animal died, leaving 9 EtoH and $8 \mathrm{NaCl}$ control animals in the Mixed Protocol.

When mice were allowed to behaviorally thermoregulate in the gradient, most tolerance to EtoH was acquired during the first few days of exposure, as detailed in the Results section following; the Mixed Protocol did not, however, test mice in the gradient on Day 3. This omission was deliberate, because it seemed (based upon extensive experience with the behavior of mice in the gradient tubes) that running mice for more than 2 consecutive days in the gradient without a break greatly increased the risk of highly erratic mouse behavior in the tubes. To test this hypothesis, in a second procedure ("Behavior Protocol") implanted mice were injected with 2.75 g EtOH/kg (or an equivalent volume of $0.98 \mathrm{NaCl}$ ) daily for 4 days and tested each day in the gradient device. Nine mice were implanted for this experiment. One EtoH animal died, 
leaving 4 EtOH and 4 control mice to complete the Behavior Protocol.

The mice in the behavioral tolerance studies were able to maintain body temperature at the regulated level after injection by choosing the appropriate ambient temperatures on gradient days. This was contrasted with the effect in mice injected every day for 11 days and held at laboratory temperature $\left(22 \pm 1^{\circ} \mathrm{C}\right.$ ) ("Box Protocol"). Each mouse was weighed, then placed alone in a clean plastic cage without bedding positioned atop a mini-mitter receiver, connected to the computer as already described. Preinjection $\mathbf{T}_{\mathbf{i}}$ was monitored for $10 \mathrm{~min}$. Then each mouse was injected i.p. with $2.75 \mathrm{~g} / \mathrm{kg}$ EtOH or an equivalent volume of $0.98 \mathrm{NaCl}$ (left or right side of the abdomen on alternate days), and immediately returned to the same cage occupied before injection. Internal temperature was monitored for a minimum of $1 \mathrm{hr}$ postinjection. On Day 11, blood samples were taken for BEC analysis according to the procedure described previously. Nine mice were implanted with mini-mitters for this study. one control animal died part way through the experiment, leaving 5 EtoH and $3 \mathrm{NaCl}$ mice to complete the Box Protocol experiment.

Thermoregulation During Withdrawal from Ethanol Dependency in Genetically Heterogeneous Mice

Two studies of withdrawal from EtOH dependency were performed. The first utilized genetically heterogeneous coN 
mice, the second was done using the HOT and COLD selected lines of mice.

For the first study, 9 coN mice were trained in the gradient and implanted with mini-mitters as described. Physical dependence on EtOH was induced in an inhalation chamber according to a procedure developed by Goldstein (1972) as modified by Crabbe et al (1983a) and performed at the Portland V.A. Research Center, to which the mice were transported 3 days after implantation surgery. They remained at the VA for an additional 3 days before induction of dependency was initiated. Photoperiod in the inhalation chamber at the V.A. Research Center (12:12 L:D, with lights on at 0600 ) was similar but not identical to photoperiod in the animal room at Portland State University (12:12 I:D, with lights on at 0630).

In the inhalation chamber at the V.A. Research Center, mice were housed in wire-mesh cages subdivided to hold 6 mice each in individual compartments $(16 \mathrm{~cm} \times 17.5 \mathrm{~cm} \times 18 \mathrm{~cm}$ for each mouse). Cages were hung on guide rails in one of 3 large Plexiglas chambers, each with its own air supply, allowing control and experimental animals to be housed under similar environmental conditions. A stainless steel drop pan, lined with absorbent material which was changed daily, was placed beneath each hanging cage. An individual closed food hopper and water bottle were always available for each mouse; in addition, a few food pellets were placed on the floor of each 
compartment. The temperature in the chambers was maintained at $29 \pm 1^{\circ} \mathrm{C}$.

Ethanol was introduced into the chamber by a piston pump, which pumped liquid EtoH from a reservoir via silastic tubing, through an 18 ga needle and onto a filter paper wick suspended vertically from one corner of the chamber. Ethanol concentration was adjusted by changing the flow rate. Air was taken from the hospital compressed air supply and passed through a glass tube filled with Drierite. Air flow was controlled at $551 / \mathrm{min}$, which resulted in turnover of the air/EtoH vapor mixture within the chamber about every $9 \mathrm{~min}$ (chamber volume $=487$ 1). Three small fans mounted beneath the cage racks insured thorough mixing of EtOH vapor and air. Air and vapor were exhausted to the hospital exhaust system. Ethanol concentration on the first day of vapor inhalation was maintained at an average of $4 \mathrm{mg} / \mathrm{l}$. On Day 2 the EtOH pump rate was increased to yield an average EtOH concentration of $6.5 \mathrm{mg} / 1$, and increased again to an average of $9 \mathrm{mg} / \mathrm{l}$ on Day 3. Air samples $(500 \mu \mathrm{l})$ were drawn from the chambers approximately every $30 \mathrm{~min}$ from $0800 \mathrm{hr}$ to $1600 \mathrm{hr}$, and also at $2200 \mathrm{hr}$, using a gas tight syringe (Hamilton Model 1001) inserted through a rubber septum mounted in the chamber. For the subset of these experiments in which dependency induction was initiated at $0300 \mathrm{hr}$, chamber air was sampled at that time also. The EtOH vapor concentration of each sample was measured using a Hewlett-Packard Model 5890 gas 
chromatograph (Roach and Creaven, 1968, as modified by Crabbe et al, 1989).

On Day 1, at $0800 \mathrm{hr}$ mice were weighed and injected i.p. with a priming dose of EtOH $(1.5 \mathrm{~g} \mathrm{EtOH} / \mathrm{kg}, 20 \% \mathrm{v} / \mathrm{v})$ and with pyrazole hydrochloride (Sigma; $68.1 \mathrm{mg} / \mathrm{kg}$ ) in $0.98 \mathrm{NaCl}$, and placed immediately in the inhalation chamber. Pyrazole control animals were injected with $0.98 \mathrm{NaCl}$ (instead of EtOH) and with pyrazole, and housed in a neighboring chamber with air circulation as described above, but without the addition of EtOH vapor. NaCl control animals were injected with $0.9 \%$ $\mathrm{NaCl}$ only, and otherwise treated as described, minus EtOH vapor. After 24 and $48 \mathrm{hrs}$ of exposure to EtOH vapor the mice were briefly removed from the inhalation chambers at $0800 \mathrm{hr}$, weighed, and given injections of pyrazole or NaCl before being placed back in the chambers. When the mice were removed at 24 and $48 \mathrm{hr}$, tail blood samples were drawn from half of the mice and analyzed for BEC. At withdrawal from the chambers at 0800 on Day 4, final blood samples were taken from all mice. Mice were returned to their home cages, transported back to Portland State University, and placed in the gradient tubes. Because withdrawing and control mice were monitored for many hours in the gradient, a water container with sip tube was positioned at the cold end of each tube, allowing mice to drink at will. Pilot experiments showed that mice would willingly venture into the cold extreme for a drink when thirsty. Activity, $T_{i}$ and $T_{\text {sel }}$ were monitored until 26 hrs 
post-withdrawal, then mice were removed from the tubes, weighed, placed in their home cages and returned to the animal room. This experiment was repeated 4 times as described. Because some animals died in the inhalation chamber or during the gradient experiment afterwards, a total of 11 withdrawal animals, $8 \mathrm{NaCl}$ control mice and 9 pyrazole control mice contributed data for analysis.

The timing of this experiment was such that the expected time of maximum withdrawal severity coincided with the time of heightened activity seen in normal mice around lights-out time. To clarify the effect of the normal day-night activity cycle of the mouse on behavior during withdrawal, a single group of 8 mice was trained, implanted with mini-mitters, transported to the V.A. Research Center, divided into 2 groups (4 EtoH and 4 pyrazole control animals) and treated precisely as described above, except that the induction of dependence was initiated at $0300 \mathrm{hr}$ instead of at $0800 \mathrm{hr}$. Therefore, tail blood samples were obtained and injections of pyrazole were given at $0300 \mathrm{hr}$ on Day 2 and Day 3. The mice were removed from the chambers at $0300 \mathrm{hr}$ on Day 4, and run in the gradient from $0600 \mathrm{hr}$ until $2100 \mathrm{hr}$ (18 hrs post-withdrawal) on Day 4.

In a third experiment, the $T_{\mathbf{i}}$ of mice was monitored during induction of dependence and withdrawal at constant ambient temperature. Thirty mice were divided into 3 groups of 10 mice each (EtOH, pyrazole controls and $\mathrm{NaCl}$ controls). 
Dependence was induced in the inhalation chamber as described above, and after 72 hrs of exposure to EtOH vapor, mice were removed from the chamber and monitored for 24 hrs of withdrawal at a constant ambient temperature of $29.5 \pm 1^{\circ} \mathrm{C}$. This temperature was similar to the $T_{\text {sel }}$ of $C O N$ mice withdrawing from EtoH dependency in the temperature gradient. Throughout induction and withdrawal, $T_{r e}$ of all mice was measured at $0800,1000,1200,1400,1600$ and 2000 hrs.

Thermoregulation During Withdrawal from Ethanol Dependency in Selected Lines of Mice

A separate series of withdrawal experiments was conducted using the selected lines of mice. Eighteen of each of the HOT1, COLD1, HOT2 and COLD2 genotypes were trained in the gradient and implanted with mini-mitters. All were placed in the vapor chambers as described above, with 9 EtOH withdrawal and 9 pyrazole control animals of each genotype. To achieve the desired total of animals, eight separate groups of 9 mice each were implanted sequentially, with each group a combination of HOT1, COLD1, HOT2 and COLD2 animals. Group 1 consisted of 3 HOT1 mice (2 EtOH, 1 pyrazole), 2 HOT2 mice (1 EtoH, 1 pyrazole), 2 COLD 1 mice ( 1 EtoH, 1 pyrazole) and 2 COLD2 mice (1 EtOH, 1 pyrazole). Group 2 consisted of 2 HOT1 (1 EtoH, 1 pyrazole), 3 HOT2 (2 EtOH, 1 pyrazole), 2 COLD1 (1 EtoH, 1 pyrazole) and 2 COLD2 (1 EtoH, 1 pyrazole) mice; etc. six animals died during the experiment, so a ninth group was 
added, consisting of 1 HOT2, 3 COLD1 and 2 COLD2 mice, to complete the total of 18 mice per genotype.

The initial withdrawal study using genetically heterogeneous mice indicated that the burst of activity near the time of usual lights-out was due to the typical increase in activity that occurs in normal mice at that time, and not due to withdrawal from EtoH. Because starting each experiment at $0300 \mathrm{hr}$ was inconvenient, the HOT and COLD mice used in this study were kept on an altered photoperiod of 12:12 L:D, with lights on at $1200 \mathrm{hr}$. The animals were housed in the animal room at Portland State University which continued on a 12:12 L:D cycle beginning at $0630 \mathrm{hr}$, so a special enclosure was built to contain the withdrawal mice that consisted of a large metal frame placed on a table, and completely enclosed by black plastic taped carefully together. For air circulation, inlet and outlet tubes were installed in opposite sides of the enclosure, equipped with muffin fans and bent to exclude light. Within the enclosure 2 fluorescent lights on timers provided the desired photoperiod for the mice. Animals were maintained on the altered photoperiod for 2 wks before training was begun. In human subjects the time course of adaptation to a $9 \mathrm{hr}$ shift in photoperiod varies between 7 days (moving from east to west) and 12 days (moving from west to east, same distance) (Hensel et al, 1973). Training in the gradient tubes and surgical implantation of mini-mitters occurred after $1200 \mathrm{hr}$. The inhalation chambers used for this 
study at the V.A. Research Center were likewise equipped with black plastic and fluorescent lights on timers to duplicate the altered photoperiod.

The process of induction of dependency and testing in the gradient occurred for these mice exactly as already described, except that induction of dependency was begun, and subsequent weighing and tail blood sample harvesting accomplished at times which varied slightly. Table II details the timing of critical events for all the groups in this experiment. These events occurred during the last part of the dark period for the mice, so lights were turned off in the V.A. laboratory when these mice were outside of the vapor chambers.

TABLE II

WITHDRAWAL IN SELECTED LINES OF MICE TIMING OF CRITICAL EVENTS

\begin{tabular}{cllll} 
Group & $\begin{array}{l}\text { Enter } \\
\text { Chamber } \\
\text { Day 1 }\end{array}$ & $\begin{array}{l}\text { Leave } \\
\text { Chamber } \\
\text { Day 4 }\end{array}$ & $\begin{array}{l}\text { Enter } \\
\text { Gradient } \\
\text { Day 4 }\end{array}$ & $\begin{array}{l}\text { Leave } \\
\text { Gradient } \\
\text { Day 4 }\end{array}$ \\
\hline 1 & 0800 & 0800 & 1045 & 2250 \\
2 & 0800 & 0630 & 0900 & 2040 \\
3 & 0730 & 0730 & 1000 & 2130 \\
4 & 0900 & 0730 & 1000 & 2140 \\
5 & 0730 & 0730 & 1000 & 2130 \\
6 & 0730 & 0730 & 1000 & 2130 \\
7 & 0730 & 0730 & 1000 & 2130 \\
8 & 0730 & 0730 & 1000 & 2145 \\
9 & 0730 & 0730 & 1000 & 2130
\end{tabular}

For this experiment, blood samples for BEC measurement were taken from all mice every day during induction of dependency. The mice were removed from the vapor chamber on 
Day 4 after 72 hrs in the chamber, and brought to Portland State University in a cardboard box carefully covered with black plastic to exclude light. The mice were left in a darkened room to rest and eat for about $1 \mathrm{hr}$, then inserted into the gradient tubes and monitored until 14 hrs postwithdrawal.

Body Temperature Response to i.c.v. 5-HT in Selected Lines of Mice at constant Ambient Temperature

The HOT and COLD mice were selected only for their differential $T_{\text {re }}$ response to acute EtOH; this study investigated the response of the selected lines to central 5HT. Thirty-four HOT1, COLD1, HOT2 and COLD2 mice from selected generation 20,12 to 15 weeks old, were utilized. The mice were implanted with permanent indwelling brain cannulae as previously described. Animals were allowed 14 days to recover from brain implant surgery because pilot experiments revealed that most mice struggled vigorously when initially placed in the restraint device. Pulling back against the restraint device, as the mice were wont to do, could cause the scalp incision to tear open and bleed unless the wound was completely healed.

On the day of an injection, mice were brought from the animal room to the experiment room $\left(27 \pm 1^{\circ} \mathrm{C}\right)$. A mouse was placed in a guillotine-style restraint device in which 2 foampadded halves encircled the neck and painlessly but firmly restrained the animal. The upper section of the restrainer 
was held in place with set screws, and the floor of the device was padded with a piece of disposable diaper. After an initial struggle, the animals quieted and tolerated the device. Rectal temperature was monitored with a thermocouple, the output of which was measured on a Honeywell Electronik 195 strip chart recorder. The thermocouple tip, covered with a tiny bead of plastic, was lubricated with vaseline, inserted $2 \mathrm{~cm}$ into the rectum, and held in place with thin strips of tape around the tail. For some experimental runs, mice were equipped with an additional thermocouple affixed with tape to the surface of the tail and attached to a second channel on the strip chart recorder, to track changes in tail temperature.

To perform a brain injection, the indwelling stylet (ref. Figure 4) was removed from the guide cannula and a 33-ga hollow injection stylet was inserted. Each injection stylet was equipped with a 26-ga collar which abutted the 26-ga indwelling cannula to insure correct injection depth. The stylet collar and cannula were secured together with a small collar of PE-20 tubing that fit snugly over both. The injection stylet was attached by PE-20 tubing to a sterile filter $(0.22 \mu \mathrm{m}, \mu S T A R$, costar $C o$.$) and a 10 \mu l$ syringe containing the injection solution.

once the animal was fully instrumented the light was dimmed. To minimize the effects of restraint stress, injections were made soon after placement in the restraint 
device (5 to $10 \mathrm{~min}$ ). All statistical comparisons were therefore performed utilizing the difference between maximum $T_{\text {re }}$ response to $5-H T$, and $T_{r e}$ at the same time after injection of control solution. A dose of $0.3,0.8,2.0,5.0$ or $11.0 \mu \mathrm{g}$ 5-HT was injected in a total volume of $1.7 \mu l$ over a period of 2 min. The injections were prepared by diluting 5hydroxytryptamine creatinine sulfate complex (Sigma Chemical Co.) with the proper amount of $0.9 \% \mathrm{NaCl}$. Control solution was prepared by diluting $11 \mu \mathrm{g}$ creatinine (creatinine hemisulfate salt, Sigma Chemical Co.) with $0.98 \mathrm{NaCl}$ to a total volume of $1.7 \mu \mathrm{l}$. Sham control injections were also performed, which followed the procedure outlined, except that no solution was injected. Mice receiving 5-HT were left alone for at least $15 \mathrm{~min}$ after $T_{\text {re }}$ had begun to rise from the postinjection low point, or until $T_{\text {re }}$ had returned to normal levels. Mice were monitored for a minimum of $50 \mathrm{~min}$ following control injections. All injections occurred between $0900 \mathrm{hr}$ and $1600 \mathrm{hr}$. Injections were spaced at least $48 \mathrm{hr}$ apart. The initial injection for every mouse was made using a $5.0 \mu \mathrm{g}$ or $11.0 \mu \mathrm{g}$ dose of $5-\mathrm{HT}$ and a short stylet $10.6 \mathrm{~mm}$ longer than the indwelling cannula) to confirm patency of the implant. If no response was observed, longer stylets $10.9 \mathrm{~mm}$ or $1.2 \mathrm{~mm}$ ) were utilized in turn. Once the effectiveness of the implant had been confirmed, control injection, sham injection and other injections of 5-HT were performed in 
random order until a mouse had been tested with all solutions, or the implant was damaged or blocked, or the animal died.

\section{Thermorequlatory Response to i.c.v. 5-HT in selected}

Lines of Mice in a Temperature Gradient

Four HOTl and 4 COLDl mice, 8 wks old, were doubly implanted with indwelling brain cannulae and mini-mitters and trained in the gradient tubes, as described above. A few days prior to testing the behavioral response, these mice were placed in the restraint device and given a brain injection of $5.0 \mu \mathrm{g}$ 5-HT to confirm cannula patency. On the day of an experiment, preinjection $T_{i}$ and $T_{\text {sel }}$ data were collected for $1 \mathrm{hr}$. In order to mimic the conditions of the i.c.v. 5-HT injections done at constant ambient temperature, an enclosure made of dark plastic was constructed on a laboratory bench, large enough to contain the animal in the restrainer, the injection syringe, a small light, and the upper body of the experimenter. Within this enclosure a mouse was placed in the restrainer, the indwelling stylet replaced with the injection cannula, and the mouse allowed to rest for $2 \mathrm{~min}$. The mouse was then injected in the lateral ventricle with control solution or $11.0 \mu \mathrm{g}$-HT following the protocol previously described in detail. At the conclusion of the injection procedure the indwelling stylet was replaced and the mouse immediately returned to the same tube occupied before injection. Postinjection $T_{i}$ and $T_{s e l}$ were monitored remotely for a minimum of $1 \mathrm{hr}$ after injection. Data were collected 
from each individual after both a control and a 5-HT injection.

DATA ANALYSIS

The statistics package solo (BMDP statistical software, Inc., Los Angeles, CA) was utilized for statistical analysis of all data. Analysis of variance (ANOVA) was utilized to test for differences in response, but the specifics of the statistical procedures differ among the studies. Following the general introduction, therefore, the approach to data analysis utilized for each experiment will be discussed under the relevant headings. For all analyses, an $\alpha$ level of $\mathfrak{p}<0.05$ was accepted as significant. Significant $F$ and $\mathfrak{p}$ values are reported within the text of the Results section. All measures of variability refer to standard error of the mean.

The effects of an injected drug on temperature regulation are best understood during the period immediately following the injection, when all responses are having their maximal effect and body temperature is exhibiting the greatest rate of change. After an injection of $\mathrm{NaCl}, \mathrm{EtOH}$ or 5-HT, changes may be observed in both the $T_{i}$ and $T_{s e l}$ of a mouse. If the effect of the injection is to alter the set point for body temperature, effector response and $T_{i}$ will exhibit coordinated postinjection changes. The thermoregulatory index (TI) has been established to allow a quantitative evaluation of postinjection changes from preinjection baseline data. This 
index combines postinjection changes from preinjection internal and selected temperatures into a single value. Positive values indicate increases in the regulated temperature, while negative values indicate decreases in the regulated temperature. In several of the behavioral experiments which follow, temperature responses will be compared using this measure. An additive model is employed (Hammel et al, 1963; Hammel, 1970; Corbit, 1973; stolwijk and Nadel, 1973) to represent the interaction between $T_{i}$ and $T_{\text {sel }}$ in the following equation:

$$
T I=\alpha\left(T_{c_{e}}-T_{c_{1}}\right)+\left(T_{s \theta 1_{e}}-T_{s \theta 1_{1}}\right)
$$

where

$$
\begin{aligned}
T I & =\text { thermoregulatory index } \\
\alpha & =\text { weighting for internal temperature } \\
T_{c_{0}} & =\text { core temperature after injection } \\
T_{c_{1}} & \text { initial (baseline) core temperature } \\
T_{\text {sel }_{0}} & \text { selected temperature after injection } \\
T_{\text {sel }_{1}} & \text { initial (baseline) selected temperature }
\end{aligned}
$$

A value of 10 is assumed for $\alpha$. This represents the relatively greater importance of internal temperature to the regulator as a stimulus in the activation of thermoregulatory effector responses. This value reflects the results of appropriate comparisons on medium and small mammals by several investigators (Hammel, 1970; Chappell et al, 1978; Heller, 1978; Mercer and Simon, 1984). 
Thermoregulatory Effect of Acute Ethanol in

Genetically Heterogeneous Mice

Repeated measures ANOVA was used to evaluate the effect of EtoH over time. Temperature responses were evaluated in two ways. First, for each individual, the last $20 \mathrm{~min}$ of $T_{i}$ and $T_{\text {sel }}$ before injection were used as a baseline, and mean TI calculated for the 0 to $40 \mathrm{~min}$ postinjection period and used as 1 datum to represent a single animal in a particular trial. In addition, $T_{i}$ and $T_{\text {sel }}$ were compared separately by utilizing $40 \mathrm{~min}$ postinjection means in separate ANOVA analyses.

Thermoregulatory Effect of Acute Ethanol

in Selected Lines of Mice

Factorial ANOVA with repeated measures was used to evaluate the effect of EtOH. Independent development of the HOT1-COLD1 and HOT2-COLD2 replicate pairs was intended to control for trait-irrelevant inbreeding and genetic drift. The detection of a similar response difference in both replicate pairs would be evidence that the difference has developed as a result of selection pressure, and not by chance. Therefore between subjects factors of both selected Line and Genetic Replicate, as well as Drug or Dose, and within subjects factor Time were utilized in the analyses, although not all factors were used in every analysis (see below). A posthoc Fisher's ISD test was employed where appropriate to detect significant differences between levels of Drug, Dose or Time. 
To compare the effect of the $2.65 \mathrm{~g} \mathrm{EtOH} / \mathrm{kg}$ injection initially given to all mice, the $T_{i}$ and $T_{s e l}$ of each animal, recorded every $6 \mathrm{sec}$, were summed to individual 10 min means. Responses were evaluated over the $-10 \mathrm{~min}$ (preinjection) to $+60 \mathrm{~min}$ (postinjection) period, and analyzed using the factors Selected Line, Genetic Replicate, and Time. Comparison of the TI values after the $\mathrm{NaCl}$ and $2.65 \mathrm{~g}$ EtOH $/ \mathrm{kg}$ injections utilized the same factors in the ANOVA protocol as were used to compare the raw temperature data, with the addition of the factor Drug, to compare the effects of control and EtoH injections.

For analysis of dose response curves, a 60 min mean of the six 10 min postinjection TI values was calculated for each animal after $\mathrm{NaCl}$ and the various doses of EtOH, and utilized in the repeated measures ANOVA protocol. The HOT and COLD mice received different doses of EtOH, so responses were only compared between Genetic Replicate (within factor Dose). Because the HOT2 mice appeared to have a slightly higher threshold for EtoH hypothermia than did the HOT1 mice, they alone received the $3.0 \mathrm{~g} \mathrm{EtOH} / \mathrm{kg}$ dose. A separate one-way ANOVA was performed to examine the effects of control injection and all levels of EtOH on the HOT2 mice.

Analysis of activity ( $\mathrm{cm} / 6 \mathrm{sec}$ sample interval) after control and EtOH injections followed the same procedure as that explained above for the dose response analyses, using 60 
min average activity calculated for each animal at each condition.

\section{Influence of Time of Day on Response to Acute Ethanol}

The purpose of this study was to verify that the normal time frame within which most gradient experiments were conducted was not a time of unusual temperature response to EtoH. In order to illustrate the various processes and relationships which might be changing over the course of 24 $\mathrm{hr}$, the data were grouped and plotted in several ways. First, for each mouse, 10 min mean $T_{i}$ and $T_{\text {sel }}$ were calculated for 60 min of the baseline run, and for 60 min postinjection after $\mathrm{NaCl}$ and EtOH. $60 \mathrm{~min}$ mean $\mathrm{T}_{\mathbf{i}}$ and $\mathrm{T}_{\text {sel }}$ were generated for each individual under all three conditions by combining the sequential $10 \mathrm{~min}$ means; these $60 \mathrm{~min}$ means were plotted and responses compared. Next, individual $10 \mathrm{~min} T \mathrm{TI}$ values were calculated for the $\mathrm{NaCl}$ and EtOH runs using as baseline, instead of preinjection temperatures (which did not exist), the last $10 \mathrm{~min} T_{i}$ and $T_{\text {sel }}$ from the baseline run for each mouse. These $10 \mathrm{~min}$ TI values were summed for each individual, and $60 \mathrm{~min}$ grand mean TI values plotted and inspected. Last, the difference between the TI after $\mathrm{NaCl}$ and EtoH was calculated as sequential $10 \mathrm{~min}$ intervals for each individual, and the mean difference between the two conditions plotted over time for each of the times of day at which this experiment was run. 
Development of Tolerance to Ethanol Hypothermia

Repeated measures ANOVA was used to analyze body temperature response to EtOH over time in the Mixed and Box Protocols. For the Mixed Protocol, the TI was calculated for each individual for $60 \mathrm{~min}$ postinjection, and the effects of EtOH and NaCl compared on Days 1, 2, 4, 7 and 11 of the 11 days of exposure (the gradient days in the Mixed Protocol). For the Box Protocol, 60 min mean postinjection change from preinjection baseline $T_{i}$ was calculated for each individual on each day, and response to EtOH and $\mathrm{NaCl}$ was compared over the 11 days of injection. The behavioral data collected from the mice in the 4 day Behavior Protocol were not analyzed.

Repeated measures ANOVA was used to examine the effect of continuing exposure on rate of EtoH metabolism, by comparing measured $\mathrm{BEC}$ from each individual at $60 \mathrm{~min}, 120 \mathrm{~min}$ and 180 min postinjection (repeated measure) on each day (Day 1, 2, 4 , 7 and 11 of EtoH exposure, Mixed Protocol only). A few blood samples were spoiled or lost; individuals with a data point missing for 1 of the 3 time points on a given day were excluded for that day. In addition, ANOVA with repeated measures was used to compare BEC $(60,120$ and $180 \mathrm{~min}$ postinjection) of samples from Day 11 of the Mixed and Box Protocols. Again, individuals not represented by a sample value at all 3 time points were excluded.

As a measure of animal health in these mice subjected to the stress of daily injection, changes in body weight were 
monitored. Repeated measures ANOVA was used to compare weight change of each individual (percent change from weight prior to surgery) in the Mixed, Behavior and Box Protocols on Day 1 through Day 4. Body weight changes were also compared using ANOVA, for the full 11 days of the Mixed and Box Protocol groups.

Thermorequlation During Withdrawal from Ethanol Dependency in Genetically Heterogeneous Mice

The temperature responses and activity of the withdrawing and control mice were examined using ANOVA. Internal temperature, $T_{\text {sel }}$ and activity (cm/10 sec sample interval) were calculated; in addition, the drive of each animal to dissipate heat was approximated by taking the difference between $T_{i}$ and $T_{\text {sel }}\left(T_{i}-T_{\text {sel }}\right)$. For each mouse, mean $T_{i}, T_{\text {sel }},\left(T_{i}-\right.$ $\mathrm{T}_{\text {sel }}$ ) and activity were calculated over the 4 to $10 \mathrm{hr}$ postwithdrawal period and utilized for statistical analysis. The time interval chosen for analysis corresponds to the period when withdrawal seizure susceptibility is maximal in mice that have reached similar blood EtOH levels through comparable induction procedures (Goldstein and Kakihana, 1975). The factor Drug (EtOH, pyrazole and NaCl) was utilized in a single factor ANOVA on each of the variables individually. Because activity differed significantly among the Drug groups, and because activity affects heat production and $T_{i}$, an analysis of covariance (ANCOVA) was used to test 
for a significant effect of the covariate activity upon each of the temperature measures $\left(T_{i}, T_{s e l}\right.$, and $\left.\left[T_{i}-T_{\text {sel }}\right]\right)$.

For the mice monitored at constant ambient temperature during induction and withdrawal, $T_{i}$ of mice in the EtOH, pyrazole and NaCl groups was compared using ANOVA before induction was begun, at the beginning of withdrawal on Day 4, and at 12 hrs postwithdrawal. During induction, the $T_{i}$ of each mouse was measured 4 times per day; a mean of these 4 measures was generated to yield one datum for each animal per day, and ANOVA with repeated measures was used to test for significant differences among the groups in $T_{i}$ during the induction process. Finally, for each animal, $T_{i}$ measurements taken on the day of withdrawal at 4,6 and 8 hrs postwithdrawal (measurements taken within the anticipated zone of maximum withdrawal intensity) were combined into a single mean for each individual, and used in the ANOVA protocol to test for significant differences in $T_{i}$ during withdrawal.

Thermoregulation During withdrawal from Ethanol Dependency in Selected Lines of Mice

The temperature responses and activity of the withdrawing and control HOT and COLD mice were examined using ANOVA in a manner similar to that described above for the genetically heterogeneous mice. For each mouse, mean $T_{i}, T_{\text {sel }},\left(T_{i}-T_{\text {sel }}\right)$ and activity were calculated over the 4 to $10 \mathrm{hr}$ postwithdrawal period and utilized for statistical analysis. The factors Selected Line, Genetic Replicate and Drug (EtoH or pyrazole) 
were utilized in a multifactorial ANOVA on each of the variables individually. Because ANOVA detected a significant difference between the replicates in activity, again ANCOVA was used to test for a significant effect of the covariate activity upon each of the temperature measures $\left(T_{i}, T_{\text {sel }}\right.$, and $\left.\left[T_{i}-T_{\text {sel }}\right]\right)$.

Repeated measures ANOVA (factors Line, Replicate and Day) was employed to test for significant differences in BEC during induction of dependence in the inhalation chamber. A few blood samples were spoiled or lost; only animals with BEC values for all 3 days were included in the analysis.

Body Temperature Response to i.C.V. 5-HT in Selected Lines of Mice at Constant Ambient Temperature

Rectal temperatures were transcribed from the chart recorder tracings. Following the procedure of Berendsen and Broekkamp (1990), all comparisons were made relative to control animals, utilizing the difference between an individual's $T_{\text {re }}$ after 5-HT and the mean $T_{r e}$ for the same genotype after control injection, at the same time postinjection. One min differences were calculated for each individual over the total response period. The point of maximum difference (maximum temperature response to 5-HT) was utilized as the test statistic for analysis.

Differences in response were tested for using ANOVA. Factors of Selected Line, Genetic Replicate and Dose were utilized in the ANOVA protocol. A posthoc Fisher's ISD test 
was employed where appropriate to detect significant differences between levels of Dose.

To compare responses to control creatinine sulfate and sham injections, a 45 min postinjection mean $T_{r e}$ was calculated for each animal and evaluated in an ANOVA with fixed factors of Selected Line, Genetic Replicate, and Condition (creatinine sulfate or sham).

Thermoregulatory Response to i.c.V 5-HT in Selected Lines of Mice in a Temperature Gradient

For the behavioral experiments, again the test statistic used was the maximal difference between $T_{i}$ after 5-HT and after control injection. Maximum response to $11.0 \mu \mathrm{g} \mathrm{5-HT}$ of НОТ1 mice in the restrainers was compared to the maximum response of HOT1 mice in the gradient tubes; likewise, the maximum responses of COLDl mice in the restrainers and gradient tubes were compared. Fixed factors of selected Line and condition (restrained or behaviorally thermoregulating) were utilized in the ANOVA protocol.

To monitor the effect of injections on activity, mean cm moved per 5 sec sample interval was calculated for each individual. 
RESULTS

THE EFFECTS OF ACUTE ETHANOL ON THERMOREGULATION IN GENETICALLY HETEROGENEOUS MICE

The effect of acute EtOH on thermoregulation was first investigated using genetically heterogeneous mice. Figure 7 depicts continuous records of core temperature $\left(T_{i}\right)$ and $T_{\text {sel }}$ for individual mice before and after the injection of $0.9 \%$ $\mathrm{NaCl}$ (top graph), $2.25 \mathrm{~g} \mathrm{EtOH} / \mathrm{kg}$ (middle graph) or $2.60 \mathrm{~g}$ EtOH/kg (bottom graph). Points are plotted every $5 \mathrm{~min}$ for the preinjection period, and every 2 min postinjection. The changes in $T_{i}$ and $T_{s e l}$ illustrated in Figure 7 were typical of the responses of all mice used in this study to both $\mathrm{NaCl}$ and EtOH. After NaCl injection, $T_{i}$ was elevated above baseline for approximately $40 \mathrm{~min}$. The transient decrease in $\mathrm{T}_{\mathrm{sel}}$ that occurred after the $\mathrm{NaCl}$ injection was likely a response to the increase in $T_{i}$ produced by the injection procedure. After injection of $2.25 \mathrm{~g}$ EtoH $/ \mathrm{kg}$, both $T_{\mathbf{i}}$ and $T_{\text {sel }}$ declined below preinjection levels. This decrease was pronounced after an injection of $2.60 \mathrm{~g}$ EtoH $/ \mathrm{kg}$; mice selected markedly cooler temperatures for a long period after injection, and $\mathbf{T}_{\mathbf{i}}$ declined also.

To clarify the relationship between the measured $\mathbf{T}_{\mathbf{i}}$ and $T_{\text {sel }}$ and the calculated TI, the data shown in Figure 7 have 


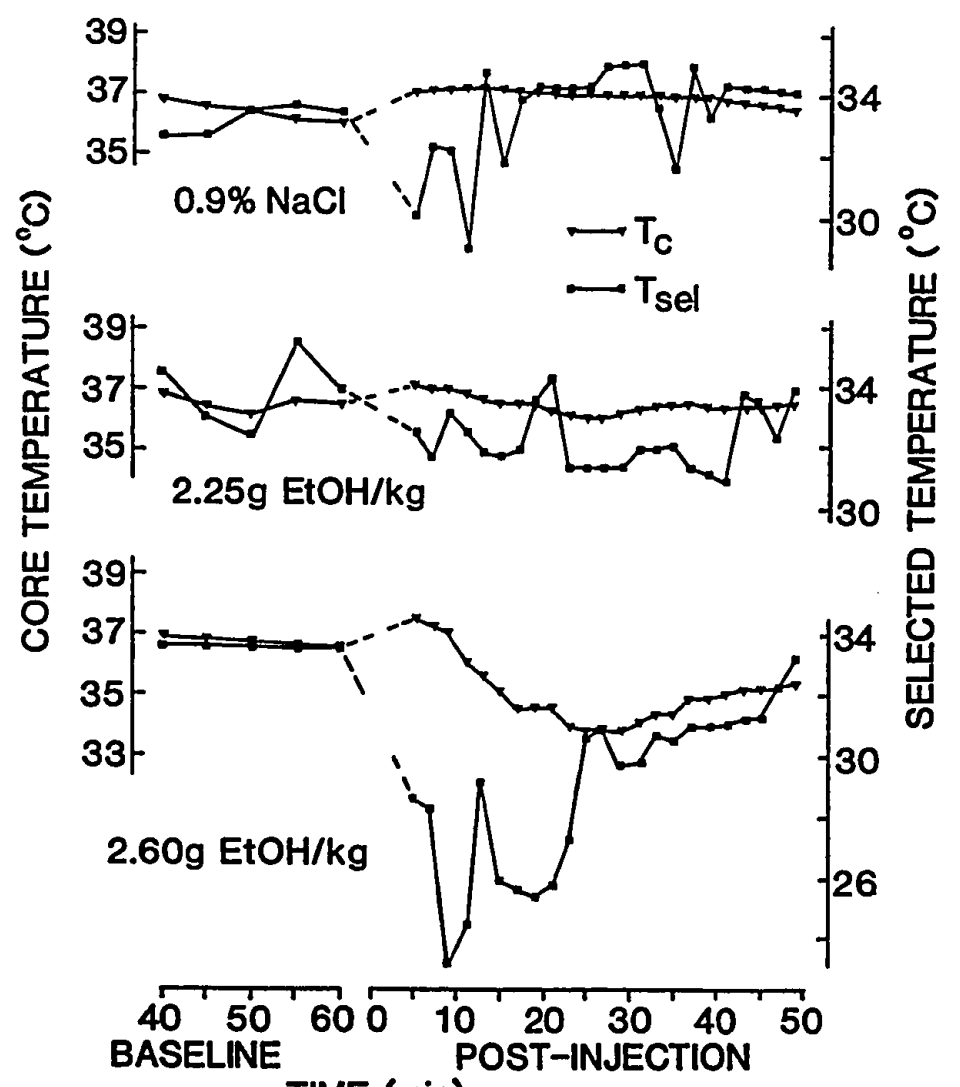

TIME (min)

Figure 7. Thermoregulatory responses of three individual HS mice to acute EtOH or NaCl. Individual records of $T_{i}$ and $T_{\text {sel }}$ before and after injection of $\mathrm{NaCl}$ or 2 doses of EtoH.

been replotted in Figure 8 as changes in the TI as a function of time. Figure 9 shows the change in the TI for all animals in this study. In Figures 8 and 9, the top line represents the change in the TI over time after an injection of $\mathrm{NaCl}$; the middle line shows the change after an injection of $2.25 \mathrm{~g}$ EtOH $/ \mathrm{kg}$; and the bottom line represents the change after 2.60 g EtOH/kg.

In both these figures, the negative values for the TI following EtOH administration indicate a decrease in the 


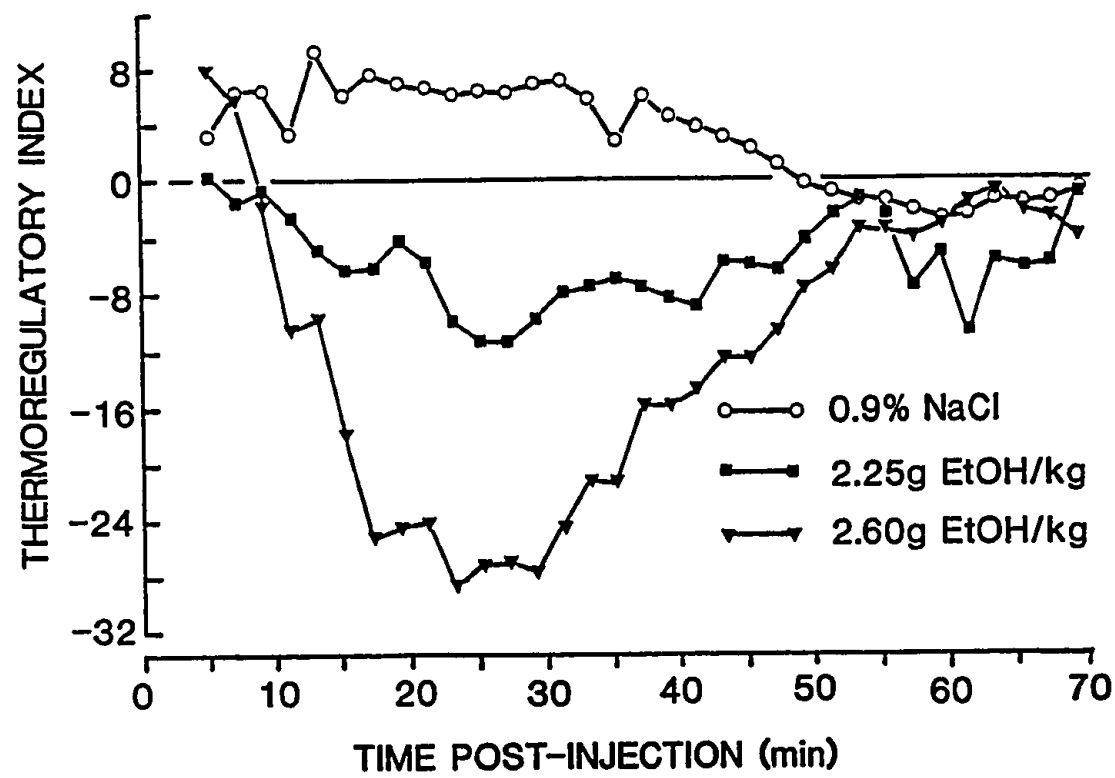

Figure 8. Responses of three individual mice transformed to thermoregulatory index values. Postinjection data replotted from Figure 7 as changes in the TI for $60 \mathrm{~min}$ after injection of EtOH $(2.25$ or $2.6 \mathrm{~g} / \mathrm{kg})$ or $0.9 \% \mathrm{NaCl}$.

regulated temperature. To analyze the experiments statistically, mean TI was calculated for the 0 to $40 \mathrm{~min}$ postinjection period and used as 1 datum to represent a single animal in a particular trial. Repeated measures ANOVA revealed a significant difference between the response to $\mathrm{NaCl}$ and either the lower $\left(F_{1,18}=78.95, \underline{p}<0.0001\right)$ or the higher $\left(F_{1,18}=218.05, p<0.0001\right)$ dose of EtOH, and also between the 2 doses of EtOH $\left(F_{1,18}=44.13, \underline{p}<0.0001\right)$.

A similar analysis of $T_{i}$ and $T_{\text {sel }}$ for the $40 \mathrm{~min}$ postinjection period showed that $T_{i}$ was significantly lower after injection of either $2.25 \mathrm{~g}$ EtOH $/ \mathrm{kg} \quad\left(F_{1,18}=123.47\right.$, $\underline{p}<0.0001)$ or $2.60 \mathrm{~g}$ EtOH $/ \mathrm{kg} \quad\left(F_{1,18}=202.75, \underline{p}<0.0001\right)$ than 


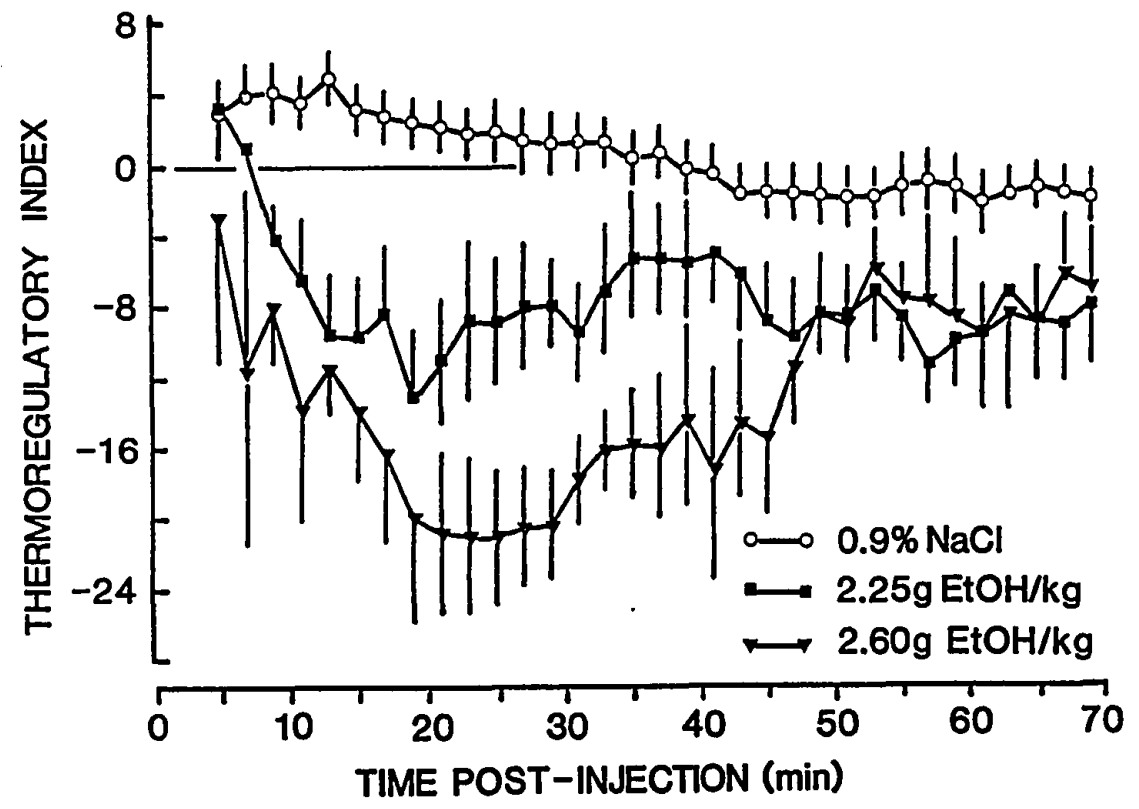

Figure 9. Thermoregulatory index for $60 \mathrm{~min}$ after injection of $\mathrm{NaCl}$ or two doses of EtOH. Group data (mean \pm S.E.M.) for changes in the TI of HS mice after $\mathrm{NaCl}(n=11), 2.25 \mathrm{~g} \mathrm{EtOH} / \mathrm{kg}(n=7)$ or $2.60 \mathrm{~g}$ EtOH $/ \mathrm{kg} \quad(n=4)$.

after $\mathrm{NaCl}$ injection. Internal temperature was also significantly lower after the higher dose, than after the lower dose of EtOH $\left(F_{1,18}=17.73, p<0.0001\right)$. Temperatures selected after $2.25 \mathrm{~g} \mathrm{EtOH} / \mathrm{kg}$ or $\mathrm{NaCl}$ were not significantly different $(p>0.1)$, but the animals chose significantly cooler temperatures after $2.60 \mathrm{~g} \mathrm{EtOH} / \mathrm{kg}$ than after either $\mathrm{NaCl}$ $\left(F_{1,18}=19.69, p<0.0001\right)$ or the lower dose of EtOH $\left(F_{1,18}=10.79\right.$, p<0.01). During the $20 \mathrm{~min}$ following the $2.60 \mathrm{~g} \mathrm{EtOH} / \mathrm{kg}$ injection, when $T_{i}$ was rapidly falling, the mice selected about $26^{\circ} \mathrm{C}$ in the gradient tubes, and showed a decrease in $T_{i}$ of $1.7 \pm 0.6^{\circ} \mathrm{C}$. The 4 mice that were injected with $0.98 \mathrm{NaCl}$ in 
a separate experiment and placed in plastic containers without bedding at $26^{\circ} \mathrm{C}$ showed a slight decrease in $T_{i}$ of $0.4 \pm 0.3^{\circ} \mathrm{C}$. Activity of the mice injected with $2.60 \mathrm{~g}$ EtOH $/ \mathrm{kg}$ and placed in the gradient tubes in the absence of a thermal gradient was normal, but all 6 mice preferred the end of the tube opposite to the end into which they had been inserted, and repeatedly attempted to escape by pushing up the barriers and crawling out. In contrast, when animals were placed in tubes with the thermal gradient in place they spent virtually no time at the extreme ends of the tubes, and escape attempts were rare.

Temperatures at the hot and cold extremes of the gradient tubes were intended to be sufficiently aversive to discourage the mice from spending appreciable time at those locations, and to ensure that a wide enough range of ambient temperature was available that the animals could express temperature preference without choice limitations. The behavior of these animals in the tubes in the absence of a temperature gradient demonstrated that the mice normally position themselves in the tubes in response to the temperature gradient, rather than in response to some other cue such as lighting variation, air flow or odor. 
THE EFFECTS OF ACUTE ETHANOL ON THERMOREGULATION IN SELECTED LINES OF MICE

The thermoregulatory effects of acute EtOH were also quantified in the lines of mice selected in replicate for an attenuated (HOT1 and HOT2 mice) or augmented (COLD1 and COLD2 mice) hypothermic response to i.p. EtoH. The responses of all HOT and COLD mice to the common dose of EtOH $(2.65 \mathrm{~g} \mathrm{EtOH} / \mathrm{kg})$ are illustrated in Figure 10. Internal temperatures $\left(T_{\text {int }}\right)$ are shown in the upper panel and $T_{\text {sel }}$ in the lower panel for $10 \mathrm{~min}$ before, and $60 \mathrm{~min}$ after injection. For this and subsequent figures, where ANOVA reported no significant effect of Genetic Replicate on either $T_{\text {int }}$ or $T_{\text {sel, }}$ HOT and COLD mice were grouped.

Analysis of $T_{\text {int }}$ revealed a significant effect of Line $\left(F_{1,31}=43.98, \underline{p}<.0001\right)$ and Time $\left(F_{6,186}=6.19, \underline{p}<.0001\right)$, and $a$ significant Line $X$ Time interaction $\left(F_{6,186}=7.10, \underline{p}<0.0001\right)$. The postinjection $T_{\text {int }}$ of COLD mice was significantly lower than preinjection temperature at all postinjection time intervals $(\underline{p}<.05)$, while the postinjection and preinjection $T_{\text {int }}$ of the HOT mice did not differ.

Analysis of $T_{\text {sel }}$ showed no effect of Line, but a significant effect of Time $\left(F_{6,174}=9.31, \underline{p}<.0001\right)$, and a significant Line $X$ Time interaction $\left(F_{6,174}=3.79, \underline{p}<.01\right)$. The HOT and COLD mice were therefore compared at each level of Time. Selected temperatures did not differ before injection; after injection, HOT and COLD mice differed only for the first 

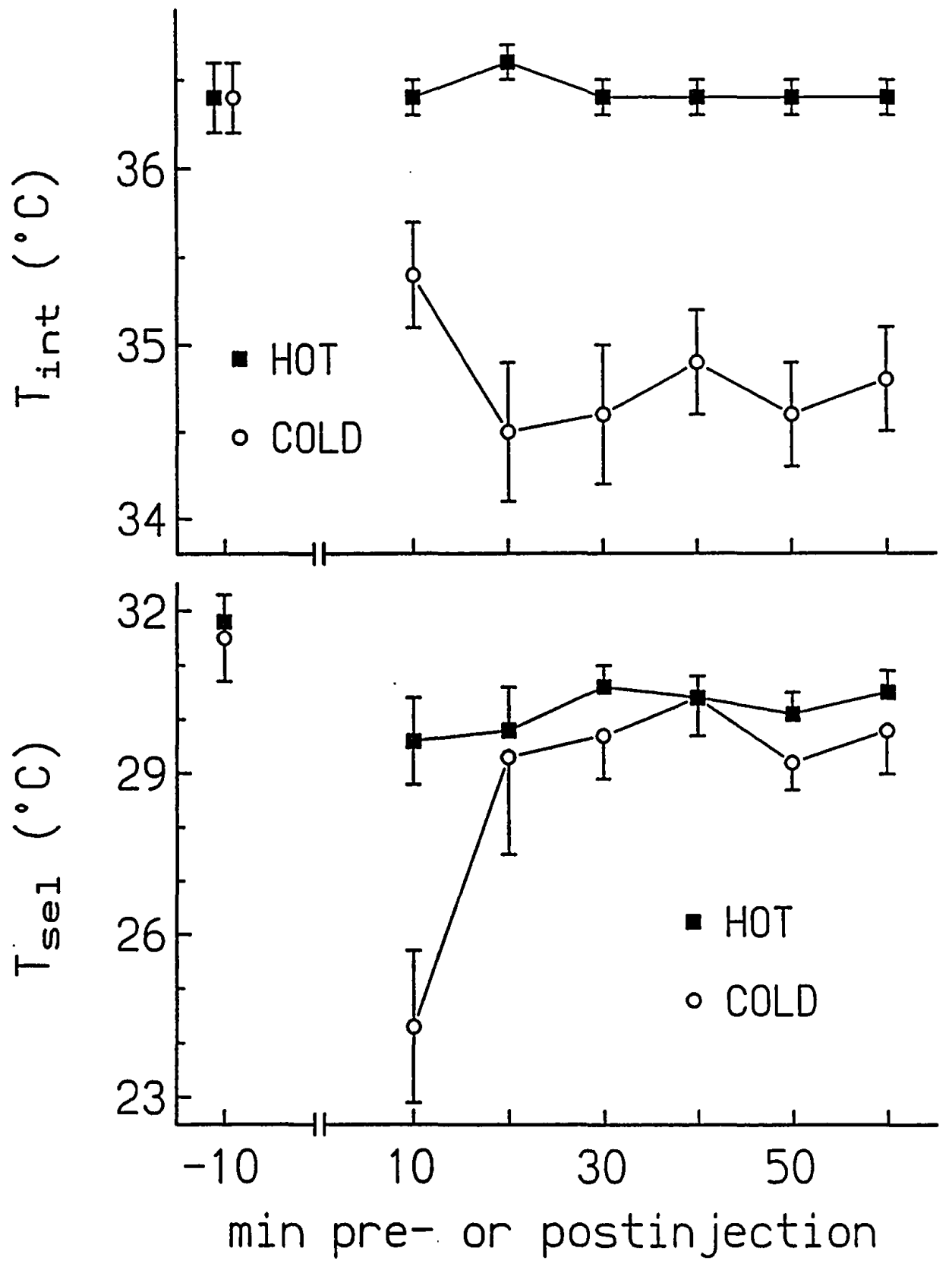

Figure 10. Thermoregulatory responses of HOT and COLD mice to acute EtOH. $\mathbf{T}_{\text {int }}$ (upper plot) and $\mathbf{T}_{\text {sel }}$ (lower plot) responses to $2.65 \mathrm{~g} / \mathrm{kg}$ EtOH in HOT $(n=17)$ and COLD $(n=16)$ mice. Shown are 10 min mean \pm S.E.M. for $10 \mathrm{~min}$ before and $60 \mathrm{~min}$ after injection. (Preinjection $\mathrm{T}_{\text {int }}$ 's identical; symbols offset.) 
10 min postinjection time interval $\left(F_{1,31}=11.64, \underline{p}<.01\right)$. Postinjection $T_{\text {sel }}$ was significantly lower than before injection.

As illustrated in Figure 10, during the first $10 \mathrm{~min}$ after the $2.65 \mathrm{~g} / \mathrm{kg}$ dose of EtOH, $T_{\text {int }}$ of the COLD mice declined substantially below preinjection values. At the same time, these mice selected very cool temperatures. Like the genetically heterogeneous mice in the first study, the COLD mice utilized the powerful effector mechanism of thermoregulatory behavior to lower $\boldsymbol{T}_{\text {int }}$ yet further, as evidenced by the additional decrease in $T_{i n t}$ during the second 10 min postinjection period. For the HOT mice, since this dose had a marginal effect, the situation was more complex. Internal temperatures of the HОT mice were similar before and after injection, while $T_{\text {sel }}$ after injection was lower than before injection. Because $T_{\text {int }}$ and $T_{\text {sel }}$ are not independent measures for freely behaving animals in a temperature gradient, it is misleading to consider one without the other. Therefore, the measured variables of $T_{\text {int }}$ and $T_{\text {sel }}$ plotted in Figure 10 have been replotted in Figure 11 as changes in the TI over time after the common dose of $2.65 \mathrm{~g} \mathrm{EtOH} / \mathrm{kg}$. To compare the effects of control and EtOH injections on the regulated temperature, Figure 11 also shows the TI values after Nacl control injections.

Analysis of the TI of all genotypes after $\mathrm{NaCl}$ and 2.65 g EtOH/kg using ANOVA revealed no significant effect of 


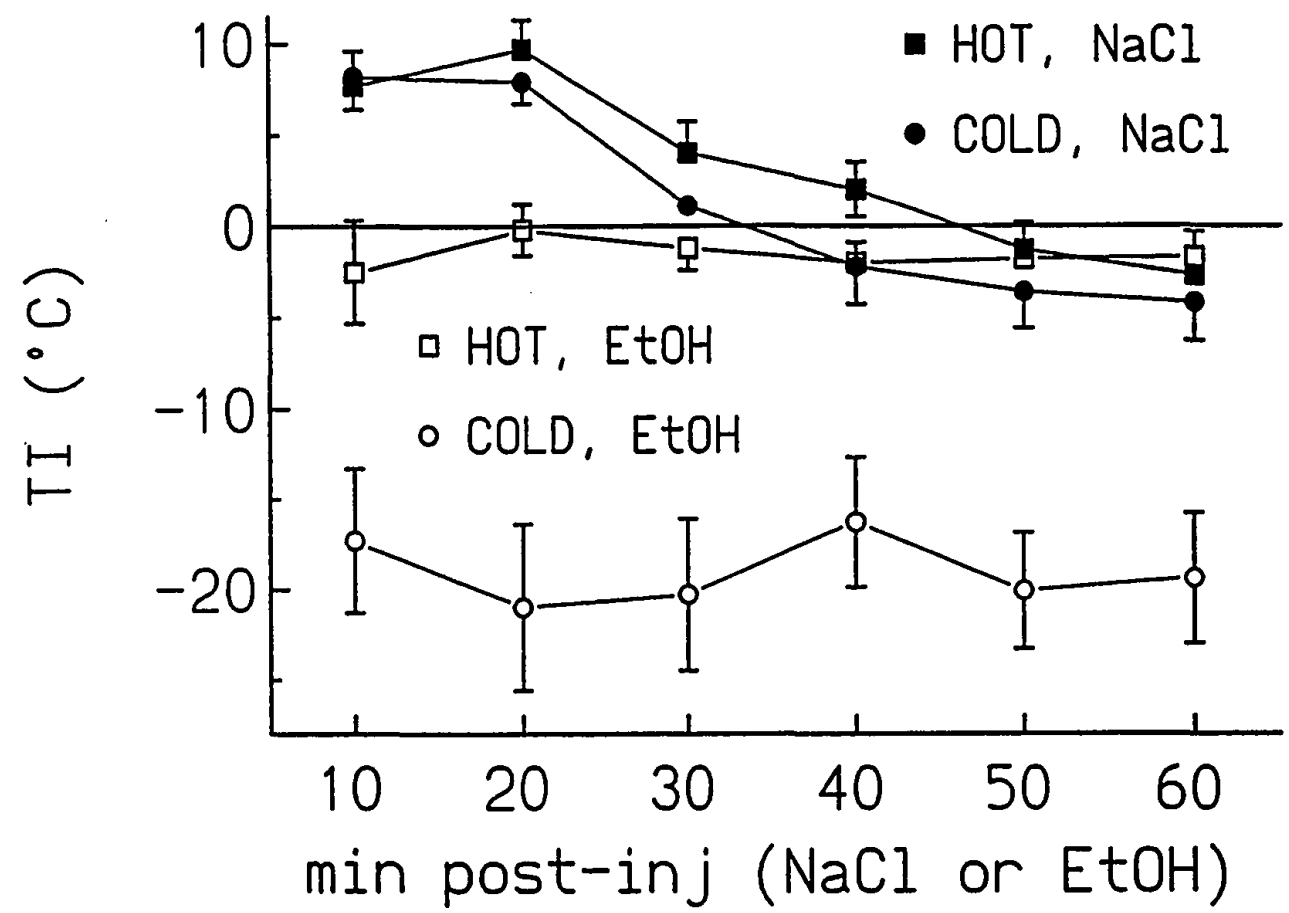

Figure 11. Responses of HOT and COLD Mice transformed to thermoregulatory index values. Shown are sequential 10 min mean \pm S.E.M. TI values for $60 \mathrm{~min}$ after injection of $0.9 \% \mathrm{NaCl}$ or 2.65 $\mathrm{g} / \mathrm{kg}$ EtOH (HOT mice, $\mathrm{n}=17$; COLD mice, $\mathrm{n}=16$ ).

Genetic Replicate. Significant main effects of Line $\left(F_{1,31}=63.13, \underline{p}<.0001\right)$, Time $\left(F_{5,155}=8.93, \underline{p}<.0001\right)$, and Drug (EtOH or $\mathrm{NaCl})\left(F_{1,31}=44.03, \underline{p}<.0001\right)$, and significant Line $\mathrm{X}$ Drug $\left(F_{1,31}=16.55, \underline{p}<.001\right)$ and Time $X$ Drug $\left(F_{5,154}=7.92, \underline{p}<.0001\right)$ interactions were reported by ANOVA. The 3 way interaction was not significant. To further clarify the analysis, a twoWay ANOVA (factors Line and Time) was run separately on the responses to EtOH or to NaCl. Only the factor line was significant for the response to EtOH $\left(F_{1,31}=49.52, \underline{p}<.0001\right)$. In contrast, Time (but not Line) was significant for the 
response to $\mathrm{NaCl}\left(\mathrm{F}_{5,155}=75.05, \underline{\mathrm{p}}<.0001\right)$. Posthoc Fisher's LSD reported that the first 20 min differed significantly from the last $40 \mathrm{~min}$, and the third and fourth $10 \mathrm{~min}$ periods differed from all others, during the response to NaCl injection ( $\underline{p}<.05$ for all comparisons). For neither two-way ANOVA (on NaCl or EtoH) was there a significant Iine $\mathrm{X}$ Time interaction.

These statistical results make it clear that, in the original multifactorial analysis, the significance of the factor Time was due to the response to control injection. After NaCl injection, the TI was significantly elevated for about $20 \mathrm{~min}$, then gradually declined to preinjection levels. The HOT and COLD animals did not differ in this response. In contrast, HOT and COLD animals differed significantly in their response to $2.65 \mathrm{~g} \mathrm{EtOH} / \mathrm{kg}$, but Time had no significant effect on the drug response for the 60 min postinjection period.

Due to the markedly greater sensitivity of the COLD mice to acute EtOH, $2.65 \mathrm{~g} \mathrm{EtOH} / \mathrm{kg}$ was the only dose level common to all mice. To examine the response of the mice to varying doses of EtOH, COLD mice were further tested at doses of 2.0 and $2.25 \mathrm{~g} \mathrm{EtOH} / \mathrm{kg}$, while HOT mice were given a dose of 2.85 g EtoH $/ \mathrm{kg}$. An additional dose of $3.0 \mathrm{~g} \mathrm{EtOH} / \mathrm{kg}$ was used for the HOT2 mice only. The 60 min mean postinjection TI values for control and all EtoH injections are shown in Figure 12.

When ANOVA was applied to the responses of the COLD mice, a significant effect of Dose on the TI was reported $\left(F_{3,39}=16.69, \underline{p}<.0001\right)$. No significant effect of Genetic 


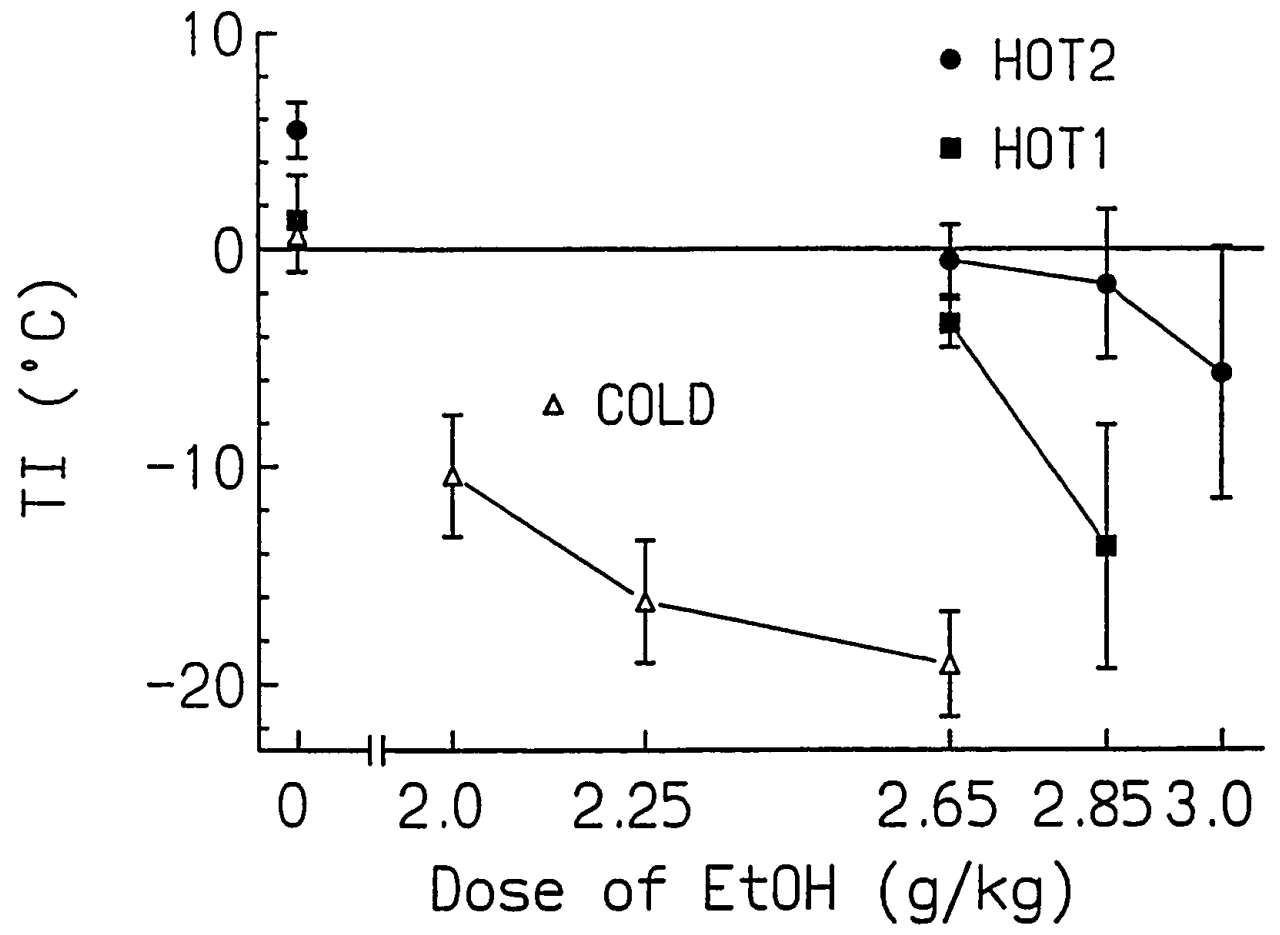

Figure 12. Dose response curves for HOT and COLD mice after acute EtOH. TI of response (mean \pm S.E.M.) for $60 \mathrm{~min}$ after injection of $\mathrm{NaCl}(0 \mathrm{~g} / \mathrm{kg})$ or indicated doses of EtOH. COLD1 and COLD2 mice did not differ and are combined ( $\mathrm{NaCl}$ and $2.65 \mathrm{~g} / \mathrm{kg}$, $\mathrm{n}=16 ; 2.25 \mathrm{~g} / \mathrm{kg}, \mathrm{n}=15 ; 2 \mathrm{~g} / \mathrm{kg}, \mathrm{n}=14$ ). Differences were detected between HOT1 ( $n=9 /$ dose) and HOT2 $(n=8 /$ dose) mice, and they are shown separately.

Replicate or significant Replicate $\mathrm{x}$ Dose interaction was detected. Posthoc analysis reported that the effect of $\mathrm{NaCl}$ injection ( $0 \mathrm{~g} \mathrm{EtOH} / \mathrm{kg}$ ) was significantly different from the effects of all doses of EtOH, and that the effects of the 2.0 and $2.65 \mathrm{~g} \mathrm{EtOH} / \mathrm{kg}$ doses differed from each other $(\underline{p}<.05)$; the effect of the $2.25 \mathrm{~g}$ EtOH $/ \mathrm{kg}$ dose was intermediate to both, and did not differ from either.

Analysis of the responses of the HOT mice revealed a different pattern. Analysis of responses to the $0,2.65$ and 
$2.85 \mathrm{~g} \mathrm{EtOH} / \mathrm{kg}$ doses using ANOVA detected a significant effect of both Replicate $\left(F_{1,15}=7.79, \underline{p}<.05\right)$ and Dose $\left(F_{2,30}=7.12\right.$, $\mathrm{p}<.01)$ on the TI of HOT mice, although the Replicate X Dose interaction did not reach significance. Posthoc analysis indicated that the effects of control injection and the 2.85 g EtOH/kg dose were significantly different (p<.05). A separate one-way ANOVA was performed on the HOT2 mice only, including data from the $3.0 \mathrm{~g}$ EtoH/kg dose given only to those animals. The main effect of Dose did not achieve significance.

Figure 13 shows the activity of the animals in the thermal gradient tubes after injections of $\mathrm{NaCl}$ or EtoH. Once again, because the dose ranges employed in the lines were different, the activity responses of HOT and COLD mice were analyzed separately.

Analysis of the activity of COLD mice revealed a significant Dose effect $\left(F_{3,39}=4.75, \underline{p}<.01\right)$. Posthoc Fisher's LSD reported that activity of COLD mice was significantly elevated by the $2.0 \mathrm{~g} \mathrm{EtOH} / \mathrm{kg}$ dose, above activities measured after control or the other EtOH injections ( $<<.05)$. similarly, analysis of responses of HOT mice detected a significant Dose effect $\left(F_{2,45}=9.82, \underline{p}<.001\right)$. Posthoc analysis revealed that activity of HOT mice after $2.65 \mathrm{~g} / \mathrm{kg}$ was significantly elevated $(\underline{p}<.05)$ compared to activities after $\mathrm{NaCl}$ or the $2.85 \mathrm{~g} / \mathrm{kg}$ Etor dose. 


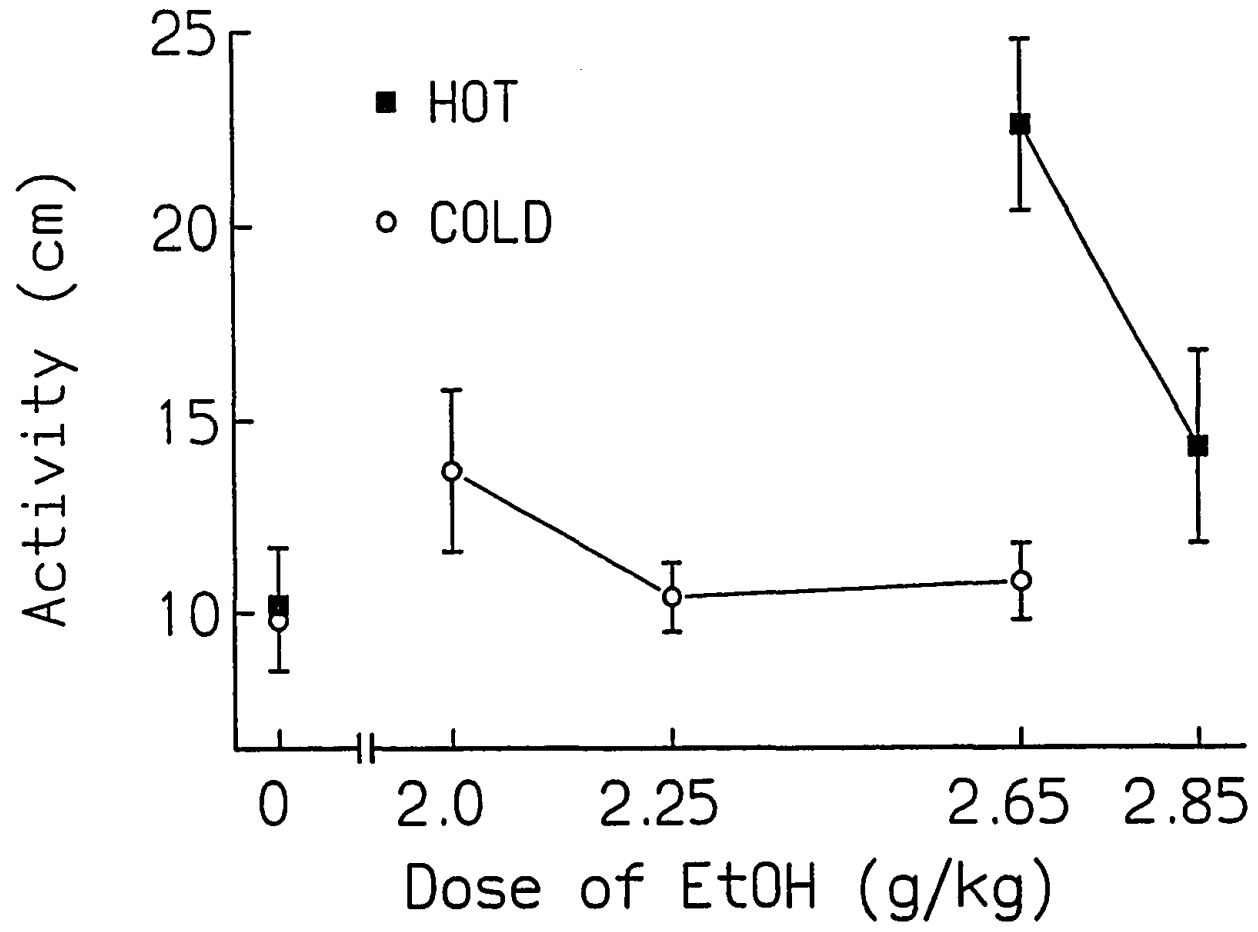

Figure 13. Activity responses of HOT and COLD mice to increasing doses of EtOH. HOT and COLD mice received i.p. injections of $\mathrm{NaCl}(0 \mathrm{~g} / \mathrm{kg})$ or indicated doses of EtoH. Activity expressed as mean \pm S.E.M. cm travelled in gradient tubes per 6 sec sample interval, averaged over the $60 \mathrm{~min}$ test. Shown are combined HOT1 and HOT2 mice ( $n=17 /$ dose), and combined COLD1 and COLD2 mice (NaCl and $2.85 \mathrm{~g} / \mathrm{kg}, \mathrm{n}=16 ; 2.25 \mathrm{~g} / \mathrm{kg}, \mathrm{n}=15 ; 2 \mathrm{~g} / \mathrm{kg}, \mathrm{n}=14)$.

\section{INFLUENCE OF TIME OF DAY ON THERMOREGULATORY}

RESPONSE TO ETHANOL

The internal temperature $\left(T_{i}\right)$ of COLD2 mice in the mouse room prior to experimental manipulation at 6 times of day are presented in Figure 14. These temperatures partition into 2 groups, with temperatures measured during lights-on (0800, 1200 and $1600 \mathrm{hr}$ ) much lower than temperatures measured during lights-off $(2000,2400$ and $0400 \mathrm{hr})$. 


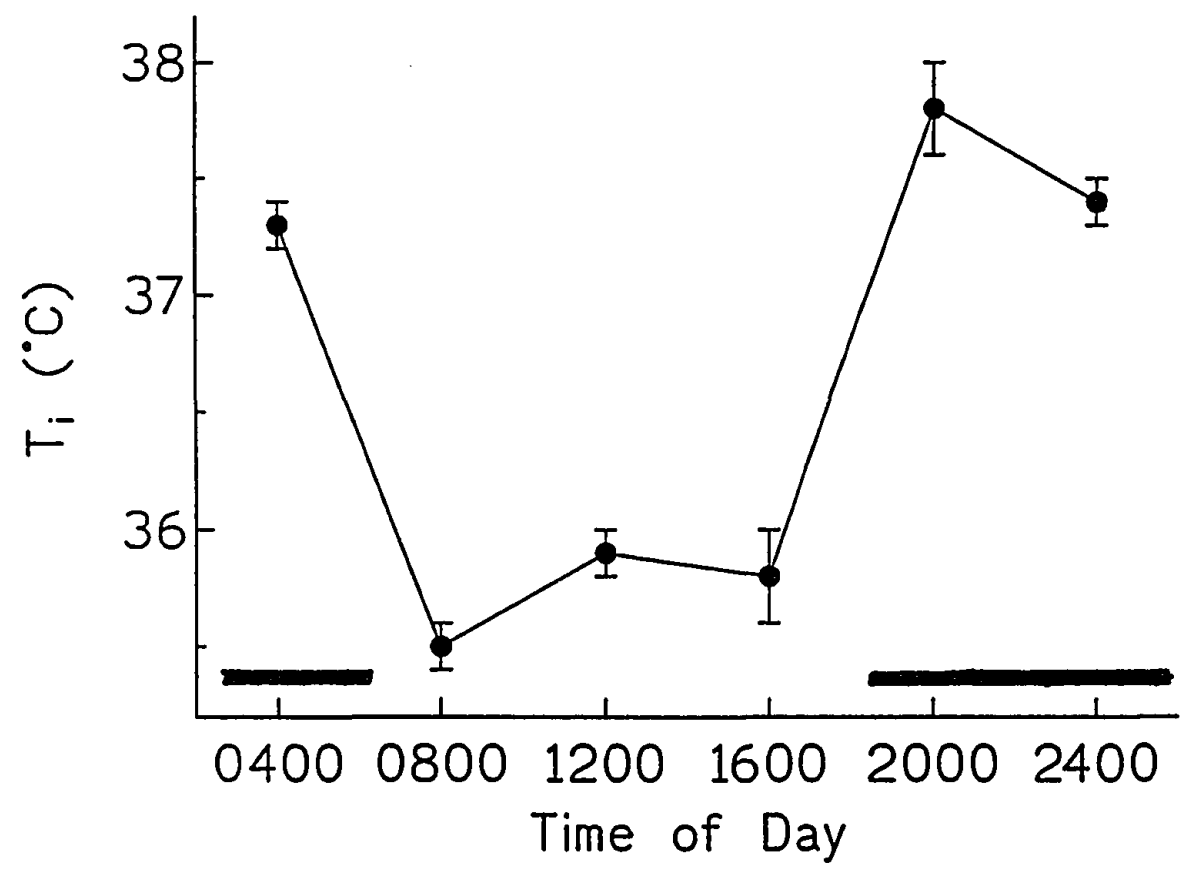

Figure 14. Baseline internal temperatures at various times of day. $T_{i}$ of COLD2 mice $(n=9)$ in animal room prior to experimentation. Black bars show lights-off time in animal room.

Figure 15 presents $T_{i}$ (top panel) and $T_{\text {sel }}$ (bottom panel) of COLD2 mice after $0.9 \% \mathrm{NaCl}, 2.6 \mathrm{~g}$ EtOH/ $\mathrm{kg}$ or no injection (baseline) at 6 times of day.

A 60 min mean $T_{i}$ and $T_{\text {sel }}$ was calculated for each animal under each condition, and summed over animals to yield the data plotted in this figure. Both $T_{i}$ and $T_{\text {sel }}$ values after EtOH were lower than after $\mathrm{NaCl}$ or in the baseline condition, at all times of day. It appears that both temperature measures were sensitive to time of day; this seemed particularly true of $\mathbf{T}_{\text {sel }}$.

To simplify the data, the TI was calculated at $10 \mathrm{~min}$ intervals, at each time of day, for each individual. In lieu 

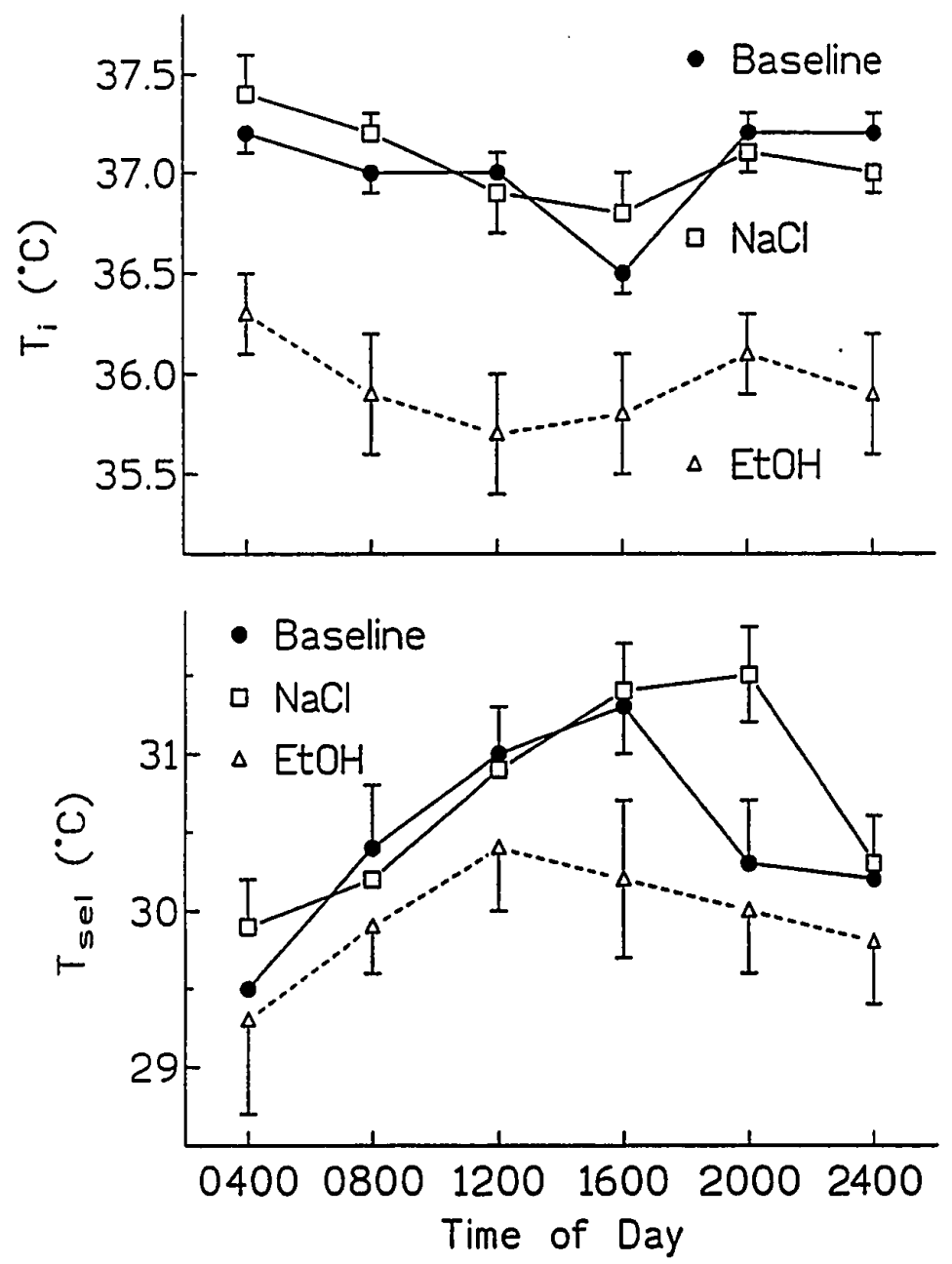

Figure 15. Thermoregulatory responses of COLD2 mice to EtOH, $\mathrm{NaCl}$ or no drug at various times of day. $T_{i}$ top panel) and $T_{\text {sel }}$ (bottom panel) of COLD2 mice in the temperature gradient at indicated times throughout the day/night cycle, expressed as $60 \mathrm{~min}$ mean \pm S.E.M. after injection of $2.6 \mathrm{~g} / \mathrm{kg} \mathrm{EtOH,} \mathrm{an}$ equivalent volume of $0.9 \% \mathrm{NaCl}$, or no injection (Baseline) ( $n=9$; each mouse tested once at each time under each condition).

of preinjection data, the last $10 \mathrm{~min}$ of baseline (noinjection) $T_{\mathbf{i}}$ and $T_{\text {sel }}$ was utilized in the $T I$ equation. For each individual, $10 \mathrm{~min}$ mean TI values were summed to a $60 \mathrm{~min}$ postinjection mean, and these individual means combined to 
yield the data presented. Figure 16 shows clearly that the TI after EtOH was below the TI after NaCl at all times of day tested, and also that the temperature response varied with time of day, with a higher TI of response under both conditions observed at $1600 \mathrm{hr}$.

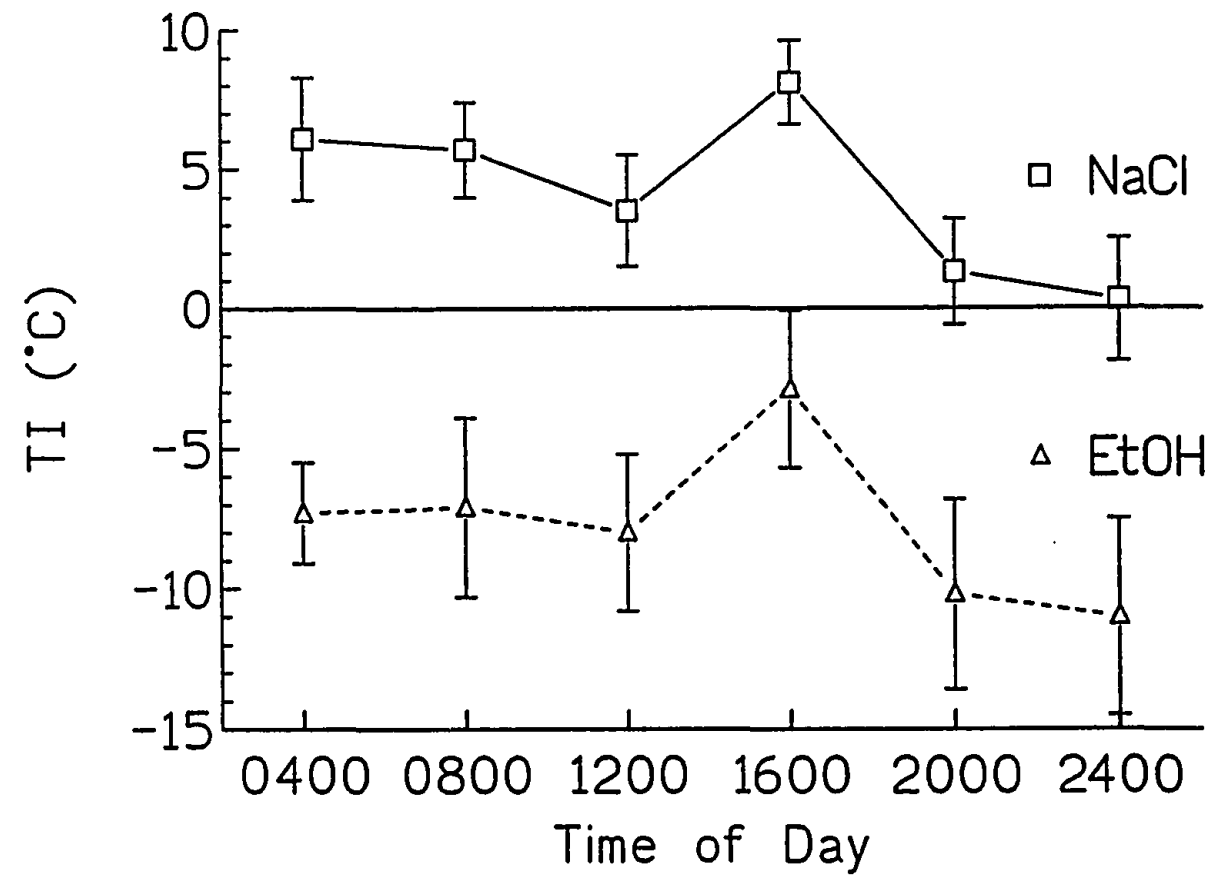

Figure 16. Responses of COLD2 mice at various times of day transformed to thermoregulatory index values. 60 min mean \pm S.E.M. TI after injection of $2.75 \mathrm{~g} / \mathrm{kg}$ EtOH or an equivalent volume of $0.9 \%$ $\mathrm{NaCl}$. Baseline data utilized in lieu of preinjection data to calculate $\mathrm{TI}(\mathrm{n}=9$; each mouse tested once at each time under each condition).

The purpose of this experiment was to determine if the usual time for mice to be run in the gradient was representative of the body temperature response to EtOH. Data from gradient experiments have often been analyzed by comparing the temperature response to EtOH with the response 
to $\mathrm{NaCl}$, so the difference between those responses at various times of day was a point of great interest. The data were therefore transformed once more.

For each individual mouse, successive $10 \mathrm{~min}$ post-EtOH TI values were subtracted from the TI values for the same individual at the same postinjection time period after $\mathrm{NaCl}$, and these 10 min individual mean differences summed across all animals to yield $10 \mathrm{~min}$ group mean differences, at all times of day tested, for $60 \mathrm{~min}$ postinjection. The results are presented in Figure 17. The top panel shows the family of difference curves representing the lights-on times of day, and the bottom panel shows the difference curves for the dark period. Standard errors have been left off for clarity. Inspection of these curves reveals that during the lights-on times the mice achieved a greater difference between the body temperature response to EtOH and NaCl than they did during the dark times. The response at $1200 \mathrm{hr}$ appeared to show the greatest peak difference between the responses, yet by the end of this postinjection period the difference between EtOH and $\mathrm{NaCl}$ conditions was small. The response at $1600 \mathrm{hr}$ was similar. Responses during the dark period appeared slightly blunted; the peak difference between the conditions was somewhat smaller. 


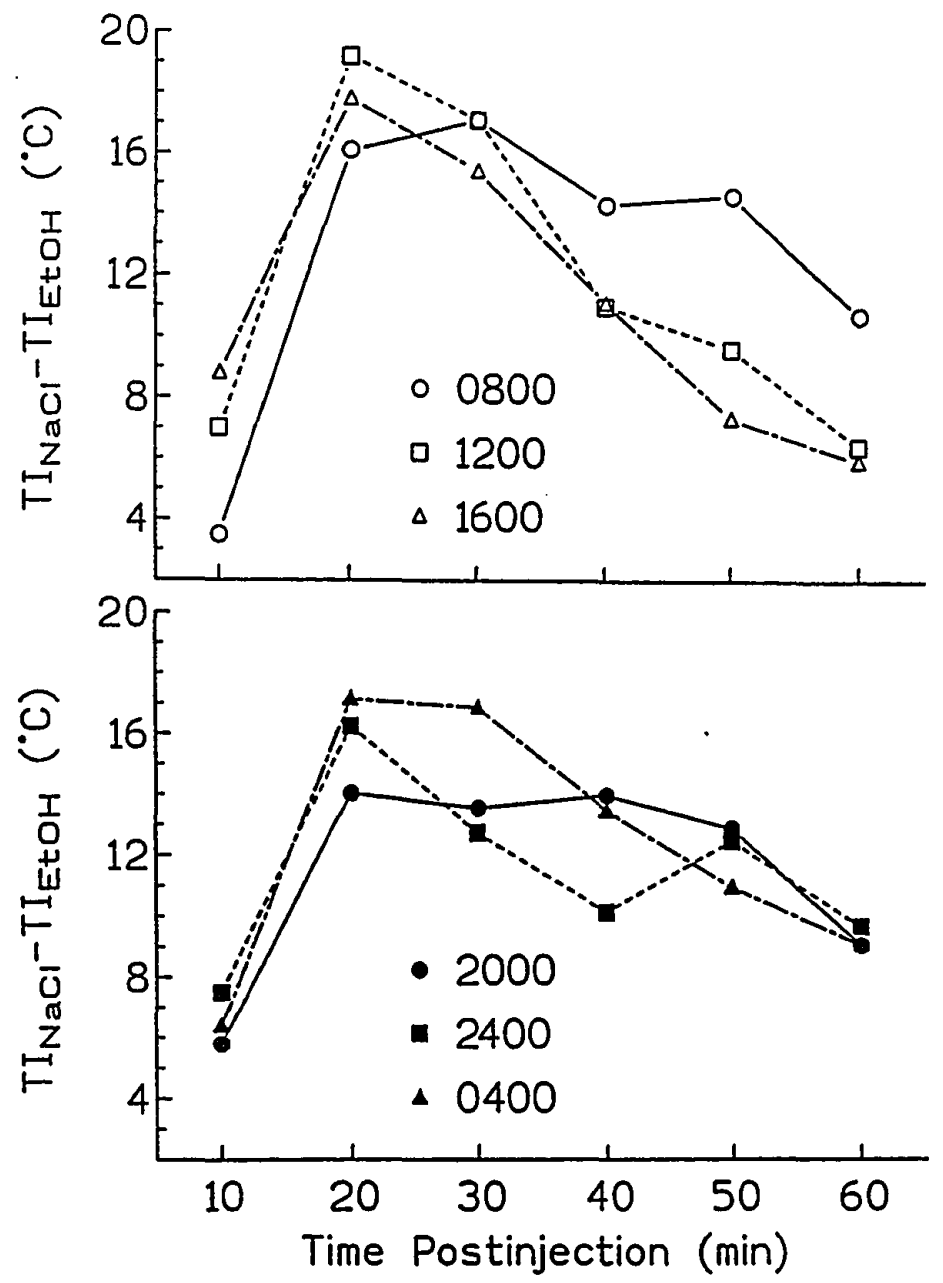

Figure 17. Difference between thermoregulatory index after $\mathrm{NaCl}$ and EtOH at various times of day. TI of response of COLD2 mice to $2.75 \mathrm{~g} / \mathrm{kg}$ EtOH subtracted from TI of response to $0.9 \% \mathrm{NaCl}$ at 10 min intervals for $60 \mathrm{~min}$ postinjection at indicated times. Top panel, lights-on times; bottom panel, lights-out times $(n=9 ;$ each mouse tested once at each time under each condition).

DEVELOPMENT OF TOLERANCE TO ETHANOL HYPOTHERMIA

The temperature responses of genetically heterogeneous mice on the first day of exposure to $\mathrm{NaCl}$ and $2.75 \mathrm{~g} / \mathrm{kg} \mathrm{EtOH}$ in the Mixed Protocol experiment are presented in Figure 18. 
The top panel shows $T_{i}$ and the bottom panel $T_{s e l}$ for the final $10 \mathrm{~min}$ preinjection, and at $10 \mathrm{~min}$ intervals for $60 \mathrm{~min}$ postinjection. The responses of these mice on their first day in the temperature gradient were typical of the responses of mice to acute EtOH already discussed.
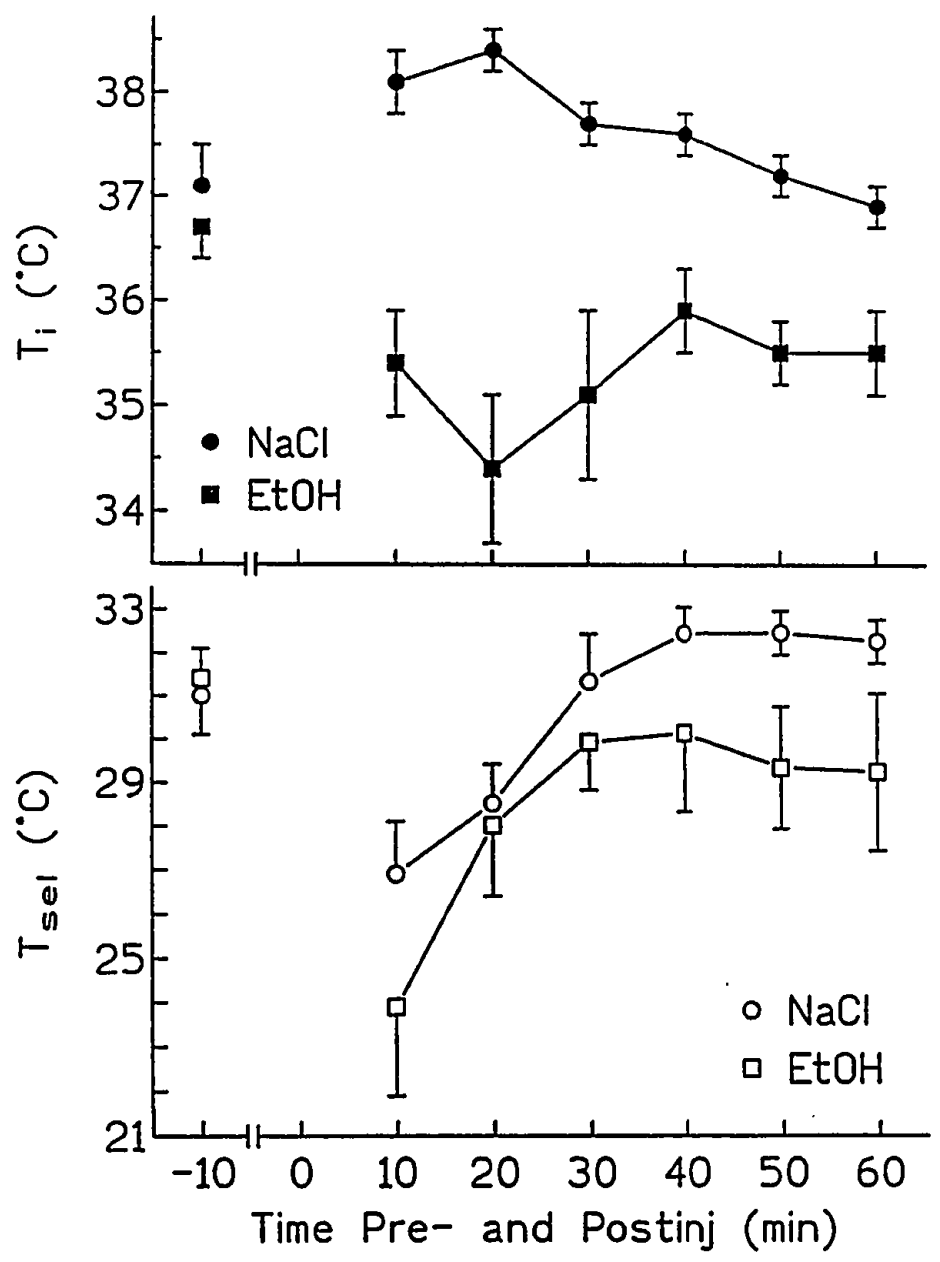

Fiqure 18. Responses of HS mice to acute EtOH or NaCl on Day 1 of Mixed Protocol tolerance experiment. Shown are $T_{i}$ (top panel) and $T_{\text {sel }}$ (bottom panel) (mean \pm S.E.M.) of HS mice in the temperature gradient at $10 \mathrm{~min}$ intervals for $10 \mathrm{~min}$ before and $60 \mathrm{~min}$ after injection of $2.75 \mathrm{~g} / \mathrm{kg}$ EtOH $(n=9)$ or an equivalent volume of $0.9 \% \mathrm{NaCl}(n=8)$. 
For all gradient days (Days $1,2,4,7$ and 11 ), the $T_{i}$ and $\mathbf{T}_{\text {sel }}$ were converted to $T I$ values, shown in Figure 19.
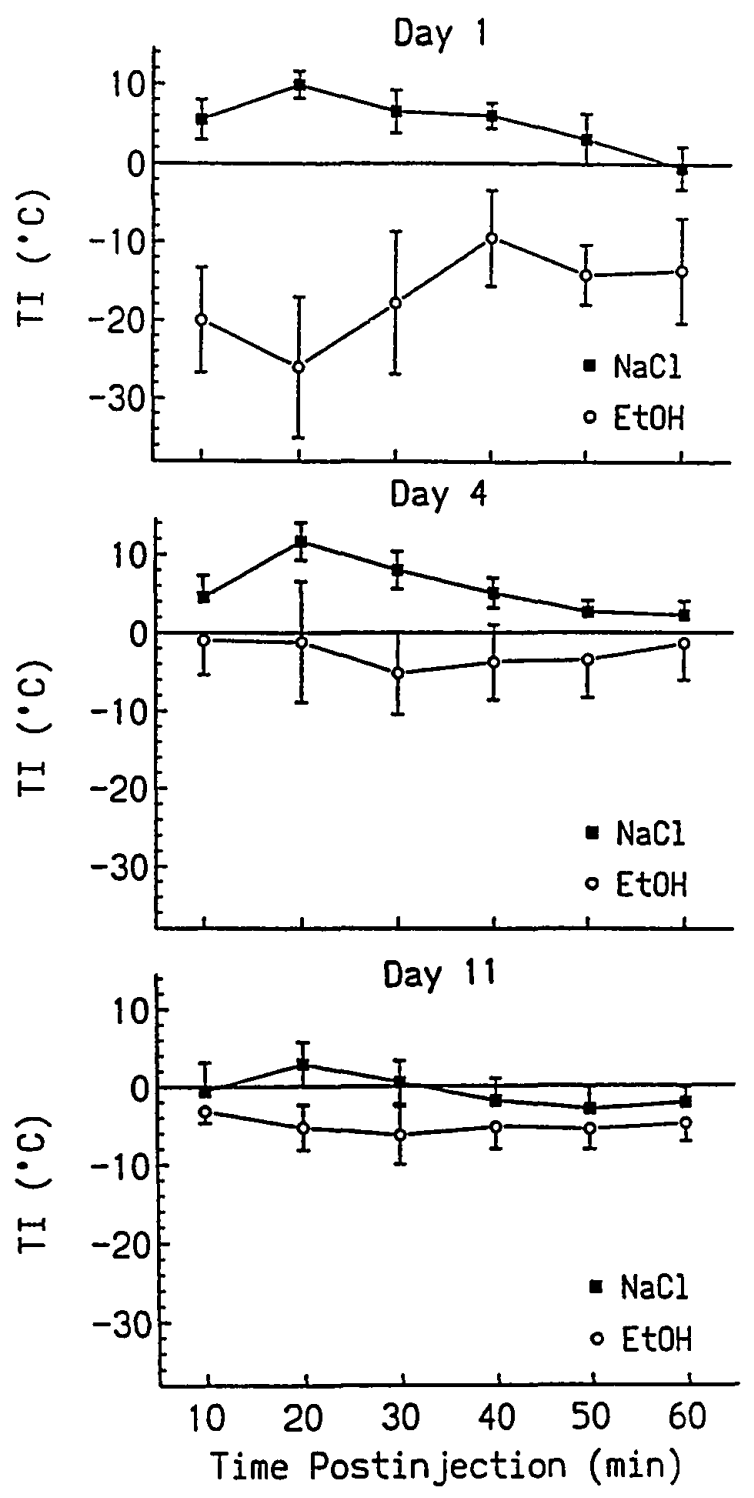

Figure 19. Thermoregulatory index of response of HS mice to NaCl or EtoH on Day 1, Day 4 and Day 11 of Mixed Protocol tolerance experiment. HS mice after $2.75 \mathrm{~g} / \mathrm{kg}$ EtoH $(n=9)$ or $0.9 \% \mathrm{NaCl}(n=8)$ on Day 1 , Day 4 and Day 11, Mixed Protocol tolerance experiment; 10 min mean \pm S.E.M. TI, for $60 \mathrm{~min}$ postinjection. 
In Figure 19 the top panel shows TI after NaCl or EtOH on Day 1, the middle panel shows the same information for Day 4, and in the bottom panel the data from Day 11 are presented. The thermoregulatory responses of the animals to both $\mathrm{NaCl}$ and EtoH changed considerably over the 11 days of this experiment; in addition, the responses to $\mathrm{NaCl}$ or EtoH grew closer together over this period of time.

The function of control injections is to reveal the effects of an experimental procedure minus the drug. Therefore, to isolate the effect of repeated exposure to drug only, the difference between response to EtOH and to $\mathrm{NaCl}$ was examined. Figure 20 presents a family of curves representing the difference between mean TI after EtOH and mean TI after $\mathrm{NaCl}$, at $10 \mathrm{~min}$ intervals for $60 \mathrm{~min}$ postinjection, on all gradient days of the Mixed Protocol experiment.

on Day 1 the difference between responses was marked. This difference was greatly attenuated on Day 2, and continued to lessen throughout the course of the experiment. Figure 21 presents the same data in a different way. A mean 60 min TI was calculated for each individual, and individual values combined to yield the mean $60 \mathrm{~min}$ TI after $\mathrm{NaCl}$ and EtOH on all gradient days of the Mixed Protocol experiment.

Repeated measures ANOVA reported significant main effects of Drug $\left(F_{1,13}=9.66, \underline{p}<.01\right)$ and Time $\left(F_{4,52}=3.72, \underline{p}<.01\right)$, and a significant Drug $X$ Time interaction $\left(F_{4,52}=4.45, \underline{p}<.005\right)$. Over the course of this experiment, the hypothermic response to 


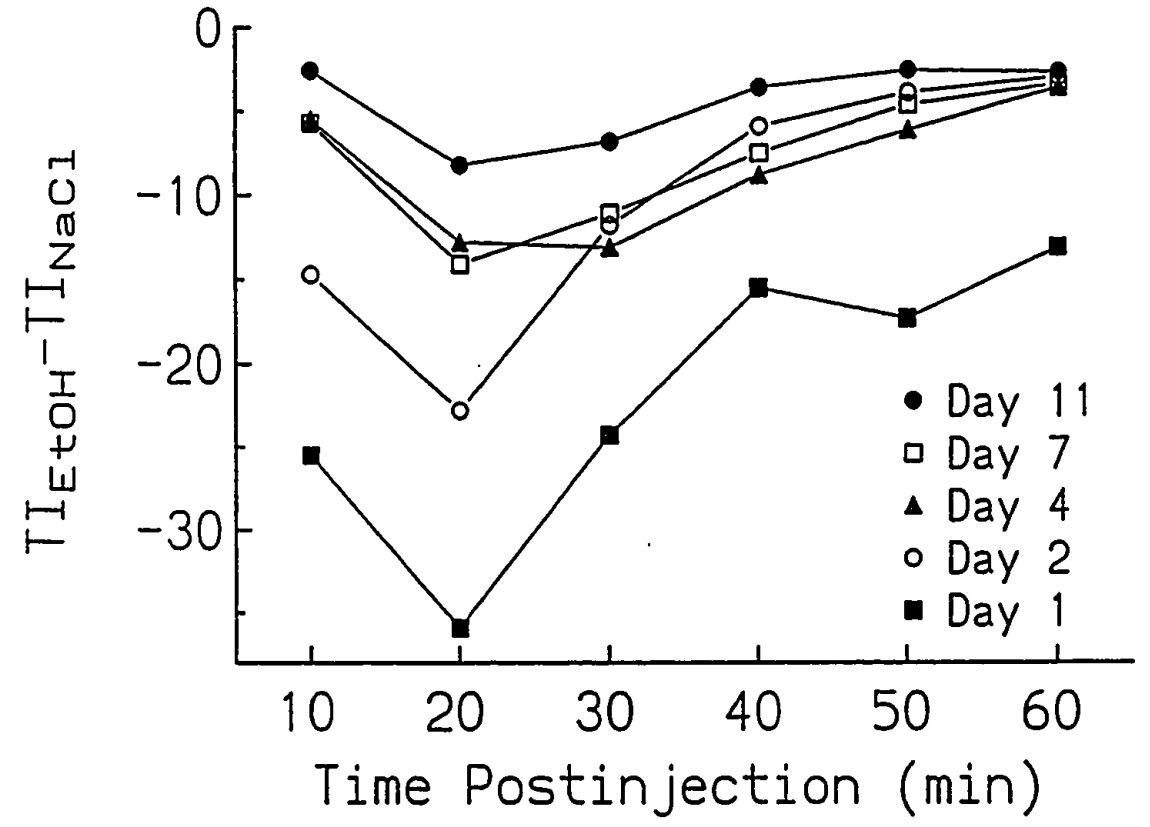

Figure 20. Difference between thermoregulatory index after EtOH and $\mathrm{NaCl}$ on gradient days of Mixed Protocol tolerance experiment. Mean TI of response of HS mice to $2.75 \mathrm{~g} / \mathrm{kg}$ EtOH $(n=9)$ minus mean TI of response to $0.9 \% \mathrm{NaCl}(n=8) ; 10 \mathrm{~min}$ intervals for 60 min postinjection on the 5 gradient days of the 11 day Mixed Protocol tolerance experiment.

EtOH became greatly attenuated. The diminished response fits the definitions of both rapid and chronic tolerance presented in the Introduction.

Through the course of the 11 days of the Mixed Protocol, the mice increased their rate of metabolism of EtoH, reflecting the development of dispositional tolerance. The top portion of Table III shows mean BEC at 60,120 and $180 \mathrm{~min}$ postinjection during the Mixed Protocol experiment, on the 5 days on which animals were run in the gradient tubes. 


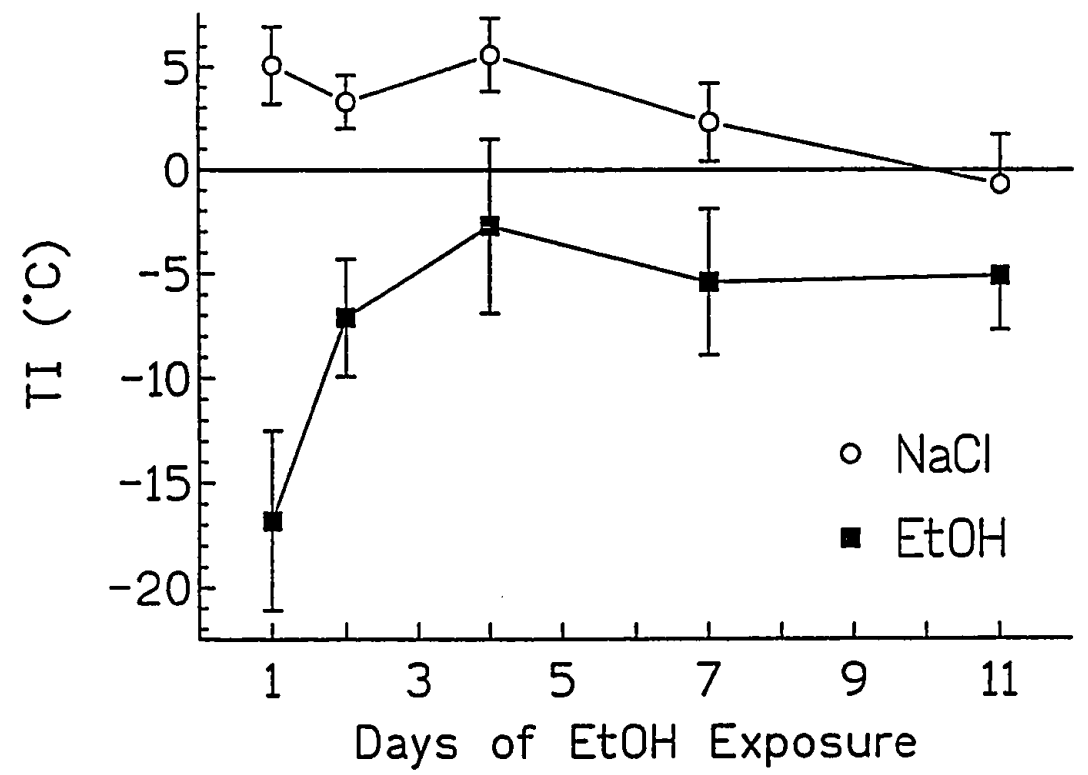

Figure 21. Thermoregulatory index of response of HS mice to EtOH and NaCl on gradient days of Mixed Protocol tolerance experiment. TI after injection of $2.75 \mathrm{~g} / \mathrm{kg}$ EtOH $(n=9)$ or $0.9 \% \mathrm{NaCl}(n=8) ; 60 \mathrm{~min}$ mean \pm S.E.M. per day for 5 days of gradient exposure in Mixed Protocol tolerance experiment.

TABLE III

BLOOD ETHANOL CONTENT

$(\mathrm{mg} / \mathrm{ml})$

DAY $n \quad 60 \mathrm{~min} \quad 120 \mathrm{~min} \quad 180 \mathrm{~min}$

MIXED PROTOCOL

\begin{tabular}{rrrrr}
1 & 7 & $2.97 \pm .2$ & $2.20 \pm .2$ & $1.47 \pm .2$ \\
2 & 8 & $2.47 \pm .3$ & $2.11 \pm .2$ & $1.31 \pm .1$ \\
4 & 8 & $2.59 \pm .3$ & $1.95 \pm .1$ & $1.02 \pm .1$ \\
7 & 6 & $2.26 \pm .1$ & $1.74 \pm .2$ & $0.88 \pm .1$ \\
11 & 9 & $2.30 \pm .1$ & $1.52 \pm .1$ & $0.78 \pm .1$ \\
\multicolumn{5}{c}{ BOX PROTOCOL }
\end{tabular}

11

5

$2.64 \pm .2$

$1.60 \pm .1$

$0.89 \pm .1$ 
Repeated measures ANOVA reported significant main effects both of Day $\left(F_{4,32}=7.72, \underline{p}<.0005\right)$ and Time $\left(F_{2,64}=139.59, \underline{p}<.0001\right)$ on the BEC; the interaction of main effects was not significant $(p>7)$.

In the Behavior Protocol, animals were injected daily with EtOH or $\mathrm{NaCl}$ and run in the gradient (data not shown). This experiment was performed because, after the Mixed Protocol experiments were complete, it became obvious that most tolerance to the hypothermic effect of EtoH was acquired in the first few days of exposure, but the Mixed Protocol did not include running the mice in the gradient on Day 3 . The Behavior Protocol mice were injected and run in the gradient for 4 consecutive days, when the experiment was discontinued because the behavior of the animals had become completely erratic; upon being placed in the tubes, the mice would dash from one end to the other, apparently seeking a route of escape, and not exhibiting interpretable thermoregulatory behavior. This result seemed to confirm the original supposition that running mice in the gradient tubes daily, without a rest, would prove too stressful for them, and make it impossible to collect reliable behavioral data.

In contrast to the Mixed Protocol tolerance experiment, where on 5 of the 11 days of exposure to EtOH or NaCl the mice were able to express their regulated body temperature by adopting a favorable thermal environment in the gradient tubes, the mice participating in the Box Protocol experiment 
were held at laboratory temperature $\left(22 \pm 1^{\circ} \mathrm{C}\right)$ after their daily EtOH or $\mathrm{NaCl}$ injection. Mean $\mathrm{T}_{\mathbf{i}}$ values measured for $10 \mathrm{~min}$ preinjection, and at 10 min intervals for 60 min postinjection are presented in Figure 22 for the first and last days of EtoH exposure in the Box Protocol experiment.

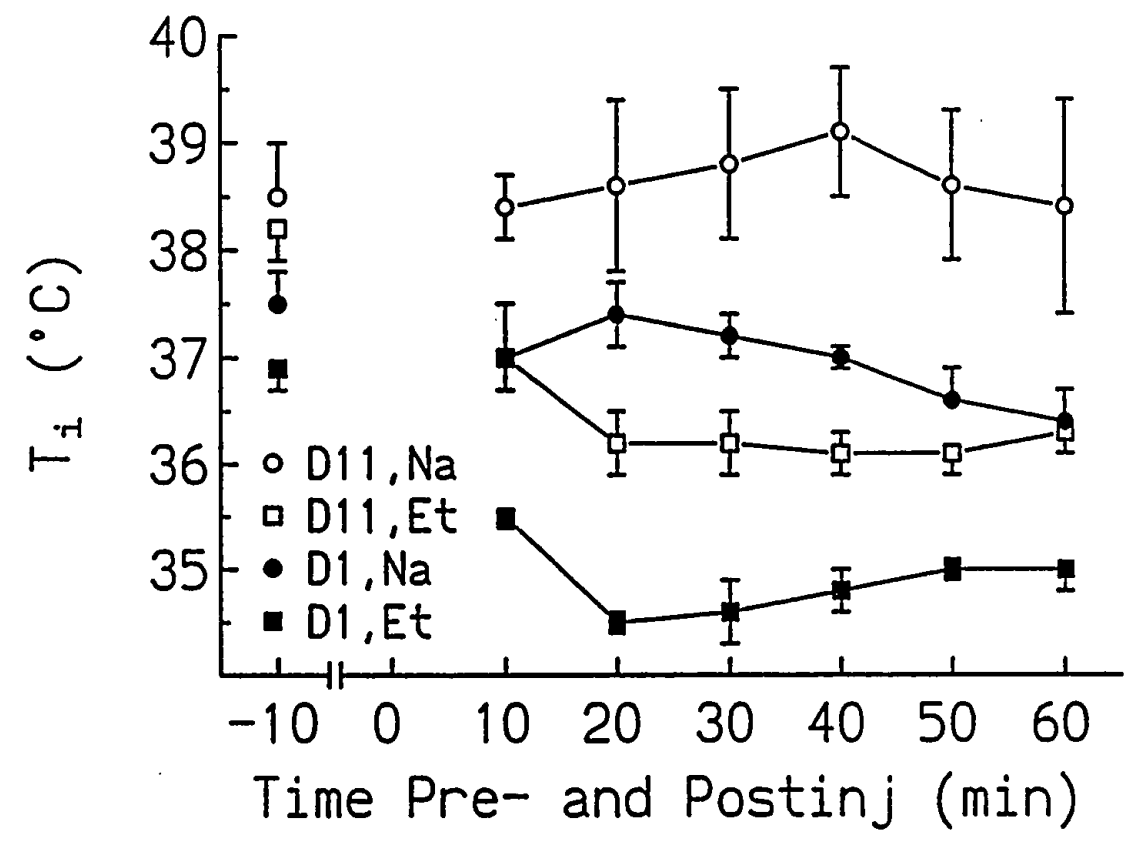

Figure 22. Temperature responses of HS mice to EtOH or NaCl on first and last days of Box Protocol tolerance experiment. $T_{i}$ (mean \pm S.E.M.) of HS mice for $10 \mathrm{~min}$ before, and at $10 \mathrm{~min}$ intervals for 60 min after $2.75 \mathrm{~g} / \mathrm{kg}$ ethanol (Et, $\mathrm{n}=5$ ) or $0.9 \% \mathrm{NaCl}$ $(\mathrm{Na}, \mathrm{n}=3)$ at $22 \pm 1^{\circ} \mathrm{C}$ on Day 1 (DI) and Day 11 (D11) of the Box Protocol tolerance experiment.

On both days, mice receiving EtoH experienced a decline from preinjection $T_{i}$ after injection. The same is true for animals receiving $\mathrm{NaCl}$, although the decline was not so great as for the EtOH animals. In addition, a singular effect of repeated injection exposure is apparent in this figure. For both groups of mice, preinjection $T_{i}$ increased markedly from 
Day 1 to Day 11. Likewise, the curves representing postinjection responses on Day 11 are displaced substantially upwards from their Day 1 location for both the $\mathrm{NaCl}$ and $\mathrm{EtOH}$ animals.

In Figure 23 data are presented for all 11 days of this experiment, as mean 60 min postinjection $T_{i} \cdot$

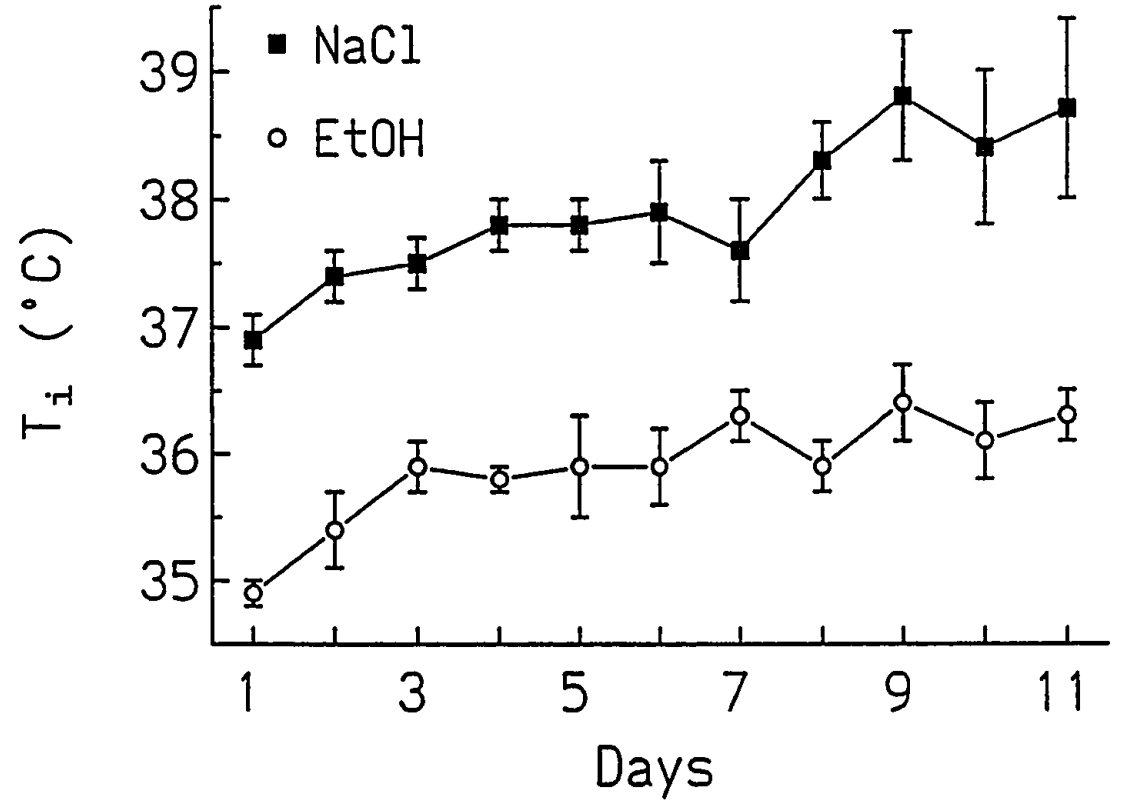

Figure 23. Temperature responses of HS mice to EtoH or NaCl on all eleven days of Box Protocol tolerance experiment. $T_{i}$ of $\mathrm{HS}$ mice (60 min mean \pm S.E.M.) after $2.75 \mathrm{~g} / \mathrm{kg}$ EtOH $(n=5)$ or $0.9 \% \mathrm{NaCl}$ $(n=3)$ at $22 \pm 1^{\circ} \mathrm{C}$ for all days of Box Protocol tolerance experiment.

Inspection of the curve for animals who received EtOH reveals that the degree of absolute $T_{i}$ decline after EtOH grew less through the course of the experiment. Although the attenuation in response to EtOH was not great (about $1^{\circ} \mathrm{C}$ ), this curve might be interpreted as evidence of chronic 
tolerance development in these animals. At the same time, however, $T_{i}$ response to $\mathrm{NaCl}$ rose at a similar rate. In addition, as is shown in Figure 22 , preinjection $T_{i}$ also rose substantially from Day 1 to Day 11 in both groups of animals.

To account for the rising preinjection baseline $T_{i}$ in both groups, the data from Figure 22 were replotted in Figure 24 as change from preinjection $T_{i}$.

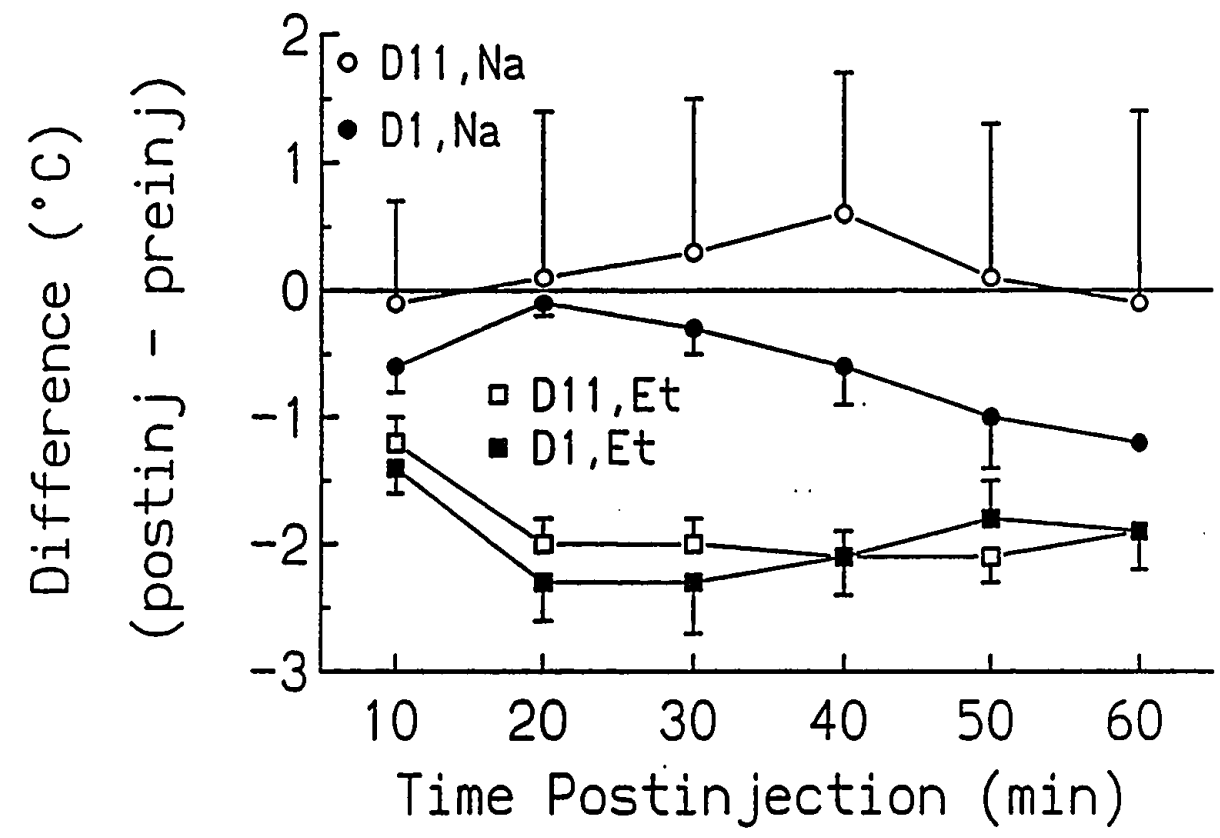

Figure 24. Change from preinjection temperature of HS mice after EtOH or NaCl on first and last days of Box Protocol tolerance experiment. For each individual, 10 min mean preinjection $T_{i}$ was subtracted from successive 10 min mean postinjection $T_{i}$ for $1 \mathrm{hr}$ after $2.75 \mathrm{~g} / \mathrm{kg}$ ethanol (Et, $n=5)$ or an equivalent volume of $0.9 \% \mathrm{NaCl}(\mathrm{Na}$, $n=3$ ) at $22 \pm 1^{\circ} \mathrm{C}$ on Day 1 (DI) and Day 11 (DII) of the Box Protocol tolerance experiment. Individual values summed to yield group mean \pm S.E.M.

When the rising baseline was taken into account, it appeared that the response to EtOH was essentially identical 
on Day 1 and Day 11. The response to NaCl seemed elevated on Day 11 over the response on Day 1.

For analysis of the effect of the entire 11 days of exposure to EtOH in the Box Protocol experiment, a 60 min mean postinjection change from preinjection $T_{i}$ was calculated for each individual. Group means are plotted in Figure 25.

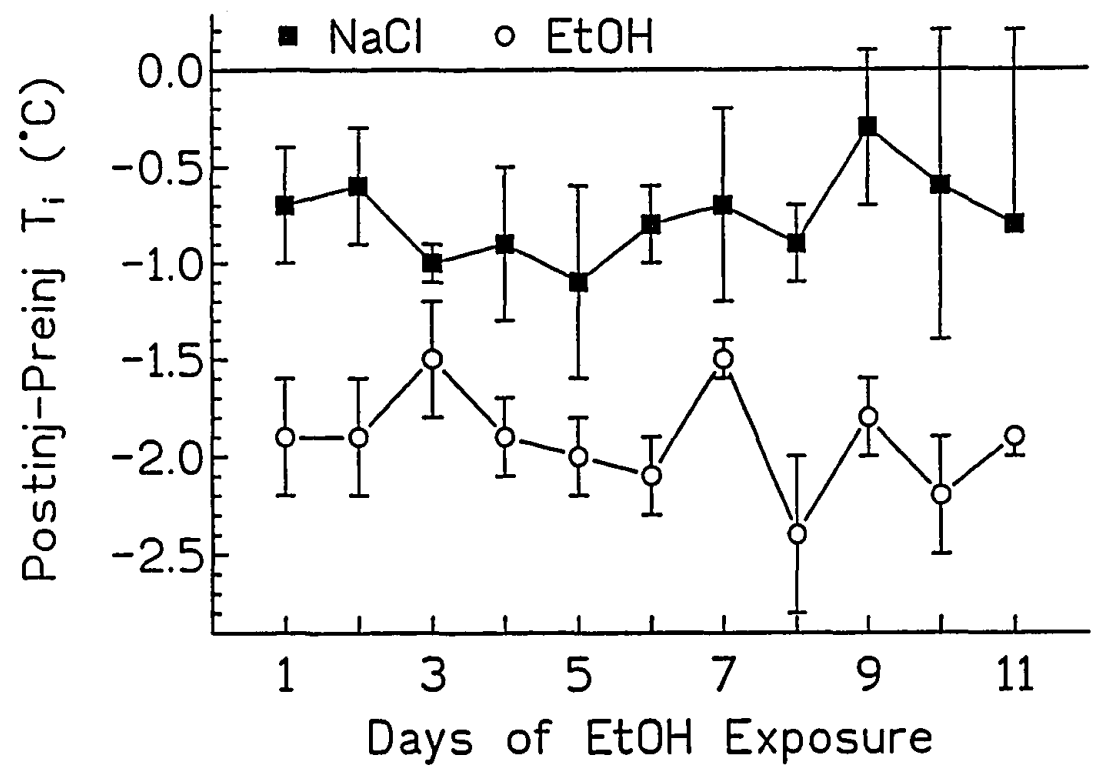

Figure 25. Change from preinjection temperature of HS mice after EtOH or $\mathrm{NaCl}$ on all eleven days of Box Protocol tolerance experiment. For each HS mouse on each day, mean 10 min preinjection $T_{i}$ was subtracted from successive 10 min mean postinjection $T_{i}$ after $2.75 \mathrm{~g} / \mathrm{kg}$ EtOH $(n=5)$ or $0.9 \%$ NaCl $(n=3)$ at $22 \pm 1^{\circ} \mathrm{C}$. Individual 10 min means were summed to a $60 \mathrm{~min}$ postinjection mean per individual, and these combined to yield group 60 min mean \pm S.E.M.

Repeated measures ANOVA reported a significant main effect of Drug $\left(F_{1,6}=20.21, \underline{2}<.005\right)$, but no significant effect of Time ( $p>.2)$ and no significant interaction. Thus, the statistical test confirms what can be observed by inspecting 
Figure 25. When rising preinjection temperature was taken into account, the amount of $T_{i}$ change after either $\mathrm{NaCl}$ or EtoH was negligible over the 11 days of this experiment.

On Day 11, BEC was measured in the Box Protocol animals. The results are shown at the bottom of Table III. Although the BEC appears slightly higher on Day 11 in the Box, than in the Mixed Protocol mice, ANOVA detected no significant difference between the 2 Protocols in Day 11 BEC (p >.1). Although the effect of Time on BEC was highly significant $\left(F_{2,24}=345.4, \underline{p}<.0001\right)$, there was no significant Protocol $x$ Time interaction ( $p>1$ ).

Every mouse was weighed on the day of mini-mitter implantation surgery and on every experimental day. No difference was detected using ANOVA in the amount of weight lost between implantation surgery and experimental Day 1 among mice receiving $\mathrm{NaCl}$ or EtOH in the Mixed, Behavior and Box Protocol groups $(n=33, p>.1)$, although the weight lost between surgery day and experimental Day 1 was significant ( $p<.0001$, loss $=4.2 \pm .7 \%$ ). Repeated measures ANOVA found no significant differences among the 3 Protocol groups ( $p>.1$ ) or between the animals given injections of $\mathrm{NaCl}$ or $\mathrm{EtOH}(p>.1)$ when the first 4 days of all 3 Protocols were compared. Figure 26 presents the percent weight change over 11 days of experimentation for mice in the Mixed and Box Protocols only. When these 25 animals were compared over the entire 11 days of the experiment, ANOVA reported no significant difference between 
the Protocols ( $p>$. 7), or between animals treated with EtOH and those treated with $\mathrm{NaCl}(p>.1)$. The interactions were likewise not significant ( $\mathrm{Q} \geq 3$ for all interactions).

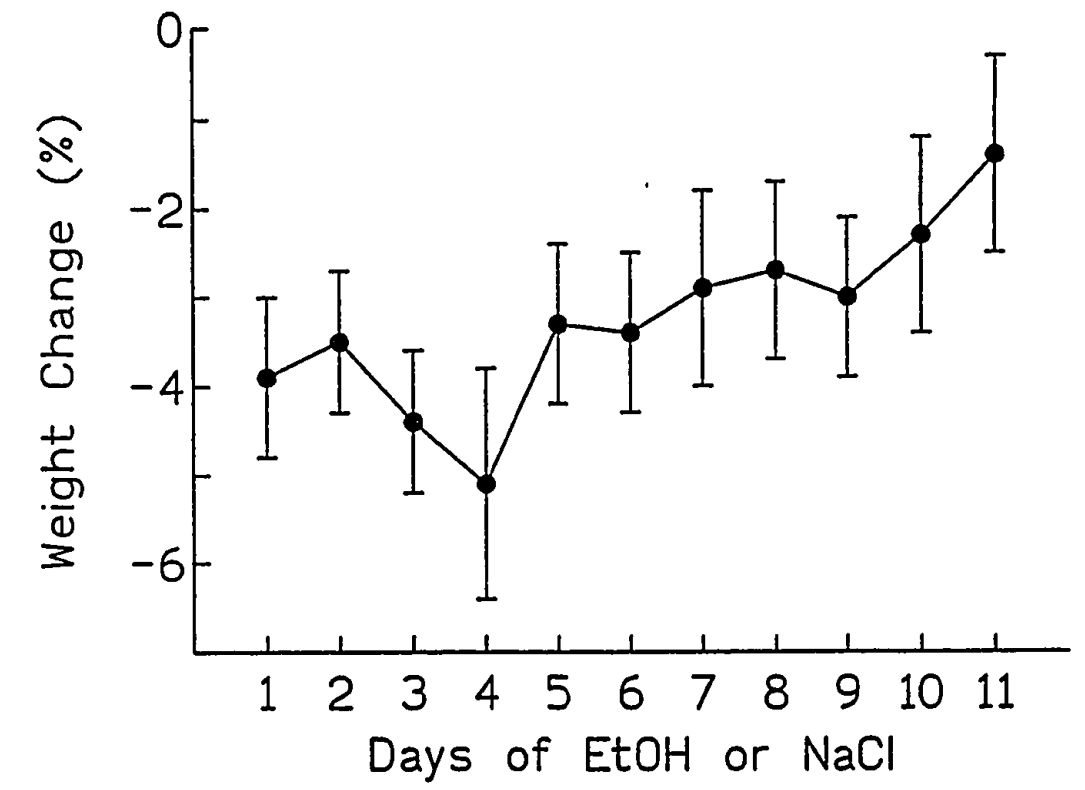

Figure 26. Body weight changes of HS mice in tolerance experiments. Percent weight change (mean \pm S.E.M.) from presurgery (mini-mitter implantation) weight for HS mice on all 11 days of Mixed and Box Protocol tolerance experiments. ANOVA detected no significant effect of Protocol or Drug on weight change, so data from all mice were combined for this figure $(n=25)$.

Because there was no difference between Protocols or treatments, the results from all mice have been grouped for Figure 26. On Day 1 of the experimental regimen, the mice had not regained the weight lost after surgery. After a slight gain, they experienced an additional loss of weight from Day 2 to Day 4 of the tolerance regimen, then gained weight steadily for the remainder of the experiment. Although visual inspection of this curve appears to reveal an effect of time, 
in fact ANOVA reported that the factor Time was not significant $(p>.3)$. When the Behavior Protocol mice were included for the analysis of the first 4 days only (data not shown), Time was likewise not significant $(p>.1)$. The lack of significance of the factor Time is probably due to the large standard errors associated with this weight change data.

THERMOREGULATION DURING WITHDRAWAL FROM ETHANOL DEPENDENCY IN GENETICALLY HETEROGENEOUS MICE

Figure 27 shows the mean $T_{i}$ (top panel), $T_{\text {sel }}$ (middle panel) and activity (bottom panel) for genetically heterogeneous mice withdrawing from EtOH dependency, and for pyrazole and $\mathrm{NaCl}$ control mice, in the temperature gradient tubes from 2.5 to 26 hrs after removal from the EtoH dependency-induction vapor chambers. For all 3 groups, $T_{i}$ was quite similar for the time in the gradient, except for a few hours beginning about $10 \mathrm{hrs}$ postwithdrawal. This time corresponded to lights-out time for these mice during their experience in the vapor chamber at the VA $(1800 \mathrm{hr})$, and was $0.5 \mathrm{hr}$ prior to lights-out in the Portland State University animal room (1830), where they had long been housed. In contrast, $\mathrm{T}_{\text {sel }}$ of the withdrawing mice was clearly lower than that of the other groups for at least 16 hrs post-withdrawal, and remained slightly lower for the entire time in the gradient. 

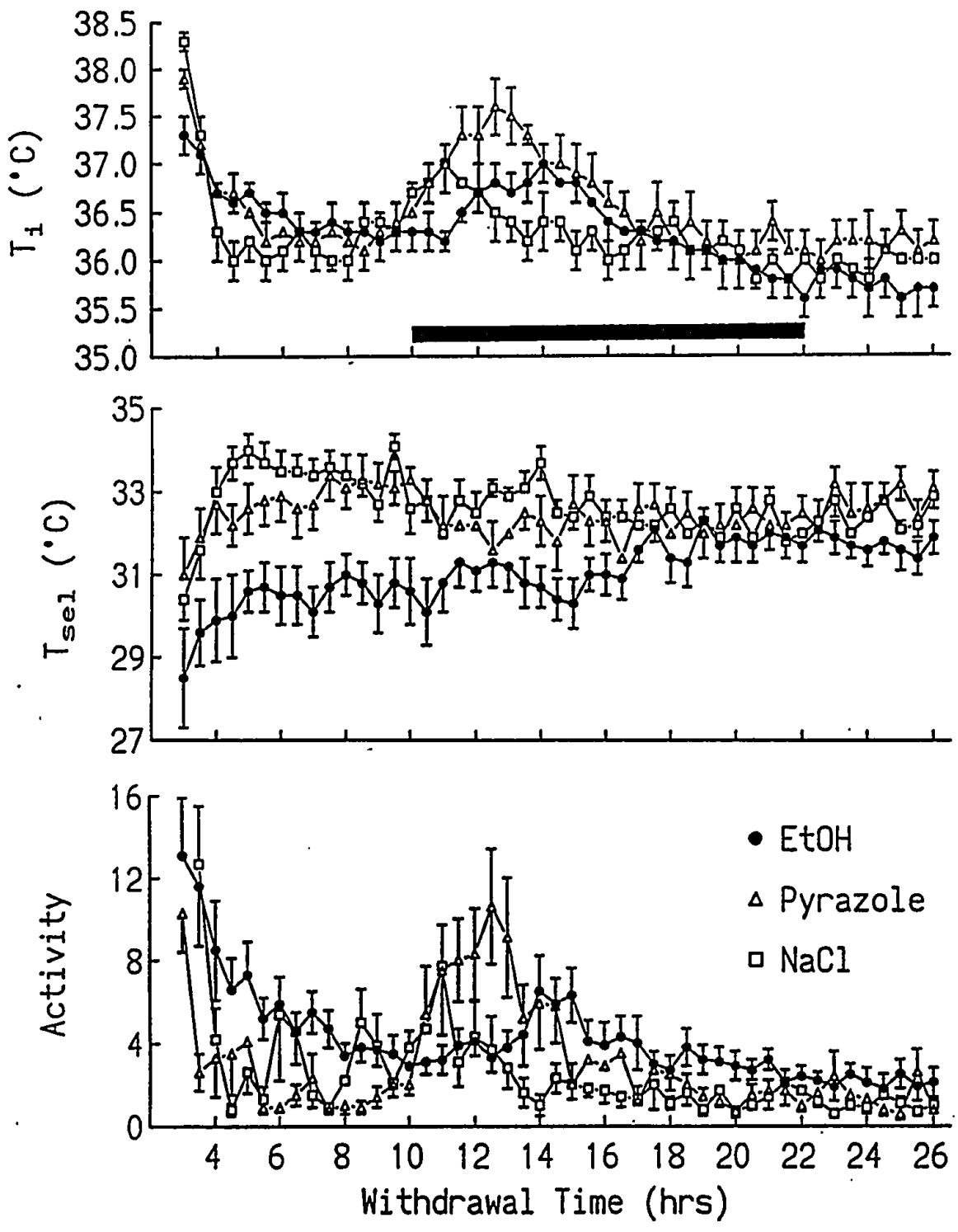

Figure 27. Thermoregulation and activity of HS mice during withdrawal from EtOH dependency in a temperature gradient. 30 min mean \pm S.E.M. $T_{i}$ (top), $T_{\text {sel }}$ (middle) and activity $(\mathrm{cm} / 10 \mathrm{sec}), 3.5-26 \mathrm{hrs}$ postwithdrawal after 3 days of EtOH vapor + pyrazole (EtoH, $n=11$ ), pyrazole $(n=9)$, or Nacl $(n=8)$. Bar shows normal lights-out; light level in gradient did not change during withdrawal.

Activity of the withdrawing mice was, in general, slightly higher than that of the control groups, except for 
the mid-withdrawal time period, when both activity and $T_{i}$ of the control mice exceeded that of the withdrawing mice. However, even when the withdrawing mice were substantially less active than the control mice (about 10 to $14 \mathrm{hrs}$ postwithdrawal), the withdrawing mice continued to prefer lower temperatures than did the control animals. For data analysis, a mean of each variable was calculated for each individual over the 4 to $10 \mathrm{hr}$ postwithdrawal period, and individual values combined to yield a grand mean for each of the 3 treatment groups. Those grand means are presented in Table IV.

TABLE IV

$$
T_{i}, T_{\text {sel }} \text { AND ACTIVITY IN WITHDRAWING HS MICE }
$$$$
\text { (4-10 hrs postwithdrawal) }
$$

\begin{tabular}{lrrrr} 
Group & $\mathrm{n}$ & $\mathrm{T}_{\mathbf{i}},{ }^{\circ} \mathrm{C}$ & $\mathrm{T}_{\text {sel }},{ }^{\circ} \mathrm{C}$ & Act, $\mathrm{Cm} / 10 \mathrm{~s}$ \\
\hline EtoH withdrawal & 11 & $36.4 \pm .1$ & $30.5 \pm .5$ & $5.2 \pm .8$ \\
Pyrazole control & 9 & $36.3 \pm .2$ & $32.9 \pm .5$ & $1.7 \pm .3$ \\
Nacl control & 8 & $36.2 \pm .1$ & $33.5 \pm .3$ & $2.9 \pm .5$
\end{tabular}

A significant difference in Activity among the 3 groups for the 4-10 hr postwithdrawal period was revealed by ANOVA $\left(F_{2,25}=8.97, \underline{p}<.05\right)$; the EtoH withdrawal group was significantly $(\alpha=.05)$ more active than either of the 2 control groups, which were not different from each other. Because activity affects heat production, and therefore potentially each of the other variables measured in this experiment, the other variables were examined utilizing the ANCOVA protocol, 
with Activity as covariate. No significant effect of activity on $T_{i}$ was reported by ANCOVA ( $\left.p>0.3\right)$, while ANOVA found no significant differences between the 3 groups in $T_{i}(p>0.3)$. Indeed, as Table IV shows, the $T_{i}$ values for the 3 treatment groups were nearly identical. However ANCOVA revealed a significant effect of the covariate Activity upon $T_{\text {set }}$ $\left(F_{1,24}=5.04, \underline{p}<.05\right)$ and a significant Drug effect on $T_{\text {sel }}$ also $\left(F_{2,24}=6.23\right.$, p<.01). During the 4 to $10 \mathrm{hr}$ postwithdrawal period, temperatures selected by the withdrawing animals were significantly lower than those selected by the control groups, as is shown in Table IV.

The temperature responses of the 4 mice whose exposure to EtoH began and ended at $0300 \mathrm{hr}, 5 \mathrm{hrs}$ earlier than the other EtoH withdrawal mice discussed above, are presented in Figure 28. The usual lights-out time for these animals is indicated by the dark bar. These mice entered their evening active phase at a later stage of the withdrawal process. During the 10-16 hr postwithdrawal period, the period during which $\mathbf{T}_{\mathbf{i}}$ did not remain stable in the groups of mice discussed above, this latter group of animals showed no major changes in $T_{i}$.

Rectal temperature data collected from the 3 groups of mice maintained at $29.5^{\circ} \mathrm{C}$ throughout both induction of and withdrawal from EtOH dependence are presented in Table $V$. Temperatures were not different among the groups before induction (Initial Induction: $\mathrm{p}>.8$ ), nor at 12 hrs postwithdrawal $(p>.6)$. There was however a highly significant 

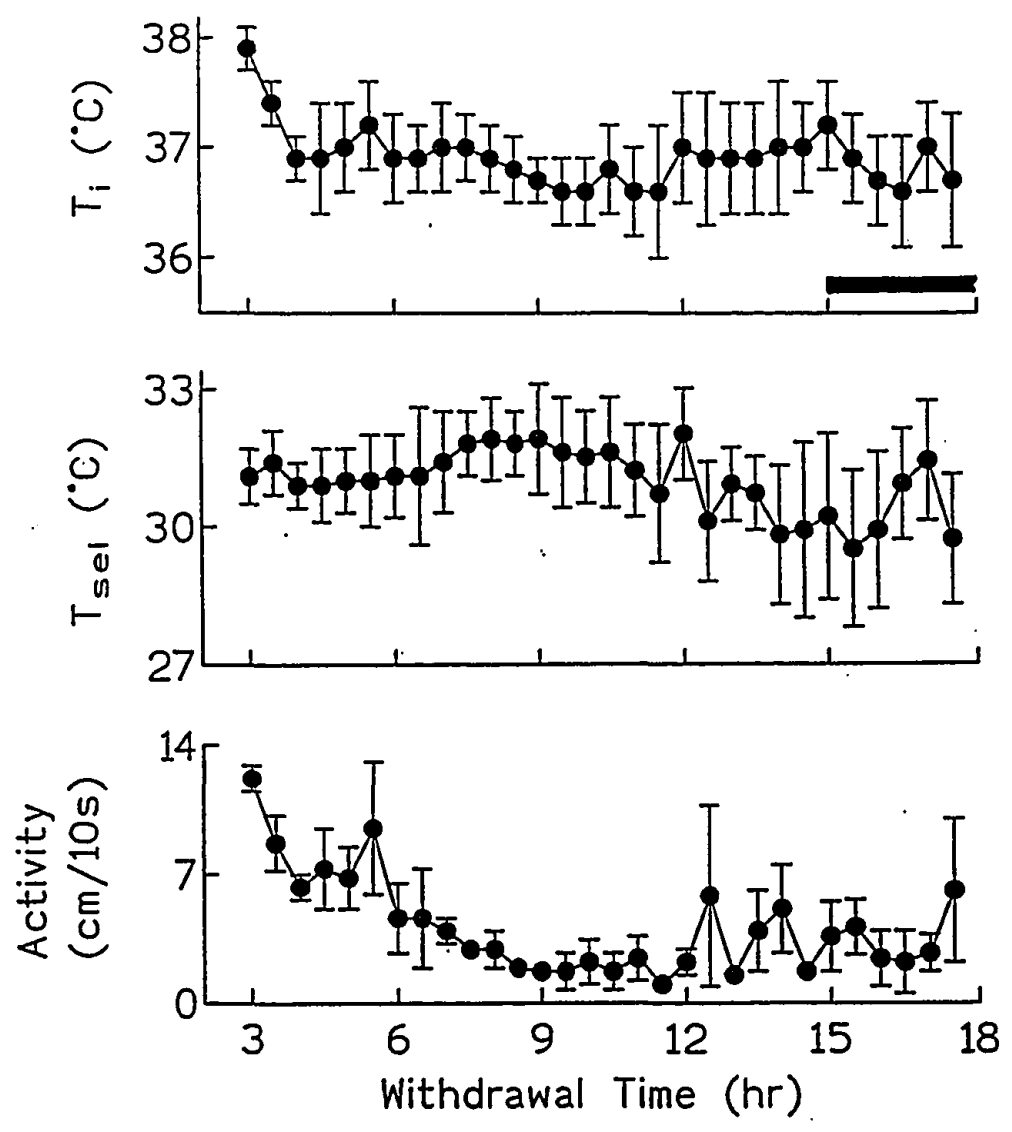

Figure 28. Thermoregulation and activity of HS mice during withdrawal from EtOH dependency begun at $0300 \mathrm{hr}$ in a temperature gradient. $30 \mathrm{~min}$ mean \pm S.E.M. $T_{i}$, (top), $T_{\text {sel }}$ (middle) and activity (cm/10 sec, bottom) of HS mice for 3-18 hrs postwithdrawal after 3 days of EtOH vapor + pyrazole $(n=4)$. Bar shows normal lights-out; light level in gradient did not change during withdrawal period.

difference on Day 4 when animals were removed from the vapor chamber (Initial withdrawal: $F_{2,27}=22.03, \underline{p}<.0001$ ); $T_{i}$ for the animals in the NaCl group was significantly $(\alpha=.05)$ higher than $T_{i}$ of the other 2 groups. During induction of dependency (Day 1, Day 2 and Day 3) ANOVA with repeated measures found a significant effect of Drug (EtOH, pyrazole or NaCl) 
TABLE V

BODY TEMPERATURES DURING INDUCTION OF AND WITHDRAWAL FROM ETHANOL DEPENDENCY AT CONSTANT AMBIENT TEMPERATURE

$\left({ }^{\circ} \mathrm{C} \pm\right.$ S.E.M.; $\mathrm{n}=10$ for each group)

Induction

\begin{tabular}{lllll} 
Group & Initial & Day $1^{\circ}$ & Day 2 & Day 3 \\
\hline Ethanol & $38.8 \pm 0.1$ & $37.2 \pm 0.1$ & $37.0 \pm 0.1$ & $36.8 \pm 0.1$ \\
Pyrazole & $38.9 \pm 0.1$ & $37.3 \pm 0.2$ & $36.9 \pm 0.1$ & $36.9 \pm 0.2$ \\
NaCl & $38.7 \pm 0.2$ & $38.3 \pm 0.2$ & $38.2 \pm 0.1$ & $38.5 \pm 0.1$
\end{tabular}

Withdrawal

Group Initial Period of Hour 12 Max Withdrawal ${ }^{b} \quad$ Postwithdrawal

$\begin{array}{llll}\text { Ethanol } & 36.7 \pm 0.1 & 37.0 \pm 0.1 & 37.0 \pm 0.2 \\ \text { Pyrazole } & 36.6 \pm 0.2 & 36.4 \pm 0.1 & 36.9 \pm 0.2 \\ \text { NaCl } & 38.1 \pm 0.2 & 36.6 \pm 0.2 & 36.8 \pm 0.1\end{array}$

${ }^{8}$ Days 1, 2 and 3 reflect the grand mean of measurements taken at 0800, 1100, 1600 and 2000 hrs

Mean of measurements taken 4, 6 and 8 hrs after removal from EtOH vapor.

$\left(F_{2,27}=3.49, \underline{p}<.05\right)$, a significant effect of Time $\left(F_{2,54}=127.56\right.$, p<.0001), and a significant Drug $x$ Time interaction $\left(F_{4,54}=6.72, \underline{p}<.0005\right)$. Throughout the 3 days of induction both EtOH and pyrazole mice showed a trend towards decreasing $T_{i}$, whereas NaCl mice maintained $T_{i}$ higher than either of the other 2 groups, and in fact were even warmer on Day 3 than on Day 1 (hence the main effects interaction). During the period of anticipated maximum withdrawal severity, however, ANOVA detected no significant temperature difference among the groups ( $p>.1)$. 
The drive of mice to dissipate heat, characterized as $\left(T_{i}-T_{s e l}\right)$, is presented in Figure 29 for all mice monitored in the gradient during withdrawal.

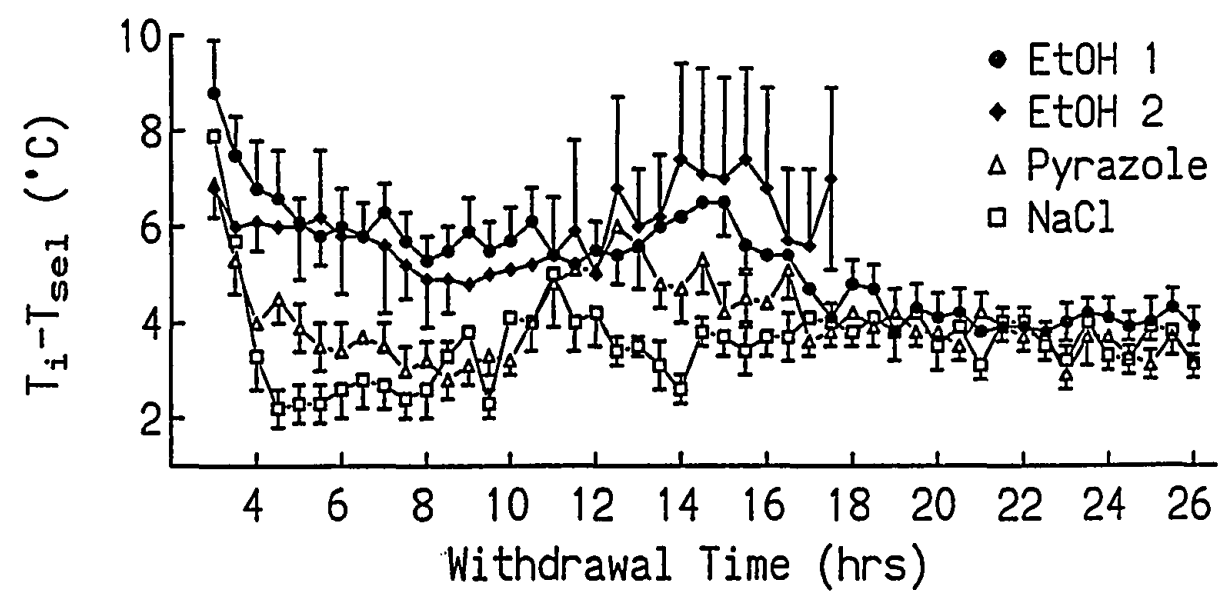

Figure 29. Drive of HS mice to dissipate heat during withdrawal from EtOH dependency in a temperature gradient. 30 min mean \pm S.E.M. $T_{i}-T_{\text {sel }}$ of HS mice in withdrawal after 3 days of EtoH vapor + pyrazole begun at 0800 (EtOH $1, n=11$ ), EtOH + pyrazole begun at 0300 (EtOH 2, $n=4$ ), or after control pyrazole $(n=9)$ or $\mathrm{NaCl}(n=8)$ injections.

For the 4-10 hr postwithdrawal period, mean values calculated for mice withdrawing from EtOH dependency $\left(5.9 \pm 0.5^{\circ} \mathrm{C}\right)$ were compared with the pyrazole $\left(3.5 \pm 0.4^{\circ} \mathrm{C}\right)$ and $\mathrm{NaCl}\left(2.7 \pm 0.3^{\circ} \mathrm{C}\right)$ control groups using ANCOVA with Activity as covariate. A significant effect of Activity $\left(F_{1,24}=8.55\right.$, $\underline{p}<.01$ ) and a significant difference between the Drug groups $\left(F_{2,24}=8.79, \underline{p}<.005\right)$ were detected. Withdrawing EtoH mice showed a significantly $(\alpha=.05)$ higher drive for heat dissipation (as estimated by the difference between $T_{i}$ and $T_{\text {sel }}$ ) than did mice in either of the control groups. 
Figure 30 illustrates the diminishing difference over time between EtOH and control animals in their drive to dissipate heat.

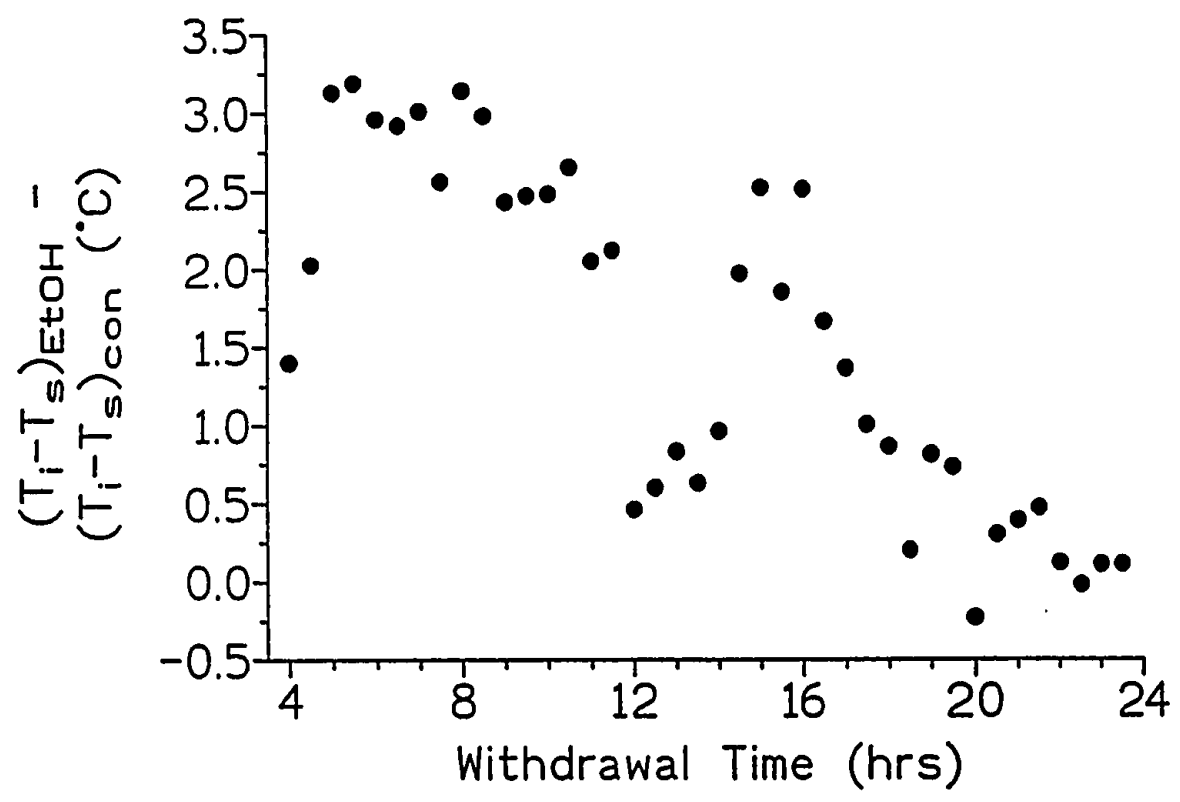

Figure 30. Difference between withdrawing and control HS mice in drive to dissipate heat in a temperature gradient. Mean of 26-hr EtoH withdrawal group $(n=11)$ minus mean of combined pyrazole and Nacl control groups (con, $n=17$ ), at 30 min intervals, as a function of withdrawal time.

For this figure, each successive $0.5 \mathrm{hr}$ mean $\left(\mathrm{T}_{i}-\mathrm{T}_{\text {sel }}\right)$ value for the combined control groups was subtracted from the mean of the witharawing mice for the same time period. Except for the period of heightened activity and varying $T_{i}$ already discussed, the difference between control and experimental animals decreased in a linear manner over the course of the monitoring period. 
For all mice that experienced withdrawal in the temperature gradient, the mean BEC at the time of removal from the vapor chamber at the initiation of withdrawal was $1.5 \pm$ $0.1 \mathrm{mg} / \mathrm{ml}$.

THERMOREGULATION DURING WITHDRAWAL FROM ETHANOL DEPENDENCY IN SELECTED LINES OF MICE

Table VI presents a summary of the responses of the selected lines of mice during withdrawal from EtoH dependency, and of similar pyrazole control mice.

TABLE VI

RESPONSES OF SELECTED LINES, 4-10 HRS POSTWITHDRAWAL ( $n=9 /$ genotype/condition)

\begin{tabular}{|c|c|c|c|c|}
\hline Condition & HOT1 & $\begin{array}{l}\text { Gen } \\
\text { COLD1 }\end{array}$ & НОТ2 & COLD2 \\
\hline $\begin{array}{l}\mathrm{T}_{\mathbf{i}}\left({ }^{\circ} \mathrm{C}\right) \\
\text { EtoH } \\
\text { Pyrazole }\end{array}$ & $\begin{array}{l}36.3 \pm .2 \\
36.1 \pm .2\end{array}$ & $\begin{array}{l}36.0 \pm .2 \\
36.0 \pm .1\end{array}$ & $\begin{array}{l}36.5 \pm .2 \\
35.4 \pm .2\end{array}$ & $\begin{array}{l}35.8 \pm .2 \\
35.6 \pm .2\end{array}$ \\
\hline 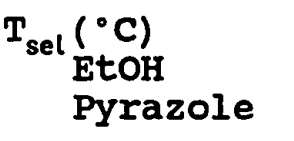 & $\begin{array}{l}31.3 \pm .2 \\
31.1 \pm .3\end{array}$ & $\begin{array}{l}30.6 \pm .4 \\
31.4 \pm .1\end{array}$ & $\begin{array}{l}29.8 \pm .6 \\
31.2 \pm .2\end{array}$ & $\begin{array}{l}30.9 \pm .4 \\
31.8 \pm .2\end{array}$ \\
\hline $\begin{array}{c}\mathrm{T}_{\mathbf{i}}-\mathrm{T}_{\text {sel }}\left({ }^{\circ} \mathrm{C}\right) \\
\text { EtoH } \\
\text { Pyrazole }\end{array}$ & $\begin{array}{l}5.0 \pm .4 \\
5.0 \pm .4\end{array}$ & $\begin{array}{l}5.4 \pm .5 \\
4.6 \pm .2\end{array}$ & $\begin{array}{l}6.6 \pm .6 \\
4.1 \pm .1\end{array}$ & $\begin{array}{l}5.0 \pm .4 \\
3.8 \pm .3\end{array}$ \\
\hline $\begin{array}{c}\text { Act }(\mathrm{cm} / 10 \mathrm{sec} \\
\text { EtoH } \\
\text { Pyrazole }\end{array}$ & $\begin{array}{l}3.4 \pm .6 \\
7.0 \pm 3.0\end{array}$ & $\begin{array}{l}3.5 \pm .7 \\
3.1 \pm .8\end{array}$ & $\begin{array}{l}3.4 \pm .4 \\
1.8 \pm .2\end{array}$ & $\begin{array}{l}3.1 \pm .4 \\
2.4 \pm .4\end{array}$ \\
\hline
\end{tabular}

For the variables presented in Table VI, a mean was generated for each individual for the 4 - $10 \mathrm{hr}$ postwithdrawal 
time period of anticipated maximum withdrawal severity, and means combined to yield grand means for each genotype under each condition. Initial ANOVA on activity showed a significant effect of Replicate $\left(F_{1,64}=4.19, p<.05\right)$, but no significant effect of Line (p>.2) and no significant interactions. (At $\mathrm{p}=.077$ the Drug $\mathrm{x}$ Replicate interaction approached, but did not achieve significance.)

It is apparent from Table VI that 1 genotype differed from the others in this measure; the very high level of activity by the HOTl pyrazole control mice was likely responsible for the statistical significance of the factor Replicate in this initial analysis. The other 3 genotypes showed increased activity under the EtOH withdrawal condition. This result is similar to that obtained from the withdrawal experiments involving the genetically heterogeneous mice (ref. Table IV).

similar to the analysis of results from the genetically heterogeneous mice, because of the effect of activity on heat production and $T_{i}$, further analysis of the variables was performed using ANCOVA, with activity as covariate. A significant effect of Activity on $T_{i}\left(F_{1,63}=5.46, p<.03\right)$, a significant difference in $T_{i}$ between Drug groups $\left(F_{1,63}=9.86\right.$, $\underline{p}<.01)$, and a significant Line $x$ Drug interaction $\left(F_{1,63}=6.39, p<.02\right)$ was reported by ANCOVA. The main effect of Line was not significant $(p>.1)$; the main effect of Replicate approached, but did not achieve significance $(p=.058)$. The $T_{i}$ 
of HOT1, COLD1 and COLD2 mice was similar in the EtOH and pyrazole groups, in agreement with the results for genetically heterogeneous mice. Again a single genotype exhibited a different response; the $T_{i}$ of HOT2 mice withdrawing from EtOH was substantially above that of the HOT2 pyrazole control animals. Table VI also reveals a tendency for coLD2 withdrawing mice to maintain $T_{i}$ slightly above that of colD2 pyrazole mice, while COLDl mice show identical $T_{i}$ under the 2 conditions. In consequence ANCOVA detected, not only a significant main effect of Drug on $T_{i}$ (EtoH > pyrazole), but also a significant Line $x$ Drug interaction.

A significant effect of the covariate Activity on $T_{\text {sel }}$ was reported by ANCOVA $\left(F_{1,63}=5.64, \underline{p}<.03\right)$, as well as a significant difference in $T_{\text {sel }}$ between Drug groups $\left(F_{1,63}=12.36\right.$, p<.001), and a significant Line $\mathrm{x}$ Replicate interaction $\left(F_{1,63}=7.01, p<.02\right)$. The other main effects and interactions neither achieved, nor approached significance ( $p>.15$ for all tests). The COLD1, HOT2 and COLD2 mice withdrawing from EtOH, like their genetically heterogeneous cousins, preferred a significantly cooler environment than did similar pyrazole control animals. Withdrawing HOT1 mice, however, selected slightly higher temperatures than HOTl control animals. This difference in the HOTI mice was detected in the significant Line $\mathrm{X}$ Replicate interaction. The significance of this interaction indicates that the temperature response of the selected lines (HOT or COLD) depended upon which replicate 
they belonged to. COLDl mice selected slightly lower ambient temperatures overall than did HOTl mice. The reverse is seen in the Replicate 2 pair, where the COLD2 mice selected higher temperatures overall than did the HOT2 mice. The foundation of this difference, of course, is the similar $T_{\text {sel }}$ in HOTI withdrawing and control mice.

Analysis using ANCOVA detected a significant effect of Activity on the drive of the animals to dissipate heat, characterized as $\left(\mathrm{T}_{\mathrm{i}}-\mathrm{T}_{\mathrm{sel}}\right)\left(\mathrm{F}_{1,63}=10.37, \mathrm{Q}<.003\right)$. The main effect of Drug on $\left(T_{i}-T_{s e l}\right)$ was highly significant $\left(F_{1,63}=21.54\right.$, p<.0001). Clearly (Table VI), COLD1, HOT1 and COLD2 mice undergoing withdrawal showed a substantially increased drive to dissipate heat, compared to similar pyrazole control mice. This result is in agreement with the results obtained from withdrawal experiments with genetically heterogeneous mice previously considered. The effect in these 3 genotypes was large enough to propel the overall factor to statistical significance, despite the lack of any difference in $\left(T_{i}-T_{s e l}\right)$ between HOTI withdrawing and control animals.

There was no significant main effect on $\left(T_{i}-T_{s e l}\right)$ of Line (p>.1) or Replicate (p>.8), and no significant Line $x$ Drug interaction $(p>.3)$. However the Line $x$ Replicate $\left(F_{1,63}=6.27\right.$, $\underline{p}<.02)$ and Replicate $X$ Drug $\left(F_{1,63}=4.11, \underline{p}<.05\right)$ interactions achieved significance in the ANCOVA test. Although both Replicate 1 and Replicate 2 withdrawing mice showed a greater $\left(T_{i}-T_{s e l}\right)$ than did similar controls, the difference between the 
Drug conditions was far less for Replicate 1. This was due to the lack of any difference under different drug conditions for the HOTl mice, and was the source of the significant Replicate $x$ Drug interaction. The significant Line $x$ Replicate interaction arose from the fact that the HOT2 mice showed a higher $\left(T_{i}-T_{\text {sel }}\right)$ than did the HOTI mice, while the COLD replicates are opposite in response (COLD1 higher than COLD2). Detailed responses of all genotypes during withdrawal in the temperature gradient are presented separately in Figure 31 (COLD1 mice), Figure 32 (COLD2 mice), Figure 33 (HOT1 mice) and Figure 34 (HOT2 mice). Each figure shows $T_{i}$ in the upper left panel, $T_{\text {sel }}$ at the bottom left, $\left(T_{i}-T_{\text {sel }}\right)$ (drive to dissipate heat) at the upper right, and activity in the lower right panel as $0.5 \mathrm{hr}$ means for withdrawing and pyrazole control mice, 3 through $14 \mathrm{hrs}$ postwithdrawal.

Generally the responses of COLD1 and COLD2 mice were similar to each other, and to responses of the genetically heterogeneous mice during withdrawal. For the course of the monitoring period, $T_{i}$ and activity of withdrawing and control COLD1 and COLD2 mice were alike (Figures 31 and 32). However withdrawing COLD mice selected cooler temperatures to maintain a given $T_{i}$, than similar control mice did. This is reflected in the higher $\left(T_{i}-T_{\text {sel }}\right)$ shown for both COLD1 and COLD2 withdrawing mice, relative to similar controls.

HOTI withdrawing mice (Figure 33) inaintained $T_{i}$ similar to, or slightly above that of control HоTl mice, much like the 

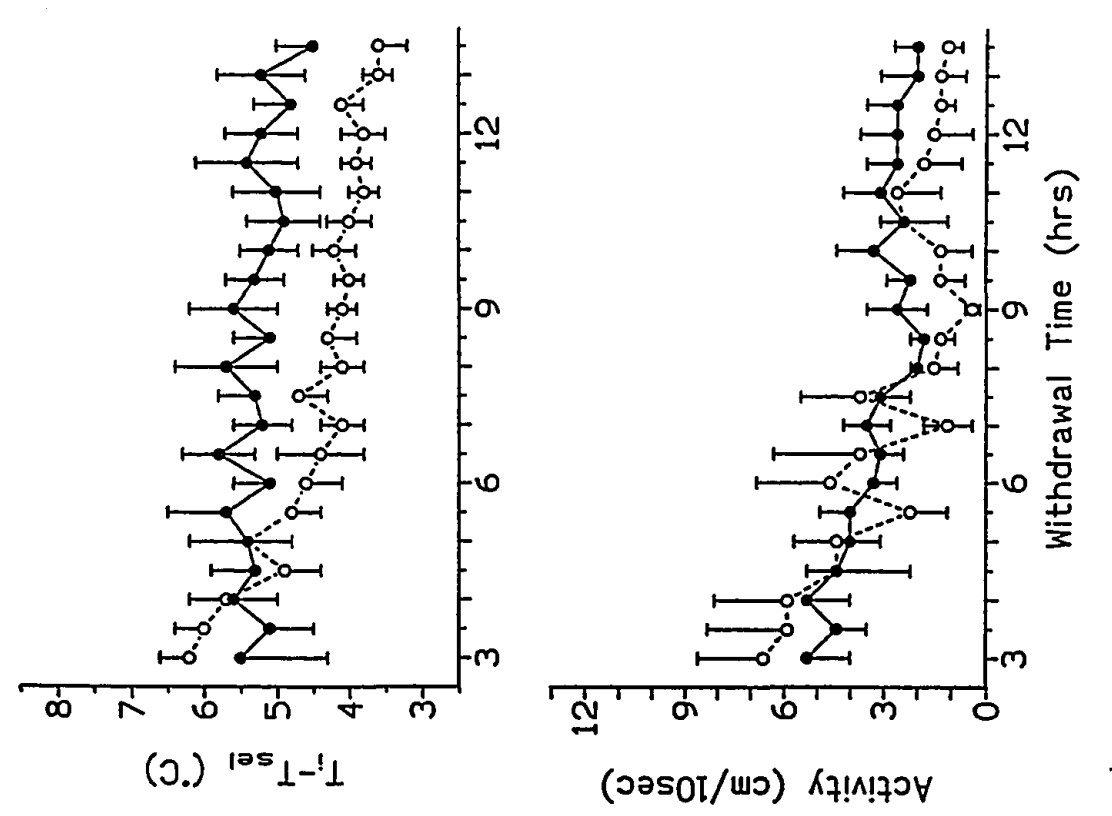

탕걱염

फ्ये

ॠू

o 0 过

대엄

总

if क्स

3 出

的岳

in

है ह ह

$0+1$ 望苛

동요

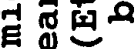

त田满

(อ.) ${ }^{\text {las }} 1-!$

옹동

O

0 म्प Eक

0 '

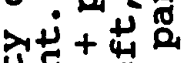

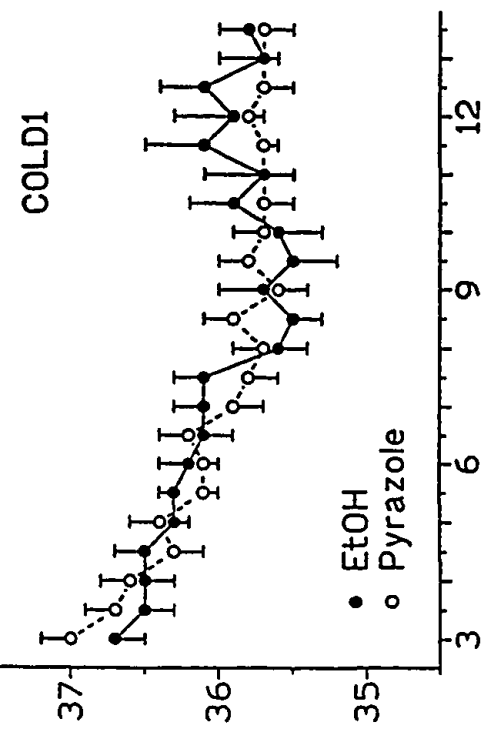

(ว.) !

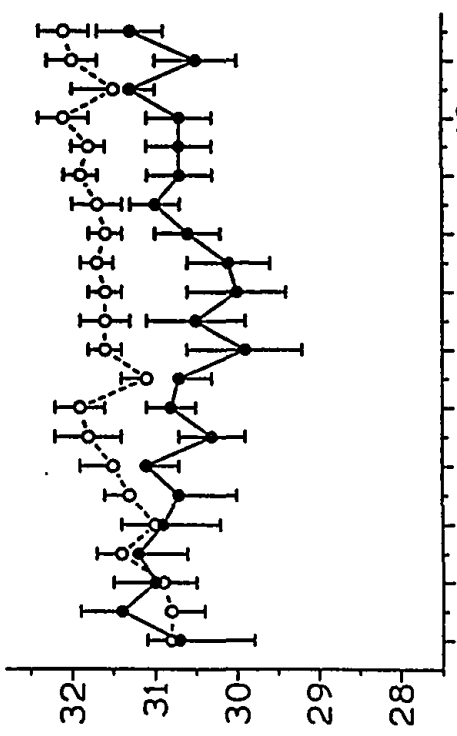

(ว.) ${ }^{10 s} 1$

$\rightarrow 0$

궁요

点

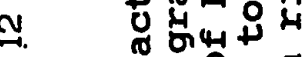

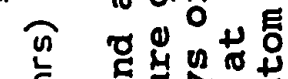

选

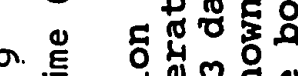

i

उ

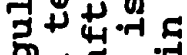

कुष

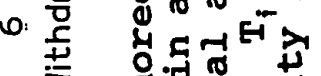

芝

द्व

起骂望

ơ

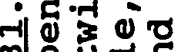

过年

ข.

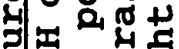

붕 थ पू

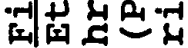




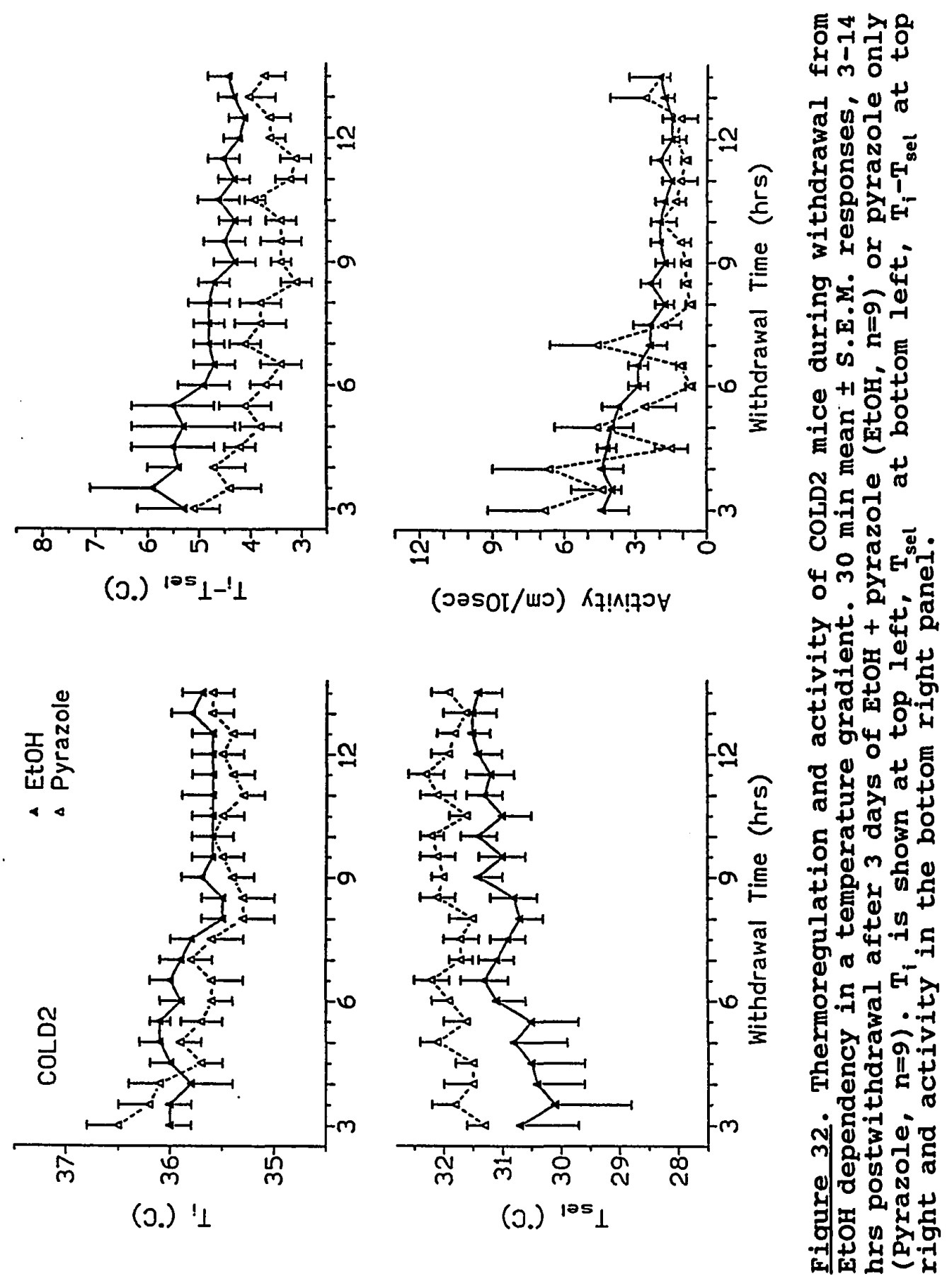



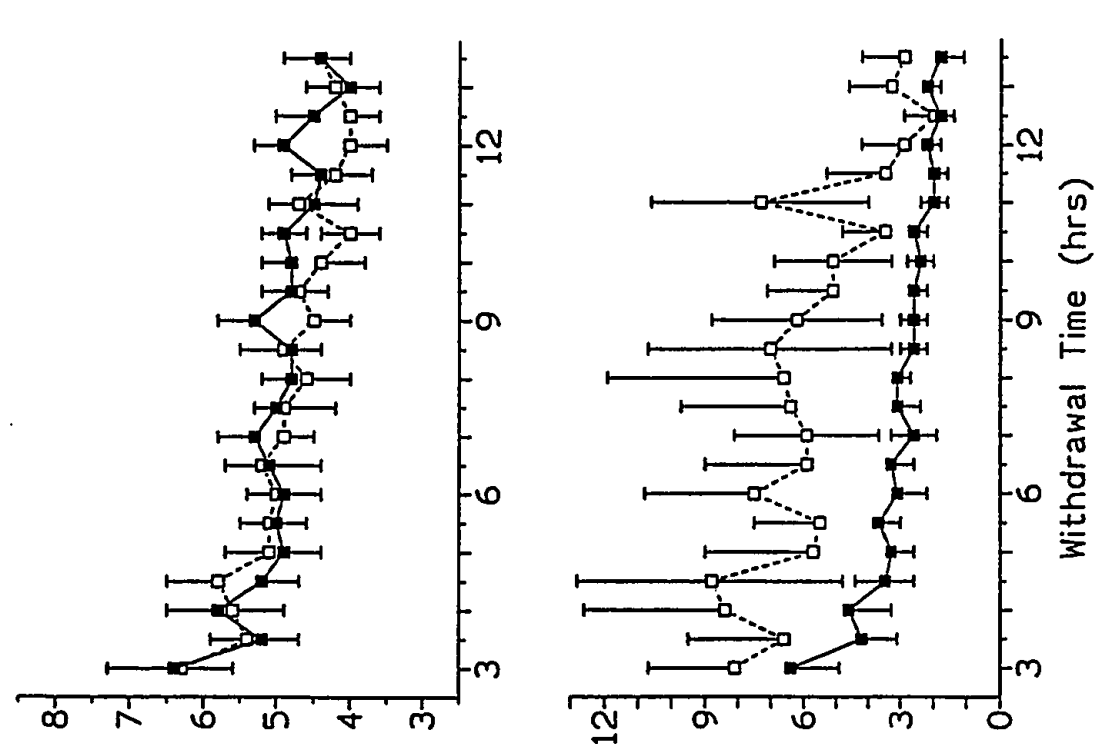

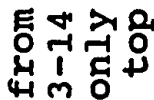

$-10$

3 o

द्व

농영타

문

\$ 员可

34 म

क्टि

年

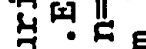

ช。

d +1 至

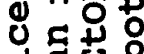

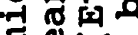

E苗

도도엄

(ว.) ${ }^{105} 1-!$

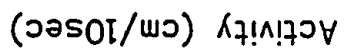

正

山잉 प्रें

. व

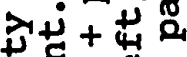

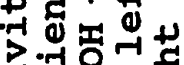

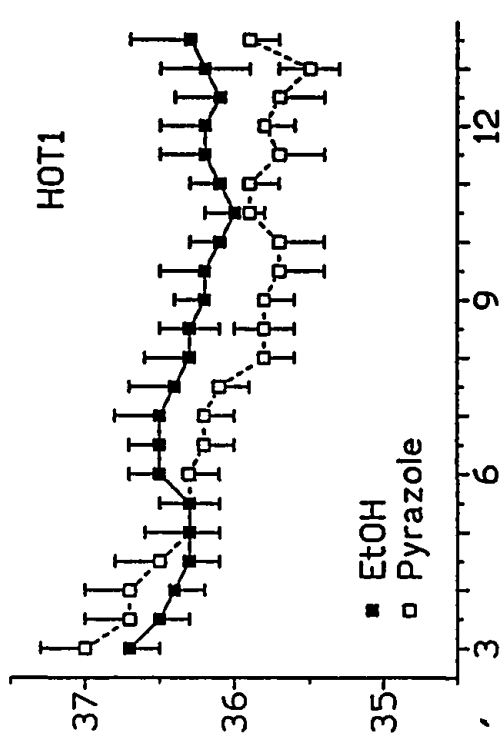

(0.) ! 1

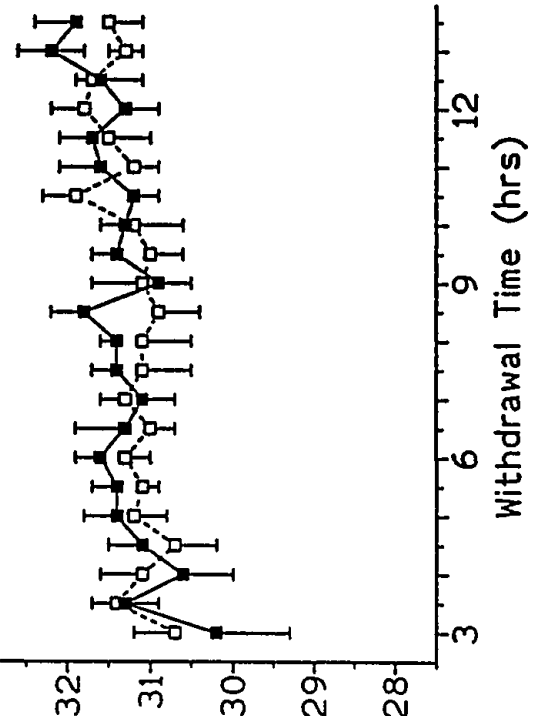

(ว.) ${ }^{10 s} \perp$

- 항

Uु

$00^{\circ}+$ 目

द्व

平通

ᄃ 0

势的岳

园

7 正

का

मू द्व

舟范

प्ष

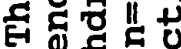

.

लंख

m.

o) 0 \%

40

경

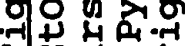

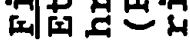




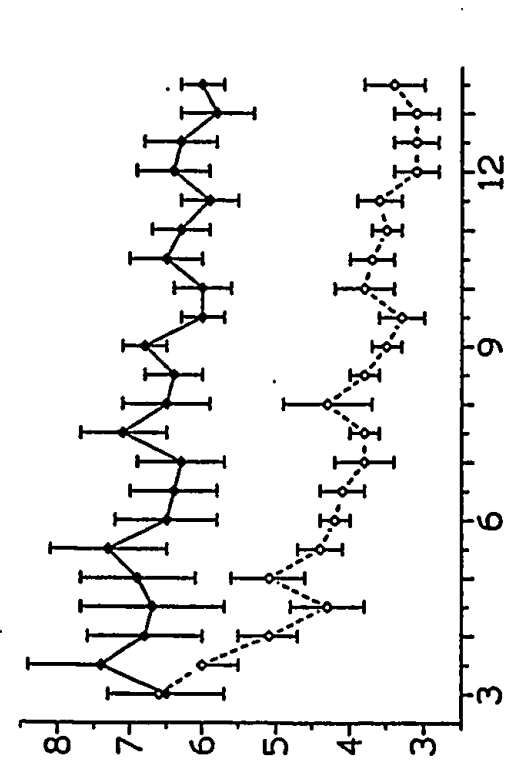

(ว.) ${ }^{105} 1-!$

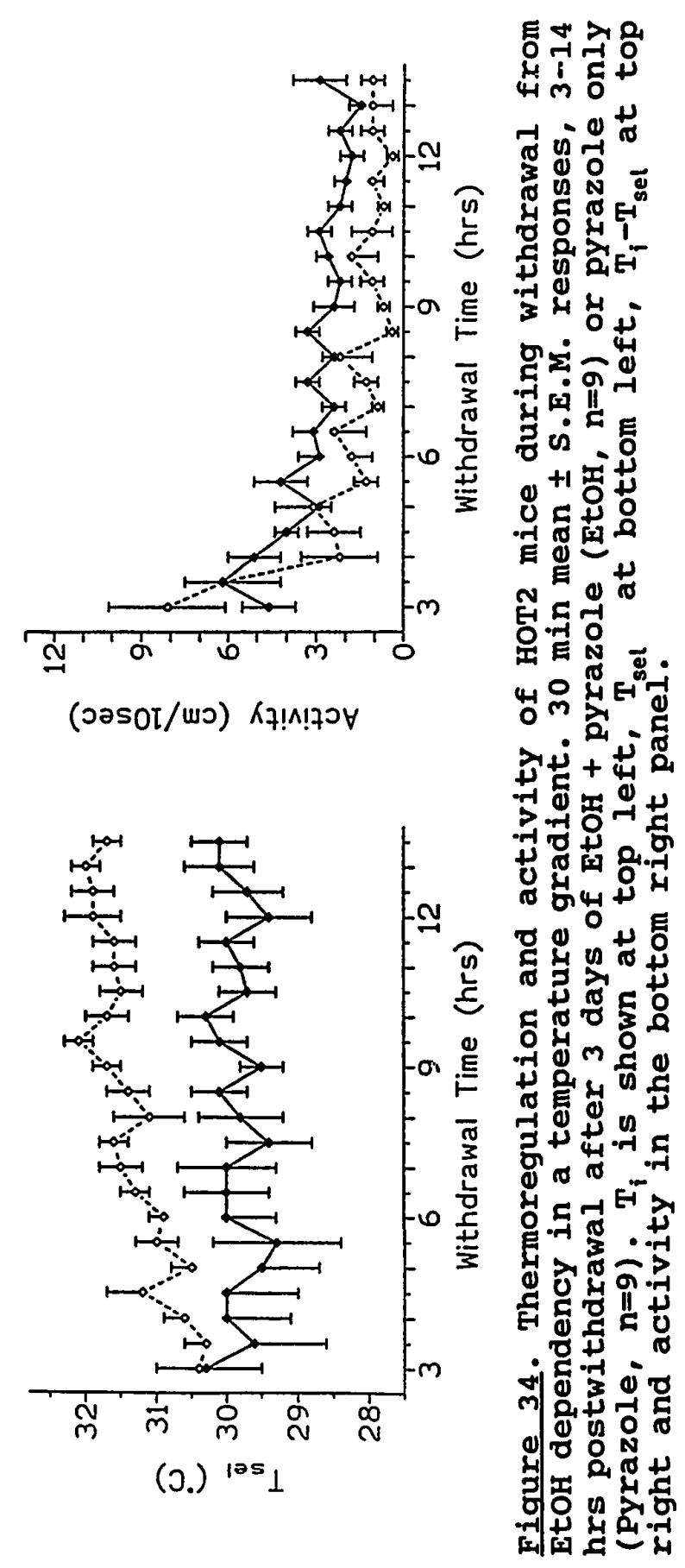


COLD mice. But unlike the COLD mice, neither $T_{\text {sel }}$ nor $\left(T_{i}-T_{\text {sel }}\right)$ differed between HOTl withdrawing and control mice. The control HOTl animals were very active in the gradient, however, far more active than HOTl withdrawing animals (or any other genotype).

HOT2 mice (Figure 34) present an interestingly different picture. Withdrawing НОT2 mice selected cooler temperatures than control HOT2 mice did, maintained a much higher $\left(\mathrm{T}_{\mathbf{i}}-\mathrm{T}_{\text {sel }}\right)$, and exhibited similar levels of activity. However the $T_{i}$ of withdrawing НОT2 mice remained substantially higher throughout the monitoring period than $T_{i}$ of control HOT2 mice.

Figure 35 presents, for each of the 4 genotypes, mean difference between withdrawing and pyrazole control animals (EtoH-pyrazole) in their drive to dissipate heat during the monitoring period.

without the complication of the onset of the lights-out period, the responses of all genotypes appeared fairly stable over this period of time (contrast with Figure 30). Of the genotypes, only HOT2 mice showed a magnitude of difference that approached the difference between withdrawing and control genetically heterogeneous mice at the beginning of their withdrawal time in the gradient (Figure 30). In contrast, there was almost no difference between HOTl withdrawal and control mice. The COLD1 and COLD2 mice were fairly similar to each other, each showing a moderate increase in the drive of withdrawing mice to dissipate heat. 


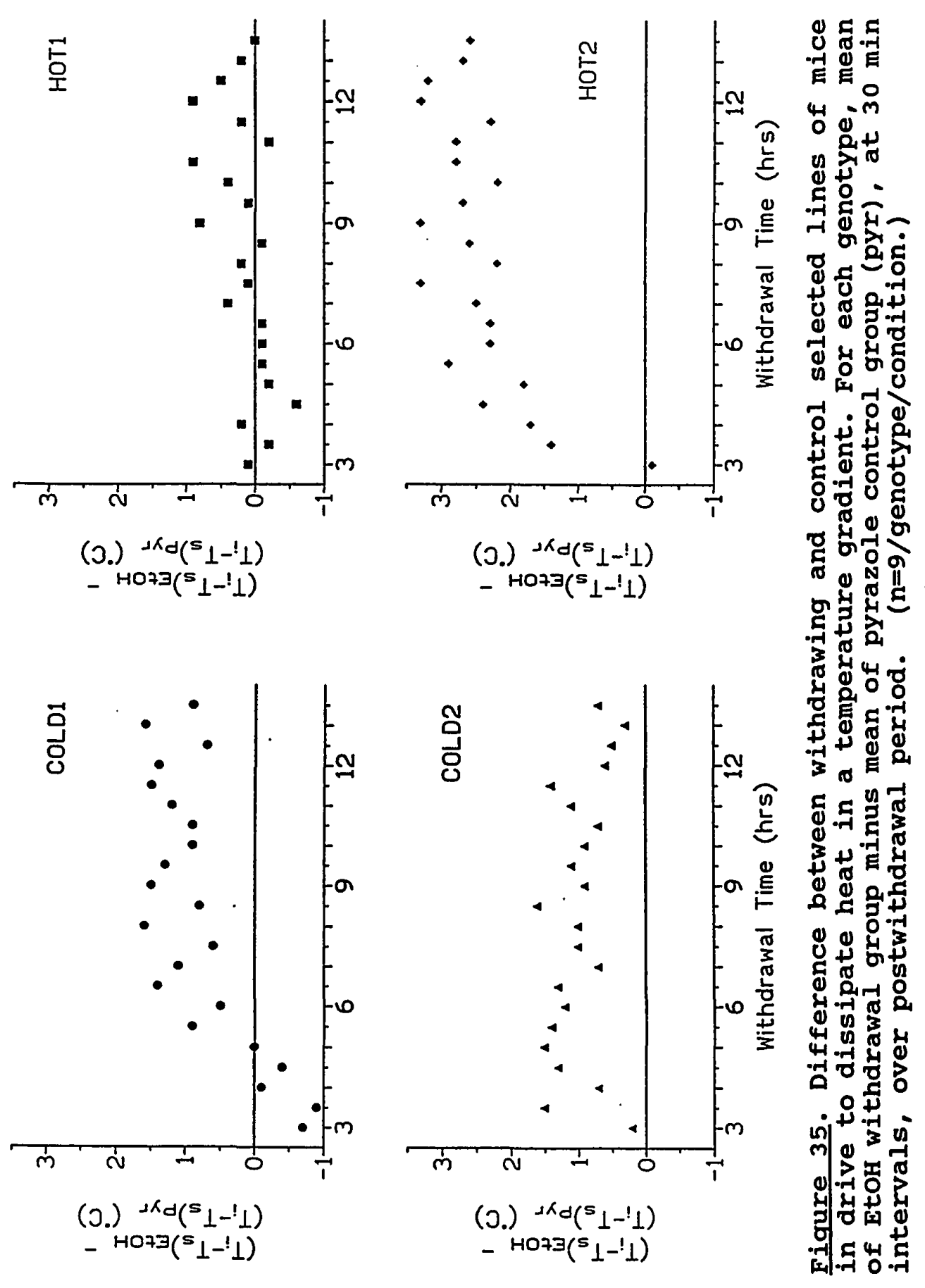


Repeated measures ANOVA on BEC, which was measured for each mouse every day during induction, detected no significant difference due to Replicate or Line ( $p>.8$ for either). The effect of Time was significant $\left(F_{2,64}=255.14, \underline{p}<.0001\right)$, with measured BEC values of $0.8 \pm 0.1 \mathrm{mg} / \mathrm{ml}$ on Day $2,1.5 \pm 0.1 \mathrm{mg} / \mathrm{ml}$ on Day 3 and $2.1 \pm 0.1 \mathrm{mg} / \mathrm{ml}$ on Day 4 at the initiation of withdrawal.

TEMPERATURE RESPONSE TO i.c.v. 5-HT

IN SELECTED LINES OF MICE

The $T_{\text {re }}$ responses of an individual HOT2 mouse and an individual COLD2 mouse immediately before, and for $60 \mathrm{~min}$ after i.c.v. injections of control solution or two doses of 5HT are presented in Figure 36.

After either dose of 5-HT, $\mathrm{T}_{\text {re }}$ declined immediately after injection; such a response was typical of all genotypes after 5-HT, although the magnitude and duration of response varied. The responses of these individuals to control injections were also typical. Following such injections, all genotypes manifested a high $T_{\text {re' }}$ which showed little or no decrease for the course of the monitoring period. Concurrent rectal and tail temperature data was collected from a subset of mice before and after an i.c.v. injection of $11.0 \mu \mathrm{g} \mathrm{5-HT.} \mathrm{The}$ typical response of an individual mouse shown in Figure 37 reveals a prompt postinjection increase in tail temperature, shortly followed by a decrease in $\mathrm{T}_{\mathrm{re}}{ }^{\circ}$ Tail temperature in 


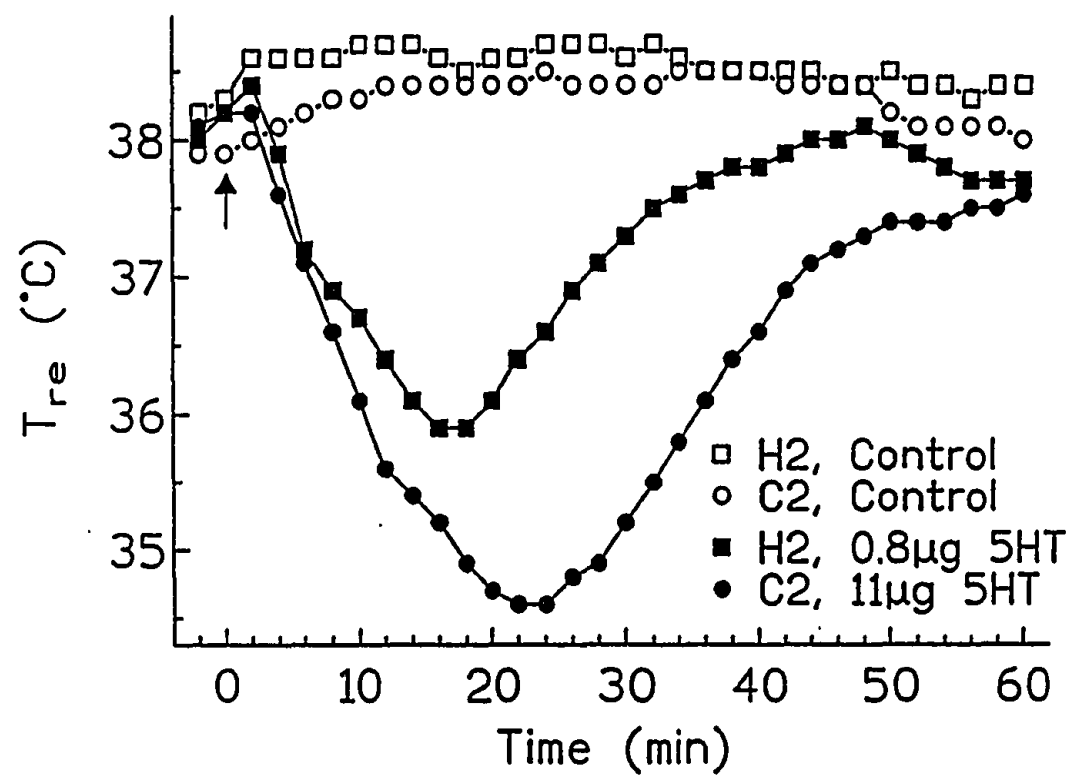

Figure 36. Temperature responses of individual mice to i.c.V. 5-HT or creatinine. Changes in $T_{\text {re }}$ of 1 HOT2 (H2) and 1 COLD2 (C2) individual after injection of control solution (11.0 $\mu \mathrm{g}$ creatinine) or a low $(0.8 \mu \mathrm{g}, \mathrm{H} 2$ mouse) or a high $(11.0 \mu \mathrm{g}, \mathrm{C2}$ mouse) dose of 5-HT in the lateral ventricle of the brain. Injections occurred in the $2 \mathrm{~min}$ period beginning at Time $=0$ as indicated by the arrow.

these animals remained elevated for approximately $20 \mathrm{~min}$, after which tail temperature declined below preinjection values and $T_{\text {re }}$ began a return toward normal.

Postinjection $T_{\text {re }}$ for all 4 genotypes after both control and sham injections are presented in Table VII. The differences between lines and conditions were small, and in no case statistically significant.

Mean responses over time (difference between $T_{r e}$ after 5HT and after control injection, at the same postinjection time) are shown in Figure 38 for all genotypes at 4 doses of 5-HT. At the highest dose (Figure 38A), the 4 genotypes 


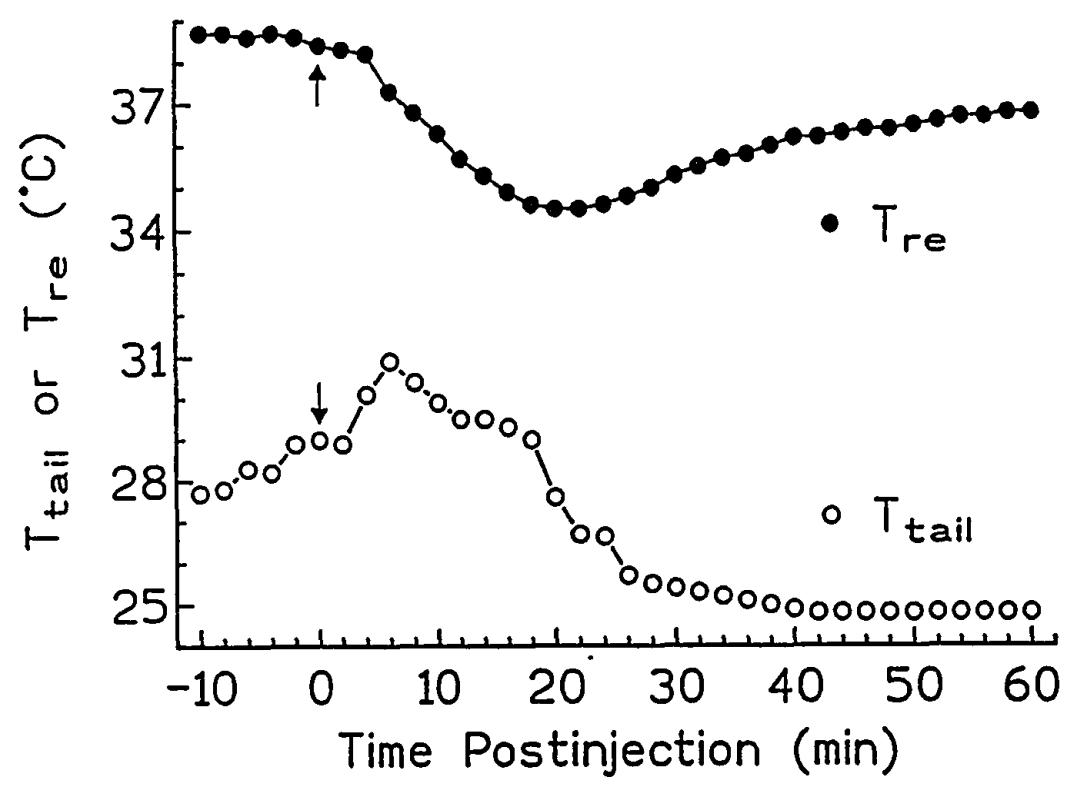

Figure 37. Response of an individual mouse to a single dose of i.c.v. 5-HT. Changes in $T_{\text {toil }}$ and $T_{\text {re }}$ of a HOT2 mouse at $2 \mathrm{~min}$ intervals before, and for $60 \mathrm{~min}$ after injection of $11.0 \mu \mathrm{g} \mathrm{5-HT}$ into lateral brain ventricle. Injection occurred in the $2 \mathrm{~min}$ period beginning at time $=0$, indicated by an arrow.

\section{TABLE VII}

$T_{\text {re AFTER CREATININE SULFATE CONTROL SOLUTION }}$ OR SHAM INJECTION

$$
\text { (60 min mean } \pm \text { S.E.M.) }
$$

Genotype

\begin{tabular}{lllll} 
Injection & HOT1 & HOT2 & COLD1 & COLD2 \\
\hline Control & $\begin{array}{c}38.6 \pm 0.4 \\
n=5\end{array}$ & $\begin{array}{c}38.6 \pm 0.4 \\
n=5\end{array}$ & $\begin{array}{c}38.4 \pm 0.2 \\
n=9\end{array}$ & $\begin{array}{c}38.1 \pm 0.2 \\
n=9\end{array}$ \\
Sham & $\begin{array}{c}38.5 \pm 0.1 \\
n=4\end{array}$ & $\begin{array}{c}38.1 \pm 0.1 \\
n=3\end{array}$ & $\begin{array}{c}38.3 \pm 0.2 \\
n=6\end{array}$ & $\begin{array}{c}38.0 \pm 0.2 \\
n=5\end{array}$
\end{tabular}

exhibited relatively similar decreases in $T_{r e}$, for similar lengths of time. However, during rewarming the $T_{\mathrm{re}}$ of HOT1 


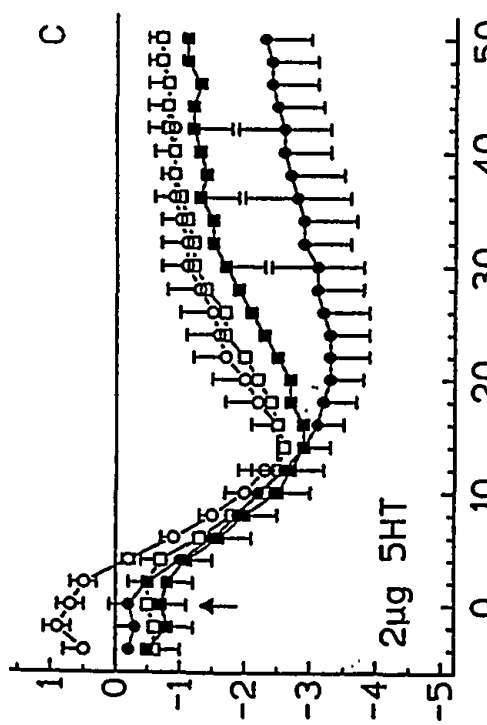

(כ.) ןадquoJ wosf $f f ! 0$

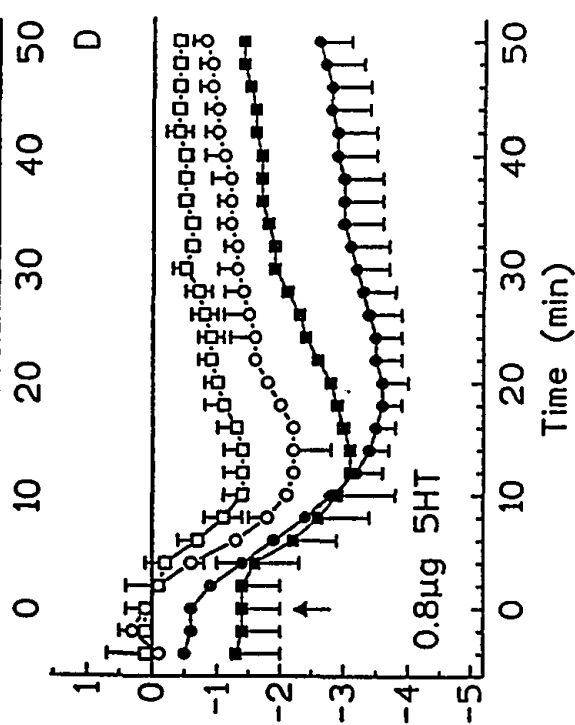

(כ.) ן 10دquoว wodt $1+! 0$

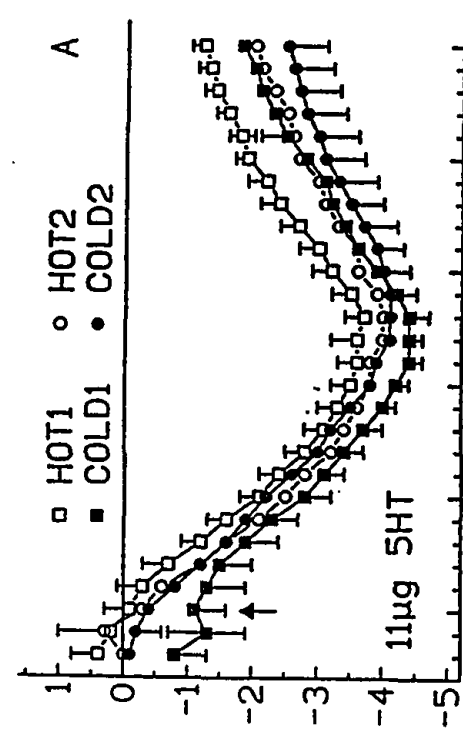

(כ.) 10دquoว wost ft!lo

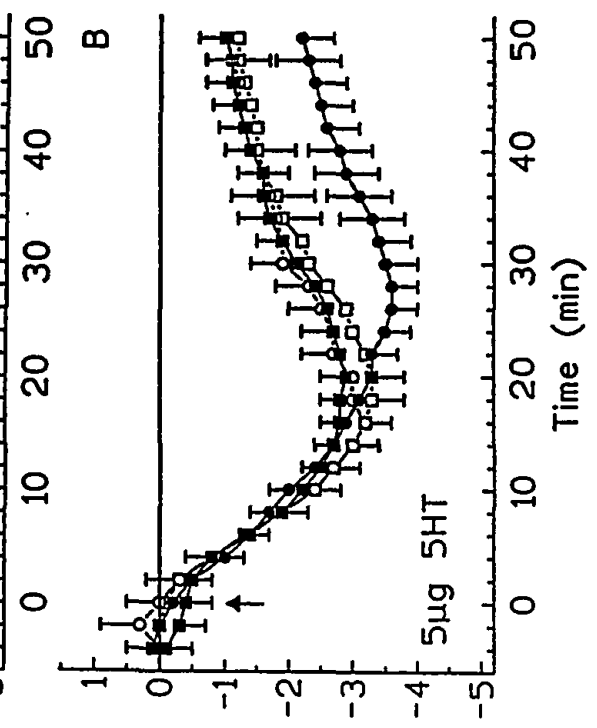

(ว.) josquos wost $t+10$

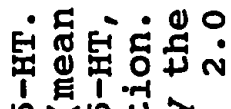

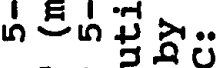
$>$ 幽过。 I 0 约出 .

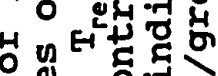
बन ठन ठ ขู

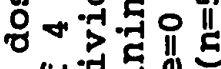
4

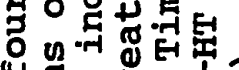
廿 P 影鸟 ป. -

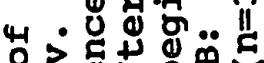
$0>0$

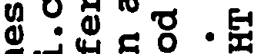
द्न

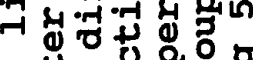
出 थ गै ठ 过是 $N$

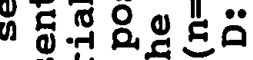
山

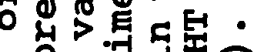

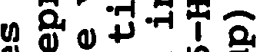
ขै แ⿺ 丶万

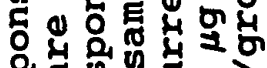

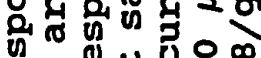

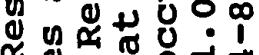

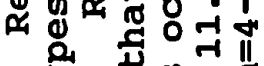

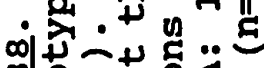

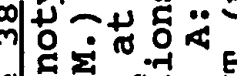

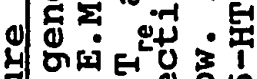
م

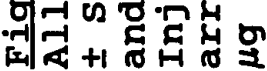


mice increased slightly faster than, and that of CoLD2 mice somewhat more slowly than that of the HOT2 and COIDI animals. Greater differences between the genotypes began to appear at the lower doses of 5-HT. After injection of $5.0 \mu \mathrm{g}$ (Figure 38B), the response of COLD2 mice was of greater magnitude, and of longer duration than responses of the other 3 genotypes. Following administration of the $2.0 \mu \mathrm{g}$ dose (Figure 38c) the difference between the COLD2 mice and the others became even more apparent; in addition, the COLDl mice showed a tendency toward a greater response than the HOT1 mice.

The $0.8 \mu \mathrm{g}$ dose (Figure 38D) elicited the most complete separation between the curves for the genotypes, with curves representing COLD mice well below those for Нот mice.

The dose response curves for HOT and COLD mice are presented in Figure 39. The response variable plotted is the difference between $T_{r e}$ after 5-HT and after control injection, at the point of maximum $T_{r e}$ response to 5-HT. Analysis using ANOVA revealed a significant effect of selected Line $\left(F_{1,91}=7.05, \underline{p}<.01\right)$ and Dose $\left(F_{4,91}=6.58, \underline{p}<.001\right)$. No significant effect of Replicate, or significant interactions were detected. Posthoc testing $(\alpha=.05)$ reported a significant difference between the $11.0 \mu \mathrm{g}$ and all other doses, and also between the $0.3 \mu \mathrm{g}$ and $5.0 \mu \mathrm{g}$ doses. Because ANOVA detected no effect of Replicate on the response of the animals, values for all HOT and all COLD mice were combined for this figure. 


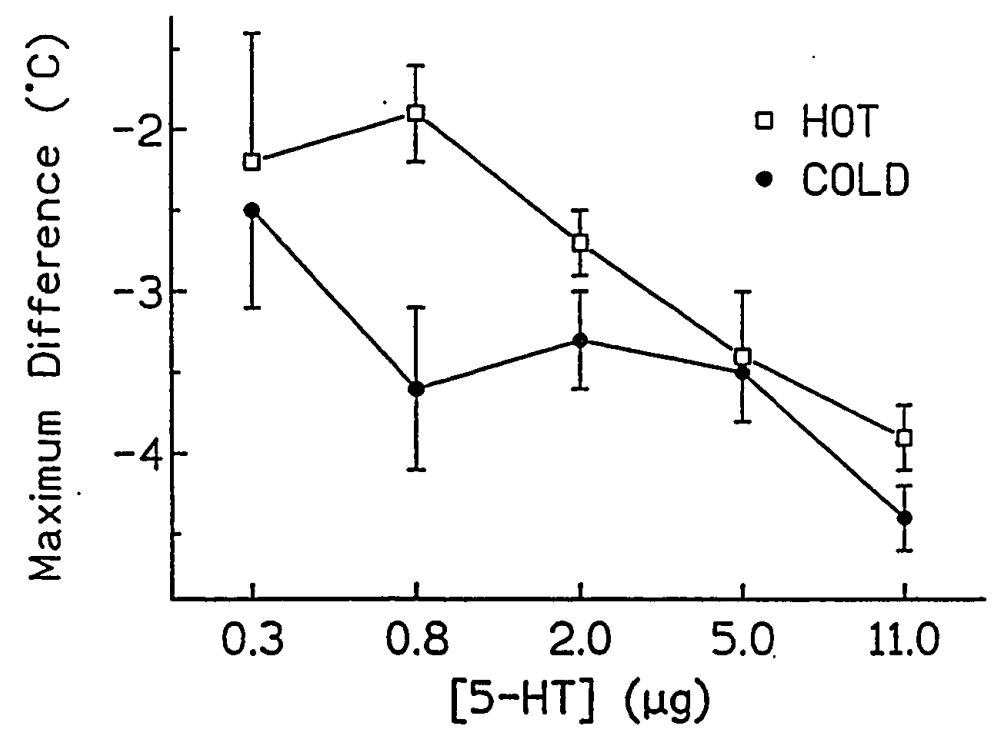

Figure 39. Dose response curves for HOT and COLD mice after all doses of i.c.v. 5-HT. HOT (HOTl + HOT2) and COLD (COLD1 + COLD2) mice combined for this figure. Response variable is maximum difference between individual $T_{\text {re }}$ after i.c.v. 5-HT, and $T_{r e}$ at that same time after $11 \mu \mathrm{g}$ i.c.v. creatinine control injection. Each data point represents mean \pm S.E.M. HOT mice: $0.3 \mu \mathrm{g}, \mathrm{n}=5$; $0.8 \mu \mathrm{g}, \mathrm{n}=7 ; 2 \mu \mathrm{g}, \mathrm{n}=12 ; 5 \mu \mathrm{g}, \mathrm{n}=13 ; 11 \mu \mathrm{g}, \mathrm{n}=10$. COLD mice: $0.3 \mu \mathrm{g}, \mathrm{n}=7 ; 0.8 \mu \mathrm{g}, \mathrm{n}=11 ; 2 \mu \mathrm{g}, \mathrm{n}=13 ; 5 \mu \mathrm{g}$, $n=19 ; 11 \mu g, n=14$.

It is clear that with increasing doses of 5-HT, the mice exhibited greater maximum declines in $T_{r e}$ below control values. The responses of the combined COLD mice plateaued between the $0.8 \mu \mathrm{g}$ and $5.0 \mu \mathrm{g}$ doses, so that the curves for HOT and COLD mice come together at the $5.0 \mu \mathrm{g}$ dose. Nevertheless, it is apparent that the COID mice were generally more sensitive to 5-HT than were the HOT mice.

The results of the behavioral experiments are typified by the responses of individual animals shown in Figure 40. The upper panel shows $T_{i}$ (measured with mini-mitter) and 

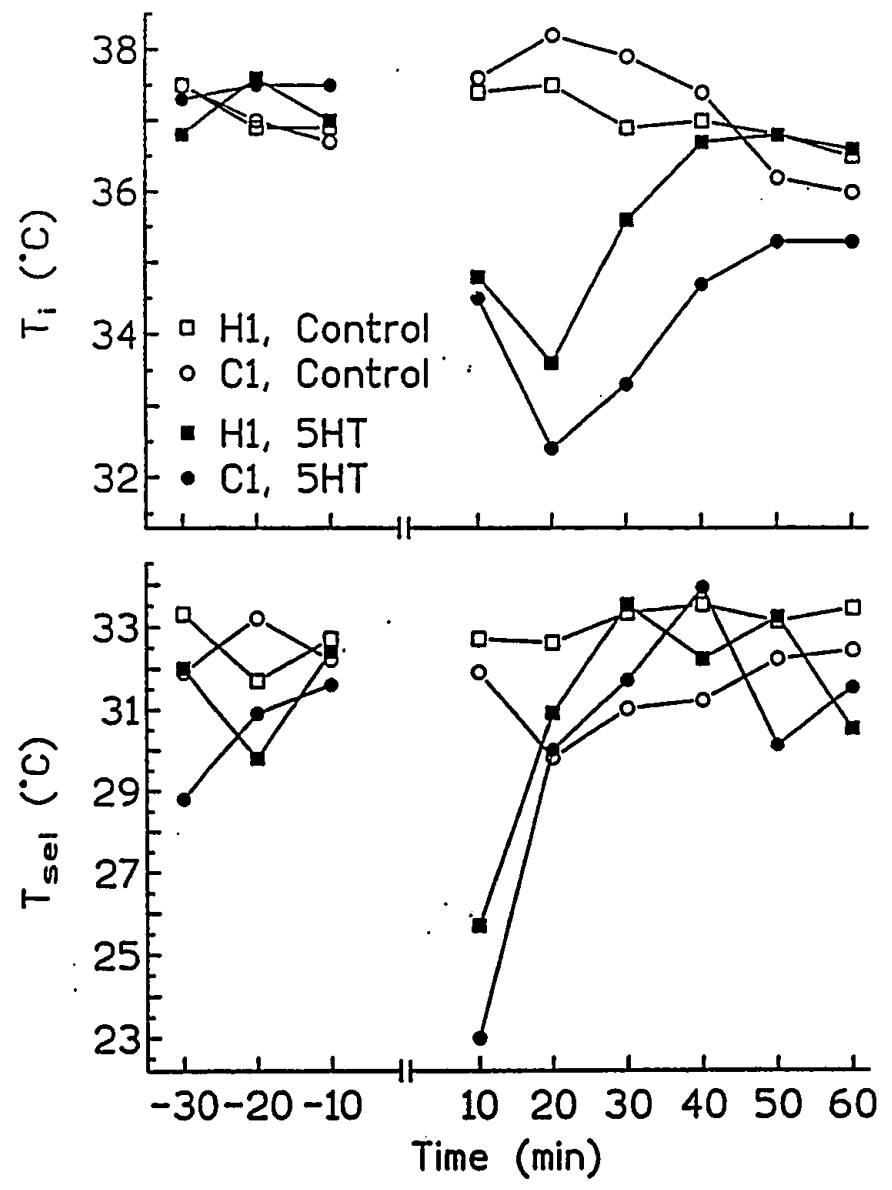

Figure 40. Thermoregulatory responses of 2 individual mice in a temperature gradient after i.c.V. 5-HT or creatinine. Shown are 10 min mean temperatures for $30 \mathrm{~min}$ before and $60 \mathrm{~min}$ after injection of $11.0 \mu \mathrm{g}$ creatinine control solution or $11.0 \mu \mathrm{g} \mathrm{5-HT}$ into the lateral brain ventricle of individual HOTI (H1) and COLDI (Cl) mice. $\mathbf{T}_{\mathbf{i}}$ (measured with an implanted telemetry device) is shown in upper panel, and $\mathrm{T}_{\text {sel }}$ in lower panel.

the lower panel shows $T_{\text {sel }}$ of individual HOT1 and COLDI animals for $30 \mathrm{~min}$ before, and $60 \mathrm{~min}$ after injection of $11.0 \mu \mathrm{g} \mathrm{HT}$ or creatinine sulfate control solution.

Before injection, both $T_{i}$ and $T_{s e l}$ were similar in these individuals. After an injection of 5-HT, the mice immediately 
moved to very cool locations in the gradient tubes. This thermoregulatory choice increased the temperature differential between mouse and environment, enabling rapid heat loss and a speedy decline in $T_{i}$ of both the HOTl and COLDl animals. In contrast, after a control injection the animals showed the transitory rise in $T_{i}$ that is a typical response to control injections.

The mice developed very low body temperatures after 5-HT, but at no time were they comatose. Activity of the mice in the gradient tubes is shown in Table VIII.

TABLE VIII

ACTIVITY AFTER CONTROL OR 5-HT INJECTION

(Mean \pm S.E.M. Cm/5 sec)

\begin{tabular}{lcc} 
& GENOTYPE \\
HOT1 & COLD1 & COMBINED \\
$\mathrm{n}=4$ & $\mathrm{n}=4$ & $\mathrm{n}=8$ \\
\hline
\end{tabular}

Control

$\begin{array}{rrrr}30-0 \text { min preinj } & 4.7 \pm 1.7 & 6.8 \pm 2.3 & 5.7 \pm 2.0 \\ 0-30 \text { min postinj } & 11.9 \pm 4.8 & 16.2 \pm 5.3 & 14.0 \pm 3.2 \\ 30-60 \text { min postinj } & 6.5 \pm 4.2 & 6.3 \pm 2.9 & 6.4 \pm 2.2 \\ \text { Diff (post-preinj) } & 7.2 \pm 4.2 & 9.4 \pm 5.6 & 8.3 \pm 3.0\end{array}$

$11.0 \mu \mathrm{g} 5-\mathrm{HT}$

$\begin{array}{rrrr}30-0 \text { min preinj } & 8.4 \pm 1.7 & 11.9 \pm 4.0 & 10.2 \pm 2.0 \\ 0-30 \text { min postinj } & 4.7 \pm 1.3 & 4.0 \pm 1.0 & 4.3 \pm 0.7 \\ 30-60 \text { min postinj } & 1.9 \pm 0.7 & 1.7 \pm 0.7 & 1.8 \pm 0.4 \\ \text { Diff (post-preinj) } & -3.8 \pm 2.6 & -7.9 \pm 3.7 & -5.9 \pm 2.1\end{array}$


Although activity was lower after 5-HT injections than after control injections, the animals continued to move about in the tubes.

Figure 41 shows the maximum difference between $T_{i}$ after $11.0 \mu \mathrm{g} \mathrm{5-HT}$ and after control injection attained by HOT1 and COLDI mice in the restrainers (measured with rectal thermocouple) or behaviorally thermoregulating (measured with implanted mini-mitter).

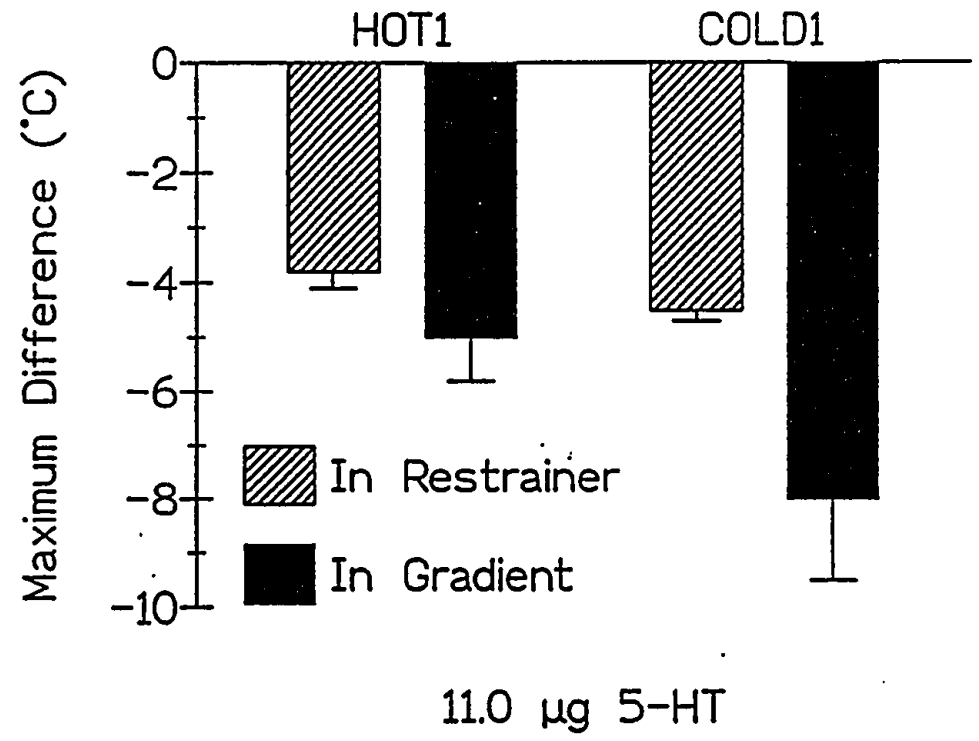

Figure 41. Comparison of temperature responses of mice after i.c.v. 5-HT at constant ambient temperature, or in a temperature gradient. Shown are maximum difference between $T_{i}$ after $11.0 \mu \mathrm{g} \mathrm{5-}$ $H T$, and $T_{i}$ after control injections into the lateral brain ventricle of HOT1 $(n=6)$ and COLDl $(n=7)$ mice in the restraint device at constant ambient temperature, and HOTI $(n=4)$ and COLDI $(n=4)$ mice in the temperature gradient (mean \pm S.E.M.). $T_{j}$ monitored with rectal thermocouple in restraint device, and with implanted telemetry device in gradient. 
The behavioral experiments were intended to test the hypothesis that the decline in $T_{r e}$ observed after i.c.v. 5-HT in restrained animals, monitored at ambient temperatures below thermoneutrality, was a regulated phenomenon. The 2 conditions, restrained at constant ambient temperature or freely behaving in the temperature gradient tubes, were therefore compared using an ANOVA with fixed factors of Selected Line (HOTI or COLDI), and Condition (Restrained or Behaviorally Thermoregulating). A significant effect of both Selected Line $\left(F_{1,17}=7.25, \underline{p}<.05\right)$ and Condition $\left(F_{1,17}=12.03\right.$, $\underline{p}<.01)$ was detected. 
DISCUSSION

\section{THERMOREGULATORY BEHAVIOR DURING ACUTE \\ EXPOSURE TO ETHANOL}

The highly significant decrease in the thermoregulatory index after acute ethanol indicated that, at the doses tested, ethanol produced a decrease in the level of the regulated temperature in mice. The fall in core temperature that followed ethanol injections involved both physiological and behavioral responses, since the decreased ambient temperature selected by the mice was not, by itself, sufficient to cause a major fall in body temperature.

Previous studies utilizing behavioral measures have suggested that ethanol produces a decrease in the thermoregulatory set point, but changes in core temperature were not carefully monitored. In one study, ethanol injections of $3.0 \mathrm{~g} / \mathrm{kg}$ caused $\mathrm{BALB} / \mathrm{C}$ strain male mice to select cooler temperatures (Gordon and Stead, 1986), and the authors concluded that a regulated decrease in body temperature had occurred. Unfortunately this study did not measure internal temperature during behavioral thermoregulation. Internal temperature was measured later, in a separate experiment in which animals were injected with ethanol and left in a metabolic chamber at three different 
ambient temperatures for one hour; colonic temperature was measured only once, sixty minutes after injection. The dose utilized $(3.0 \mathrm{~g}$ EtoH $/ \mathrm{kg})$ is a high dose, which in many strains of mice causes behavioral and physiological derangement. The study yields no information about the time course of body temperature response to doses of ethanol that affect thermoregulatory behavior. In another study (Gordon et al, 1988a) the authors likewise claimed to have demonstrated a regulated fall in body temperature after ethanol. In this study, rats received $3.0 \mathrm{~g}$ EtoH/kg by gavage. Thermoregulatory behavior was monitored for two hours in a temperature gradient, but internal temperature was not measured until two hours after injection. Again, the study yields a paucity of information about the regulatory effect of this dose of ethanol in the rat. In a more interesting study, ten minutes after a $1.5 \mathrm{~g}$ EtoH/ $\mathrm{kg}$ injection, rats escaped a radiant heat source significantly faster than did control rats injected with saline (Lomax et al, 1980). In this study rectal temperature was measured only once, but it was measured at a time when ethanol was probably exerting an effect on the regulated temperature (at the time of escape from heat).

Findings that ethanol decreases the regulated temperature of rats and mice appear to be contradicted by a study (Myers, 1981) which reported a poikilothermic effect of ethanol on thermoregulation. The most likely explanation for this discrepancy lies in the dose levels utilized. At lower doses, 
such as those employed in the acute ethanol studies presented here, ethanol lowers the regulated body temperature. At higher doses, all aspects of physiological function, including temperature regulation, are disrupted. For example, at doses of ethanol above $1.5 \mathrm{~g} / \mathrm{kg}$, rats became ataxic and were unable to respond behaviorally (Lomax et al, 1980). In pilot studies reported here, doses of $2.75 \mathrm{~g} \mathrm{EtOH} / \mathrm{kg}$ and above exerted the same effect in genetically heterogeneous mice. Since the mass specific metabolic rate of the mouse is about twice that of the rat (Schmidt-Nielsen, 1984, p.62), doses employed by Myers (1981) (2.0 or $4.0 \mathrm{~g} \mathrm{EtOH} / \mathrm{kg})$ were probably more disruptive to rats than the doses used in the present series of studies were to mice.

Control injections, like ethanol injections, caused the mice to choose a cooler environment. However, to consider changes in selected temperature apart from changes in core temperature occurring at the same time is misleading. After saline injection, mice selected cooler temperatures while their internal temperatures were higher than normal. Because internal and selected temperatures moved in opposite directions, it is reasonable to infer that the animals were using their ability to select a cooler environment as a means to oppose the rise in internal temperature induced by the stress of handling and injection. In contrast, after ethanol injection the animals selected cooler temperatures at the same time that internal temperature was falling. Consistent choice 
of a cooler environment at the same time that body temperature is declining indicates a preference for a reduced body temperature, suggesting a decrease in the thermoregulatory set point. By combining the two temperature measures (internal and selected temperature), the thermoregulatory index yielded a more complete picture of the status of the regulated temperature than either measured parameter could express in isolation. The difference between a decrease in selected temperature (coupled with a rise in internal temperature) after saline and a decrease in selected temperature (coupled with a decrease in internal temperature) after ethanol is clearly illustrated by the differences in the thermoregulatory index.

Both HOT and COLD mice, like the genetically heterogeneous mice, responded to ethanol with a regulated decrease in body temperature. The dose of ethanol required to elicit an effect was greater in HOT mice than in COLD mice. This suggests the possibility that a major difference in the response of the central nervous system regulator of body temperature to ethanol has been selected for in these mice. These results were apparent in both replicates of the selected lines, indicating that the measured difference in response truly reflects the effects of the genes determining acute ethanol sensitivity, on which selection pressure was exerted.

Experiments involving measurement of rectal temperature before and after various doses of ethanol (Crabbe et al, 1989) 
likewise have revealed a substantial difference between the lines. A dose response curve showing change in rectal temperature after $1,2,3$ or $4 \mathrm{~g} \mathrm{EtOH} / \mathrm{kg}$ in HOT and COLD mice from the seventh selected generation (Crabbe et al, 1989) revealed that COLD mice experienced the same decline in rectal temperature after a $2 \mathrm{~g}$ EtOH/kg injection, as did HOT mice after a $4 \mathrm{~g}$ EtoH $/ \mathrm{kg}$ injection (about $2^{\circ} \mathrm{C}$ ). More recent studies have shown that with continuing generations of selection, equivalent responsiveness is now seen at doses of about $5 \mathrm{~g}$ EtOH/kg (HOT mice) and $2 \mathrm{~g}$ EtOH/kg (COLD mice) (Feller and Crabbe, in preparation). Given the constraints of behavioral experiments in the temperature gradient, where animals must retain motor coordination in order to exercise thermoregulatory choice, it was indeed a challenge to find a single dose of ethanol both large enough to affect the regulated body temperature of the HOT mice, and small enough to avoid producing ataxia and loss of behavioral capabilities in the COLD mice.

The thermoregulatory index of both HOT and COLD mice was significantly lower after an effective dose of ethanol than after control injections of saline. Although sensitivity varied among the genotypes, the data clearly indicated a decrease in the regulated body temperature of both HOT and COID mice in response to ethanol. The selected lines did not seem to differ in their fundamental response to ethanol, but only in the magnitude of response to a given dose; COLD mice 
were significantly more sensitive than HOT mice. In addition, although the difference was not significant, the HOT1 mice tended to exhibit slightly greater sensitivity to ethanol hypothermia than did the нот2 mice. This observation stands in contrast to previously published findings that, for the last several generations, the HOT1 mice have exhibited smaller hypothermic responses to $3 \mathrm{~g}$ EtOH/ $\mathrm{kg}$ than the HOT2 mice when tested by measuring rectal temperature response at room temperature (Phillips and Crabbe, 1991). Further testing of a larger number of HOT mice in the gradient would be required to confirm or disprove the existence of a significant difference between the replicates in their thermoregulatory response to ethanol. Meanwhile, the substantial differences between the two experimental paradigms make any direct comparison between them difficult.

COLD mice experienced a greater decrease in rectal temperature than did HOT mice after intraperitoneal injections of hydralazine, which principally acts as a peripheral vasodilator (Feller and Crabbe, 1991). It was concluded by the authors that selection has produced some alteration in vascular mechanisms between the HOT and COLD mice, accounting for some of their difference in sensitivity to ethanol. Although a such difference in vasodilatory response to ethanol may exist, it is unlikely to have made an important contribution to the difference in response to ethanol observed in the gradient situation, because a behaviorally 
thermoregulating mouse could easily compensate for heat loss due to peripheral vasodilation by adjusting its position in the gradient.

The regulated decrease in body temperature observed after ethanol increases the probability of survival after potentially toxic doses of ethanol in mice (Dinh and Gailis, 1979; Malcolm and Alkana, 1983; Finn et al, 1989). Decreased temperature also increases the threshold for depression and impaired motor coordination caused by the drug in both mice and rats (Malcolm and Alkana, 1981; Pohorecky and Rizek, 1981; Wenger and Alkana, 1984). Ethanol, like high temperature, causes a decrease in cell membrane viscosity (Goldstein, 1983, p.50; Goldstein, 1984). This effect is intensified at higher temperatures (Chin and Goldstein, 1981). Lower temperatures would therefore be expected to oppose the membrane disordering effect of ethanol. A regulated lowering of body temperature after ethanol may have developed as an adaptive strategy in an animal whose wild ancestors consumed fermenting fruits; consumption of fruit during certain parts of the year (especially late summer) has been documented for wild wood mice (Watts, 1968).

The effects of saline or acute ethanol on activity did not differ between the replicate lines. Both HOT and COLD mice experienced a significant increase in activity at lower doses of ethanol $(2.0 \mathrm{~g} \mathrm{EtOH} / \mathrm{kg}$ for COLD mice, $2.65 \mathrm{~g} \mathrm{EtOH} / \mathrm{kg}$ for HOT mice), and a depression of activity at higher doses. 
This response is consistent with previous studies which have shown locomotor stimulation by low to moderate doses of ethanol, and depression of activity by high doses of the drug (Buckalew and Cartwright, 1968; Carlsson et al, 1972; Ahlenius et al, 1974; Jarbe and Ohlin, 1977; Crabbe et al, 1982b). In one study, HOT and COLD mice from the tenth generation of selection were injected with $2 \mathrm{~g} \mathrm{EtOH} / \mathrm{kg}$ and tested in an open field apparatus (Crabbe et al, 1988). Under those conditions, the COLDI and HOT1 mice showed a similar stimulation of activity by ethanol, compared to activity after an injection of saline. COLD2 mice, however, showed less activation, and HOT2 mice more activation by ethanol than did the COLD1 - HOT1 replicate pair. In contrast to the results of crabbe et al, the present study revealed no difference between the replicates in the effect of ethanol injection on activity. However, it is certainly true that two dimensional movement in a thermally homogeneous, brightly lit open field is quite different from one dimensional movement in a dimly lit, thermally heterogeneous tube. The paradigms are so dissimilar that direct comparison is difficult.

The HOT2 mice appeared to exhibit increased emotionality, as compared to the HOT1 or the COLD mice. The HOT2 mice became noticeably more reactive to handling during the course of these experiments than did the other animals. They were more difficult to catch in the home cage, and much more likely to squeak in response to restraint and injection. HOT2 mice 
may also have exhibited a tendency towards a higher threshold than HОTl mice for the hypothermic effect of ethanol, as discussed above, although the effect was not statistically significant.

Moderate doses of acute ethanol caused both lowered core temperatures and a concomitant selection of cooler ambient temperatures in behaviorally thermoregulating mice. This effect is consistent with the hypothesis that acute ethanol causes a decrease of regulated body temperature in the mouse. The poikilothermia that has been observed by other investigators after ethanol administration is likely an effect of using much higher, disruptive doses of the drug.

\section{INFLUENCE OF TIME OF DAY ON THERMOREGULATORY}

BEHAVIOR AFTER ACUTE ETHANOL

Measurements of baseline internal temperatures of COLD2 mice at various times throughout their daily light and dark cycles recorded higher temperatures during the dark, and lower temperatures during the light period. These results agree with circadian baseline temperature data which has been collected using rats (Sturtevant and Garber, 1980; Briese, 1985; Kant et al, 1991) and mice (Deimling and Schnell, 1980) and, more generally speaking, with data for most or all endothermic animals, and for many ectotherms as well (for a review see Refinetti and Menaker, 1992). Animals which exhibit a daily cycling between higher and lower regulated 
body temperatures maintain the higher temperature during the active and awake portion of the cycle, and the lower temperature during the quiet or sleeping hours (Refinetti and Menaker, 1992). For the nocturnal mouse nighttime is the active time, and the variation in baseline temperature shown by these COLD2 mice was typical and unsurprising.

Data in the literature indicating that ethanol hypothermia is greater during the light and less during the dark (Haus and Halberg, 1959; Walker and Soliman, 1982) have been collected using rectal probes to measure internal temperature of animals held at laboratory ambient temperature. The situation from the viewpoint of the mouse is, of course, quite different in a thermal gradient, where each animal is able to control his heat exchange with the environment by using behavior. A comparison of the thermoregulatory response of COLD2 mice to saline or to ethanol using the thermoregulatory index indicated a slightly larger difference between the two conditions during hours of light than during hours of darkness, but the effect was far smaller than the effect of time-of-day on baseline body temperature already discussed. In order to maximize the sensitivity of the general experimental regimen, it was desirable to conduct thermoregulatory experiments during a time of day when difference in response to control and ethanol injections was maximal in mice. These data tend to support the choice of the hours between 1000 and 1400 as the basic time frame within 
which most experiments occurred. An implication that there is no effect of photoperiod on body temperature response to ethanol is not intended. However it seems likely that, at least for COLD2 mice, the excitement of being moved from the familiar environment of the animal room, receiving an injection, and being placed in a gradient tube obscured any time-of-day effect that might have been detectable if a more sensitive paradigm had been used.

One caveat must be added. The photoperiod experiments were conducted using COLD2 mice only. The absence of major photoperiod effects on the response of this genotype to ethanol argued against making the substantial investment of time and resources that would be necessary to similarly characterize the other three genotypes. However, it is possible that another genotype might possess an inherently greater dependence of ethanol sensitivity on time-of-day, or perhaps a stress response that interacts with the body temperature response to ethanol differently at different times of day. Based on information from colD2 mice only, the possibility cannot be dismissed that, were the other genotypes to be similarly tested, an effect of selected line, genetic replicate, or both might be detected.

DEVELOPMENT OF TOLERANCE TO ETHANOL HYPOTHERMIA

Mice exposed to ethanol daily for eleven days and allowed to behaviorally thermoregulate in a temperature gradient on 
five of those days in the Mixed Protocol experiment clearly developed functional tolerance to the hypothermic effect of ethanol, in contrast to similar mice injected with the same dose of ethanol and afterwards held at room temperature in the Box Protocol experiment. Although all mice received the same number of injections and the same cumulative exposure to ethanol, their ability to acquire various types of tolerance differed greatly depending upon whether they were allowed to behaviorally thermoregulate, or not.

All mice developed dispositional (metabolic) tolerance after eleven days of ethanol injections. Blood ethanol concentrations measured in mice on the last day of the Mixed Protocol experiment did not differ from those measured in similar mice of the Box Protocol group. Development of acute tolerance was not assessed in these experiments. In the development of other forms of functional tolerance, however, the groups differed in important ways. The Mixed Protocol mice manifested both rapid and chronic tolerance, when postinjection internal and selected temperatures were compared against preinjection baseline measures using the thermoregulatory index. In contrast, the Box Protocol mice showed no change in the difference between postinjection and preinjection internal temperatures over the entire eleven days of exposure; apparently, this group of animals developed neither rapid nor chronic functional tolerance to the 
hypothermic effect of ethanol, despite their ability to acquire dispositional tolerance.

The ability of the Mixed Protocol mice to develop rapid and chronic tolerance is not surprising. The ability of both mice (Crabbe et al, 1979; Rigter et al, 1980; Tabakoff et al, 1980; Crabbe et al, 1982a; Crabbe et al, 1989; Erwin et al, 1992) and rats (Lê et al, 1986; Khanna et al, 1991; MackenzieTaylor and Rech, 1991; Tampier and Quintanilla, 1991; Khanna et al, 1992; Pohorecky and Roberts, 1992; stewart et al, 1992) to develop such tolerance has been amply documented in the literature. What has, however, been lacking in the literature is a clear demonstration that the tolerance which develops to ethanol hypothermia is a regulated phenomenon. Almost invariably, when tolerance to body temperature change after ethanol has been investigated, temperature has been assessed by taking rectal temperature measurements at room temperature without monitoring any thermoregulatory effector mechanisms (Crabbe et al, 1979; Rigter et al, 1980; Tabakoff et al 1980; Crabbe et al, 1982a; Lê et al, 1986; Melchior, 1990; Khanna et al, 1991; Mackenzie-Taylor and Rech, 1991; Pohorecky and Roberts, 1991; Tampier and Quintanilla, 1991; Erwin et al, 1992; Khanna et al, 1992 ; Pohorecky and Roberts, 1992 ; Stewart et al, 1992). As expressed by Rigter et al (1980), "Whether the rapid tolerance to ethanol is specifically or indirectly mediated by the thermoregulatory centers remains to be determined". A similar statement could have been made about 
chronic tolerance. But results from the Mixed Protocol experiment are unambiguous. Based on the thermoregulatory behavior of the Mixed Protocol mice, it seems justified to conclude that both the rapid and the chronic tolerance to ethanol hypothermia that occur in mice are, indeed, regulated phenomena.

The mice in the Box Protocol experiment responded to repeated ethanol very differently than similar mice in the Mixed Protocol experiment. Why did the Box Protocol mice show such a striking difference from their cousins in the Mixed Protocol experiment? And why did the Box Protocol mice also show such a difference from rodents in other laboratories which have developed both rapid and chronic ethanol tolerance, as measured by a decrease in the difference between preinjection and postinjection rectal temperature, in experiments conducted at room temperature?

The answer to the first question can be sought by examining the similarities and differences between the two Protocols. There should have been no important differences among the mice themselves, since they were of a similar age and were the offspring of the same breeding stock of animals. Mixed and Box Protocol mice were exposed to an equal amount of handling, to the same amount of ethanol, and to the same number of injections. They were moved from the animal room to the laboratory and back the same number of times, and were alone during experiments (as opposed to remaining with their 
brothers in the home cage). Every mouse had gone through implantation surgery. All these events were probably very stressful for the mice, but these stresses were applied equally to both groups. There were, however, likely two major differences in the two experimental procedures, from the viewpoint of the mice.

First, the mice in the gradient tubes were in an environment that was specifically designed to minimize stress for them during experiments. The tubes were dark and close, constructed to be as similar to a mouse burrow as a plastic tube can be. The tubes were also under water that was constantly bubbled with air; the bubbling noise presumably served as white noise to screen out any random laboratory sounds. The mice in the clear plastic boxes were exposed to light and visual disturbance as well as to laboratory sounds, with nowhere to hide. It seems reasonable to assume that the box environment was more stressful for the mice than the tube environment.

The assumption that the box environment was stressful appears to be borne out by the dramatic rise over eleven days in preinjection internal temperatures of both saline- and ethanol-treated Box Protocol mice. It is well known that exposure to a variety of stressors causes an elevation of internal temperature in rodents (Briese and de Quijada, 1970; Poole and Stephenson, 1977 ; Borsini et al, 1989; Morley et al, 1990; Briese and Cabanac, 1991; Cabanac and Briese, 1991; 
Briese, 1992). This effect may initially be accentuated (rather than ameliorated) by repeated exposure to the stressor (Briese and de Quijada, 1970). Habituation may occur given sufficient time and repetitions (Briese and de Quijada, 1970; Morley et al, 1990; Cabanac and Briese, 1991). From the first to the eleventh experimental day, baseline internal temperatures of both ethanol- and saline-treated Box Protocol mice increased by about $1^{\circ} \mathrm{C}$.

The assumption that the box environment was more stressful than the tube environment is also supported by the striking difference between the Box and Mixed Protocol salinetreated mice. The difference between preinjection and postinjection internal temperatures in the Box Protocol saline mice remained essentially constant over the eleven days of the experiment. This phenomenon of progressively increasing preinjection baseline temperatures (rectal temperature measurement) was also reported for a subset of a large panel of inbred mice (Crabbe et al, 1982a). In that experiment, genetic correlations both with acute temperature response to ethanol, and with development of tolerance to that response were quantified. of twenty inbred strains assessed, four (SWR/J, BUB/BnJ, SEA/GnJ and $\mathrm{SJI} / J$ ) showed a progressively increasing baseline temperature, like the Box Protocol mice; when quantified as postinjection change from preinjection baseline, no tolerance development was measured in those four inbred strains. In sharp contrast, the thermoregulatory index 
of the Mixed Protocol saline-treated mice, a measure which reflects postinjection changes from preinjection baseline, showed a gradual decline over the course of the experiment; by the eleventh day, the saline mice in the Mixed Protocol group showed no postinjection change from preinjection baseline.

Do the results from the Behavior Protocol experiment contradict the assumption that the box environment was more stressful for the mice than the gradient tubes? In the Behavior Protocol, mice were run daily in the gradient. The experiment was terminated on the fourth gradient day, when the behavior of this group of mice had become so erratic in the tubes that collection of meaningful selected temperature data was impossible. This agitated behavior was interpreted as a sign of stress resulting from daily bouts in the gradient. clearly, daily gradient runs were stressful to the mice. The mice in the boxes did not exhibit particularly agitated behavior. However, it seems most probable, not that the tubes were more stressful than the boxes, but that the mice expressed their stress differently in the dim and roomy tubes, than in the small, brightly lit boxes.

Many examples may be found in the literature of mice and rats expressing tolerance to ethanol hypothermia when rectal temperature is assessed at laboratory temperature. Why should the results from the Box Protocol mice have differed from the results obtained in other laboratories? The stress of rectal temperature measurements and the handling associated with 
taking such measurements have been shown to accentuate the development of tolerance to ethanol hypothermia (Mansfield and Cunningham, 1980). In one study (C.I. Cunningham, personal communication) tolerance was assessed in two groups of rats which were in all ways similar except that one group was implanted with mini-mitters so that internal temperature could be assessed in a nonstressful manner, while a rectal probe was used to measure temperature in the second group. It was found that tolerance to ethanol hypothermia developed rapidly in the group experiencing the added stress of rectal temperature measurement, but over several days of ethanol injections no tolerance developed in the mini-mitter-implanted group of rats. It seems possible that a similar phenomenon occurred in the Box Protocol mice. However, another study compared development of tolerance in two groups of mice whose rectal temperatures were taken before injection, then either once (forty-five minutes after injection) or nine times (every five minutes) during the forty-five minute postinjection period. No effect of repeated handling and repetitive rectal temperature measurements on the development of tolerance to ethanol hypothermia was detected (Crabbe et al, 1979). It may be that rats and mice differ in how stress affects the acquisition of tolerance. On the other hand, it may also be true that stress can only accelerate tolerance development to a finite degree, and that for the mice in the latter study, the baseline rectal temperature measurement followed closely 
by handling and injection was sufficiently stressful to pass that threshold.

Thus we are left with something of a paradox. Perhaps it is true that the mice in the boxes were insufficiently stressed to cause the development of functional tolerance. But they were also probably under more stress than the mice in the tubes, which manifested both rapid and chronic tolerance. The answer to this puzzle may lie in the second important difference between the Mixed and Box Protocol animals - the difference in their abilities to achieve their regulated temperatures. Given the extremes of temperature available in each tube, it was clearly possible for the mice in the gradient to rapidly gain or lose heat, to adjust body temperature to the regulated level. Possibilities were far more limited for mice in the boxes. Perhaps, at a laboratory temperature far below thermoneutral, the mice in the boxes were unable to express any functional tolerance that may have developed because effector mechanisms available to them were insufficient to allow them to mitigate the fall in body temperature that occurred after ethanol injection each day.

This speculation does not, of course, explain the difference between the Box Protocol mice, and mice in other laboratories which have been able to express functional tolerance at similar temperatures. In the literature, surprisingly, conditions under which mice or rats are tested for tolerance have at times been incompletely specified 
(Grieve and Littleton, 1979; Tabakoff et al, 1980; MackenzieTaylor and Rech, 1991; Tampier and Quintanilla, 1991). But in other studies (Crabbe et al, 1979; Rigter et al, 1980; Crabbe et al, 1982a; Crabbe et al, 1989; Melchior, 1990) it was implied or clearly stated that after injection mice were returned to the home cage with conspecifics. Animals in tolerance experiments may also receive ethanol by inhalation (Grieve and Littleton, 1979), gavage (Tampier and Quintanilla, 1991), or by voluntary consumption (Mackenzie-Taylor and Rech, 1991; Erwin et al, 1992), all possibly in the company of cagemates. In that case, although the ambient temperature of the laboratory may be far below thermoneutral, mice have available to them a potent mechanism for increasing body temperature - huddling close to other mice. This important difference may offer a partial explanation for the discrepancy between this and some other studies.

Although there has been an enormous effort devoted to understanding the processes responsible for the development of drug tolerance, it remains a poorly understood phenomenon. clearly the acquisition of tolerance involves a multifaceted and complex mechanism. Several processes with different time courses occur to produce the diminution in drug effect that we define as tolerance. Dispositional tolerance, the simple increase in rate of drug metabolism, may occur in the absence of functional tolerance (Mackenzie-Taylor and Rech, 1991) and vice versa (Crabbe et al, 1979; Rigter et al, 1980; Tabakoff 
et al, 1980; Khanna et al, 1991; Mackenzie-Taylor and Rech, 1991). In an experiment using fifteen inbred strains of mice (Crabbe et al, 1982a), rectal temperature decline (change from preinjection baseline) was measured at thirty and sixty minutes after acute ethanol, for eight days of injections. The statistical correlation between temperature response after acute ethanol, and blood ethanol content sixty minutes after injection did not differ significantly from zero. By the end of the experiment (the eighth day), some of the strains had developed functional tolerance, and some had not. Three of the strains showed no change from the first day in blood ethanol concentration after injection, and the other twelve showed a higher blood ethanol content than on the first day; an orthogonal comparison between change in rectal temperature at thirty or sixty minutes after injection and blood ethanol concentration at the same times revealed no statistically significant correlation. As concluded by crabbe et al (1982a),

We feel that we are able to discount an important role for metabolic factors in influencing strain differences in sensitivity and tolerance ... we found no evidence that changes in (blood ethanol content) over days were genetically associated with hypothermic tolerance ... we feel that our (blood ethanol content) data allows us to assert that ethanol dose and metabolism play a minor role, if any, in sensitivity and tolerance to ethanol hypothermia as we have assessed it here.

Considering that the effects of ethanol on body temperature occur almost immediately after injection, while blood levels 
are still rising and the relevant enzyme systems are saturated, this lack of correlation is not surprising.

There are at least two important aspects to functional tolerance (besides the doubtful contribution from dispositional tolerance) which are experimentally separable. The first is cellular or physiological tolerance. Ethanol affects a variety of neurotransmitter systems. Up- or downregulation of receptors in response to a decrease or increase in neurotransmitter may be important in functional tolerance development (Kalant and Lê, 1984; Pohorecky and Brick, 1988). Part of functional tolerance may be mediated by changes in the lipid constituents of the cell membrane, rendering a cell less susceptible to disordering by ethanol (Rottenberg et al, 1981), or secondarily affecting receptor function. Such physiological or cellular processes may be responsible for the tolerance to ethanol hypothermia that develops in rats (Lê et al, 1986; Mackenzie-Taylor and Rech, 1991) and mice (Grieve and Littleton, 1979; Rigter et al, 1980) even when a decline in body temperature after ethanol is prevented. No measurements were made on the mice in the present series of experiments to yield information relevant to this aspect of tolerance acquisition. It seems highly unlikely, however, that repeated exposure to ethanol would have stimulated cellular tolerance development in the Mixed Protocol mice, and not in the Box Protocol mice. 
The second component of functional tolerance appears to be based upon conditioning or learning processes. The classical conditioning model hypothesizes that the circumstances surrounding ethanol administration elicit a conditioned response that is opposite in direction to the effects normally associated with acute ethanol (Holloway et al, 1992). This process is difficult to understand and to quantify, partly because it is difficult to design experiments to test the effect of learning alone. An interesting experiment was performed using rats and heroin (Max, 1990). A group of rats was given heroin injections every other day for thirty days in a distinctive room. On alternate days, the rats were given injections of dextrose in a different, also distinctive room. On the test day, in either the "heroin room" or the "dextrose room", all rats were given a dose of heroin large enough to kill most or all naive rats; many more rats survived in the "heroin room" than in the other. Since the histories of the two groups were the same, this result implies that the animals expecting a heroin dose produced a response to compensate for and antagonize the lethal effect of the drug, while the animals expecting dextrose did not; development of tolerance appeared to be a function of expectation. In the case of the Mixed and Box Protocol mice, however, it seems unlikely that conditioning differences could have contributed to the observed difference in mouse response. Although the tube and box environments were very different, 
both environments offered a predictable set of cues for drug administration and subsequent drug effects. Thus, one would expect the mice in both Protocols to have been equally conditioned to receiving ethanol under their equally predictable test conditions. Indeed, one might expect more thorough conditioning in the Box Protocol group, since for them, ethanol administration occurred with unwavering predictability, whereas the Mixed Protocol mice received ethanol in both tube and box environments.

It has been argued that tolerance is a response to a functional disturbance; "... without a functional disturbance, no adaptation can occur because there is no stimulus to provoke an adaptation" (Poulos and Cappell, 1991). This idea is supported by the very slow development of tolerance to ethanol hypothermia in mice and rats when their body temperature is not allowed to decline after injection, or by results indicating that stress both increases internal temperature decline after ethanol (Peris and Cunningham, 1986), and accelerates tolerance development (Mansfield and Cunningham, 1980). Such acceleration may be the result of the increased functional disturbance (increased decline in body temperature) when stress and ethanol are combined. However, the Box Protocol mice certainly experienced a decline in body temperature after ethanol; this functional disturbance did not precipitate the development of tolerance. 
In summary, when Mixed Protocol mice were allowed to select a preferred temperature in a temperature gradient they manifested both rapid and chronic functional tolerance to the thermoregulatory effects of a moderate dose of ethanol. Although acute ethanol caused a downward adjustment of the regulated body temperature, this effect diminished rapidly in mice with an intact behavioral effector mechanism. In contrast, similar Box Protocol mice injected with the same dose of ethanol and held at laboratory temperature did not develop measurable functional tolerance to ethanol's hypothermic effects, as assessed by postinjection change from preinjection baseline temperature. Both groups of mice developed dispositional tolerance to ethanol.

It seems likely that the box environment was at least as stressful as, and possibly more stressful than the tube environment. Evidence from other laboratories indicates that stress accentuates the development of tolerance to ethanol hypothermia, but this effect was not observed in the Box Protocol mice. The difference between the Mixed and Box Protocol mice can probably not be explained on the basis of differences in conditioning and association (learning), or because of differential functional disturbance. The most likely explanation for the observed difference in tolerance development is that the Mixed Protocol mice were able to maintain their regulated temperature using thermoregulatory behavior, while the Box Protocol mice had no effector 
mechanisms available to them that were sufficiently powerful to counteract the increased conductance caused by the drug.

Although the present experiment detected no development of functional tolerance to ethanol hypothermia in the Box Protocol animals, other laboratories have been able to document the development of such tolerance in mice at room temperatures. The cause of this discrepancy is unclear. The answer may be, in part, that temperatures of the Box Protocol mice were monitored with mini-mitters, while in other laboratories rectal temperatures have almost invariably been measured. Another part of the answer may lie in the fact that the Box Protocol mice were housed with siblings, but tested alone.

\section{THERMOREGULATORY BEHAVIOR DURING WITHDRAWAL} FROM ETHANOL DEPENDENCY

Consideration of the thermoregulatory data collected from genetically heterogeneous mice undergoing withdrawal from ethanol dependency in the temperature gradient reveals two major points. First, the regulated body temperature of these mice was altered very little, if at all, during withdrawal from ethanol dependence. Second, much cooler temperatures were selected by the withdrawing mice; this would significantly increase the ability of the withdrawing animals to dissipate heat. Whether withdrawing in a temperature gradient or at a constant ambient temperature of $29.5^{\circ} \mathrm{C}$, the 
previously dependent mice maintained their body temperatures at levels similar to those of control mice. Under the conditions of this study, the accuracy of the regulator of body temperature was not impaired. The variability in body temperature of withdrawing and control animals was comparable. This similarity of both level and variability of internal temperature under withdrawing and control conditions occurred despite the generally greater activity of the withdrawing animals, and their preference for cooler ambient temperatures in the gradient.

The increased drive of withdrawing mice to dissipate heat (about $2.7^{\circ} \mathrm{C}$, as approximated by the difference between internal and selected temperatures) may reflect a need to deal with an increase in metabolic heat production. Signs of sympathetic hyperactivity such as elevated heart rate and increased blood pressure are typical in withdrawing human patients (Victor, 1966; Gross et al, 1974). In laboratory animals, increases in the release (Cohen et al, 1980) and in the metabolites (Ahtee and Svartstrom-Fraser, 1975) of the catecholamines are seen during withdrawal. Both epinephrine and norepinephrine increase overall metabolic rate, and can cause significant increases in heat production (Hoffman and Lefkowitz, 1990); selection of a cooler ambient temperature would enable a withdrawing mouse to dissipate this additional heat. In an earlier study (Ritzmann and Tabakoff, 1976), withdrawing mice solved this problem in a different way. In 
a $34^{\circ} \mathrm{C}$ environment, the internal temperatures of withdrawing mice stabilized at about $39^{\circ} \mathrm{C}, 2^{\circ} \mathrm{C}$ above that of the controls. An increased drive to dissipate heat could theoretically reflect a decreased conductance, rather than an increased heat production. However, available evidence from human subjects indicates the peripheral vasculature is dilated rather than constricted during withdrawal (Godfrey et al, 1958).

Increased heat production may appear difficult to reconcile with the results of previous studies using mice. Withdrawal hypothermia has been observed by many investigators (Ritzmann and Tabakoff, 1976; Tabakoff and Ritzmann, 1977; Harris, 1979), and is described as one of the most widely used procedures to quantify withdrawal severity (Pohorecky and Brick, 1988). However, in the above studies mice underwent withdrawal at an ambient temperature of either $22^{\circ} \mathrm{C}$ or $25^{\circ} \mathrm{C}$. These temperatures are well below the thermoneutral zone of the mouse. In the current study, the presumed increase in heat production was counteracted by a decrease of about $2.7^{\circ} \mathrm{C}$ in the selected temperature. Indeed, withdrawing animals in this study that were kept at a constant $29.5^{\circ} \mathrm{C}$ (similar to the temperatures preferred by mice experiencing withdrawal in a temperature gradient) were able to maintain internal temperatures comparable to those of control mice. Under the conditions of this study, the postulated increase in heat production (measured as the difference between the drive to 
dissipate heat of withdrawing mice and of control mice) decreased in a linear manner over about twenty-two hours.

At temperatures below about $29^{\circ} \mathrm{C}$, however, mice would need to produce additional heat in order to maintain body temperature. During withdrawal, the ability to augment heat production beyond an increased baseline level may be impaired. Chronic ethanol intake leads to hypoglycemia and severe liver dysfunction, which continues into withdrawal (Lieber, 1989). Mice exposed to $22^{\circ} \mathrm{C}$ for the first five hours of withdrawal exhibited a mean internal temperature of $35^{\circ} \mathrm{C}$. They were then moved to a $4^{\circ} \mathrm{C}$ environment, and one hour afterwards internal temperature had fallen to $31^{\circ} \mathrm{C}$. The corresponding mean internal temperatures of control animals were $37^{\circ} \mathrm{C}$ in the $22^{\circ} \mathrm{C}$ environment, and $35^{\circ} \mathrm{C}$ in the $4^{\circ} \mathrm{C}$ environment (Ritzmann and Tabakoff, 1976).

From this evidence, it is possible to construct a picture of the thermoregulatory capabilities of an animal experiencing ethanol withdrawal. The regulated temperature itself is little altered, either in level or in accuracy. However, an increased metabolic rate requires the dissipation of a greater than normal heat load. Finally, the capacity to augment heat production beyond this increased baseline level is severely compromised.

This picture is consistent with most of the available data. Freund (1979) noted that humans undergoing withdrawal were vasodilated and sweating, and yet had an elevated 
internal temperature. This was interpreted as indicating an increased heat production, but not necessarily an alteration in the regulated body temperature. This evidence appears to be at variance with typical observations of hypothermic withdrawing mice in the literature. However when comparing different species, differences in size, insulation, and metabolic capabilities must be taken into account. Although the lower critical temperature for the mouse may be somewhat decreased during withdrawal, it is still substantially above normal laboratory temperature. The typically observed decline in mouse body temperature would result if mice were unable to augment heat production sufficiently to counteract the ambient temperature at which withdrawal was experienced.

Interpreting the results of studies on withdrawing rats is more difficult. The lower critical temperature of this species is about $27^{\circ} \mathrm{C}$ (Gordon, 1990). If the added heat production of withdrawal is taken into account, the lower critical temperature for a rat undergoing withdrawal would be close to normal laboratory temperature, and the internal temperature of the withdrawing rat less affected in such an environment than would be the temperature of the mouse. Data available from the literature support this line of reasoning. In a $23.5^{\circ} \mathrm{C}$ environment, rats previously exposed to ethanol vapor for ten days were removed from the vapor chamber and monitored for spontaneous withdrawal signs, handling induced convulsions, and changes in body temperature. Withdrawal 
signs were maximal from eight to twelve hours after the initiation of withdrawal. During this four hour period, the mean of five measurements of internal temperature was $37.3^{\circ} \mathrm{C}$ for both withdrawing and control rats (Ferko and Bobyock, 1978). In experiments from a different laboratory, ethanol in the form of a liquid diet was administered to rats for two weeks (Pohorecky et al, 1974) or six weeks (Brick and Pohorecky, 1977). Both groups went through withdrawal at an ambient temperature of $21^{\circ} \mathrm{C}$. The two week induction group showed maximal withdrawal signs ten to fifteen hours after the ethanol diet was removed. At a withdrawal time of twenty-four hours, internal temperatures of withdrawing rats averaged $0.7^{\circ} \mathrm{C}$ lower than controls. Withdrawal signs were maximal from about seventeen to twenty-three hours for the six week induction group. The mean of two measurements of internal temperature (at sixteen and twenty hours) indicated that withdrawing animals averaged $0.5^{\circ} \mathrm{C}$ below the control group. Although the decrease in internal temperature was not statistically significant in either of the above cases, the lower body temperatures may indicate that at an ambient temperature of $21^{\circ} \mathrm{C}$, withdrawing rats are reaching the limits of their ability to augment heat production.

In the latter six week induction study (Brick and Pohorecky, 1977), behavioral responses were also investigated. The rats were run twice, during the period of severe withdrawal symptoms, in a T-maze which allowed them the choice 
between $2^{\circ} \mathrm{C}, 19^{\circ} \mathrm{C}$ and $30^{\circ} \mathrm{C}$. Each run lasted slightly longer than four minutes. The mean temperature chosen by the withdrawing rats $\left(24.6^{\circ} \mathrm{C}\right)$ was considerably higher than that preferred by the controls $\left(16.2^{\circ} \mathrm{C}\right)$. Several factors may explain the divergence between the behavior of these rats and that of mice in temperature gradients. The rats were given only a very brief opportunity to select a preferred temperature; in the time available, their selection had little chance to produce a change in internal temperature. Since internal temperature was somewhat lower in the withdrawing animals before the maze trials, a preference for warmer temperatures may have reflected an attempt to increase body temperature. Another factor involves a basic difference in the thermoregulatory behavior of mice and rats. Normal mice are careful to remain well within their thermoneutral zone, and almost always select temperatures above $30^{\circ} \mathrm{C}$. Rats, on the other hand, are relatively tolerant of mild cold stress; rats in a temperature gradient typically select a range of temperatures from $19^{\circ} \mathrm{C}$ to $25^{\circ} \mathrm{C}$ (Gordon, 1990). It seems possible that the metabolic derangements accompanying withdrawal would render withdrawing rats far less tolerant of low temperatures - at least of those lower than what would be necessary to dissipate any fixed increase in the metabolic rate.

The results of the study examining thermoregulatory behavior during withdrawal in the selected lines of mice 
generally confirmed results from the study of the genetically heterogeneous mice; the data indicated a higher heat production, but little effect on the regulated temperature of selected lines of mice experiencing withdrawal in a temperature gradient. However the selected lines did differ from each other and from the mice in the initial study in a few specific and interesting ways.

The temperature and activity profiles of the withdrawing COLD1 and COLD2 mice were quite similar to each other, and to the genetically heterogeneous mice in the first study. Withdrawing COLD mice maintained internal temperature comparable to that of similar control mice, indicating that the regulator of body temperature was not affected during withdrawal. Withdrawing COLD mice also selected cooler temperatures than did similar control mice. This suggests a greater heat production in withdrawing animals, heat which was dissipated by choosing to occupy cooler locations in the gradient, as already discussed in detail. Like the genetically heterogeneous mice, activity of the withdrawing COLD mice during the time of expected maximum withdrawal severity was somewhat higher than that of similar control animals. The differential between activity levels of withdrawing and control COLD mice was not, however, as great as the differential seen in the first study. This likely explains the smaller difference in drive to dissipate heat between withdrawing and control CoLD mice, as compared to the 
genetically heterogeneous mice. For withdrawing mice in the first study, given that the regulator of body temperature was not affected, selection of a cooler environment was required for two reasons - to dissipate the heat of an augmented metabolic rate, and to dissipate heat generated by higher levels of activity. The COLD mice had likewise to cope with an increase in metabolic heat production, but the additional heat load generated by increased activity was substantially smaller in the COLD mice. Therefore, the difference between selected temperature of withdrawing and control COLDI mice (about $0.8^{\circ} \mathrm{C}$ ) and COLD2 mice (about $0.9^{\circ} \mathrm{C}$ ) was smaller than the difference for the mice in the original study (about $\left.2.7^{\circ} \mathrm{C}\right)$.

The HOTI mice presented quite a different picture. Like all the mice already discussed, internal temperatures of withdrawing and control HOTI mice were similar, indicating that the regulated temperature was not affected by withdrawal in these animals. However withdrawing and control HOTI mice also selected similar temperatures in the gradient, and the difference between internal and selected temperatures was identical under the two conditions. From these data alone, no difference between withdrawing and control HOTI mice is apparent. The difference between the conditions becomes obvious only when their levels of activity are compared. While the HOTl withdrawing mice showed activity levels similar to those of the other three genotypes, the HOTl control mice 
evidenced an unusually high level of activity, much higher than withdrawing HOT1 mice, or any of the other three genotypes under any condition. It seems probable that the heightened activity of the control HOTl mice generated sufficient body heat that they were, in this respect, simi.lar to the withdrawing mice; the increased heat production becaisse of activity in the control HOTl mice equalled the increased metabolic heat production in similar withdrawing animals. In neither case was the regulated temperature affected. But for different reasons, both withdrawing and control HOTI mice had a similar increased burden of heat to dissipate, and in consequence selected similar temperatures in the gradient. The reason for increased activity by the HOT1 control mice is unknown. Indeed, the difference between HOTI withdrawing and control mice may not be due to an enhancement of activity in controls, but rather to suppression of activity in withdrawing mice.

The HOT2 mice withdrawing from ethanol, like the COLD mice already discussed, were slightly more active than similar control mice, selected lower temperatures, and maintained a higher difference between internal and selected temperatures than controls. But despite the fact that withdrawing HOT2 mice selected the lowest temperatures in the gradient of any genotype or condition, internal temperatures of withdrawing HOT2 mice remained substantially above those of similar control mice for the entire monitoring period. Upon first 
inspection of the data it certainly appears that this genotype differed from all other mice studied in the temperature gradient during withdrawal; there seemed to be an effect of withdrawal upon the regulated temperature of the HOT2 mice. These mice had available to them in the gradient tubes much cooler temperatures than those they actually chose. Had they occupied a cooler location, these animals could have greatly increased the differential between internal and ambient temperature, to assist a further decline in internal temperature. They did not choose to do so, although under other conditions mice have selected much lower temperatures in the gradient than those selected by these withdrawing HOT2 animals. However, it is possible that during withdrawal from ethanol the mice find normally acceptable temperatures aversive. A floor effect may have limited the temperature selection behavior of the HOT2 mice. Like the withdrawing mice in a study discussed above (Ritzmann and Tabakoff, 1976), which coped with a $34^{\circ} \mathrm{C}$ environment by maintaining internal temperature at about $39^{\circ} \mathrm{C}$, the HOT2 mice may have preferred to maintain internal temperature at a higher level rather than to occupy a thermally unpleasant location in the gradient.

Given the significant positive correlation in panels of inbred mouse strains between initial hypothermic sensitivity and ability to develop tolerance (Crabbe et al, 1982a), and the significant negative correlation between withdrawal severity and ability to develop tolerance to ethanol 
hypothermia (Crabbe et al, 1983b), one would predict that the COLD mice, so sensitive to the hypothermic effect of acute ethanol, would show a much less severe withdrawal reaction than the HOT mice. It would be useful to be able to compare withdrawal severity between the selected lines based upon this thermoregulatory behavior data.

Withdrawal severity in mice is most often assessed by scoring the severity of convulsions, from mild convulsions elicited by lifting the mouse and spinning it gently, to violent spontaneous convulsions, which may even result in death (Goldstein, 1972). A variety of other symptoms of withdrawal have been scored or observed in the mouse, including muscle tremors or rigidity, gait abnormalities, stiff tail, spontaneous vocalization, hyperreactivity, changes in activity, and (as already discussed in detail) "hypothermia" (Friedman, 1980). Most of these symptoms are impossible to assess when a mouse is in a gradient tube. Activity, however, was one of the measured parameters. Unfortunately, activity during withdrawal has been much less well characterized than seizures. But decreases in activity, compared to controls, have been noted in rats withdrawing from oral ethanol (Hunter et al, 1975; Pohorecky, 1976; Brick and Pohorecky, 1977) and in mice after three days of ethanol vapor inhalation (Freed and Michaelis, 1978). However another group saw decreased activity in most rats, but increased activity in 
individuals which had consumed less ethanol (Liljequist et al, 1977).

No pre-ethanol-exposure baseline activity data is available for the selected lines. (Activity data for one hour in the gradient is, of course, available and has been presented; but for the withdrawal study, mice were in the tubes for a much longer period of time.) such baseline data would be helpful in determining whether the difference in activity between the HOTl control and withdrawing mice was due to suppression of normal activity in the withdrawing mice, or stimulation of activity due to some unknown cause in the controls. However since the HOT1 control data is available, it does not seem unreasonable to accept this data and tentatively conclude that the difference in activity between the HOTl groups is due to hypoactivity on the part of the withdrawing animals. If this is true, then at least on the basis of one measure, that of activity, the HOT1 mice were more affected than the other genotypes during withdrawal that is, the difference in activity can be taken as evidence of a more severe withdrawal reaction in the HOTl genotype.

The other indication of relatively greater witharawal severity that can be gleaned from the data is the difference between the internal temperatures of HOT2 control and withdrawing mice already discussed. If the arguments made above are valid, then the higher internal temperature in HOT2 withdrawing mice is evidence of a greater increase in 
metabolic heat production in this genotype than in any other. Again, on the basis of one measure, the HOT2 mice appear to have experienced a more severe withdrawal reaction than the other genotypes.

What of the COLD mice? These mice appear much like the genetically heterogeneous mice in the first study, except for a smaller stimulation of activity during withdrawal. Therefore, although the reasoning is somewhat indirect, the data presented support a tentative conclusion that a more severe withdrawal reaction occurred in the HOT, than in the COLD mice.

TEMPERATURE RESPONSE TO CENTRALLY ADMINISTERED SEROTONIN

Injections of serotonin into the lateral ventricle of the brain caused a dose-dependent decline in rectal temperature in all genotypes of mice in this study. The COLD mice were more sensitive than the HOT mice to the effect of this neurotransmitter on body temperature. This difference was significant in both replicates of the selected lines. The existence of a significant difference between HOT and COLD mice in their body temperature response to serotonin, in light of the fact that the lines were selected only for their response to ethanol, suggests that the serotonergic system is involved in the response of the regulator of body temperature to ethanol. Both HOT1 and COLDl mice lowered their internal temperatures further during behavioral thermoregulation in the 
temperature gradient than did similar mice in the restraint device. This suggests that the decline in body temperature after serotonin was a regulated phenomenon.

Evidence supports the hypothesis that centrally administered serotonin affects body temperature in rodents. In rats, intracerebroventricular serotonin caused a fall in body temperature in both fully restrained animals at $22^{\circ} \mathrm{C}$ (Feldberg and Lotti, 1967) and partially restrained animals at $23.5^{\circ} \mathrm{C}$ (Crawshaw, 1972). In the mouse, intracerebroventricular serotonin caused a dose-dependent fall in esophageal temperature of unrestrained animals at $21^{\circ} \mathrm{C}$ (Brittain and Handley, 1967), and in rectal temperature of animals kept at $22^{\circ} \mathrm{C}$ (Ritzmann and Tabakoff, 1970). Hypothermia following intracerebroventricular serotonin was prevented by methysergide, a serotonin antagonist (Burks and Rosenfeld, 1979).

Serotonin injections into the preoptic/anterior hypothalamic area of rats held at $17^{\circ} \mathrm{C}$ produced dose-dependent decreases in rectal temperature (Cox and Lee, 1979). Rats held in a calorimeter at either $8^{\circ} \mathrm{C}$ or $22^{\circ} \mathrm{C}$ also showed a decrease in rectal temperature after injections of serotonin into the preoptic area, due to decreased metabolic heat production at the lower temperature, and to both decreased metabolism and cutaneous vasodilation at the higher temperature (Lin et al, 1983). In contrast, injections of serotonin into the preoptic/anterior hypothalamic area 
produced dose-dependent increases in hypothalamic temperature in partially restrained rats at $23.5^{\circ} \mathrm{C}$ (Crawshaw, 1972). However, when the rats in the latter study were trained to bar press for heat at an ambient temperature of $-7^{\circ} \mathrm{C}$, bar press rates did not change after serotonin injections, suggesting that a regulated change in body temperature had not occurred. These differences in body temperature response may have been due to differences in cannula placement, since the injections in the latter study (Crawshaw, 1972) were administered into a site posterior and inferior to the effective sites in the other studies (Cox and Lee, 1979; Lin et al, 1983).

Microiontophoretic application of serotonin to thermosensitive hypothalamic neurons excited warm-sensitive, and inhibited cold-sensitive neurons (Murakami, 1973), a response consistent with a role for serotonin in mediating a decrease in the regulated body temperature. Ascending serotonergic input to the hypothalamus arises mainly from the raphé nuclei (Brück and Hinckel, 1990). It is postulated that peripheral warm receptors in trunk skin (and possibly in the body core) ascend to the raphe nuclei, stimulating serotonincontaining neurons which project to the hypothalamus to activate warm-sensitive and inhibit cold-sensitive neurons, thus stimulating heat loss responses (Brück and Hinckel, 1990). A recent study used ${ }^{14} \mathrm{C}$-labelled $\alpha$-methyl-L-tryptophan ( $\alpha$-MTrp), a synthetic analogue of L-tryptophan (the serotonin precursor which crosses the blood-brain barrier and is 
transported into the neuron), to study transport in the serotonergic system with autoradiography following administration of the tracer to rats (Nagahiro et al, 1990). The chemical is hydroxylated to 5-hydroxy- $\alpha-L-t r y p t o p h a n$, decarboxylated to 5-hydroxy- $\alpha$-methyl-tryptamine ( $\alpha-\mathrm{M} 5 \mathrm{HT})$, and transported like serotonin; but since it is not a substrate for monoamine oxidase, it remains for a long time in the brain (Nagahiro et al, 1990). Autoradiographic studies using $\alpha$-Mtrp showed that net transport was from the raphe nuclei to terminal fields, including the hypothalamus, after conversion to $\alpha-\mathrm{M} 5 \mathrm{HT}$; retrograde transport was not observed (Nagahiro et al, 1990).

As long ago as 1957 it was recognized that multiple serotonin receptor subtypes might exist (Glennon, 1986). Today the family of serotonin receptors is large and, apparently, still growing, with pharmacologically distinct 5$\mathrm{HT}_{1}, 5-\mathrm{HT}_{2}, 5-\mathrm{HT}_{3}$ and $5-\mathrm{HT}_{4}$ types recognized (Chalmers and Watson, 1991). The 5-HT, receptors are a particularly eclectic class with at least five subtypes distinguished $\left(5-\mathrm{HT}_{1 \mathrm{~A}}, 5-\right.$ $\mathrm{HT}_{1 B}, 5-\mathrm{HT}_{1 C}, 5-\mathrm{HT}_{10}$ and $5-\mathrm{HT}_{1 \mathrm{P}}$ ) (Frazer et al, 1990; Göthert and Schlicker, 1990). This $5-\mathrm{HT}_{1}$ group mediates a variety of behaviors in rodents, including hypothermia (Mylecharane, 1989; Göthert and Schlicker, 1990). For the study of the 5$\mathrm{HT}_{2}$ and $5-\mathrm{HT}_{3}$ receptor subtypes, highly selective antagonists are available (Mylecharane, 1989). Highly selective competitive antagonists for all of the $5-\mathrm{HT}_{1}$ receptors are not 
available, and classification has generally been made with the use of agonists and antagonists with overlapping affinities for the various 5-HT, receptor subtypes (Göthert and Schlicker, 1990). Several selective agonists do exist for the 5-HT ${ }_{1 \wedge}$ subtype, however (Göthert and Schlicker, 1990), and this subtype has been the best characterized. stimulation of the $5-\mathrm{HT}_{11}$ receptor subtype has been shown to decrease body temperature in humans (Lesch et al, 1990), rats (Hjorth, 1985; Gudelsky et al, 1986; Higgins et al, 1988; Bill et al, 1991; Hillegaart, 1991) and mice (Goodwin et al, 1985; Berendsen and Broekkamp, 1990; Bill et al, 1991; Meller et al, 1992). Stimulation of the $5-\mathrm{HT}_{11}$ receptor has also been shown to suppress locomotor activity in mice (Berendsen and Broekkamp, 1990). The activity of HOTI and COLDl mice in the temperature gradient was decreased after serotonin, as compared to activity after control injections. Although (probably due to the small number of animals tested in the gradient) the effect of selected line was not significant, activity of the cold1 mice tended to be depressed more than that of the HOT1 mice. The pharmacology of the serotonergic system is confusing, and the pharmacological evidence linking serotonin with ethanol hypothermia is not clear. A schematic diagram illustrating a serotonergic neuron with postsynaptic target serotonin receptors is illustrated in Figure 42 . These two neurons could be imagined to be a dorsal raphé serutonergic 
neuron, and a target hypothalamic neuron, for reference in the following discussion.

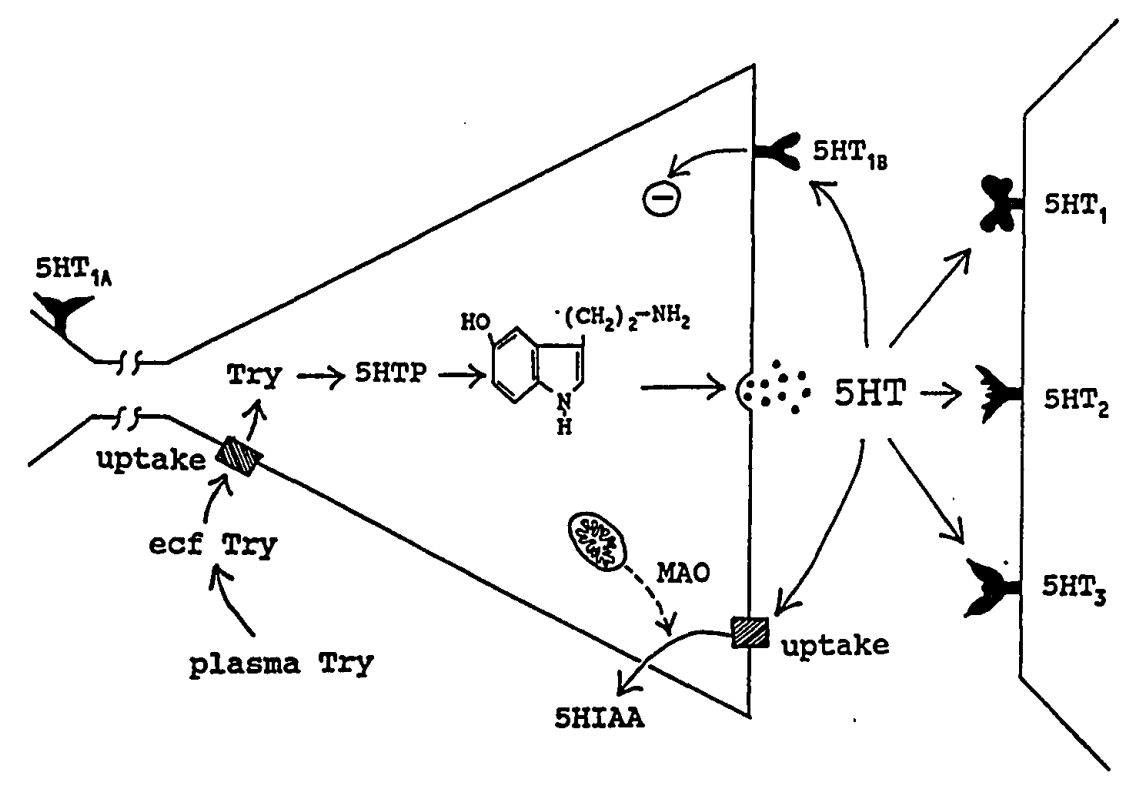

Figure 42. The serotonergic neuron. Plasma tryptophan (Try) transported from blood into brain by specific carrier (not shown); enters serotonergic neuron by specific, carrier-mediated process. Try converted to 5-hydroxytryptophan (5HTP) by enzyme try hydroxylase; this is the ratelimiting step in the pathway. 5HTP converted to serotonin (5-hydroxytryptamine, 5HT) by enzyme 5HTP decarboxylase. 5HT released into synaptic cleft can act upon postsynaptic $5 \mathrm{HT}_{1}, 5 \mathrm{HT}_{2}$ or $5 \mathrm{HT}_{3}$ receptors or inhibitory presynaptic $\mathbf{5 H T}_{\mathbf{}_{\mathrm{B}}}$ autoreceptors, or be taken back into neuron and metabolized to 5hydroxyindoleacetic acid (5HIAA) by monoamine oxidase (MAO) in outer mitochondrial membrane. $5 \mathrm{HT}_{1 \mathrm{~A}}$ autoreceptor on cell body may regulate firing frequency of cell. Cell bodies of serotonergic neurons found in and around midline raphé nuclei; projections widely distributed (figure and legend adapted from Kandel et al, 1991, pg. $216 \& 878$; Martin, 1991).

In the rat brain, high levels of $5-\mathrm{HT}_{14}$ receptor gene mRNA (indicating synthesis of $5-\mathrm{HT}_{1 \mathrm{~A}}$ receptors), as well as a high density of $5-\mathrm{HT}_{1 \mathrm{~A}}$ receptors were evident in the dorsal raphé 
(Chalmers and Watson, 1991). These 5-HT ${ }_{14}$ receptors are located presynaptically, as somatodendritic (cell body) receptors, and postsynaptically (Göthert and Schlicker, 1990; Bill et al, 1991; Chalmers and Watson, 1991). Hypothermia could occur after stimulation of excitatory postsynaptic 5-HT receptors, facilitating transmission along 5-HT pathways, or by stimulation of inhibitory somatodendritic receptors, which would reduce release of serotonin from axon terminals.

Electrical stimulation of the midbrain raphe nuclei caused a decrease in rectal temperature of rats held in a calorimeter at $8^{\circ} \mathrm{C}$ or $22^{\circ} \mathrm{C}$, due to decreased metabolism at both temperatures, and also to cutaneous vasodilation at the higher temperature (Lin et al, 1983). The serotonin synthesis inhibitor p-chloroamphetamine, which produces significant and prolonged depletion of brain serotonin and hyperthermia when given by itself intracerebroventricularly (Pohorecky et al, 1976), produced decreases in the magnitude of ethanol-induced hypothermia in the rat in one laboratory (but see below) (Frankel et al, 1978). This evidence, when considered together with examples of hypothermia after intracerebroventricular or preoptic/anterior hypothalamic administration of serotonin, as discussed above (Feldberg and Lotti, 1967; Crawshaw, 1972; Cox and Lee, 1979; Lin et al, 1983) suggests that hypothermia may occur in the rat after stimulation of an excitatory postsynaptic $5-\mathrm{HT}_{1 \mathrm{~A}}$ receptor, facilitating transmission along serotonergic pathways. 
However there is also evidence from rats that hypothermia after serotonin may occur via stimulation of inhibitory serotonergic cell body receptors, and that a decrease (rather than an increase) in serotonin stimulates heat loss responses. In the rat at $21^{\circ} \mathrm{C}$, direct application of either serotonin or the 5-HT ${ }_{1 \wedge}$ agonist 8-OH-DPAT into the dorsal raphe (possibly acting on inhibitory somatodendritic receptors) produced a significant decrease in rectal temperature, which was partially antagonized by (-)pindolol (Hillegaart, 1991), a stereoselective 5-HT 1 /1B antagonist (Chalmers and Watson, 1991). In contrast to Frankel et al's results mentioned above, in a different laboratory, intracerebroventricular pchloroamphetamine (to deplete brain serotonin) produced a significant potentiation of ethanol-induced fall in rectal temperature at $21^{\circ} \mathrm{C}$ (Pohorecky et al, 1976). Such depletion also did not attenuate the hypothermic response to intraperitoneal 8-OH-DPAT (Bill et al, 1991). Similarly, response to 8-OH-DPAT was not altered in rats by lesioning serotonergic neurons with 5,7-dihydroxytryptamine (Lê et al, 1980; Bill et al, 1991). Treatment of rats with the drug Lilly 110140, which specifically inhibits serotonin reuptake at presynaptic terminals (thereby presumably resulting in increased stimulation of postsynaptic serotonin receptors) significantly attenuated the decline in rectal temperature after ethanol (Pohorecky et al, 1976). If an increase in serotonin attenuates ethanol hypothermia, and if the 
hypothermic response to systemic 8-OH-DPAT is not altered by destruction of serotonergic neurons, it is possible that excitatory postsynaptic $5-\mathrm{HT}_{1 \mathrm{~A}}$ receptors mediate 8-OH-DPAT hypothermia, and perhaps ethanol hypothermia as well, in the rat.

Less evidence is available for the mouse. Lesioning central serotonergic neurons with 5,7-dihydroxytryptamine abolished the hypothermic response to 8-OH-DPAT (Goodwin et al, 1985; Bill et al, 1991), as did treatment with pchlorophenylalanine (Goodwin et al, 1985). Crabbe and Feller (1993) have demonstrated that COLD mice are more sensitive than HOT mice to 8-OH-DPAT-induced hypothermia; lesioning serotonergic neurons with 5,7-dihydroxytryptamine significantly attenuated the rectal temperature decline after ethanol in COLD, but not in HOT mice. If destruction of serotonergic neurons attenuates 8-OH-DPAT-induced hypothermia, one might postulate involvement of somatodendritic receptors, at least in the COLD mouse (since any postsynaptic 5-HT $1 \mathrm{~A}$ receptor sites would be still be available after lesioning). In such a system a decrease in serotonin release would stimulate heat loss responses, perhaps by decreasing inhibitory input to neurons controlling these responses, or decreasing excitatory input to neurons controlling the opposite responses (heat conservation/production). This idea is difficult to reconcile with the response, observed in both COLD and HOT mice, of a decrease in the regulated body 
temperature after injection of serotonin into the brain (increase in serotonin levels), or the observation that depletion of brain serotonin by p-chlorophenylalanine did not alter the hypothermic response of mice to 8-OH-DPAT (Meller et al, 1992).

While suggestive, few of the studies using whole animals discussed above allow conclusions to be drawn about thermoregulatory effects of manipulation of the serotonergic system, or about the participation of serotonin in the thermoregulatory sequelae of ethanol administration. In contrast, the existence of a difference in body temperature response to serotonin in both replicates of the selected HOT and COLD lines of mice is powerful evidence for the importance of serotonin in the mediation of ethanol-induced hypothermia. In the absence of genotypic variation, phenotypic differences reflect differences in environmental influence (Hegmann and Possidente, 1981). The reverse can also be said, that in the absence of environmental differences, phenotypic differences reflect genetic differences. When appropriate care is taken in the genetic selection process to control both for traitirrelevant inbreeding (i.e. by replication of the selection experiment) and for differences in environmental effects, differences that are detected between selected lines in some non-selected trait can be inferred to have arisen as a result of changes in gene frequencies related to the selected trait (Crabbe et al, 1988). 
Based upon the behavior of the animals tested in the temperature gradient, the decline in body temperature after serotonin appeared to be a regulated phenomenon. Although mice, like all endothermic vertebrate animals, have autonomic effectors available to them to maintain body temperature at the regulated level, behavioral adjustments can be made almost immediately if a range of ambient temperatures is accessible. For the animals tested only in the restraint device at constant ambient temperature, behavioral possibilities for implementing heat loss were limited to minor postural adjustments. Other available thermoregulatory effector mechanisms were vascular and metabolic responses. Metabolism was not measured. Tail surface temperature measurements in a subset of mice indicated that tail vasodilation occurred almost immediately in response to serotonin injection. The time course of change in body temperature, which occurred shortly after tail vasodilation, suggested that this was an important avenue of heat loss for these mice. However, based upon data from the restrained animals alone, one cannot distinguish with certainty between regulatory effects and derangement. In the gradient tubes, however, a wide range of ambient temperatures was available to the animals. Both HOTI and COLDI mice utilized this opportunity to decrease internal temperatures beyond the decreases observed in similar animals in the restrainers, suggesting that the avenues of heat loss available in the restrainers were insufficient to enable the 
animals to attain the lower set point temperature that followed the serotonin injections. The time course of the behavioral effect plainly showed that the animals chose very cool ambient temperatures even as their internal temperatures were falling, clear evidence of a decline in the regulated body temperature in response to intracerebroventricular serotonin. The tendency for activity of the COLD1 mice to be more depressed by serotonin provides additional support for the hypothesis that the $5-\mathrm{HT}_{1 \mathrm{~A}}$ receptor is involved in the mediation of ethanol hypothermia, and that a difference between the HOT and COLD mice in body temperature response to ethanol has resulted from a selection-induced difference between the lines in the $5-\mathrm{HT}_{1 \wedge}$ receptor subtype.

\section{CONCLUSION}

In conclusion, moderate doses of ethanol cause a decrease in both internal and selected temperatures of behaviorally thermoregulating mice, indicating that ethanol causes a decrease in the set point for regulated body temperature in mice. This conclusion was drawn from evidence collected using genetically heterogeneous animals, and was confirmed by the responses of lines of mice which were selected specifically for sensitivity and resistance to the effect of ethanol on rectal temperature. HOT and COLD mice differed substantially in their thermoregulatory response to ethanol. It therefore appears that genetic selection for a difference between Hот 
and COLD mice in rectal temperature response to ethanol has resulted in a selection-induced difference in the central nervous system regulator of body temperature. Elucidation of the neurophysiological and neuropharmacological mechanisms underlying the difference between HOT and COLD mice holds promise for substantially advancing our understanding of the mechanisms by which ethanol exerts its acute thermoregulatory effects.

Although the baseline internal temperatures of COLD2 mice varied as expected with the light-dark cycle in the animal room, there was little effect of time of day on the thermoregulatory response to ethanol in the temperature gradient. This lack of effect was likely due to the significant arousal and stress associated with transportation from the animal room to the laboratory, and beginning an experiment. These data gave no indication that the normal time for ethanol experiments, approximately 1000 to 1400 hour, was a time of unusual temperature response to ethanol. However the possibility that another genotype might show a difference in response to ethanol at different times of day cannot, on the basis of these data, be excluded.

Over the course of eleven days of repeated ethanol injections, mice permitted to regulate their body temperature via selection of ambient temperatures in a temperature gradient developed both rapid and chronic functional tolerance to the thermoregulatory effects of ethanol. These results 
clearly indicate that both rapid and chronic tolerance to ethanol hypothermia are regulated phenomena in mice. The mice also developed dispositional tolerance, but this is unlikely to have contributed to the regulatory tolerance observed. similar mice held at room temperature after ethanol injection also developed dispositional tolerance, but evidenced no development of functional tolerance to ethanol hypothermia, as assessed by postinjection change from preinjection temperature. The most likely explanation for the difference between these two groups in their ability to express functional tolerance is that the mice in the gradient were able to achieve regulated body temperature by utilizing their uncompromised behavioral thermoregulatory abilities, while the mice in the boxes were unable to prevent loss of body heat after ethanol injection with the effector mechanisms at their disposal. It is not clear why the mice in the boxes differed from mice in the literature which, when injected at room temperature, were able to manifest tolerance to the effect of ethanol on rectal temperature. The reason for the difference may lie in part with differences in the methods used for measuring body temperature, and in part with differences in housing and testing conditions.

Genetically heterogeneous mice undergoing withdrawal from ethanol dependence selected cooler temperatures and were more active than similar control mice, but withdrawing mice did not show any alteration in the regulated body temperature. These 
findings, as well as results available from the literature, support the hypothesis that withdrawing mice, despite an increase in metabolic heat production, regulate their body temperature at a level similar to normal mice. However, their capacity to augment heat production above the increased baseline is compromised.

This hypothesis was supported by results obtained using the selected HOT and COLD lines of mice. COLD mice responded much like genetically heterogeneous mice during withdrawal. The two replicate HOT lines of mice differed from the other mice in interesting ways. НОT1 control mice were much more active than similar withdrawing mice; the additional heat generated by this activity probably resulted in the similarity in selected, as well as internal temperatures measured in withdrawing and control mice of this genotype. HOT2 withdrawing mice selected the lowest temperatures in the gradient of any genotype or condition, but nevertheless maintained internal temperatures significantly above similar control mice. The hypothesis was advanced that the differences in the HOT genotypes constitute evidence of a more severe withdrawal reaction in the HOT, than in the COLD mice. The HOT and COLD lines of mice which have been selected for a difference in thermoregulatory response to ethanol, also exhibited a significant difference in body temperature response to intracerebroventricular serotonin. During the development of the phenotypic difference between these lines 
it seems likely that selection pressure was exerted on the genes that control the expression of the serotonergic system. The results presented combined with evidence from the literature support a role for the serotonergic system, probably via the $5-\mathrm{HT}_{1 A}$ receptor subtype, in the mediation of the regulated decrease in body temperature that occurs following moderate doses of ethanol.

\section{FUTURE DIRECTIONS}

The results obtained from these studies could be used as a foundation for a variety of further explorations into the effect of ethanol on body temperature, especially using the HOT and COLD selected lines of mice.

Tolerance is the most complicated phenomenon examined in this series of experiments. It seems plain that although the regulated nature of both rapid and chronic functional tolerance to the effect of ethanol on body temperature has been clearly demonstrated here, many questions about thermoregulatory tolerance to ethanol remain to be answered. It would be of great value to quantify tolerance development in the selected lines. Studies measuring rectal temperature response to ethanol have indicated that cold mice develop tolerance while HOT mice do not, but it is not known whether the difference is a regulatory difference between the lines. It would be interesting to examine the effect of practiced responding on regulation, by exposing one group of animals to 
ethanol before a run in the gradient, and another group of animals after they complete a run in the gradient; on the last day both could be injected with ethanol and run in the gradient tubes, and their responses compared. What influence does lowered body temperature per se have on tolerance acquisition in HOT and COLD mice? This question could be approached by clamping mouse body temperature at various temperatures from high to low after ethanol administration. Along the same lines, influence of previous temperature could be approached by acclimating HOT and COLD mice to various ambient temperatures, and characterizing the effect (if any) on the development of regulated functional tolerance to ethanol.

Clearly a further characterization of HOT and COLD mice during withdrawal from ethanol dependency would be of great interest. The gradient studies generally appear to indicate increased heat production but no alteration of the regulated temperature during withdrawal, but questions about metabolism can only be definitively answered in a metabolic chamber. Such a study using HOT and COLD mice would reveal whether the selected lines differ in metabolism during withdrawal.

Finally, the specific site upon which ethanol acts to produce a decline in the regulated temperature has not been defined. It would be valuable to administer ethanol directly into sites within the hypothalamus via indwelling brain cannulae, and to measure the regulatory responses of mice. If 
an active site is localized, it may be possible to utilize pharmacological methods to precisely define the neurotransmitter system(s) responsible for producing a regulated decline in body temperature after ethanol. 
REFERENCES

Abu-Murad, C. and R.G. Thurman. Reversal of tolerance to ethanol associated with the induction of physical dependence on ethanol in the rat. In: R.G. Thurman (Ed.), Alcohol and Aldehyde Metabolizing systems - IV, Advances in Experimental Medicine and Biology, Vol. 132, Plenum Press, New York, 1980, pp. 697-704.

Adair, E.R. and B. Wright. Behavioral thermoregulation in the squirrel monkey when response effort is varied. J. Comp. Physiol. Psychol. 90:179-184, 1976.

Ahlenius, S., R. Brown, J. Engel, T.H. Svensson and B. Waldeck. Antagonism by nialamide of the ethanol-induced locomotor stimulation in mice. J. Neural Transm. 35:175178,1974 .

Ahtee, L. and M. Svartstrom-Fraser. Effect of ethanol dependence and withdrawal on the catecholamines in rat brain and heart. Acta Pharmacol. Toxicol. 36:289-298, 1975.

Alkana, R.I., J.F. DeBold, D.A. Finn, M. Babbini and P.J. Syapin. Ethanol-induced depression of aggression in mice antagonized by hyperbaric exposure. Pharmacol. Biochem. Behav. 38:639-644, 1991.

Belknap, J.K. Genetic factors in the effects of alcohol: Neurosensitivity, functional tolerance and physical dependence. In: H. Rigter and J. Crabbe (Eds.), Alcohol Tolerance and Dependence, Elsevier/North Holland Biomedical Press, Amsterdam, 1980, pp. 157-180.

Berendsen, H.H.G. and C.I.E. Broekkamp. Behavioral evidence for functional interactions between 5-HT-receptor subtypes in rats and mice. Br. J. Pharmacol. 101:667$673,1990$.

Berge, 0.-G. and I. Garcia-Cabrera. Effects of ethanol on body temperature of rats at high ambient pressure. Pharmacol. Biochem. Behav. 39:37-41, 1991.

Bernstein, S.E. Physiological characteristics. In: E.J. Green (Ed.), Biology of the Laboratory Mouse, McGraw-Hill Book Co., New York, 1966, pp. 337-350. 
Bill, D.J., M. Knight, E.A. Forster and A. Fletcher. Direct evidence for an important species difference in the mechanism of 8-OH-DPAT-induced hypothermia. Br. J. Pharmacol. 103:1857-1864, 1991.

Blatteis, C.M. Functional anatomy of the hypothalamus from the point of view of temperature regulation. In: $\mathrm{z}$. Szelényi and M. Székely (Eds.), contributions to Thermal Physiology, Akademiai Kiado, Budapest, 1980, pp. 3-12.

Borsini, F., A. Lecci, G. Volterra and A. Meli. A model to measure anticipatory anxiety in mice? Psychopharmacol. 98:207-211, 1989.

Boulant, J.A. Hypothalamic control of thermoregulation: Neurophysiological basis. In: P.J. Morgane and J. Panskepp (Eds.), Handbook of the Hypothalamus, Vol. 3 , Part A, Marcel Dekker, New York, 1980, pp. 1-82.

Boulant, J.A., M.C. Curras and J.B. Dean. Neurophysiological aspects of thermoregulation. In: L.C.H. want (Ed.), Advances in Comparative and Environmental Physiology, Vol. 4, Springer-Verlag, Berlin, 1989, pp. 117-160.

Boulant, J.A. and J.D. Hardy. The effect of spinal and skin temperature on the firing rate and thermosensitivity of preoptic neurons. J. Physiol. 240:639-660, 1974.

Boulant, J.A. and N.I. Silva. Neuronal sensitivities in preoptic tissue slices: Interactions among homeostatic systems. Br. Res. Bull. 20:871-878, 1988.

Brick, B.S. and L.A. Pohorecky. Ethanol withdrawal: Altered ambient temperature selection in rats. Alcoholism: clin. Exper. Res. 1:207-211, 1977.

Brick, J., I.A. Pohorecky, W. Faulkner and M.N. Adams. Circadian variations in behavioral and biological sensitivity to ethanol. Alcoholism: Clin. Exp. Res. $8: 204-211$, 1984 .

Briese, E. Cold increases and warmth diminishes stressinduced rise of colonic temperature in rats. Physiol. Behav. 51:881-883, 1992.

Briese, E. Rats prefer ambient temperatures out of phase with their body temperature circadian rhythm. Br. Res. 345:389-393, 1985 .

Briese, E. and M. Cabanac. Stress hyperthermia: Physiological arguments that it is a fever. Physiol. Behav. 49:1153$1157,1991$. 
Briese, E. and M.G. de Quijada. Colonic temperature of rats during handling. Acta Physiol. Latinoam. 20:97-102, 1970 .

Brittain, R.T. and S.L. Handley. Temperature changes produced by the injection of catecholamines and 5hydroxytryptamine into the cerebral ventricles of the conscious mouse. J. Physiol. 192:805-813, 1967.

Broadhurst, P.L. and J.L. Jinks. The inheritance of mammalian behavior re-examined. J. Hered. 54:170-176, 1963.

Brothwell, D. The pleistocene and holocene archaeology of the house mouse and related species. In: R.J. Berry (Ed.), Biology of the House Mouse, Academic Press, London, 1981, pp. 1-13.

Brück, K. and P. Hinckel. Thermoafferent networks and their adaptive modifications. In: E. Schönbaum and P. Lomax (Eds.), Thermorequlation: Physiology and Biochemistry, Pergamon Press, Inc., New York, 1990, pp. 129-152.

Brück, K. and E. Zeisberger. Adaptive changes in thermoregulation. In: E. Schönbaum and P. Lomax (Eds.), Thermoregulation: Physiology and Biochemistry, Pergamon Press, Inc., New York, 1990, pp. 255-307.

Buckalew, L. and G. Cartwright. General and differential behavioral effects of five ethanol dosages on the albino rat. Psychol. Rep. 23:1151-1154, 1968 .

Burks, T.F. and G.C. Rosenfeld. Neurotransmitter mediation of morphine hypothermia in rats. Life Sci. 24:1067-1074, 1979.

Cabanac, A. and E. Briese. Handling elevates the colonic temperature of mice. Physiol. Behav. 51:95-98, 1991.

Cabanac, M. Physiological role of pleasure. Science 173:1103-1107, 1971.

Carlisle, H.J. Initiation of behavioral responding for heat in a cold environment. Physiol. Behav. 3:827-830, 1968.

Carlsson, A., J. Engel and T.H. Svensson. Inhibition of ethanol-induced excitation in mice and rats by $\alpha-$ methylp-tyrosine. Psychopharmacologia 26:307-312, 1972. 
Chalmers, D.T. and S.J. Watson. Comparative anatomical distribution of $5-\mathrm{HT}_{1 A}$ receptor mRNA and $5-\mathrm{HT}_{1 \mathrm{~A}}$ binding in rat brain - a combined in situ hybridisation/in vitro receptor autoradiographic study. Brain Research 561:51$60,1991$.

Chappell, M.A., A.V. Calvo and H.C. Heller. Hypothalamic thermosensitivity and adaptations for heat-storage behavior in three species of chipmunks (Eutamias) from different thermal environments. J. Comp. Physiol. $125: 175-183,1978$.

Chin, J.H. and D.B. Goldstein. Effects of low concentrations of ethanol on the fluidity of spin-labeled erythrocyte and brain membranes. Mol. Pharmacol. 13:435-441, 1977.

Chin, J.H. and D.B. Goldstein. Membrane-disordering action of ethanol: Variation with membrane cholesterol content and depth of the spin label probe. Mol. Pharmacol. 19:425$431,1981$.

Cohen, L., E. Sellers and K. Flattery. Ethanol and sympathetic denervation effects on rat adrenal catecholamine turnover. J. Pharmacol. Exp. Ther. 212:425-429, 1980 .

Corbit, J.D. Behavioral regulation of body temperature. In: J.D. Hardy, A.P. Gagge and J.A.J. Stolwijk (Eds.), Physiological and Behavioral Temperature Regulation, Charles C. Thomas, Springfield, IL, 1970, pp. 777-801.

Corbit, J.D. Behavioral regulation of hypothalamic temperature. Science 166:256-258, 1969.

Corbit, J.D. Voluntary control of hypothalamic temperature. J. Comp. Physiol. Psychol. 83:394-411, 1973.

Corbit, J.D. and T. Ernits. Specific preference for hypothalamic cooling. J. Comp. Physiol. Psychol. 86:2427, 1974 .

Cossins, A.R. and K. Bowler. Temperature Biology of Animals, Chapman and Hall, London, 1987.

Cox, B., M.D. Green and P. Lomax. Behavioral thermoregulation in the study of drugs affecting body temperature. pharmacol. Biochem. Behav. 3:1051-1054, 1975.

Cox, B. and T.F. Lee. Possible involvement of 5hydroxytryptamine in dopamine-receptor-mediated hypothermia in the rat. J. Pharm. Pharmacol. 31:352-354, 1979. 
Crabbe, J.C. and D.J. Feller. Serotonin and genetic differences in sensitivity and tolerance to ethanol hypothermia. Psychopharmacol., In Press, 1993.

Crabbe, J.C., D.J. Feller and J.S. Dorow. Sensitivity and tolerance to ethanol-induced hypothermia in genetically selected mice. J. Pharmacol. Exp. Ther. 249:456-461, 1989.

Crabbe, J.C., D.J. Feller and T.J. Phillips. Selective breeding for two measures of sensitivity to ethanol. In: R.A. Deitrich and A.A. Pawlowski (Eds.), Initial Sensitivity to Alcohol, NIAAA Monograph \#20, U.S. Government Printing Office, Washington, D.C., 1990a, pp. 123-151.

Crabbe, J.C., J.S. Janowsky, E.R. Young, A. Kosobud, J. Stack and $H$. Rigter. Tolerance to ethanol hypothermia in inbred mice: Genotypic correlations with behavioral responses. Alcoholism: Clin. Exp. Res. 6:446-458, 1982a.

Crabbe, J.C., N. Johnson, D. Gray, A. Kosobud and E.R. Young. Biphasic effects of ethanol on open-field activity: Sensitivity and tolerance in C57BL/6N and DBA/2N mice. J. Comp. Physiol. Psychol. 96:440-451, 1982b.

Crabbe, J.C. and A. Kosobud. Sensitivity and tolerance to ethanol in mice bred to be genetically prone or resistant to ethanol withdrawal seizures. J. Pharmacol. Exp. Ther. $239: 327-333,1986$.

Crabbe, J.C., A. Kosobud, D.J. Feller and T.J. Phillips. Use of selectively bred mouse lines to study genetically correlated traits related to alcohol. In: K. Kuriyama, A. Takada and H. Ishii (Eds.), Biomedical and social Aspects of Alcohol and Alcoholism, Elsevier science Publishers B.V. (Biomedical Division), Excerpta Medica, Amsterdam, 1988, pp. 427-430.

Crabbe, J.C., A. Kosobud, B.R. Tam, E.R. Young and C.M. Deutsch. Genetic selection of mouse lines sensitive (COID) and resistant (HOT) to acute ethanol hypothermia. Alcohol Drug Res. 7:163-174, 1987.

Crabbe, J.C., A. Kosobud, E.R. Young and J.S. Janowsky. Polygenic and single-gene determination of responses to ethanol in BXD/Ty recombinant inbred mouse strains. Neurobehav. Toxicol. Teratol. 5:181-187, 1983a. 
Crabbe, J.C., A. Kosobud, E.R. Young, B.R. Tam and J.D. McSwigan. Bidirectional selection for susceptibility to ethanol withdrawal seizures in Mus musculus. Behav. Genet. 15:521-536, 1985.

Crabbe, J.C., T.J. Phillips, A. Kosobud and J.K. Belknap. Estimation of genetic correlation: Interpretation of experiments using selectively bred and inbred animals. Alcoholism: Clin. Exp. Res. 14:141-151, 1990b.

Crabbe, J.C., H. Rigter, J. Uijlen and C. Strijbos. Rapid development of tolerance to the hypothermic effect of ethanol in mice. J. Pharmacol. Exp. Ther. 208:128-133, 1979 .

Crabbe, J.C., E.R. Young and A. Kosobud. Genetic correlations with ethanol withdrawal severity. Pharmacol. Biochem. Behav. 18: Suppl. 1, 541-547, 1983b.

Crawshaw, L.I. Effects of intracerebral 5-hydroxytryptamine injection on thermoregulation in rat. Physiol. Behav. $9: 133-140,1972$.

Crawshaw, I.I. Temperature regulation in vertebrates. Annu. Rev. Physiol. 42:473-491, 1980.

Crawshaw, I.I., L.P. Wollmuth, C.S. O'Connor, R.N. Rausch and L. Simpson. Body temperature regulation in vertebrates: Comparative aspects and neuronal elements. In: $E$. Schönbaum and P. Lomax (Eds.), Thermoregulation: Physiology and Biochemistry, Pergamon Press, New York, 1990, pp. 209-220.

Cunningham, C.I. and L.L. Bischof. Stress and ethanol-induced hypothermia. Physiol. Behav. 40:377-382, 1987.

Curras, M.C., J.G. Dean and J.A. Boulant. Effects of ouabain on neuronal thermosensitivity in hypothalamic tissue slices. Fed. Proc. 45:406, 1986.

Deimling, M.J. and R.C. Schnell. Circadian rhythms in the biological response and disposition of ethanol in the mouse. J. Pharmacol. Exp. Ther. 213:1-8, 1980.

Devor, E.J. and C.R. Cloninger. Genetics of alcoholism. Annu. Rev. Genet. 23:19-36, 1989.

Dib, B. and M. Cabanac. Skin or hypothalamus cooling: A behavioral choice by rats. Brain Res. 302:1-7, 1984 .

Dinh, T.K.H. and L. Gailis. Effect of body temperature on acute ethanol toxicity. Life Sciences 25:547-552, 1979. 
Eckhart, M., T. Harford, C. Kaelber, E. Parker, L. Rosenthal, R. Ryback, G. Salmoiraghi, E. Vanderveen and K. Warren. Health hazards associated with alcohol consumption. JAMA 246:648-666, 1981 .

Erwin, V.G., R.A. Radcliffe and B.C. Jones. Chronic ethanol consumption produces genotype-dependent tolerance to ethanol in IS/Ibg and SS/Ibg mice. Pharmacol. Biochem. Behav. 41:275-281, 1992 .

Feldberg, w. and V.J. Lotti. Temperature responses to monoamines and an inhibitor of MAO injected into the cerebral ventricles of rats. Br. J. Pharmacol. Chemother. 31:152-161, 1967.

Feller, D.I. and J.C. Crabbe. Effect of alcohols and other hypnotics in mice selected for differential sensitivity to hypothermic actions of ethanol. I. Pharmacol. Exp. Ther. 256:947-953, 1991.

Ferko, A.P. and E. Bobyock. Physical dependence on ethanol: Rate of ethanol clearance from the blood and effect of ethanol on body temperature in rats. Toxicol. Appl. Pharmacol. 46:235-248, 1978.

Festing, M.F.W. and D.P. Lovell. Domestication and development of the mouse as a laboratory animal. In: R.J. Berry (Ed.), Biology of the House Mouse, Academic Press, London, 1981, pp. 43-62.

Finn, D.A., M. Bejanian, B.L. Jones, R.F. McGivern, P.J. Syapin, J.C. Crabbe and R.L. Alkana. Body temperature differentially affects ethanol sensitivity in both inbred strains and selected lines of mice. J. Pharmacol. Exp. Ther. 253:1229-1235, 1990.

Finn, D.A., M. Bejanian, B.L. Jones, P.J. Syapin and R.L. Alkana. Temperature affects ethanol lethality in C57BL/6, 129, IS and SS mice. Pharmacol. Biochem. Behav. $34: 375-380,1989$.

Frankel, D., J.M. Khanna, H. Kalant and A.E. LeBlanc. Effects of acute and chronic ethanol administration on serotonin turnover in rat brain. Psychopharmacol. 57:239-242, 1978.

Frazer, A., S. Maayani and B.B. Wolfe. Subtypes of receptors for serotonin. Annu. Rev. Pharmacol. Toxicol. 30:307$348,1990$.

Freed, W.J. and E.K. Michaelis. Glutamic acid and ethanol dependence. Pharmacol. Biochem. Behav. 8:509-514, 1978. 
Fregly, M.J. and D.E. Spiers. Effect of ethanol on body temperature regulation in the rat. In: J.R. Hales (Ed.), Thermal Physiology, Raven Press, New York, 1984, pp. 217220.

Freund, G. Ethanol induced changes in body temperature and their neurochemical consequences. In: E. Majchrowicz and E.P. Noble (Eds.), Biochemistry and Pharmacology of Ethanol, Vol. 2, Plenum Press, New York, 1979, pp. 439452 .

Freund, G. Hypothermia after acute ethanol and benzyl alcohol administration. Iife Sciences 13:345-349, 1973.

Friedman, H.J. Assessment of physical dependence on and withdrawal from ethanol in animals. In: H. Rigter and J.C. Crabbe (Eds.), \&̈icohol Tolerance and Dependence, Elsevier/North Holland Biomedical Press, Amsterdam, 1980, pp. 93-121.

Gallaher, E.J. and D.A. Egner. Rebound hyperthermia follows ethanol-induced hypothermia in rats. Psychopharmacol. (Berlin) 91:34-39, 1987.

Gardner, E.J. Principles of Genetics, John wiley \& Sons, New York, 1975.

Gianoulakis, c. Characterization of the effects of acute ethanol administration on the release of $\beta$-endorphin peptides by the rat hypothalamus. Eur. J. Pharmacol. $180: 21-29,1990$.

Gilliam, D.M. and A.C. Collins. Circadian and genetic influences on tissue sensitivity and sleep time to ethanol in IS and Ss mice. Pharmacol. Biochem. Behav. $18: 803-808,1983$.

Glennon, R.A. Central serotonin receptors as targets for drug research. J. Med. Chem. 30:1-12, 1986.

Glue, P. and D. Nutt. Overexcitement and disinhibition: Dynamic neurotransmitter interactions in alcohol withdrawal. Br. J. Psychiatry 157:491-499, 1990.

Godfrey, L., M.D. Kissen and T.M. Downs. Treatment of the acute alcohol-withdrawal syndrome. Quart. J. Stud. Alc. $19: 118-124$, 1958 . 
Goedde, H.W. and D.P. Agarwal. Acetaldehyde metabolism: Genetic variation and physiological implications. In: H.W. Goedde and D.P. Agarwal (Eds.), Alcoholism: Biomedical and Genetic Aspects, Pergamon Press, New York, 1989, pp. 21-56.

Goldberg, L. and U. Rydberg. Inhibition of ethanol metabolism in vivo by administration of pyrazole. Biochem. Pharmacol. 18:1749-1762, 1969.

Goldstein, D.B. Alcohol and biological membranes. In: H.W. Goedde and D.P. Agarwal (Eds.), Alcoholism: Biomedical and Genetic Aspects, Pergamon Press, New York, 1989, pp. 87-112.

Goldstein, D.B. Pharmacology of Alcohol, Oxford University Press, New York, 1983.

Goldstein, D.B. Rates of onset and decay of alcohol physical dependence in mice. J. Pharmacol. Exp. Ther. 190:377383,1974 .

Goldstein, D.B. Relationship of alcohol dose to intensity of withdrawal signs in mice. J. Pharmacol. Exp. Ther. 180:203-215, 1972 .

Goldstein, D.B. The effects of drugs on membrane fluidity. Annu. Rev. Pharmacol. Toxicol. 24:43-65, 1984 .

Goldstein, D.B., J.H. Chin and R.C. Lyon. Ethanol disordering of spin-labeled mouse brain membranes: Correlation with genetically determined ethanol sensitivity of mice. Proc. Nat1. Acad. Sci. USA 79:4231-4233, 1982.

Goldstein, D.B. and R. Kakihana. Alcohol withdrawal reactions in mouse strains selectively bred for long or short sleep times. Life Sci. 17:981-986, 1975.

Goldstein, D.B. and N. Pal. Alcohol dependence produced in mice by inhalation of ethanol: Grading the withdrawal reaction. Science 172:288-290, 1971 .

Gonzalez, L.P. and R. Sun. Electrophysiological and neurochemical effects of ethanol on hippocampal $\mathrm{CA}_{3}$ neurons. In: R.w. Watson (Ed.), Alcohol and Neurobiology, CRC Press, Boca Raton, FL, 1992, pp. 201219.

Goodrich, C., R. Lechner and $\mathbf{w}$. Slone. Central versus peripheral effects on temperature preference and body temperature following alteration of 5-HT in maturing mice. Physiol. Behav. 46:203-209, 1989. 
Goodwin, G.M., R.J. De Souza and A.R. Green. The pharmacology of the hypothermic response in mice to 8-hydroxy-2-(di-npropylamino)tetralin (8-OH-DPAT). Neuropharmacol. 24:1187-1194, 1985 .

Gorbman, A., W.W. Dickhoff, S.R. Vigna, N.B. Clark and C.L. Ralph. Comparative Endocrinology, John Wiley \& Sons, New York, 1983.

Gordon, C.J. Thermal biology of the laboratory rat. Physiol. Behav. 47:963-991, 1990.

Gordon, C.J., L. Fogelson, F. Mohler, A.G. Stead and A.H. Rezvani. Behavioral thermoregulation in the rat following the oral administration of ethanol. Alcohol Alcoholism 23:383-390, 1988a.

Gordon, C.J., F.S. Mohler, W.P. Watkinson and A.H. Rezvani. Temperature regulation in laboratory mammals following acute toxic insult. Toxicology 53:161-178, 1988b.

Gordon, C.J. and A.G. Stead. Effect of alcohol on behavioral and autonomic thermoregulation in mice. Alcohol 3:339$343,1986$.

Göthert, M. and E. Schlicker. Identification and classification of 5-HT, receptor subtypes. J. Cardiovasc. Pharmacol. 15 (suppl. 7):S1-57, 1990.

Grayson, J. Responses of the microcirculation to hot and cold environments. In: E. Schönbaum and P. Lomax (Eds.), Thermoregulation: Physiology and Biochemistry, Pergamon Press, New York, 1990, pp. 221-234.

Green, E.L. Breeding systems. In: E.L. Green (Ed.), Biology of the Laboratory Mouse, McGraw-Hill Book Co., New York, 1966a, pp. 11-22.

Green, M.C. Mutant Genes and Linkages, In: E.I. Green (Ed.), Biology of the Laboratory Mouse, McGraw-Hill Book Co., New York, 1966b, pp. 87-150.

Grieve, S.J. and J.M. Littleton. Ambient temperature and the development of functional tolerance to ethanol by mice. J. Pharm. Pharmacol. 31:707-708, 1979.

Gross, M.M., E. Lewis and J. Hastey. Acute alcohol withdrawal syndrome. In: B. Kissin and H. Begleiter (Eds.), The Biology of Alcoholism, Plenum Press, New York, 1974, pp. 191-263. 
Gudelsky, G.A., J.I. Koenig and H.Y. Melzer. Thermoregulatory responses to serotonin (5-HT) receptor stimulation in the rat: Evidence for opposing roles of $5 \mathrm{HT}_{2}$ and $5 \mathrm{HT}_{1 \mathrm{~A}}$ receptors. Neuropharmacol. 25:1307-1313, 1986 .

Guyton, A.C. Textbook of Medical Physiology, 6th Edition, W.B. Saunders Co., Philadelphia, 1981.

Hainsworth, F.R. and E.M. Stricker. Salivary cooling by rats in the heat. In: J.D. Hardy, A.P. Gagge and J.A.J. Stolwijk (Eds.), Physiological and Behavioral Temperature Regulation, Charles C. Thomas, Springfield, IL, 1970, pp. 611-626.

Hales, J.R.S. Physiological responses to heat. In: D. Robertshaw (Ed.), MTP International Review of Science, Physiology series 1 , Vol.7, Butterworths Pub., London, 1974, pp. 107-162.

Hales, J.R.S., A.A. Fawcett, J.W. Bennett and A.D. Needham. Thermal control of blood flow through capillaries and arteriovenous anastomoses in skin of sheep. pflugers Arch. 378:55-63, 1978.

Hammel, H.T. Concept of the adjustable set temperature. In: J.D. Hardy, A.P. Gagge and J.A.J. Stolwijk (Eds.), Physiological and Behavioral Temperature Regulation, Charles C. Thomas, Springfield, IL, 1970, pp. 676-683.

Hammel, H.T. Neurons and temperature regulation. In: W. S. Yamamoto and J.R. Brobeck (Eds.), Physiological Controls and Requlations, W.B. Saunders, Philadelphia, 1965, pp. 71-97.

Hammel, H.T. Regulation of internal body temperature. Annu. Rev. Physiol. 30:641-710, 1968.

Hammel, H.T., D.C. Jackson, J.A.J. Stolwijk, J.D. Hardy and S.B. Strømme. Temperature regulation by hypothalamic proportional control with adjustable set temperature. J. Appl. Physiol. 18:1146-1154, 1963.

Harkness, J.E. and J.E. Wagner. The Biology and Medicine of Rabbits and Rodents. Lea \& Febiger, Philadelphia, 1989.

Harris, R.A. Alteration of alcohol effects by calcium and other inorganic cations. Pharmacol. Biochem. Behav. $10: 527-534,1979$.

Harris, R.A. and A.M. Allan. Alcohol intoxication: Ion channels and genetics. FASEB J. 3:1689-1695, 1989. 
Haus, E. and F. Halberg. 24-Hour rhythm in susceptibility of C mice to a toxic dose of ethanol. J. Appl. Physiol. $14: 878-880$, 1959 .

Hegmann, J.P. and B. Possidente. Estimating genetic correlations from inbred strains. Behav. Genet. 11:103$114,1981$.

Heller, H.C. Hypothalamic thermosensitivity in mammals. Experientia [Suppl.] 32:267-276, 1978.

Hellstrom, B. and H.T. Hammel. Some characteristics of temperature regulation in the unanesthesized dog. Am. J. Physiol. 213:547-556, 1967.

Hensel, H. Cutaneous thermoreceptors. In: A. Iggo (Ed.), Handbook of Sensory Physiology, Vol. II: Somato-Sensory System, Springer-Verlag, Berlin, 1973a, pp. 79-110.

Hensel, H. Neural processes in thermoregulation. Physiol. Rev. 53:949-1017, 1973b.

Hensel, H., K. Brück and P. Raths. Homeothermic organisms. In: H. Precht, J. Christophersen and H. Hensel (Eds.), Temperature and Life, Springer-Verlag, New York, 1973, pp. 503-761.

Higgins, G.A., A.J. Bradbury, B.J. Jones and N.R. Oakley. Behavioral and biochemical consequences following activation of $5-\mathrm{HT}_{1}-1$ ike and GABA receptors in the dorsal raphé nucleus of the rat. Neuropharmacol. 25:993-1001, 1988.

Hillegaart, V. Effects of local application of 5-HT and 8-OHDPAT into the dorsal and median raphe nuclei on core temperature in the rat. Psychopharmacol. 103:291-296, 1991.

Himms-Hagen, J. Brown adipose tissue thermogenesis: Role in thermoregulation, energy regulation and obesity. In: E. Schönbaum and P. Lomax (Eds.), Thermoregulation: Physiology and Biochemistry, Pergamon Press, New York, 1990, pp. 327-414.

Hjorth, s. Hypothermia in the rat induced by the potent serotonergic agent 8-OH-DPAT. J. Neural. Transmission $61: 131-135,1985$. 
Hoffman, B.B. and R.J. Lefkowitz. Catecholamines and sympathomimetic drugs. In: A.G. Gilman, T.W. Rall, A.S. Nies and P. Taylor (Eds.), The Pharmacological Basis of Therapeutics, Pergamon Press, New York, 1990, pp. 187220.

Hoffman, P.L and B. Tabakoff. Ethanol and guanine nucleotide binding proteins: A selective interaction. FASEB $J$. $4: 2612-2622$, 1990.

Holloway, F.A. and D.A. King. Parallel development of ethanol tolerance and operant compensatory behaviors in rats. Pharmacol. Biochem. Behav. 34:855-861, 1989.

Holloway, F.A., D.A. King, J.B. Bedingfield and D.V. Gauvin. Role of context in ethanol tolerance and subsequent hedonic effects. Alcohol 9:109-116, 1992 .

Hori, T., A. Asami, T. Asami and T. Kiyohara. Involvement of the reticulospinal neurons in the control of cold-induced shivering. In: J.B. Mercer (Ed.), Thermal Physiology, Elsevier Science Pub., Amsterdam, 1989, pp. 89-94.

Huang, C. $-\mathrm{m}$. and R.H. Huang. Intoxication and acute tolerance to ethanol: Cerebellar granule cells. In: R.R. Watson (Ed.), Alcohol and Neurobiology, CRC Press, Boca Raton, FL, 1992, pp. 45-68.

Huey, R.B. and M. Slatkin. Costs and benefits of lizard thermoregulation. Q. Rev. Biol. 51:363-384, 1976.

Hunter, B.E., J.N. Riley, D.W. Walker and G. Freund. Ethanol dependence in the rat: $A$ parametric analysis. Pharmacol. Biochem. Behav. 3:619-629, 1975.

Iggo, A. and D.W. Young. Cutaneous thermoreceptors and thermal nociceptors. In: H.H. Kornhuber (Ed.), The Somatosensory System, Georg Thieme Pub., Stuttgart, 1975, pp. 5-22.

Ingram, D.L. and K.F. Legge. The influence of deep body temperatures and skin temperatures on peripheral blood flow in the pig. J. Physiol. (Lond.) 215:693-707, 1971.

Iriki, M. and E. Simon. Differential autonomic control of regional circulatory reflexes evoked by thermal stimulation and by hypoxia. Aus. J. Exper. Biol. Med. sci. 51 (Pt. 3):283-293, 1973 . 
Jakobson, M.E. Physiological adaptability: The response of the house mouse to variations in the environment. In: R.J. Berry (Ed.), Biology of the House Mouse, Academic Press, London, 1981, pp. 301-335.

Jarbe, T.U.C. and G.C. Ohlin. Interactions between alcohol and other drugs on open-field and temperature measurements in gerbils. Arch. Int. Pharmacodyn. Ther. 227:106-117, 1977.

Jessen, C. Thermal afferents in the control of body temperature. In: E. Schönbaum and P. Lomax (Eds.), Thermoregulation: Physiology and Biochemistry, Pergamon Press, New York, 1990, pp. 153-183.

Kakihana, R. and J.A. Moore. Effect of alcohol on biological rhythms: Body temperature and adrenocortical rhythmicities in mice. In: F. Seixas (Ed.), Currents in Alcoholism, Vol. 3, Grune and Stratton, New York, 1977, pp. 85-95.

Kalant, H. and A.D. Lê. Effects of ethanol on thermoregulation. Pharmacol. Ther. 23:313-364, 1984 .

Kalant, H., N. Woo and L. Endrenyi. Effect of ethanol on the kinetics of rat brain $\left(\mathrm{Na}^{+}+\mathrm{K}^{+}\right)$ATPase and $\mathrm{K}^{+}$-dependent phosphatase with different alkali ions. Biochem. Pharmacol. 27:1353-1358, 1978 .

Kandel, E.R., J.H. Schwartz and T.M. Jessell (Eds.), Principles of Neural Science, Elsevier, New York, 1991.

Kant, G.J., R.A. Bauman, R.H. Pastel, C.A. Myat, E. ClosserGomez and C.P. D'Angelo. Effects of controllable vs. uncontrollable stress on circadian temperature rhythms. Physiol. Behav. 49:625-630, 1991 .

Keir, W.J. and R.A. Deitrich. Development of central nervous system sensitivity to ethanol and pentobarbital in shortand long-sleep mice. J. Pharmacol. Exper. Ther. 254 :831835, 1990 .

Khanna, J.M., H. Kalant, G. Shah and J. Weiner. Rapid tolerance as an index of chronic tolerance. Pharmacol. Biochem. Behav. 38:427-432, 1991.

Khanna, J.M., H. Kalant, J. Weiner and G. Shah. Rapid tolerance and cross-tolerance as predictors of chronic tolerance and cross-tolerance. Pharmacol. Biochem. Behav. 41:355-360, 1992 . 
Kiyohara, T., M. Hirata, T. Hori and N. Akaike. Thermosensitivity of isolated hypothalamic neurones. In: J.B. Mercer (Ed.), Thermal Physiology, Elsevier Science Pub., Amsterdam, 1989, pp. 65-67.

Klaassen, C.D. Nonmetallic environmental toxicants: Air pollutants, solvents and vapors, and pesticides. In: A.G. Gilman, T.W. Rall, A.S. Nies and P. Taylor (Eds.), The Pharmacological Basis of Therapeutics, Pergamon Press, New York, 1990, pp. 345-382.

Kleinebeckel, D. and F.W. Klussmann. Shivering. In: E. Schönbaum and P. Lomax (Eds.), Thermoregulation: Physiology and Biochemistry, Pergamon Press, New York, 1990, pp. 235-253.

Kluger, M.J. Fever: Role of pyrogens and cryogens. Physiol. Rev. 71:93-127, 1991.

Lauber, P.G. of Man and Mouse, The Viking Press, New York, 1971.

Laudien, H. Activity, behavior etc. In: H. Precht, J. Christophersen, H. Hensel and W. Larcher (Eds.), Temperature and Life, Springer-Verlag, New York, 1973, pp. 441-469.

Lê, A.D., H. Kalant and J.M. Khanna. Influence of ambient temperature on the development and maintenance of tolerance to ethanol-induced hypothermia. Pharmacol. Biochem. Behav, 25:667-672, 1986.

Lê, A.D., J.M. Khanna and H. Kalant. Role of Pavlovian conditioning in the development of tolerance and crosstolerance to the hypothermic effect of ethanol and hydralazine. Psychopharmacol. 92:210-214, 1987.

Lê, A.D., J.M. Khanna, H. Kalant and A.E. LeBlanc. Effect of 5,7-dihydroxytryptamine on the development of tolerance to ethanol. Psychopharmacol. 67:143-146, 1980.

LeBrecque, G. and P.M. Bélanger. Biological rhythms in the absorption, distribution, metabolism and excretion of drugs. Pharmacacol. Ther. 52:95-107, 1991.

Lehninger, A.I. Biochemistry, 2nd Edition, Worth Pub., Inc., New York, 1975. 
Leidenheimer, N.J. and R.A. Harris. Acute effects of ethanol on GABA receptor function: Molecular and physiological determinants. In: G. Biggio, A. Concas and E. Costa (Eds.), GABAergic synaptic Transmission, Raven Press, New York, 1992, pp. 269-279.

Lerner, I.M. Genetic Homeostasis, Wiley, New York, 1954.

Lesch, K.-P., B. Poten, K. Söhnle and H.M. Schulte. Pharmacology of the hypothermic response to $5-\mathrm{HT}_{11}$ receptor activation in humans. Eur. J. Clin. Pharmacol. 39:17-19, 1990 .

Lewis, E.N., I.W. Levin and C.J. Steer. Infrared spectroscopic study of ethanol-induced changes in rat liver plasma membrane. Biochim. Biophys. Acta 986:161$166,1989$.

Lieber, C.S. Toxic and metabolic changes induced by ethanol. In: H.W. Goedde and D.P. Agarwal (Eds.), Alcoholism Biomedical and Genetic Aspects, Pergamon Press, New York, 1989, pp. 57-83.

Liljequist, S., S. Ahlenius and J. Engel. The effect of chronic ethanol treatment on behavior and central monoamines in the rat. Naunyn-Schmiedeberg's Arch. Pharmacol. 300:205-216, 1977.

Lin, M.T., J.J. Wu and B.I. Tsay. Serotonergic mechanisms in the hypothalamus mediate thermoregulatory responses in rats. Naunyn-Schmiedeberg's Arch. Pharmacol. 322:271$278,1983$.

Linakis, J.G. and C.L. Cunningham. Effects of concentration of ethanol injected intraperitoneally on taste aversion, body temperature, and activity. Psychopharmacol. 64:6165,1979 .

Livezey, G.T., J.M. Miller and W.H. Vogel. Plasma norepinephrine, epinephrine, and corticosterone stress responses to restraint in individual male and female rats, and their correlations. Neurosci. Lett. 62:51-56, 1985 .

Lomax, P., J.G. Bajorek, W.A. Chesarek and R.R.J. Chaffee. Ethanol-induced hypothermia in the rat. Pharmacol. $23: 288-294$, 1980 .

Lomax, P., T-A. Bajorek and R.R.J. Chaffee. Thermoregulatory mechanisms and ethanol hypothermia. Eur. J. Pharmacol. $71: 483-487$, 1981 . 
Lovinger, D.M., G. White and F.F. Weight. Ethanol inhibits MMDA-activated ion current in hippocampal neurons. Science 243:1721-1724, 1989 .

Mackenzie-Taylor, D. and R.H. Rech. Cellular and learned tolerances for ethanol hypothermia. Pharmacol. Biochem. Behav. 38:29-36, 1991 .

Maeda, K., Y. Imae, J. Shioi and F. Oosawa. Effect of temperature on motility and chemotaxis of Escherichia coli. J. Bacteriol. 127:1039-1046, 1976.

Magoun, H.W., F. Harrison, J.R. Brobeck and S.W. Ranson. Activation of heat loss mechanisms by local heating of the brain. I. Neurophysiol. 1:101-114, 1938.

Malcolm, R.D. and R.I. Alkana. Hyperbaric ethanol antagonism: Role of temperature, blood and brain ethanol concentrations. Pharmacol. Biochem. Behav. 16:341-346, 1982 .

Malcolm, R.D. and R.L. Alkana. Temperature dependence of ethanol depression in mice. J. Pharmacol. Exp. Ther. 217:770-775, 1981.

Malcolm, R.D. and R.L. Alkana. Temperature dependence of ethanol lethality in mice. I. Pharm. Pharmacol. 35:306$311,1983$.

Mansfield, J.G. and C.L. Cunningham. conditioning and extinction of tolerance to the hypothermic effect of ethanol in rats. J. Comp. Physiol. Psychol. 94:962-969, 1980.

Martin, K.F. Rhythms in neurotransmitter turnover: Focus on the serotonergic system. Pharmacol. Ther. 51:421-429, 1991.

Max, B. This and that: Drug tolerance and great expectations. TiPS 11:401-404, 1990 .

Mehta, A.K. and M.K. Ticku. Ethanol potentiation of GABAergic transmission in cultured spinal cord neurons involves $\gamma-$ aminobutyric acid-gated chloride channels. J. Pharmacol. Exper. Ther. 246:558-564, 1988.

Melchior, C.I. Conditioned tolerance provides protection against ethanol lethality. Pharmacol. Biochem. Behav. 37:205-206, 1990. 
Melchior, C.I. and R.F. Ritzmann. Dehydroepiandrosterone enhances the hypnotic and hypothermic effects of ethanol and pentobarbital. Pharmacol. Biochem. Behav. 43:223$227,1992$.

Meller, E., M. Chalfin and K. Bohmaker. Serotonin 5-HT receptor-mediated hypothermia in mice: Absence of spare receptors and rapid induction of tolerance. Pharmacol. Biochem. Behav. 43:405-411, 1992.

Mercer, J.B. and E. Simon. A comparison between total body thermosensitivity and local thermosensitivity in mammals and birds. Pflugers Arch. 400:228-234, 1984.

Mezey, E., J.J. Potter and R. Kvethanskỳ. Effect of stress by repeated immobilization on hepatic alcohol dehydrogenase activity and ethanol metabolism. Biochem. Pharmacol. $28: 657-663,1979$.

Morley, R.M., C.A. Conn, M.J. Kluger and A.J. Vander. Temperature regulation in biotelemetered spontaneously hypertensive rats. Am. J. Physiol. 258 (Reg. Integ. Comp. Physiol. 27):R1064-R1069, 1990.

Morrison, R.T. and R.N. Boyd. Organic Chemistry, 3rd Edition, Allyn and Bacon, Inc., Boston, 1973.

Murakami, N. Effects of iontophoretic application of 5hydroxytryptamine, noradrenaline and acetylcholine upon hypothalamic temperature-sensitive neurons in rats. Jpn. J. Physiol. 23:436-446, 1973 .

Murgatroyd, D. and J.D. Hardy. Central and peripheral temperatures in behavioral thermoregulation of the rat. In: J.D. Hardy, A.P. Gagge and J.A.J. Stolwijk (Eds.), Physiological and Behavioral Temperature Regulation, Charles C. Thomas, Springfield, IL, 1970, pp. 874-891.

Myers, R.D. Alcohol's effect on body temperature: Hypothermia, hyperthermia or poikilothermia? Brain Res. Bull. 7:209-220, 1981 .

Mylecharane, E.J. The classification of 5-hydroxytryptamine receptors. Clin. Exper. Pharmacol. Physiol. 16:517-522, 1989.

Nagahiro, S., M. Diksic, Y.L. Yamamoto and H. Riml. Noninvasive in-vivo autoradiographic method to measure axonal transport in serotoninergic neurons in the rat brain. Brain Res. 506:120-128, 1990. 
Nagasaka, T., K. Hirata, Y. Sugano and H. Shibata. Heat balance during physical restraint in rats. Jpn. J. Physiol. 29:383-392, 1979.

Nakashima, T., T. Hori and T. Kiyohara. Intracellular recording analysis of septal thermosensitive neurons in the rat. In: J.B. Mercer (Ed.), Thermal Physiology, Elsevier Science Pub., Amsterdam, 1989, pp. 69-72.

Nelson, D.O. and C.L. Prosser. Temperature-sensitive neurons in the preoptic region of sunfish. Am. J. Physiol. 241:R256-R263, 1981.

O'Connor, C.S., L.I. Crawshaw, R.C. Bedichek and J.C. Crabbe. The effect of ethanol on temperature selection in the goldfish, Carassius auratus. Pharmacol. Biochem. Behav. $29: 243-248,1988$.

Ogilvie, D.M. and R.H. Stinson. The effect of age on temperature selection by laboratory mice (Nus musculus). Canad. J. Zool. 44:511-517, 1966.

Owen, T.L., R.L. Spencer and S.P. Duckles. Effect of age on cold acclimation in rats: Metabolic and behavioral responses. Am. J. Physiol. 260:R284-R289, 1991.

Peris, J. and C.I. Cunningham. Handling-induced enhancement of alcohol's acute physiological effects. Iife sci. $38: 273-279,1986$.

Perlmutter, M.N. and J.A. Boulant. Intracellular recordings from temperature-sensitive septal and hypothalamic neurons. Soc. Neurosci. 9:517, 1983.

Petersen, D.R. and N. Atkinson. Genetically mediated responses of microsomal ethanol oxidation in mice. In: R.G. Thurman (Ed.), Alcohol and Aldehyde Metabolizing Systems - IV, Advances in Experimental Medicine and Biology, Volume 132, Plenum Press, New York, 1980, pp. 117-128.

Phillips, T.J. and J.C. Crabbe. Behavioral studies of genetic differences in alcohol action. In: J.C. Crabbe and R.A. Harris (Eds.), The Genetic Basis of Alcohol and Drug Actions, Plenum Press, New York, 1991, pp. 25-104.

Pieper, W.A., M.J. Skeen, H.M. McClure and P.G. Bourne. The chimpanzee as an animal model for investigating alcoholism. Science 176:71-73, 1972 . 
Platanow, N., B.B. Coldwell and L.P. Dugal. Rate of metabolism of radioactive ethanol in cold environment. Q. J. Stud. Alcohol $24: 385-397,1963$.

Pleschka, K. and S.C. Wang. The activity of respiratory neurons before and during panting in the cat. pflugers Arch. 353:303-315, 1975.

Plomin, R. The role of inheritance in behavior. Science $248: 183-188,1990$.

Pohorecky, I.A. Withdrawal from ethanol: simple quantitative behavioral tests for its evaluation. Psychopharmacol. 50:125-129, 1976.

Pohorecky, L.A. and J. Brick. Pharmacology of ethanol. Pharmacol. Ther. 36:335-427, 1988.

Pohorecky, I.A., J. Brick and J.Y. Sun. Serotonergic involvement in the effect of ethanol on body temperature in rats. J. Pharm. Pharmacol. 28:157-159, 1976.

Pohorecky, L.A., L.S. Jaffe and H.A. Berkeley. Effects of ethanol on serotonergic neurons in the rat brain. Res. Commun. Chem. Path. Pharmacol. 8:1-11, 1974.

Pohorecky, L.A. and A. Rizek. Biochemical and behavioral effects of acute ethanol in rats at different environmental temperatures. Psychopharmacol. 72:205-210, 1981.

Pohorecky, L.A. and P. Roberts. Daily dose of ethanol and the development and decay of acute and chronic tolerance and physical dependence in rats. Pharmacol. Biochem. Behav. $42: 831-842$, 1992 .

Pohorecky, L.A. and P. Roberts. Development of tolerance to and physical dependence on ethanol: Daily versus repeated cycles treatment with ethanol. Alcoholism: Clin. Exper. Res. 15:824-833, 1991 .

Poole, S. and J.D. Stephensen. Core temperature: Some shortcomings of rectal temperature measurements. Physiol. Behav. 18:203-205, 1977.

Poulos, C.X. and H. Cappell. Homeostatic theory of drug tolerance: A general model of physiological adaptation. Psychol. Rev. 3:390-408, 1991 .

Prosser, C.I. and F.A. Brown, Jr. Comparative Animal Physiology, W.B. Saunders Co., Philadelphia, 1961. 
Prosser, C.L. and J.E. Heath. Temperature. In: C.L. Prosser (Ed.), Environmental and Metabolic Animal Physiology, Wiley-Liss, New York, 1991, pp. 109-165.

Rall, T.W. Hypnotics and sedatives: Ethanol. In: A.G. Gilman, T.W. Rall, A.S. Nies and P. Taylor (Eds.), The Pharmacological Basis of Therapeutics, Pergamon Press, New York, 1990, pp. 345-382.

Refinetti, R. and M. Menaker. The circadian rhythm of body temperature. Physiol. Behav. 51:613-637, 1992.

Rigter, H., J.C. Crabbe and E. Schönbaum. Hypothermia in mice as an index of the rapid development of tolerance to ethanol. In: B. Cox, P. Lomax, A.S. Milton and E. Schönbaum (Eds.), Thermoregulatory Mechanisms and Their Therapeutic Implications, S. Karger, Basel, 1980, pp. 216-219.

Ritzmann, R.F. and B. Tabakoff. Body temperature in mice: A quantitative measure of alcohol tolerance and physical dependence. J. Pharmacol. Exp. Ther. 199:158-170, 1976.

Ritzmann, R.F. and B. Tabakoff. Ethanol, serotonin metabolism, and body temperature. Ann. N.Y. Acad. Sci. 273:247-255, 1970 .

Ritzmann, R.F. and B. Tabakoff. Strain differences in the development of acute tolerance to ethanol. In: $H$. Regleiter (Ed.), Biological Effects of Alcohol, Plenum Pub. Co., New York, 1980, pp. 197-210.

Roach, M. and P. Creaven. A micro-method for the determination of acetaldehyde and ethanol in brain. Clin. Chem. Acta. 21:275-278, 1968.

Roderick, T.H. and G. Schlager. Multiple factor inheritance. In: E.L. Green (Ed.), Biology of the Laboratory Mouse, McGraw-Hill Book Co., New York, 1966, pp. 151-164.

Rottenberg, H., A. Waring and E. Rubin. Tolerance and crosstolerance in chronic alcoholics: Reduced membrane binding of ethanol and other drugs. Science 213:583-585, 1981.

Rout, U.K. Alcohol dehydrogenases in the brain of mice. Alcoholism: Clin. Exp. Res. 16:286-289, 1992.

Sakata, Y., A. Morimoto, T. Watanabe and N. Murakami. Effect of preoptic/anterior hypothalamic temperature on activity of thalamic neurons in rats responding to skin temperature. In: J.B. Mercer (Ed.), Thermal Physiology, Elsevier Science Pub., Amsterdam, 1989, pp. 73-76. 
Satinoff, E. Drugs and thermoregulatory behavior. In: $P$. Lomax and E. Schönbaum (Eds.), Body Temperature: Regulation, Drug Effects, and Therapeutic Implications, Marcel Dekker, Inc., New York, 1979, pp. 151-181.

Satinoff, E. and R. Hendersen. Thermoregulatory behavior. In: W.K. Honig and J.E.R. Staddon (Eds.), Handbook of operant Behavior, Prentice-Hall, Inc., Englewood Cliffs, NJ, 1977, pp. 153-173.

Schmidt-Nielsen, K. Animal Physiology, Cambridge University Press, Cambridge, England, 1990.

Schmidt-Nielsen, K. Scaling, Cambridge University Press, Cambridge, England, 1984.

Searle, A.G. Comparative and historical aspects of the mouse genome. In: R.J. Berry (Ed.), Biology of the House Mouse, Academic Press, London, 1981, pp. 63-84.

Siegel, S. Evidence from rats that morphine tolerance is a learned response. J.Comp. Physiol. Psychol. 89:498-506, 1975.

Siemen, D. and A. Weber. Voltage-dependent and cationselective channel in brown adipocytes. In: J.B. Mercer (Ed.), Thermal Physiology, Elsevier Science Pub., Amsterdam, 1989, pp. 241-246.

Simon, E., F.-K. Pierau and D.C.M. Taylor. Central and peripheral thermal control of effectors in homeothermic temperature regulation. Amer. Physiol. Soc. Physiol. Rev. 66:235-300, 1986.

Sinensky, M. Homeoviscous adaptation - A homeostatic process that regulates the viscosity of membrane lipids in Escherichia coli. Proc. Nat'1. Acad. Sci. USA 71:522525, 1974 .

Slotnick, B.M. and C.M. Leonard. A Stereotaxic Atlas of the Albino Mouse Forebrain, DHEW Publication No. (ADM) 75100, U.S. Government Printing office, Washington, D.C., 1975.

Smolen, A. and T.N. Smolen. Demonstration of a threshold concentration for ethanol at the time of regaining the righting response in long-sleep and short-sleep mice. Alcohol Drug Res. 7:279-283, 1987.

Smolen, T.N. and A. Smolen. Blood and brain ethanol concentrations during absorption and distribution in long-sleep and short-sleep mice. Alcohol 6:33-38, 1989. 
Snell, G.D. and J.H. stimpfling. Genetics of tissue transplantation. In: E.L. Green (Ed.), Biology of the Laboratory Mouse, McGraw-Hill Book Co., New York, 1966, pp. 457-491.

Soliman, K.F.A. and C.A. Walker. Diurnal rhythm of ethanol metabolism in the rat. Experientia 35:808-809, 1979.

Spiers, D.E., R.M. Threatte and M.J. Fregly. Response to thermal stress in the rat following acute administration of ethanol. Pharmacol. 28:155-170, 1984 .

Staats, J. The laboratory mouse. In: E.L. Green (Ed.), Biology of the Laboratory Mouse, McGraw-Hill Book Co., New York, 1966, pp. 1-9.

Stewart, R.B., D.L. Kurtz, M. Zweifel, T.-K. Li and J.C. Froehlich. Differences in the hypothermic response to ethanol in rats selectively bred for oral ethanol preference and nonpreference. Psychopharmacol. 106:169174, 1992.

Stitt, J.T. Fever versus hypothermia. Fed. Proc. 38:39-43, 1979.

Stolwijk, J.A.J. and E.R. Nadel. Thermoregulation during positive and negative work exercise. Fed. Proc. 32:1607$1613,1973$.

Sturtevant, R.P. and S.I. Garber. Light-dark and feeding regimens affect circadian phasing of blood-ethanol decay rates. Pharmacol. Biochem. Behav. 13:637-642, 1980.

Tabakoff, B. and R.F. Ritzmann. The effects of 6hydroxydopamine on tolerance to and dependence on ethanol. J. Pharmacol. Exper. Ther. 203:319-331, 1977.

Tabakoff, B., R.F. Ritzmann, T.S. Raju and R.A. Dietrich. Characterization of acute and chronic tolerance in mice selected for inherent differences in sensitivity to ethanol. Alcoholism: Clin. Exper. Res. 4:70-73, 1980.

Tampier, L. and M.E. Quintanilla. Effect of 3-amino-1,2,4triazole on the hypothermic effect of ethanol and on ethanol tolerance development. Alcohol 8:279-282, 1991.

Tavel, M.E., .. Davidson and T.D. Batterton. A critical analysis of mortality associated with delerium tremens. Am. J. Med. Sci. 242:18-19, 1961. 
Ticku, M.K. and S.K. Kulkarni. Molecular interactions of ethanol with GABAergic system and potential of RO15-4513 as an ethanol antagonist. Pharmacol. Biochem. Behav. $30: 501-510$, 1988 .

Tsugawa, K. and K.Y.H. Lagerspetz. Direct adaptation of cells to temperature: Membrane fluidity of goldfish cells cultured in vitro at different temperatures. Comp. Biochem. Physiol. 1:57-60, 1990.

Van de Kar, L.D. Neuroendocrine pharmacology of serotonergic (5-HT) neurons. Annu. Rev. Pharmacol. Toxicol. 31:289$320,1991$.

Victor, M. Treatment of the alcoholic intoxication and the withdrawal syndrome: A critical analysis of the use of drugs and other forms of therapy. Psychosomat. Med. 25:636-650, 1966 .

Walker, P.Y., K.F.A. Soliman and C.A. Walker. Diurnal rhythm of ethanol hypothermic action in mice. Res. Comm. Subst. Abuse 3:503-506, 1982 .

waltman, C. and G.S. Wand. Alterations in hypothalamicpituitary-adrenal function by ethanol. In: R.R. Watson (Ed.), Alcohol and Neurobiology, CRC Press, Boca Raton, FL, 1992, pp. 249-266.

Watts, c.H.S. The foods eaten by wood mice (Apodemus sylvaticus) and bank voles (Clethrionomys glareolus) in Wytham Woods, Berkshire. J. Anim. Ecol. 37:25-41, 1968 .

Wenger, J.R. and R.I. Alkana. Temperature dependence of ethanol depression in C57BL/6 and BALB/C mice. Alcohol $1: 297-303,1984$.

Werner, J. Functional mechanisms of temperature regulation, adaptation and fever: complementary system theoretical and experimental evidence. In: E. Schönbaum and P. Lomax (Eds.), Thermoregulation: Physiology and Biochemistry, Pergamon Press, New York, 1990, pp. 185-208.

Yehuda, S. and R. J. Wurtman. Paradoxical effects of damphetamine on behavioral thermoregulation: Possible mediation by brain dopamine. J. Pharmacol. Exp. Ther. 190:118-122, 1974 .

Yuki, T. and R.G. Thurman. Mechanism of the swift increase in alcohol metabolism ("SIAM") in the rat. In: R.G. Thurman (Ed.), Alcohol and Aldehyde Metabolizing Systems - IV. Advances in Experimental Medicine and Biology, Vol. 132, Plenum Press, New York, 1980, pp. 689-695. 